\title{
Global Indian Diasporas
}

Exploring Trajectories of

Migration and Theory

EDITED BY GIJSBERT OONK

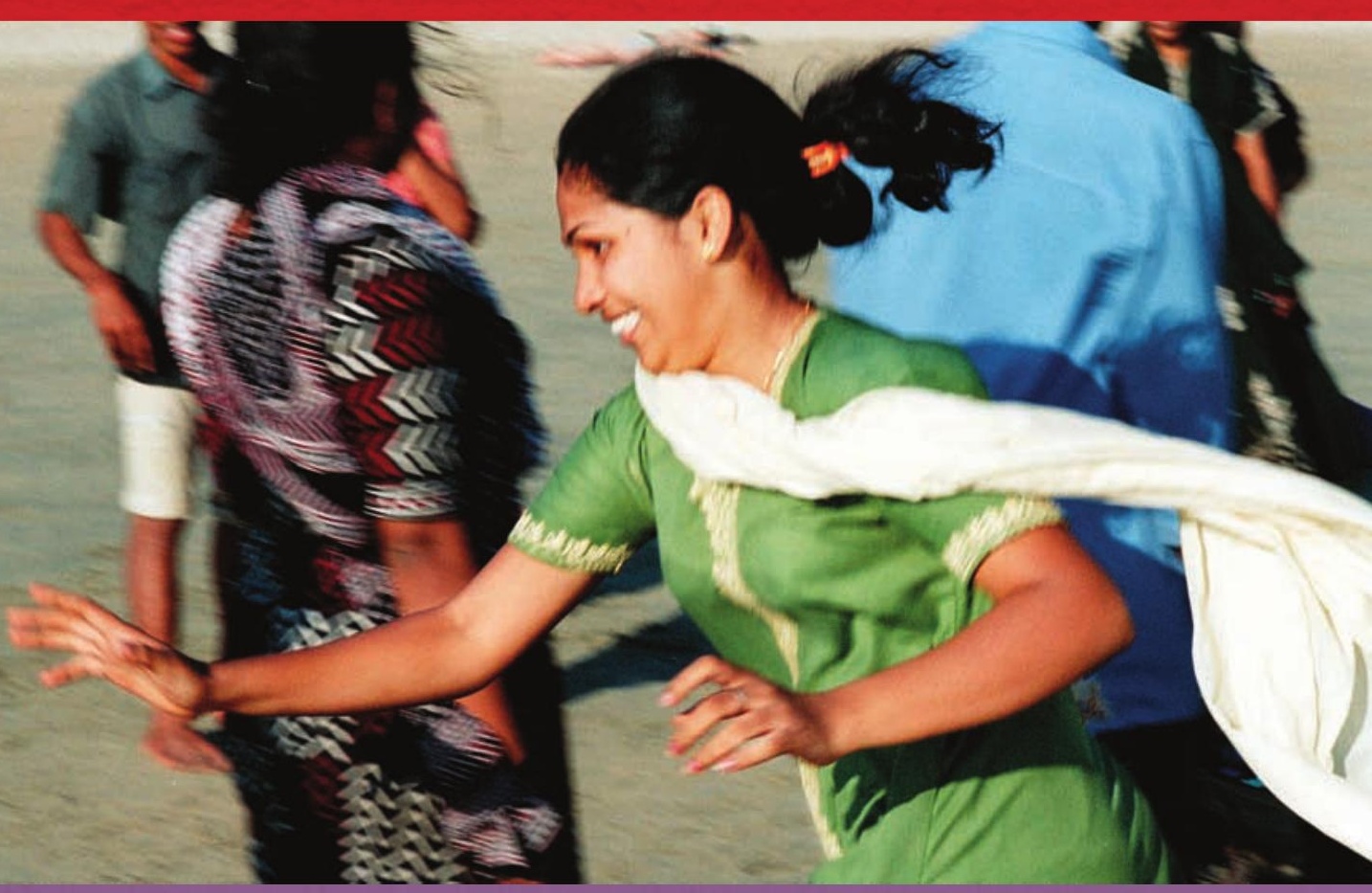


Global Indian Diasporas 
IIASP PuBLICATIONS SERES

\section{Series Editors}

Max Sparreboom and Paul van der Velde

\section{Editorial Board}

Prasenjit Duara (University of Chicago) / Carol Gluck (Columbia University) / Christophe Jaffrelot (Centre d'Études et de Recherches Internationales-Sciencespo) / Victor T. King (University of Hull) / Yuri Sadoi (Meijo University) / A.B. Shamsul (Institute of Occidental Studies / Universiti Kebangsaan Malaysia) / Henk Schulte Nordholt (Royal Netherlands Institute of Southeast Asian and Caribbean Studies) / Wim Boot (Leiden University)

The IIAS Publications Series consists of Monographs and Edited Volumes. The aim of the Series is to promote Asia-Europe Studies. The Series includes comparative research on Europe and Asia and results from cooperation between European and Asian scholars. The International Institute for Asian Studies stimulates scholarship on Asia and is instrumental in forging research networks among Asia scholars worldwide.

The International Institute for Asian Studies (IIAS) is a postdoctoral research centre based in Leiden and Amsterdam, the Netherlands. Its main objective is to encourage the interdisciplinary and comparative study of Asia and to promote national and international cooperation in the field. The institute focuses on the humanities and social sciences and, where relevant, on their interaction with other sciences. IIAS acts as an international mediator, bringing various parties together, working as a clearinghouse of knowledge and information. This entails activities such as providing information services, hosting academic organisations dealing with Asia constructing international networks, and setting up international cooperative projects and research programmes. In this way, IIAS functions as a window on Europe for non-European scholars and contributes to the cultural rapprochement between Asia and Europe.

For further information, please visit www.iias.nl 


\section{Global Indian Diasporas}

Exploring Trajectories of Migration and Theory

Edited by Gijsbert Oonk

AMSTERDAM UNIVERSITY PRESS 
IIASP PuBLICATIONS SERES

\section{Edited Volumes 1}

Cover design: Maedium, Utrecht

Layout: The DocWorkers, Almere

ISBN 9789053560358

NUR $741 / 763$

(C) IIAS / Amsterdam University Press, 2007

All rights reserved. Without limiting the rights under copyright reserved above, no part of this book may be reproduced, stored in or introduced into a retrieval system, or transmitted, in any form or by any means (electronic, mechanical, photocopying, recording or otherwise) without the written permission of both the copyright owner and the author of the book. 


\section{Table of Contents}

$\begin{array}{ll}\text { Acknowledgements } & 7\end{array}$

I Global Indian Diasporas: Exploring Trajectories of Migration and Theory

Gijsbert Oonk

\section{PART I CRITICAL HISTORICAL PERSPECTIVES}

2 Multanis and Shikarpuris: Indian Diasporas in Historical Perspective

Scott Levi

3 'We Lost our gift of Expression': Loss of the Mother Tongue among Indians in East Africa, I880-2000

Gijsbert Oonk

4 Contextualising Diasporic Identity: Implications of Time and Space on Telugu Immigrants

Chandrashekhar Bhat and T.L.S. Bhaskar

5 Separated by the Partition? Muslims of British Indian

Descent in Mauritus and Suriname

Ellen Bal and Kathinka Sinha-Kerkhoff

6 A Chance Diaspora: British Gujarati Hindus John Mattausch 


\section{PART 2 CRITICAL SOCIOLOGICAL AND ANTHROPOLOGICAL PERSPECTIVES}

7 Contested Family Relations and Government Policy: Linkages between Patel Migrants in Britain and India Mario Rutten and Pravin J. Patel

8 Diaspora Revisited: Second-Generation Nizari Ismaili Muslims of Gujarati Ancestry Anjoom Amir Mukadam and Sharmina Mawani

9 Bollywood and the Indian Diaspora: Reception of Indian Cinema among Hindustani Youth in the Netherlands Sanderien Verstappen and Mario Rutten

Io Contested Equality: Social Relations between Indian and Surinamese Hindus in Amsterdam

Brit Lynnebakke

II Afterword: Stray Thoughts of a Historian on "Indian" or "South Asian" "Diaspora(s)"

Claude Markovits

Bibliography

Contributors 


\section{Acknowledgements}

It all started during a quick lunch at the History Department of the Erasmus University Rotterdam (EUR), Netherlands. A few months after I returned from my fieldwork in East Africa, I talked with my colleague the IIAS Professor Henk Schulte Nordholt about my experiences in the field. We discussed how the growing interest in the concept of 'diaspora' fostered new ideas and academic ventures in the areas of migration and identity studies. Inspite of this apparent interest, we agreed that many scholars tended to focus on their own subject areas and their own ethnic groups. Therefore, I proposed a rough idea to set up a broad, comparative conference on diaspora. This conference would not only include specialists on the South Asian diaspora, but experts on Chinese and African diaspora as well. The idea was that specialists in the field of the South Asian diasporas would be confronted with ideas and concepts from other regions. In addition, they would present their own findings to fellow specialists.

With the support of IIAS, the conference 'The South Asian Diasporas: The Creation of Unfinished Identities in the Modern World' was held at the EUR in June 2005. Many - but not all - articles in this book were written as a result of that conference. In line with the original idea, I invited two 'outsiders' to share their knowledge and opinions with us. Kim Butler (Africanist at the University of New York) presented a keynote lecture 'Diaspora Kaleidoscope - Or Colliding Diasporas? The Meta Diaspora Concept and the Mini-Diaspora Realities'. Here, she reminded us of the ambivalent relationship between a popular academic concept and day-to-day realities. In fact this 'ambivalence' became the centre of the discussion in the two-day conference. Leo Douw (Universiteit van Amsterdam) also shared his knowledge of the Chinese diaspora discourse. I am grateful to them both for their valuable inputs.

I would like to thank the following institutions which provided financial support: IIAS, the Netherlands Foundation for Scientific Research (NWO), The Royal Netherlands Academy of Arts and Sciences 
(KNAW), the Trustfund and the Faculty of History and Arts of the EUR, Furthermore I would like to thank Theresa Oostvogels (EUR), Marloes Rozing (IIAS), Wieke Vink and Gaby van Beek (EUR students) who made fantastic contributions at the organisational level which made the conference run smoothly.

Gijsbert Oonk

History Department (FHKW)

Erasmus University Rotterdam 


\title{
1 Global Indian Diasporas
}

\section{Exploring Trajectories of Migration and Theory}

\author{
Gijsbert Oonk
}

\section{Introduction}

There are currently approximately $20,000,000$ people of South Asian origin living outside of India, Pakistan and Bangladesh, with the majority in Africa, the Caribbean, and Oceania. ${ }^{\mathrm{I}}$ Although there are regional variations in their adaptations, in many ways, they display a common 'Indian' identity. ${ }^{2}$ They may want their children to prosper in their adopted countries, but at the same time they may prefer them to adopt Indian family values, marry other Indians, and share their common culture. In other words, many South Asians living overseas tend to reproduce their Indian culture, values, language, and religion as much as possible. ${ }^{3}$ Moreover, many South Asian migrants are currently trying to re-connect with their homeland, either through modern mass media, the Internet, or personal visits. These re-connections are often seen as romantic rendezvous with the historical past and their 'original roots'. ${ }^{4}$

Within, academic 'Indian diaspora' literature, the reproduction of culture in an often-hostile environment and the relation to the homeland are key features of the diaspora concept. ${ }^{5}$ Nevertheless, in this collection, we emphasise a rather different approach. The authors, during their fieldwork and archival research, realised that there were quite a few overseas Indians who were not interested in re-connecting with the homeland. They felt that the Indian Government was excluding them from their historical roots, as in the case of many Muslim Indians after Partition and Indian Africans after their expulsion from Uganda by Idi Amin. In the case of 'twice migrants' like the Hindustanis in the Netherlands, we find that they may identify with both India and Suriname. Moreover, it has been shown that in cases where Indians do reconnect with their ancestral villages, the relationship with family members has grown ambivalent and is sometimes experienced with noticeable discomfort. In other words, re-connection with one's homeland is not self-evident. It happens or it doesn't. Though some of 
these finding are not new, they do shed some fresh light on the diaspora concept as a whole.

Thus the main aim of this collection is to gather sociological, anthropological, and historical perspectives on the 'Indian Diaspora'. The papers published in this volume present new empirical research on South Asian migrants world-wide. The authors share a strongly ambivalent feeling towards the mainstream issues highlighted in the 'South Asians in diaspora' discourse, such as the emphasis on the migrants' relation to their homeland and the reproduction of Indian culture abroad. In this sense, this book can be read as a first attempt to focus on the limits of the diaspora concept, rather than on its possibilities and range. From a comparative perspective, with examples from South Asian migrants in Suriname, Mauritius, East Africa, the UK, and the Netherlands, this collection shows that in each of these regions there are South Asian migrants who do not fit into the Indian diaspora concept. Thus we attempt to stretch the concept beyond its current use by highlighting empirical cases, which raise the question about the limits of the effectiveness of the diaspora as an academic historical/sociological concept.

This introduction begins with an outline of four different migration patterns from the South Asian continent, because the causes of migration vary, as do the length that migrants remain abroad. This will be followed by a short historiography of studies on the 'overseas Indian communities'. Here, the transition from labelling South Asian migrants 'overseas Indian communities' to 'South Asian diasporas' is highlighted. In the final section, the various articles and their perspectives are introduced.

\section{Various Migrations, One Diaspora?}

The South Asian migrants, or their ancestors, left the subcontinent as part of various migration patterns. In general, four - sometimes interweaving - currents of South Asian migration are emphasised. Each of these currents has had its own specific background, characteristics, and conditions. Some of which caused variations in the way migrants reproduced 'Indian culture' abroad and/or how they were received by the host societies. Moreover, these patterns differ in terms of age, numbers, and the historical contexts in which they emerge. In some areas, like East Africa, South Asian communities have lived for six or more generations, while in other areas, like the Gulf States they are recent arrivals. In most areas, they comprise small minorities, although in Mauritius and Fiji they are politically and economically dominant. 
The first and eldest migration flow was that of traders who began leaving the South Asian subcontinent in the earliest times and continue to do so until today in search of trade and business. Not surprisingly, Indian coastal communities had already developed all kinds of profitable ties with East Asia, East Africa, and Central Asia in pre-colonial times. One of the key characteristics of this so called 'trade diaspora' may be the fact that most of it consisted of 'temporary' or 'circular' migration. Sons were sent to search for trade elsewhere, but also to eventually return. These traders acted as filters through which other cultures were linked with their own. Frequently, they developed a more cosmopolitan lifestyle due to their exposure to other cultures. Nevertheless, perhaps it is fair to say that it was only in the nineteenth century that substantial permanent South Asian trading communities settled abroad. In the literature, the emergence of long-distance trading connections - including the circulation of capital - the changing role of women, and the notions of 'trust' became important issues. ${ }^{6}$

The second important current was that of Indian Indentured labourers who left to replace the freed slaves in the nineteenth-century plantation economies. Although most of them may have intended to return to the sub-continent, in fact, many ended up staying to create new homelands abroad. The main difference with the trade diaspora, however, is the fact that much of this migration was 'forced' and not voluntary. The main focus, thus far, has been on the travel and working conditions of the labourers, the nature of the contracts, and the number of returnees. Though recently, the interest in the reproductions of Indian culture abroad has grown. ${ }^{7}$ In the same period, some Indians migrated as clerks and teachers to serve colonial Governments overseas. They are mostly described as being part of the colonial expansion system, where Indians contributed by collaborating with the British. ${ }^{8}$

The third current includes various migrations after the Second World War. First, many Muslims migrated from India to East and West Pakistan, while Hindus departed from Pakistan to migrate to India. Hindus in Pakistan as well Muslims in India did not feel that the new governments were able to protect their minority rights. Meanwhile, many highly educated professionals left India to find jobs as teachers, lawyers, and doctors in the Europe (especially the UK), the US and Canada. This has recently occurred again with the exodus of many IT professionals. Furthermore, numerous migrants have found work as construction workers or housekeepers in the Middle East since I970s. Here again, some of them may have been 'temporary migrants', whereas others - intentionally or unintentionally - never returned. 9

Within this Post War period a fourth pattern also developed, that of the 'twice migrants' or second- (or third-) time migrants. They include Indian indentured labourers in Suriname who eventually settled in the 
Netherlands or those who were expelled from East Africa and ended up settling in the UK and Canada. They left their host countries for political rather than economic reasons. However, interestingly enough, most of them never considered re-migrating to India. They may have felt some cultural ties with the so-called 'motherland', but the economic, political, and family ties sent them elsewhere. This group was highly diverse and consisted of traders, labourers, as well as professionals. $^{\text {IO }}$

Bringing these various migration patterns together under the unifying label of 'Indian Diaspora' is no easy task. ${ }^{\mathrm{II}}$ The patterns vary regarding the causes and consequences of migration, the numbers of migrants, the periods of migration, the numbers of returnees, the manner in which they were received by their host countries, whether or not circular migration was transformed into permanent settlement and family reunion, and the questions of whether locally there was an emerging 2nd-, 3rd- and higher-generation of 'Indian migrants' as opposed to intermarriages and cultural alliances with the local communities. ${ }^{\text {I2 }}$ Furthermore, there is a wide variety of religious, regional, and ethnic backgrounds of the migrants. They are labelled 'Hindus', which, of course, entails, a variety of castes, sub-castes and 'jatis'. There is a great variety of sects and beliefs among the South Asian Muslims (Sunnis, Ismailis) as well and the other religious/ethnic groups such as the Sikhs, Jains, Goans, among others. Moreover, there is also a broad variety of regional and language backgrounds: such as the Gujaratis (Hindus and Muslims) from northwestern India, Telugu migrants from the South, Bhojpuri-speaking peoples from the north east and central India, and so on.

Generally speaking, then, this mosaic of Indian identities abroad is presented as the mirror of India itself. India is diverse, and so too are its migrants. It is acknowledged that Indian migrants abroad tend to reproduce their own religions, family patterns, and cultures as much as possible. At the same time, however, they adjust to local circumstances. Caste and language issues have to be negotiated in new environments. This is not a natural process, but one in which great efforts need to be made - sometimes in an effort to maintain one's own culture, but also with regard to the host society. In other words, these migrants differ in their cultural and religious backgrounds, in the causes and durations of their migrations, and the extent to which they adapt to local societies.

This collection discusses two basic problems concerning the Indian diaspora. One is the prefix 'Indian'. And the other is the term 'diaspora'. The implication of the first is that there is a single India with its people, who are somehow united under one flag. This is far from 
obvious. India has been described as a 'nation and its fragments' or an 'invented nation'. ${ }^{\mathrm{I} 3}$ In this literature, the unity of India is a construction or, at best, referred to as 'unity in variety'. This is even more the case for South Asians abroad, who have had to experience various processes of integration and assimilation in very different host countries. Moreover, Indians abroad do not so much identify with India as a nation but with the 'homeland', that is, the specific region where the migrants - or their descendants - come from. They often refer to themselves as Bengalis, Gujaratis, Telugus, or to their specific sub-castes, such as Patels, Lohanas, and Cutchis. Inasmuch as they have created a 'myth' about their 'homeland', it appears that region and locality are much more important in structuring the migrants' identities than 'religion' or 'nationality'. Claude Markovits rightly asserts that migrants from Gujarat, whether they were Hindus, Muslims or Jains, had more in common with each other in their experience of migration than $\mathrm{Gu}$ jarati Hindus had with Bhojupuri Hindus, or Gujarati Muslims with Bojpuri Muslims. ${ }^{\mathrm{I}}$ However, this is not the case for many South Asian migrants in the Caribbean, or the 'twice migrants' living in the UK and the Netherlands. They are descendants of Indian indentured labourers who migrated from India to the Caribbean, and from there to the UK or the Netherlands. Most of today's descendants of these migrants are barely aware of their regions of origin, be it Bihar, Bengal, or Uttar Pradesh. However, they continue to maintain, a vague notion of 'India'. Meanwhile, South Asians in the Caribbean, UK, East Africa and elsewhere are often referred to as 'Indians', while the region from which they come does not play a role. This suggests that the prefix 'Indian' has a local meaning, but not so much in terms of 'self-identification', but more as a label used by natives in the host nations. Many non-Indians, do not see India as fragmented, and the geographical masses of the sub-continent somehow presupposes a cultural unity.

This idea of a South Asian subcontinent 'unity' is nowadays reproduced in the vast and growing literature on the 'Indian diaspora', which emphasises how and to what extent 'Indian' culture was reproduced in the various host countries. Furthermore, the often ambivalent relation of migrants abroad to their homeland is highlighted. In this literature, the word 'India' is often rightly substituted for 'South Asian' to refer in particular to the pre-independence migrants whose origins lie in contemporary Pakistan or Bangladesh. Despite this, the Indian Government has recently made a strong effort to reconnect to its 'Indian diaspora' migrants. Here, the word 'Indian' is - again - clearly intended to unify the migrants whose origins lie within the current borders of the Republic of India. This means that the prefix 'Indian' has been defined - though not without problems as we will see in this collection - by the Indian State. At the same time, we realise that these 
problems beg the question: how far can the construct of a comparative Indian diaspora take us?

The second problem is the term 'diaspora'. Despite the growing acceptance of the word as representing migrant groups beside those of the Jewish diaspora, social scientists continue to disagree on two basic questions regarding diapora studies. One is: What is a diaspora? What are we studying? And the second: Who is a diaspora? In other words, do all international migrant groups belong to a diaspora? Moreover, should we consider a diaspora as a static and unchanging phenomena, or is it constantly changing? And if so, how and in what direction, and why? Moreover, from an academic point of view, the question is: What do we gain by using the 'diaspora concept', however it may be defined? Can we expect any new insights or is it just another buzzword? Obviously, the popularity of the term itself is related to the increasing relevance of representations of 'identity' and 'culture' in international politics. ${ }^{15}$ The diaspora debate over the past decade has experienced two extreme positions: One being that the term and concept refers to the specific migration of Jews, which occurred under very unique historical circumstances; while the other is that of a more universal application to all cases of migration and settlement beyond the borders of native nation-states, irrespective of the migration circumstances.

A diaspora refers to a particular kind of migration. Most scientists agree that at least a few of the following characteristics are crucial to describe a diaspora. (I) Dispersal from an original homeland to two or more countries. The causes for the dispersal may vary from traumatic experiences, as was the case with the Jews, or the African slaves, to the search for work, or the pursuit of a trade or other ambitions. (2) There must be a collective - often idealised - memory/myth of the homeland. In some cases, there is a commitment to creating and/or maintaining this homeland, as is the case with some Sikhs and their efforts to create an independent Kalisthan, or the Jews and their relation to Israel. (3) A myth of returning to one's homeland (be it now or in the future, temporary or permanent). This myth is grounded in a strong ethnic consciousness of migrants abroad, which may have prevented them from assimilating in the local society. (4) There is a sense of empathy and solidarity with similar groups elsewhere in the world and/or with events and groups in the homeland. ${ }^{16}$ Diaspora, then, is a contemporary term used to describe practically any population considered 'deterritorialised' or 'transnational', whose cultural origins are said to have arisen in a nation other than the one in which they currently reside, and whose social, economic, and political networks cross nation-state borders and, indeed, span the entire globe. According to Vertovec, for instance, intellectuals and activists from within these populations in- 
creasingly use this term, emphasising that the 'Diasporic language' appears to be replacing, or at least supplementing, minority discourse. ${ }^{\text {I7 }}$

\section{From 'Overseas Indian Communities' to the 'South Asian Diasporas'}

The study of South Asian migrants overseas is not a new phenomenon. In fact, the British Colonial Government itself was among the first to systematically observe, count, and describe the number of Indian migrants, their religious backgrounds, working conditions, and so on, in the British Colonial Empire. These reports, the correspondence and the diaries are still the main sources of South Asian migration history. This means that the migration is often seen by outsiders and not by the migrants themselves. In addition, the themes studied were allied to the knowledge of colonial officials and the desired information for the colonial rulers in the centre of the empire, London. They included such themes as numbers of migrants, questions related to travel permits, settlement conditions, tax payments, trade licenses but also typical colonial obsessions such as sati, Indian sexuality, child marriage, arranged marriages, and religion.

In the I9th and early 2oth centuries, the word 'diaspora' did not appear in these reports. The general denominator was 'overseas Indians' and this was also the phrase used by academics after Indian Independence in I947. The first two comprehensive academic overviews on the history of South Asians overseas were published in the early I950s by Kondapi (I95I) and Cumpston (I953). ${ }^{\mathrm{I}}$ Nevertheless, the interest in the overseas Indians changed once the colonial empire had collapsed. The most popular theme then became cultural persistence, the ability of Indians to retain, reconstitute, and revitalise the many aspects of their culture in an overseas setting. These studies dealt with the processes of acculturation, adaptation and, in the end, the perspective of a plural society, which was first advocated by Furnivall (I948). ${ }^{\text {I9 }}$ Early examples include regional studies by Palmer, Gillion, and Griffit. ${ }^{2 \circ}$ On the macro level, neo-Marxists developed a centre-periphery model of the global development of capitalism, which focussed on the changing push and pull factors which determined the causes of South Asian migration. The emergence of unbalanced regional economic development may have hampered, hindered, or promoted migration. ${ }^{2 \mathrm{I}}$

It has been especially since the mid-I970s that historians, geographers, and anthropologists started producing research in the field of what we now call the 'South Asian Diaspora'. F.N. Ginwala, for example, introduced the notion of the 'Indian South Africans'. The notion of local space and the embedding of Indian culture was studied by S. Shah and S. Winchester. ${ }^{22}$ However, it was, not an 'Asianist' but rather a world historian by the name of Phillip D. Curtin who proposed an 
important shift towards the construction of the South Asian Diaspora. In his book Cross-Cultural Trade in World History (Cambridge I984), he introduces the term 'trade diaspora,' including that of the South Asian 'trade diaspora'. Moreover, he emphasises the relation of cross-cultural traders to their hosts, with each other, and the way that they organised cross-cultural trade. ${ }^{23}$

This growing interest eventually culminated in a unique international conference on 'South Asian Communities overseas'. The conference and the proceedings transformed the rhetoric of South Asian migration and the history of 'Indians overseas'. Note that the word 'diaspora' was not used at this Oxford University conference until I987. The published proceedings (I99I), however, do use the term 'diaspora'. ${ }^{24}$ The book is edited by Steven Vertovec, who also used the term 'diaspora' in his introduction, which highlights the British interest in the history of South Asia in general. It especially emphasised the contribution of Oxford University Press academics. There is no reference to the concept of diaspora in its contemporary sense [see page I4]. None of the other papers use the word 'diaspora', either in the titles or in the articles themselves.

It was in the period from the late I980s to the early I990s that the term 'diaspora' became fashionable. Its connotations were no longer monopolised by the Jewish diaspora. The question was raised whether other groups of migrants could be labelled as a diaspora. Politicians and representatives of overseas communities started using the term 'diaspora'. Africans, Armenians, and indeed Indians and Chinese migrants began to refer to themselves as being part of a 'diaspora'. Moreover, the academic field began wondering how the word 'diaspora' could be useful in understanding migration, migrants, and the relation between the motherland and the host societies. This was highlighted in particular by the establishment of the Journal of Diaspora Studies in I99I.

The point of departure for the Journal of Diaspora Studies is well formulated by its general editor Khachig Tölölyan, who notes that the concept has been related to a growing field of meanings, including processes of transnationalism, de-territorialisation, and cultural hybridity. These meanings are opposed to more 'rooted forms' of identifications such as 'regions' and 'nations'. This implies a growing interest in the discourse of 'rootedness', changing identities and the relation between the local and the global. Some articles in the journal use broad 'checklists' of factors that define the groups in diaspora, including the dispersal to two or more locations; collective mythology of one's homeland; and alienation from the host nation, among others. ${ }^{25}$ These checklists facilitated a debate that arose in the early I990s on the question of whether the Jewish diaspora was unique or whether it could be com- 
plemented with an 'African', 'Chinese', Indian, Armenian, Greek, or indeed any other transnational migrant group.

This question obviously could only be answered by making a comparison between different ethnic diasporas. One of the outcomes was that it might be fruitful not to compare these diasporas based on their ethnic origin but based on the causes of migration such as being victimised (Jews, slaves) or looking for employment (indentured labour and the migration of semiskilled workers). ${ }^{26}$ At the same time, by broadening the field of diaspora studies beyond the Jewish diaspora, the question, ultimately, is: What is the usefulness of a concept that can hardly exclude transnational migrants? In other words, who in today's US cannot be defined as being part of a diaspora according to the available checklists and definitions? Indeed, contemporary studies include titles related to the Irish diaspora, the Caribbean diaspora, and so on. In other words, the question here is: What do we as social scientists gain from the concept of diaspora? How does it help us - if at all - to better understand particular aspects of migration?

A few years later (I995), Peter van de Veer edited his highly-praised volume Nation and Migration: The Politics of Space in the South Asian Diaspora. Van de Veer and other contributors questioned the radical modernity of the experience of displacement, disjuncture, and diaspora. Migration has its own particular ambiguities, based on what Van de Veer calls the dialectics of 'belonging and longing'. Here, the theme of belonging juxtaposes rootedness with uprootedness, and establishment with marginality. Longing, then, was related to the desire for change and movement. In this volume, these topics were articulated in two interrelated areas of importance: nation and migration, and nation and religion. The book presents the diverse forms and dynamics of the 'politics of space'. Interestingly, however, none of the contributors - at that time - questioned whether all South Asians abroad are part of a diaspora. South Asian migrants abroad are presumed to be part of a diaspora by definition. The question is: by which definition? The definition according to the researchers, in their desire to be precise, or according to the subject themselves?

As the diaspora concept has matured, alternative definitions, different approaches, and new suggestions for more research are emerging. Steven Vertovec (2000) proposes three meanings of Diaspora: as a social form; as a type of consciousness, and as a mode of cultural production.

The diaspora as a 'social form' refers to the process of becoming scattered. It draws on the Jewish model, and it looks at how social ties were cemented, at the process of maintaining a collective identity, at the institutionalising networks, and at the social and economic strategies as a transnational group. In addition, it focuses on their political orientations, their inability - or unwillingness - to be accepted by the 
'host society'. Especially now, where communication and transportation are relatively easy and inexpensive, the diaspora as a social form may be characterised as a 'triangular relationship' between (a) the 'globally' dispersed, yet strongly transnational organised group (b) the territorial states where groups reside, and (c) the Indian State or imagined homeland.

The diaspora as a type of consciousness emphasises the variety of experiences, a state of mind, and a sense of identity. This is described as dual or paradoxical nature. This nature has various connotations. First, it refers to the experience of discrimination and exclusion, and at the same time, the positive identification with the highly-praised historical heritage of the Indian civilisation. Second, the awareness of multi-locality, the notion of belonging 'here and there' as well as sharing the same 'roots' and 'routes'. ${ }^{27}$ The awareness of the ability to make a connection here and there, making the bridge between the local and the global. Third, double consciousness creates a 'triple consciousness', that is, the awareness of the double consciousness and being able to use it instrumentally. In addition to the identification with the host society, and the homeland, there is the identification with the locality, especially in the discourse of multiculturality. Indians in Southall, London include the awareness of being 'Southallian', emphasising their multi-racial character, within the discourse of the multi-cultural character of their local environment. ${ }^{28}$

The diaspora as a mode of cultural production emphasises the currents of cultural objects, images, and meanings back and forth, and the way these transcend, creolise, and change according to the wishes of the customers and artists. It refers to the production and reproduction of transnational social and cultural phenomena. Here, the position of youth in diaspora is highlighted They are socialised in cross-currents of different cultural fields and form an interesting market for 'diasporic cultural goods'. Moreover, they are the ones who receive and transform these new ideas and developments. Furthermore, it is clear that modern media are used to reformulate and translate the cultural traditions of the Indian diaspora. The popularity of episodes from the Ramayanan or the Mahabharata among the migrants has led to new ideas regarding 'Indian' culture'. The Indian diaspora has also found its way into the virtual existence of the Internet, with its numerous discussion lists, 'find one another through school pictures sites' and transnational marriage agents.

The Indian Government itself has recently become a factor in the diaspora debate. It generally tends to overestimate the importance of Indian 'diasporic feelings'. In its recently published Report of the High Level Commission, it states that 'Since India achieved Independence, overseas Indians have been returning to seek their roots and explore 
new avenues and sectors for mutual beneficial interaction from investment to the transfer of economic skills and technology, to outright philanthropy and charitable work. This trend has become more marked in the last decade, as the Indian economy has opened up, giving rise to a new range of opportunities for emerging generations'. ${ }^{29}$ But this is, in fact, far from true and more the consequence of wishful thinking. The main aim of the commission is to explore the possibilities of improving the relationship between India and 'Persons of Indian Origin' [PIO] and 'Non Resident Indians overseas [NRI]'. This is, of course, the result of the Indian Government's disappointment felt in the role that PIOs and NRIs have played until now. But it is not just the Indian Government that wants to re-connect with overseas Indians. The Bollywood fashion designers use the newly available cheap media techniques, one way or the other, to advertise their products to potential buyers in the Indian Diaspora. Bollywood videos and music are sold world-wide. And there are numerous Internet sites where Indians in diaspora can share their views, discuss politics, and reunite with the 'homeland', virtually. Indian fashions can be purchased not only in India, but also in the UK, Canada, and anywhere else with a sizeable 'Indian' community.

The Indian Government and industry's re-connection with the Indian Diaspora has to be seen from an instrumental perspective. That is, they choose what and who to re-connect with and they have their own reasons for doing so. Thus, for political reasons, the Indian Government chooses not to focus on 'Indian' (PIOs) Hindu and Muslims who now reside in Bangladesh and Pakistan. They do not invite them to invest in India or share dual citizenship. Moreover, some PIOs suggest that the Government focuses on the well-off PIOs, rather than the poorer ones. However, the Government denies this. It is interesting to note that the very existence of the Indian Government creates an actor with regard to the notion of 'diaspora' that barely exists in the diaspora of Africans. Nevertheless, the fact that the Indian Government followed the Chinese example of reconnection the diaspora may find some attention in western African nations in the near future. The question remains: Who is and who is not responding to these messages and why? Especially, the more negative and ambivalent responses, which have until now in particular been underestimated in the diaspora discourse, will be highlighted in numerous contributions in this collection.

The issue of inclusion in or exclusion from the diaspora is even more complex from a historical point of view. Historical sources are mostly related to particular geographical areas. In general, they are more focused on the local migrants' issues and than their social or cultural ties to their homelands. Therefore, making it extremely difficult to deduce 
the social, economic, or cultural relations with the homeland. In short, the question here is why and when do South Asian migrants overseas consider themselves as part of a 'South Asian diaspora' and what do they gain from it in economic, sociological, or cultural terms? How should researchers respond when they themselves do not feel comfortable with the terms and definitions of the diaspora framework? Each article in this collection formulates its own responses to these questions, and together they present a continuum from essentialist views to modern mosaics of impressions.

\section{The Articles}

The articles in this volume all deal with general issues related to the local identity of the 'Indian' migrants, including their attitude towards India. They emphasise that the identity of 'South Asians' is neither an unchanging, primordial identity, nor an infinitely flexible one that one can paint, fill in, or reuse at will, depending on the circumstances. The identity is constantly being negotiated in changing contexts. This assumption is true in South Asia as much as it is in the South Asian diasporas. The authors in the following articles all highlight and determine how this identity is negotiated in various parts of the world. Therefore, they focus on regions populated by South Asians, their relation to their host countries and their homeland, as well as the length of time they spend abroad.

People in diaspora are part of both a global history and a local history. Historians should emphasise the dynamic processes of changing attitudes towards the homeland, the host country, and the diasporic community itself. A historical and comparative approach may help us to understand some of these dynamics. The first section of the book is devoted to the historical perspectives of the Indian diaspora. Here we deal with the problem of a concept that was not yet in use during the period being researched. Scott Levi investigates the concept of diaspora as an analytical tool by exploring the emergence of an Indian trading diaspora during the course of the seventeenth century. He focuses on the Indian merchant communities of 'Multanis' and 'Shikarpuris' who dispersed across Afghanistan, Iran, Central Asia, the Caucasus, and much of Russia. This article shows that the definition of diaspora as used by Abner Cohen and others helped him to understand both the emergence and the social organisation of the diaspora. Here, the term 'diaspora' implies that the Multani and Shikapuri communities maintained an identity with their homeland. Nevertheless, this homeland was not India. Nor did the traders themselves identify themselves as part of the Indian diaspora. The author applies the concept to empha- 
sise particular aspects of migration; in this case, identification with the traders' geographical origins and their ambivalent relationship with their host society. He concludes that the ability of both Hindu and Muslim traders to maintain thriving communities in Central Asia may be attributed to the fact that they were widely respected as large-scale trans-regional traders, whose fortitude and commercial connections were valuable resources for the local regions. However, he also cites some exceptional cases that show that this relationship was not always a harmonious one. Levi ultimately links this century-old trade diaspora to the modern world and the Indian diasporas of the nineteenth and twentieth centuries, including its association with the socio-economic trauma which was provoked by the Partition.

In the second article, Gijsbert Oonk applies 'the perspective from below'. Taking the agent's viewpoint he argues that the first generation of Hindu Lohanas of East Africa remained close with their home villages in western India. They regularly went back for family visits, trade and marriages. However, the process of settling in led to fewer and fewer visits to the homeland as their economic and cultural orientations shifted from India to East Africa. Oonk reveals how Lohanas in East Africa initially promoted the reproduction of Gujarati language and culture during the colonial period. Nevertheless, the second and third generation of migrants lost their abilities to read, write, and speak $\mathrm{Gu}$ jarati, despite the efforts of some Hindu organisations and the wishes of the elderly members of the community. Moreover, they learned English - instead of Swahili - and this became an essential aspect of Indian education in East Africa. In other words, the second and third generation Lohanas consciously chose not to reconnect with India , Indian languages and culture and developed a more 'Indian African' identity. Oonk, therefore, argues that the diaspora concept with its strong emphasis on rootedness, homeland, reproduction of Indian culture abroad, cannot help us to understand the history of the Lohana community in East Africa'. This article reveals that the process of identifying with one's homeland is not without its struggles, and that it has both local and global significance. While, Levi could not stress the process of 'self-identification' due to the nature of the sources, Oonk shows that the Hindu Lohanas in East Africa do not consider themselves as part of the Indian diaspora, preferring instead to focus on a local Asian-African culture. By taking the perspective of the migrants themselves, this article shows that the re-linking assumed by the concept of diaspora and the Indian Government may have a strong instrumental flavour.

Meanwhile, Chandrashekar Bhat and T.L.S. Bhaskar discuss some theoretical implications of the diaspora concept. They present the idea of an 'old' and a 'new' diaspora and how this affects the degree of inter- 
action with the motherland. Here, the Telegu language is seen as one of the most important carriers of culture and identity and that Telugu migrants find it much easier to replicate caste and regional identities related to the 'original' Andhra Pradesh, because of the emergence of modern mass media and the Internet. They reveal that those who migrated in earlier generations may have identified more with their respective host countries. Furthermore, it shows a fruitful example of how identity formation can be compared within the same group. In this case, that of the Telugu migrants in the US, Mauritius, and Fiji.

The most critical contributions related to diaspora concepts are yet to come. Ellen Bal and Kathinka Kerkhoff's article forcefully integrates three diaspora perspectives. They utilise the diaspora concept as an analytical tool not unlike how academics and the Indian Government use it. Moreover, they highlight the importance of a perspective 'from below', that is from the migrants themselves. They also emphasise a comparative perspective by focussing on cases in Mauritius and Suriname. They emphasise the fact that Muslims are often excluded from the Indian diaspora category. Muslims have identified themselves in their own ways over time and geographical locations. South Asian Muslims in Suriname have long desired an undivided homeland called Hindustan, whereas in Mauritius, Muslims of British-Indian descent prefer local inclusion as a separate ethnic community. The results of this empirical research has stimulated their criticism of academics as well as of the Indian State in the way they incorporate, or exclude, Muslims in the Indian diaspora. This, again, shows the importance of localised empirical research.

John Mattausch's contribution embraces the notion that the economic success of the Gujarati community in the UK is an accident rather than something due to structural factors. He takes a long-term historical perspective in order to show that the recent economic success of that community is just a very recent phenomena. This suggests that success factors mentioned in the academic literature, like the role of the extended family or the role of the community only become important in very specific socio-economic areas. He shows that the community's twin trajectories - diversely capitalist and traditionally Hindu requires that we as social scientists consider the substantial analytical role that chance plays in explaining how the parallel developments occurred.

In the second section we focus on the sociological and anthropological research involving the Indian diaspora, which shares its 'perspective from below'. Mario Rutten and Pravin J. Patel introduce a 'two sited' approach as they integrate their research among Indian immigrants in the UK with that of the Gujarat villages of origin. They highlight the importance of the social environment of the migrants' locality of origin 
and the social environments of the localities to which they have migrated. These transnational family relations should neither be considered homogenous, nor as separate communities. They reveal that the first-generation Patel community in London shows little interest in productive investments in India, but they do show some interest in providing some religious funding. They also highlight certain levels of ambivalence in London, in their mother country, and their home villages, which the elderly people visit three months a year. Ultimately, they do not feel at home in either London or India. This shows that the migration experience and the extent of local integration has an impact on an migrant's identity to the extent that the notion of home becomes ambivalent. Interestingly enough, the authors prefer to focus more on transnational contacts than on the concept of diaspora. The strength of this type of research is that it shows two sides of the same coin. The researchers studied their subjects in the UK and their families in India. This is in strong contrast with the bulk of the empirical research, which is usually based solely on the host country, which, in turn, is due to the financial and social constraints of anthropological fieldwork.

Anjoom Mukadam and Sharmina Mawani's article explicitly compares the 'self definition' [label chosen by an individual to express one's identity] of second-generation Nizari Ismailis in both Toronto and London. They argue strongly against the dominant migrant discourse because they emphasize that second-generation migrants did not migrate - they were born in the host countries - and have become part of a larger local identity more than of a Indian 'diasporic identity'. They make a strong argument for replacing dominant essentialist conceptions like 'between two cultures' and the 'half-way generation' with a more structuralist view. By emphasising the hybrid character of the Ismaili identity, they simultaneously reveal a tendency to define themselves part of Canada or the UK rather than as part of a diaspora. Mukadam and Mawani do not deny the importance of a diasporic identity, but prefer to highlight the self-emphasised 'national' identity. This raises questions about what we omit from migrant identities, when we focus too much on the 'diaspora' as an organising method of research.

Sanderien Verstappen and Mario Rutten take a different angle. They reveal that while media are discussed in the diaspora literature, it is usually under the assumption that transnational media help reconnect diasporic communities to their home countries. However, the assumed link between media from the home country and viewers' identification with that home country is problematic and must not be taken for granted. Indian movies are very popular among Surinamese Hindustani's in the Netherlands. The audience, however, seems strikingly disinterested in the actual realities of the South Asian subcontinent itself. 
This article describes the reception of commercial Bombay cinema among Hindustani youngsters in the Netherlands.

The last article by Brit Lynnebakke shows that in the case of Hindustanis in the Netherlands, the diasporic images of the homeland do not fit the general positive connotations as suggested in the literature. These 'twice migrants' [arriving via Suriname] do not freely interact with the 'direct migrants' from India in the Netherlands. Meanwhile, the 'direct' migrants have managed to develop an image of the traditional 'Surinamese Hindus', because they have preserved the Indian tradition even better than those in India. Suriname Hindus are offended by the fact that they are not considered reliable marriage partners because of their Surinamese and/or Bihari backgrounds. Lynnebakke focuses on why a 'pan-India' identity has failed to emerge in the Netherlands. Migrations trajectories as well as educational and class differences seem to be the main reasons.

In contrast to the mainstream diaspora literature, the articles in this book emphasise the ambivalent relations of the migrants with their Indian homeland. Their migration trajectories vary from region to region; from circular migration to permanent settlement; from free migration to forced migration. While some may visit India frequently, others have settled permanently in their new host countries. Some may have created a 'cultural India abroad', while others may develop a more global outlook. The Indian Government as well as the earlier Indian Colonial officials, all responded differently to the various migration trajectories, all of which makes it very difficult to unify the migration of South Asians under a single concept of Indian diasporas. In his 'afterword' Claude Markovits emphasises that this in itself is not sufficient reason to reject the concept out of hand. And he is right, of course. But instead of focusing on the possibilities of the concept, he shows how two types of migrations (the migrations of traders and workers) may intermingle and create less analytical distinction as suggested by the diaspora literature. Therefore, this collection prefers to explore how we can interpret these various trajectories. Grounded in fieldwork and archival research, these papers share a strong feeling for a 'history from below' with an eye for nuance and variation. The authors collectively argue that empirical, contextual, comparative, and historically well-defined research will refine our understanding of complex historical as well as contemporary processes of migration.

\section{Notes}

I Figures vary from I2,000,000 to $26,000,000$ depending on whether or not they include Non-resident Indians (NRIs), 'mixed' parentage and their offspring. In general, 
these figures do not include the People of Indian Origin who now reside in Pakistan and Bangladesh. Many statistics also exclude the number of 'Indians' settled in Sri Lanka, Myanmar and Nepal.

2 The limits of the use of the word 'Indian' and the fact that this process of adaptation is not a 'natural' process will be discussed further in this introduction.

3 Recent examples include, G. Oonk, "The changing culture of the Hindu Lohana community in East Africa', Contemporary South Asia (13) I, 2004, 7-23. In this article, the process of cultural adaptation of migrants towards a new environment is described in terms of a process of stretching and closing preferences of identity from the migrants' perspective. See also, K.E. Nayar, The Sikh Diaspora in Vancouver: Three Generations amid Tradition, Modernity, and Multiculturalism. Toronto: University of Toronto Press, 2004. M. Gosine and D. Narine (eds.) Sojourners to Settlers: Indian Migrants in the Caribbean and the Americas, New York: Windsor Press 1999.

4 G. Sheffer, Diaspora Politics : At Home Abroad, Cambridge 2003; W. Saffran, Diasporas in Modern Societies, Diaspora I (I) I99I, 83-99; W. Safran, 'Comparing Diasporas: A Review Essay', Diaspora 8 (3) I998, 255-92.

5 R. Cohen, Global Diasporas, London I997, 26. Safran, ibid. 1998.

6 S. Dale, Indian Merchants and the Eurasian Trade, 1600-1750. Cambridge: Cambridge University Press 1994; C. Markovits, The Global World of Indian Merchants 1750-1947. Traders of Sindh from Bukhara to Panama. Cambridge: Cambridge University Press 2000; S. Levi, The Indian Diaspora in Central Asia and its Trade 1550-1900, Leiden: Koninklijke Brill 2002; D.W. Rudner, Caste and Imperialism in Colonial India: The Nattukotai Chetiars, Berkeley: University of California Pressi994; B. Sue-White, Turbans and Traders: Hong Kong's Indian Communities. Hong Kong: Oxford University Pressi994.

7 M. Carter, Coolitude: An Anthology of the Indian Diaspora, London: Athens Press 2002. K.O. Laurence, A Question of Labour: Indentured Immigration into Trinidad and British Guiana, 1875-1917. London: James Currey 1994.; D. Northop, Indentured Labour in the age of Imperialism 1843-1924. Cambridge: Cambridge University Press 1995. H. Tinker, A New System of Slavery: the Export of Indian Labour Overseas, 18301920, Oxford: Oxford University Press 1974.

8 Bosma, U. and G. Oonk, 'Bombay-Batavia. Parsi and Indo-European variations in mediating I800-I947', in N. Randeraad (ed.), Mediators between State and Society in Comparative Perspective. Hilversum Verloren 1998, I7-40. H. Tinker, 'Indians in South East Asia: Imperial auxiliaries,' in C. Clarke, C. Peach, S. Vertovec, South Asians Overseas: Migration and Ethnicity. Cambridge: Cambridge University Press I990.

9 M.I. Abella, 'Asian migrant and contract workers in the Middle East, in R. Cohen (ed.), the Cambridge Survey of World Migration. Cambridge: Cambridge University Press 1995, 4I8-423. K. Gardner, Global Migrants, Local Lives: Travel and Transformation in Rural Bangladesh. Oxford: Clarendon Press 1995.

Io P. Bhachu, Twice Migrants: East African Sikh Settlers in Britain. London: Tavistock Publication 1985. M. Twaddle (ed.), Expulsion of a Minority: Essays on Ugandan Asians. London: Athlone Press I975. R.S. Gowricharn, De duurzaamheid van het transnationalisme, in Migrantenstudies 2004, 252-268. C. Choeni and K. Sh. Adhin, (eds.), Van Brits Indisch Immigrant via Suriname tot Burger van Nederland. Den Haag: Sampreshan 2003 .

II See, e.g., Varma, Sushma J., and Radhika Seshan (eds.). Fractured Identity: The Indian Diaspora in Canada. New Delhi: Rawat Publication. 2005. Judith M Brown, Global South Asians: Introducing the Modern Diaspora, Cambridge University Press 2006. 
I2 K. E. Nayer, The Sikh Diaspora in Vancouver: Three Generations amid Tradition, Modernity, and Multiculturalism. London: University of Toronto Press, 2004; C. Choeni and K. Sh. Adhin, (eds), Van Brits Indisch Immigrant via Suriname tot Burger van Nederland. Den Haag: Sampreshan 2003.

I3 Partha Chatterjee, The Nations and its fragments: Colonial and Postcolonial histories, Princeton: Princeton University Press I993. G. Aloysius, Nationalism without a nation in India: New Delhi, Oxford University Press 1997.

I4 C. Markovits, The Global World, 6.

I5 Kim D. Butler, 'Defining Diaspora, Refining a Discourse', Diaspora Io (2) 2001, I89219. R. Cohen, Global Diasporas: An introduction, Seattle: University of Washington Press 1997; W. Safran, 'Diasporas in modern societies: myths of homeland and return', Diasporas (I) I I99I, 83-99. S. Vertovec, The Hindu Diaspora. Comparative Patterns. Routledge: London 2000.

I6 Cohen, Global Diasporas, 26.

I7 James Clifford 'Diasporas', Cultural Anthropology, (9) 3 I994, 3II.

I8 I. Cumpston, Indians Overseas in British Territories. London: Oxford University Press I953. C. Kondapi, Indians Overseas 1838-1949. Bombay: Oxford University Press I951.

I9 J.S. Furnivall, Colonial Policy and Practice: A comparative Study of Burma and Netherlands India. New York: Cambridge University Press I948. This literature - related to India - is well summarised in R.K. Jain, Indian communities abroad. Themes and Literature. Delhi Manohar I993.

20 K.L. Gillion, Fiji's Indian Immigrants. Melbourne: Oxford University Press I962. J.A. G. Griffith, Coloured Immigrants in Britain. London: Oxford University Press I960; M. Palmer, The History of Indians in Natal. Cape Town: Oxford University Press I957.

$2 \mathrm{I}$ G. Frank, Capitalism and Underdevelopment in Latin America, New York: Monthly Review Press I967. I. Wallerstein, 'The Rise and Future Demise of World Capitalist System: Concepts for Comparative Analyses.' In Comparative Studies in Society and History I6, I974: 387-4I5; S. Amin, Unequal development. London Monthly Development Press i976.

22 F.N. Ginwala, 'Class. Consciousness and Control: Indian South Africans, I960I946'. D.Phil., Oxford University I974; S. Shah, 'Aspects of the Geographic Analysis of Asian Immigrants in London,' D.Phil thesis, Oxford University I980; S. Winchester 'Social Activity and Spatial Structure,' D.Phil thesis Oxford University, I98I.

23 Phillip D. Curtin, Cross-Cultural Trade in World History, Cambridge:Cambridge University Press I984. His most important predecessor may be Abner Cohen, Customs and Politics in Urban Africa: A study of Hausa Migrants in Yoruba Towns. Los Angeles: University of California Press I969. He expanded on this in his 'Cultural strategies in the organization of trading diasporas', in Claude Meillassoux (ed.), The Development of Indigenous Trade and Markets in West Africa, pp. 266-8I. London: Oxford University Press 197I. See also Scott Levi's article of in this book.

24 The proceedings have been published: S. Vertovec, Oxford University Papers on India. Aspects of the South Asian Diaspora. Oxford: Oxford University Press I991.

25 Kim D. Butler, 'Defining Diaspora, Refining a Discourse, Diaspora Io (2) 200I, I892I9. R. Cohen, Global Diasporas : An introduction, Seatle WA, University of Washington Press 1997; W. Safran, 'Diasporas in modern societies: myths of homeland and return', Diasporas (I) I I99I, 83-99; S. Vertovec, The Hindu Diaspora: Comparative Patterns, London: Routledge 2000.

26 Cohen, Global Diasporas.

27 P. Gilroy, "There Ain't no Black in the Union Jack": The cultural politics of race and nation. London: Verso, I987. 
28 William Safran also emphasises that 'Diaspora consciousness is a particular kind of awareness said to be generated among contemporary transnational communities'. (Safran I99I).

29 The Indian High Level Commission, Report on the Indian Diaspora. See also: Lal, India's Missed Opportunity, London: Ashgate $200 \mathrm{I}$. 

PART 1

CRITICAL HISTORICAL PERSPECTIVES 



\title{
2 Multanis and Shikarpuris \\ Indian Diasporas in Historical Perspective
}

\author{
Scott Levi
}

\section{Defining 'Merchant Diaspora'}

In recent years, the term 'diaspora' has been more frequently used to characterise peoples existing away from their homelands. Khachig Tölölyan, editor of the journal Diaspora, asserts that the term that once described Jewish, Greek, and Armenian dispersion now shares meanings with a larger semantic domain that includes words like immigrant, expatriate, refugee, guest-worker, exile community, overseas

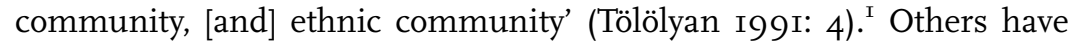
even more broadly defined diaspora as 'that segment of a people living outside the homeland' (Connor i986: I6). Expanding the definition to include virtually any group of people living beyond the boundary of its perceived homeland has enhanced the term's utility for the emerging discipline of Transnational Studies by facilitating comparative studies and providing new topics of inquiry and a model for understanding such phenomena. However, the rather amorphous and potentially confusing nature of the term's contemporary usage risks diminishing its effectiveness, motivating a narrower definition for the present discussion.

The etymology of the word 'diaspora' can be traced to the Greek 'diasporá', derived from the combination of dia, meaning 'over', and speiro, 'to sow', as in scattering or planting. The term was probably first used in the third century B.C.E. by Greek-speaking Jews in reference to their exile from the holy land and dispersion among the Gentiles in the sixth century B.C.E. ${ }^{2}$ In this context, the term refers to a situation in which a number of communities sharing a common national, religious, or ethnic identity exist apart from a common homeland. The term also implies that, over time, the communities maintain their distinctive identity, despite their existence as a distinct minority living in a host society. A diaspora community therefore avoids assimilation, and may employ any of a number of techniques to do so. These include: continued identification or interaction with its unique homeland; use of a specific language; identification with a socio-religious system other 
than that of the host society; the maintenance of a residence in a communal settlement separate from the host society; economic specialisation; and the pursuit of bilateral relations with similar, geographically dispersed diaspora communities.

In our present discussion, the use of the term 'diaspora' implies that the Multani-Shikarpuri communities maintained an identification with their homeland, an internal cohesiveness as exclusive communities, and continued to be perceived by members of the diaspora and the host society as a cultural 'other'. This follows Abner Cohen's use of the term as:

distinct as a type of social grouping in its culture and structure. Its members are culturally distinct from both their society of origin and from the societies among which they live. Its organization combines stability of structure but allows a high degree of mobility of personnel. It has an informal political organization of its own which takes care of stability of order within the one community, and the co-ordination of the activities of its various member communities in their perpetual struggle against external pressure. It tends to be autonomous in its judicial organization. Its members form a moral community which constrains the behaviour of the individual and ensures a large measure of conformity with common values and principles. It also has its own institutions of general welfare and social security. In short, a diaspora is a nation of socially interdependent, but spatially dispersed, communities (A. Cohen I97I: 267). ${ }^{3}$

Multiple historical processes may motivate groups of people to leave their homeland and form a diaspora. These can most generally be divided into the categories of provocation and attraction. Briefly, factors which might provoke the formation of a diaspora include social, economic, or political coercion which motivate groups of people to leave their homeland in search of improved opportunities elsewhere ('victim diasporas'). Conversely, diasporas may also arise out of a group's attraction to a region promising greater recompense for their labour ('labour diasporas') or, as in the present case, where they may be in a position to pursue lucrative commercial endeavours involving the mediation of cross-cultural trade ('merchant diasporas'). The latter process requires the individuals involved to relocate and regularly participate in the cultural arena of their host society. When their efforts prove successful, other individuals may be attracted to similarly profitable locations and, over time, form what has come to be known as a merchant diaspora: a network of interrelated communities established in locations strategic to their engagement in specific types of commerce and transregional 
trade (Curtin I984; Dobbin I996). The early modern dispersion of Armenian merchant communities mediating cross-cultural trade across much of Eurasia provides a classic example of a merchant diaspora (Curtin I984: I79-206; Herzig I996: 305-22).

In practical application, at least to some degree, the dichotomy established above may prove to be a false one. That is to say, the motivation of communities to live a collective expatriate existence can sometimes be ascribed to more than just one factor. For example, the migrations of Armenian merchant communities are commonly attributed to commercial incentives stemming from the convenient location of their Transcaucasian homeland, situated on overland trade routes connecting Russia and Iran (and the commercial markets to the east of Iran) with Anatolia, Syria and the Levant (Herzig I996: 3II). Armenians capitalised on their geography by actively participating in transregional trade and establishing merchant diaspora communities in numerous distant markets (Curtin I984: 185-6). Yet Armenian migrations were also known to have been motivated by factors of socio-political provocation, such as the Safavids' sixteenth- and early seventeenth-century resettlement of a large number of Armenians from their home in the Armenian town of Julfa to a dedicated suburb of Isfahan, named New Julfa (McCabe I999: 35-66). Furthermore, it is not unknown for diaspora networks that formed in response to factors of provocation to capitalise on their spatial dispersion by initiating long-distance, cross-cultural commerce between pre-existing communities (Wink I987).

Merchant diasporas tend to differ from other types of diasporas in several important respects. Most notably, they are characterised by a higher degree of mobility, a greater amount of communication between communities, and a higher degree of interaction with the indigenous population. Unlike other diaspora categories, merchant diasporas may even be peopled by a rotating, gender-specific (generally male) population. A useful list of topics of inquiry relevant to the study of modern merchant diasporas is provided by Abner Cohen:

What are the criteria of distinctiveness and of recruitment? How is the demographic adjustment between the sexes and the ages achieved? What mechanisms for communication between the members of one community and between one community and another within the same diaspora are employed? How, when denied resort to the regular exercise of organized physical coercion, is authority organized? What kinds of power are mobilized to support this authority? What is the nature of the relationship of trust between the various types of businessmen operating in them? How is credit made possible and how is it regulated? What are the procedures underlying decision-making in com- 
munal affairs? What are the characteristics of the articulating ideologies employed and what are the mechanisms by which these ideologies are kept alive? How do structure and culture affect one another in the historical development of these diasporas? (A. Cohen I97I: 268.)

Thus, one can appreciate that a study of even a contemporary merchant diaspora is a difficult, complex endeavour. How is one to conduct a thorough analysis of a pre-modern merchant diaspora? The effort necessarily requires a nearly impossible wealth and variety of information unlikely to be found in archives or to have survived the centuries. Considering the secretive attitude pre-modern merchants held toward their commercial transactions, especially those merchants rather vulnerably dispersed in diaspora communities, much of the information about individuals' commercial activities and the communities' social operations was either never recorded or was intentionally destroyed after it lost its immediate usefulness. ${ }^{4}$

Without a comprehensive source of information providing insight into the activities of a single Indian diaspora community at a specific time, one must instead take a broader approach and extrapolate from information regarding related communities scattered throughout diverse sources. Although inadequate for a sociological analyses of a single diaspora community, this methodology embraces the sources' temporal and spatial inconsistencies and improves our ability to investigate the development of the diaspora and its transformation over the longue durée. It is our contention that, in the context of the Indian diaspora communities discussed here, this approach is a useful one for gaining insight into the dynamics of this diaspora as it changed over the centuries.

\section{Multan and the Multanis}

The identification of the majority part of the Indian merchant diaspora population as 'Multanis' reflects their connection to the north-western Indian region of Multan and its capital of the same name. Multan is today a dry and dusty, though prosperous, industrial town in the southern Punjab region of Pakistan. During the medieval and early modern eras, however, the term 'Multan' (or 'Multanistan') referred to a flourishing province situated between the Punjab (to the north) and Sind (to the south). As early as the eighth century B.C.E., the city of Multan was an important commercial centre on India's north-western frontier and, in the centuries that followed, it was an attractive target for a number of invaders of India, among the more famous of whom were 
Darius I in the sixth century B.C.E. and Alexander the Great in the fourth century B.C.E. Prior to the Arab conquest of Sind in the eighth century C.E., the city of Multan was known by the designation 'Mulastana', or the Indianised 'Mulastanapura'. In the beginning of the eighth century, Muhammad ibn Qasim captured the city in the name of the Umayyad Caliph Abu al-'Abbas al-Walid I ibn 'Abd al-Malik, renamed it 'Multan', and ushered in an era of Muslim control that lasted uninterruptedly for over a millennium (Durrani I99I: I-9; Dasti I998: I-I6). Historical accounts attribute Multan's early prosperity to monetary offerings to the city's celebrated Temple of the Sun God, which is reputed to have drawn pilgrims from throughout India. In the years that followed the Arab invasions, however, Multan grew both as a commercial and cultural centre, and the patronage of its wealthy Muslim rulers attracted migrants from throughout the Islamic world. Many of these individuals settled permanently in Multan and even today their tombs exist as a monument to the history of Islam in north-western India.

In the medieval era, Multan prospered as an important outpost for the caravan traders who traversed Afghanistan, entering and leaving the subcontinent through the Khyber Pass (travelling through Kabul), the Gumal Pass (travelling through Ghazni, south of Kabul), and either the Bolan or Sanghar Passes (both of which connected Indian cities with Qandahar, the most important commercial centre in southern Afghanistan). Despite their seasonal and potentially dangerous nature, these trade routes enabled caravan traffic between a number of India's north-western urban centres and distant markets in Central Asia, Iran and beyond. The city of Multan historically benefited from its strategic location near these mountain passes and the confluence of the Ravi and Chenab rivers (the rivers have more recently changed courses and currently join some forty kilometres north of the city). For many centuries, this facilitated the movement of goods down the Indus to the Arabian Sea ports of Lahori Bandar and Thatta. Furthermore, Multan was also an important agricultural centre, renowned in the early modern era as today for its cotton production and textile industry. ${ }^{5}$

Following his visit to Multan in 9I5, the Arab geographer Mas'udi reported that Multan played a central role in India's overland trade with other regions of the Muslim world, including Khurasan, Zabulistan (an eastern region of modern Afghanistan which includes the city of Ghazna, the celebrated capital of the Ghaznavids) and Sijistan (also known as Sistan, a region in southwestern Afghanistan bordering Iran). This is confirmed by other medieval Arab geographers, including Istakhri, ibn Hawqal, Maqdisi and the famous Central Asian astronomer and traveller, al-Biruni. ${ }^{6}$ By the thirteenth century, merchants and merchant communities associated with that region had become widely known as 'Multanis' and, as these merchants directed their commercial 
enterprises north-westward in later centuries, the Multanis became increasingly associated with their commercial activities outside of the subcontinent. Thus, according to Irfan Habib, the eighteenth-century lexicon Bahâr-i 'Ajam defines the term 'Multani' as 'the general name for a Hindu in Central Asia and Persia' because the Indians who lived in those regions originated in Multan (Habib ig64: 406-7).

The significance of Multan and the Multanis grew dramatically under the dominance of the Turko-Afghan Delhi Sultanate (I206-I555). Multanis are first mentioned in association with large-scale merchantmoneylending in the historical work of the Indian author Zia al-Din Barani who, in the early fourteenth century, identified them as important financiers and transregional commercial agents for the Delhi Sultanate. Barani mentioned the Multanis in conjunction with sûdagârs (large-scale merchants), although he distinguishes between the two, and he elsewhere refers to the Multanis' propensity toward moneylending, mentioning them in relation to sahs (large-scale Hindu moneylenders) (Zia ud-Din Barani I860-62: I20, I64, 310-II). According to Barani, in an effort both to lower and standardise the price at which textiles were sold in the Sultanate, the Delhi Sultan 'Ala' al-Din Khalji (reigned I296-I3I6) issued a farmân (mandate) that required Multanis and sûdagârs to sell their textiles at fixed prices (the sultâni rate). Toward this end, 'Ala' al-Din advanced wealthy Multanis two million tanga (the currency in circulation at the time) from the treasury to subsidise their commerce in textiles throughout the Sultanate. ${ }^{7}$ Especially considering the Khaljis' Turko-Afghan origins, it is not unreasonable to conclude that, even in the fourteenth century, commercial ventures took many Multanis to the markets of Central Asia. This is likely to have increased during the reign of the fourteenth-century Central Asian conqueror Amir Timur, who purposefully diverted many Inner Asian caravan routes through Samarqand.

The Multani firms enjoyed the patronage of the Delhi Sultanate nobility, and as the firms prospered they placed larger numbers of agents at strategic locations in urban and rural markets across north India. Some agents were stationed in villages, where they advanced loans to farmers in exchange for a portion of the harvest. Other agents functioned as brokers, purchasing the remainder of the harvest for cash, loaning raw cotton to weavers in exchange for finished bolts of cloth, and moving the agricultural surplus and finished commodities from the countryside to urban or regional markets. Still other Multani agents operated as large-scale transregional traders in the subcontinent's major commercial centres. The Delhi Sultans valued the Multanis as an important source of tax income, a convenient reserve of capital in times of need, important wholesalers of agricultural goods and textiles, and, perhaps most importantly, as village moneylenders and dedicated 
operators of a rural credit system. Arguably the Multanis' greatest service to the nobility was their extension of a monetised economy into the Indian countryside, which greatly facilitated the Delhi Sultans' efforts to collect taxes in cash rather than kind.

The patronage of the Delhi Sultans was clearly a significant factor in the rise of the Multani firms, but even more important was the increasing circulation of precious metals in the Indian economy. Scholars have long observed that South Asia lacks significant reserves of gold and silver in its soil, and that pre-modern India's greatest wealth was its agricultural production. Since antiquity, the gold and silver that was minted into Indian coinage and circulated throughout the subcontinent was largely imported from abroad, exchanged in port cities and frontier towns for caravan-loads of spices, cotton textiles, dyes and other agricultural goods. During the medieval and early modern eras, several historical processes conspired to advance India's monetisation, and the prosperity of the Multani firms along with it. One of these was the deliberate effort of the Delhi Sultans, continued under the Mughals, to encourage a general increase in trade across the north-west frontier. Other factors contributed to this process as well, but the most important were the Spanish conquests in the New World and the almost single-minded fervour with which the Conquistadors seized the rich gold and silver reserves of the former Aztec and Incan Empires, melted down that which was in use, and established an elaborate network of mining settlements to extract more. Scholarship suggests that the average silver exports from the New World to Spain in the years 1565-1685 should be estimated at between 25,000 and 35,000 tons per year: an impressive sum which is argued to have doubled in the years I685-1810 (Tignor 2002: I02-4). As ships loaded with specie sailed both east and west from the New World, much of this wealth circulated around the globe and gradually found its way into the Indian Ocean. Or, in the words of the seventeenth-century French traveller to India, François Bernier, 'it should not escape notice that gold and silver, after circulating in every other quarter of the globe, come at length to be swallowed up, lost in some measure, in Hindoustan' (Bernier I891: 202). The injection of this wealth into the Indian Ocean economy had a profound effect on Indian society: one which scholars have only begun to explore.

Clearly, then, the emergence and development of the Indian merchant diaspora in Central Asia in the years following the establishment of the Mughal Empire and the Bukharan Khanate is a product of the conjunction of several historical processes. These include: increasingly active Eurasian commercial markets, the advancement of Indian commercialists' economic influence both inside and outside of the subcontinent, and a general intensification of Indo-Central Asian cultural and 
commercial contacts. The most notable result of this intensification was the growth and development in Central Asia of the Indian merchant diaspora itself. Thus, sixteenth-century sources mention Indian communities settled in the urban centres of Bukhara, Samarqand and Tashkent, as well as in certain cities in Iran. But, as the number of Indians willing to invest their time, effort and capital in commercial ventures throughout the diaspora increased, 'Multani' communities emerged in dozens of urban centres and villages across much of Eurasia.

It is important to reiterate that, although Indian merchants from Multan are likely to have frequented commercial centres in Central Asia already in the thirteenth century, available evidence suggests that they had begun to establish diaspora communities there only in the second half of the sixteenth century. Multanis are first identified as having settled and owned property in Bukhara in legal records dating to 1559 and I56I, nearly contemporary with Anthony Jenkinson's I558 report of merchants regularly coming to Bukhara from throughout north India and staying there for periods of two to three years (Ivanov I954: I09-I0, I22-3, 247-8; Jenkinson I886, I: 87). Some twenty-five years later, in 1584 , merchants from Multan were included among those unfortunate Central Asia-bound caravanners who lost their goods in a warehouse fire in Peshawar (Nizamutdinov I969: 47). Shortly thereafter, in I589-90, several Multanis are mentioned in the Majmu'a$i$ Watha'iq ('Collection of Judicial Decrees'), the register of a qâdî (Islamic judge) in Samarqand, in reference to their commercial activities in that city. ${ }^{8}$ The Multanis' importance continued to grow, and seventeenth-century sources mention an astounding number of Multanis (among other Indian merchant groups) living in communities outside of India. In I623, the Russian merchant F.A. Kotov referred to all of the Indian merchants in Isfahan, the capital of Safavid Iran, as Multanis (Kemp I959: 36-7), as did Raphaël du Mans some four decades later (du Mans: I8o-8I). In the I66os, Jean Chardin reported that the total number of 'Multani Indians' residing in the Safavid Shah's territory was in excess of 20,000 (Chardin 1686: 100). In I684-85 Englebert Kaempfer estimated the population of Multanis in Isfahan alone to be I0,000 (Kaempfer I977: 204; Dale I994: 57). At that time, Central Asia was home to an estimated 8000 Indian diaspora merchants and, although contemporary estimations are lacking, it seems reasonable to suggest that a similar number of Indians are likely to have worked in urban and rural markets of Afghanistan. The total number of Indian merchants involved in trade and moneylending ventures throughout this diaspora was likely to have been in excess of 35,000 .

Indian merchants had already spread northward from Iran into the Caucasus and neighbouring Russia by the beginning of the seven- 
teenth century. , Here they established a rather significant diaspora node in Astrakhan, the Caspian Sea port on the mouth of the Volga and a Russian possession since 1556 . From the arrival in Astrakhan of the first Indian merchants, they are documented as having maintained regular trade relations with other Indian communities in Daghestan (in the north-eastern Caucasus), Shirwan (in south-eastern Transcaucasia, modern Azerbaijan) and numerous cities on the southern coast of the Caspian Sea (Dale I994: 87-8). Although the earliest record of Indian merchants in Astrakhan identified specifically as 'Multanis' belongs to the I670s (Antonova, Gol'dberg and Lavrentsova I958: I85), this should be attributed more to the infrequency of references to the Indian merchants' region of origin or caste affiliation in seventeenthcentury Russian records than to any uniqueness in the ethnic composition of the Astrakhan community. Based on information from the I747 Russian census of Astrakhan's Indian dvor (literally a 'courtyard', although in form and function this structure resembled a standard caravanserai, especially following its reconstruction as a stone building in I673), Dale demonstrates that nearly all of the Indian merchants in Astrakhan at that time came from the city of Multan or from villages in its vicinity (Dale I994: 54; Antonova and Gol'dberg I965: 265-9). This continued to be the case until the turn of the century, even as the Astrakhan Indian community was dwindling in numbers. This is supported by the observations of Peter Pallas, who begins his I794 account of Hindu religious practices in Astrakhan with the statement that, 'during my stay at Astrakhan, I attended with pleasure at the idolatrous worship of those Indian merchants of Multanistan' (Pallas I802-3, I: 254). Three years later, Count Ivan Potocki noted that the Indian $d v o r$ was home to some sixty-seven individuals, identified as being 'for the most part from Multan and...subjects of the Afghan ruler'. ${ }^{9}$

\section{Caste and Identity in the Diaspora}

The designation 'Multani' identifies the geographical origin of the greater part of this early modern Indian diaspora, but says nothing of the diaspora's ethnic composition in terms of the Indian merchants' caste or even religious identity. This has been the source of some confusion in previous efforts to explain the ethnic complexities of these Indian diaspora communities. Because of the presence of Muslim Multanis in early references to the Indian communities in Central Asia, Muzaffar Alam has suggested that, during the Indian diaspora's early stages of development in Central Asia, it was common for Hindu merchants to abandon their Indian identity, forgo Hinduism for Islam, marry into the local community, and permanently settle in Central Asia 
(Alam I994: 219). Contrary to this notion, further analysis suggests that both Hindu and Muslim merchants from Multan province were identified as 'Multanis' regardless of their religious or caste identity. Barani in the fourteenth century had already noted, that the chief qâdî of Sultan 'Ala' al-Din Khalji, a man identified as Hamid al-Din, was the son of a Multani moneylender (Zia ud-Din Barani I860-62: 298, 353). Although sources disclose individual cases of conversion, these were the exception rather than the rule. Hindu merchants living in the diaspora are known to have gone to great lengths to keep their compatriots from renouncing their ancestral religion.

Available information suggests a significant Muslim Multani presence in sixteenth-century Central Asia. In fact, the earliest available accounts of Multanis in Central Asia are in reference to two individuals with the decidedly Muslim names of Maulana 'Omar Multani ibn Maulana 'Abd al-Wahab Multani and Baba Multani ibn 'Ali, both of whom are identified in relation to their ownership of immovable property in Bukhara (Ivanov I965: I09-10, I22-3, 247-8). Some thirty years later, the aforementioned judicial records illuminate the activities of a number of Muslim Multanis engaged in financing textile production in Samarqand..$^{\text {IO }}$ The leader of this organisation was an individual identified as Janab Darya Khan Multani ibn Janab Sheikh Sa'adi Multani. Darya Khan is mentioned in eight entries in the Majmu'a-i Watha'iq, seven of which directly relate to his involvement in the textile industry, and his business associates almost exclusively include people who shared his Indo-Islamic, possibly Afghan, heritage. Examples include Ustad Rajab Kazar Multani ibn Ustad Hussain Multani, Mankui Kazar Multani, Ustad Gujar Multani ibn Khwaja Ya'qub, and Mullah Hussain ibn Paina Multani (Majmu'a-i Watha'iq: I82b, I87b, I89a-b). ${ }^{\text {II }}$ Other entries in the same source refer to individuals identified as Allahdad ibn Jahan Shah Multani and Khwaja Ibrahim Multani ibn 'Abd Allah Multani (Majmu'a-i Watha'iq: 2a-b, I92a). ${ }^{\mathrm{I2}}$ References to Muslim Multanis are not restricted to the Indian diaspora communities in Central Asia. In I6I7 Pietro Della Valle reported that a portion of the Multani population of Isfahan was Muslim, an observation repeated by the Russian merchant Fedot Kotov in $\mathrm{I} 623$ and Adam Olearius in ${ }^{1} 637{ }^{\mathrm{I3}}$

A significant number of these Muslim Multanis were most likely Indo-Afghan merchants belonging to the largely nomadic tribe known as the Lohani (Lohana, Luharni). ${ }^{\mathrm{I}}$ It should be noted that there is some confusion regarding the Lohani ethnicity. While some authors refer to the Lohani as a Muslim Afghan Powinda tribe, others recognise the designation as a reference to a sedentary Hindu merchant caste, or conglomeration of castes, of Sind engaged in Indo-Central Asian commerce. ${ }^{15}$ Some insight into this issue can be found in the Chachnamah, a source which purports to be a Persian translation of an eighth-cen- 
tury Arabic manuscript detailing the Arab conquests of Sind under Muhammad ibn Qasim, written in I2I6-I7 by 'Ali ibn Muhammad Kufi, originally a resident of Kufa, in Iraq, but subsequently a resident of Uch, located roughly one hundred kilometres south of Multan (Mirza Kalichbeg Fredunbeg I979). This source refers to what appears to have been a rather sizeable confederation of unsettled tribes in northwestern India known as the 'Lûhâna' (Mirza Kalichbeg Fredunbeg I979: 36-7; I70-7I). It remains unclear how sizeable the confederation was at that time, although, according to Richard Burton, in the midnineteenth century the Lohani of Sind included at least fifty sub-groups (Burton I851: 315; Markovits 2000: 46-9). While the subject certainly merits further investigation, it seems reasonable to suggest that the Lohani underwent a process of bifurcation since the eighth-century Arab conquests. That is to say, over the centuries, some of the Lohani subgroups in Sind settled, adopted a commercial economy, and maintained a version of their ancestral religion, while others continued their pastoral economy and eventually became associated with Islam.

Despite this kind of conjecture, it is clear that the Lohani Powindas (a term referring to Afghan nomadic communities involved in mediatory commerce) had, by the sixteenth century, already been participating in India's north-western transregional trade for centuries by incorporating commercial ventures and the transportation of bulk commodities in their annual migrations between north India and Central Asia. In the nineteenth century, the British traveller G.T. Vigne reported that, according to Lohani tradition, they had been active in the transit trade between Hindustan and Kabul since the Ghaznavids granted them the territory of Deraband in the eleventh century and that, since the time of Babur, Lohani caravans had been engaged in the transportation of various commodities between Bukhara, the major Afghan commercial centres, and 'Hyderabad, Calcutta, Benaras, Delhi, Jypore, and the other large cities of India' (Vigne I982: 54, 68-70). Following a raid on a group of Afghan traders crossing the routes between India and Central Asia, Babur himself refers to the recently deceased Khwaja Khizr Lohani as 'a well-known and respected Afghan merchant', and it is likely that many of the I0,000 to 20,000 Indian merchants mentioned by Babur as annually travelling to Kabul were Lohani Powindas (Zahir al-Din Muhammad Babur I989: 202, 235; Dale I994: 62-5). The identification of the leader of the above-mentioned Indian commercial organisation in Samarqand by the title 'Darya Khan' further suggests that at least some of the Muslim Multanis in Central Asia were Lohani. This designation appears in reference to Afghan Lohani in historic literature dating at least as far back as the fifteenth-century Darya Khan Luharni (Lohani), an important official in the Afghan Lodi Sultanate (Dale I994: 62-4). Centuries later, during a visit to Multan in the 
I83os, Mohan Lal, the Kashmiri-born British intelligence agent and companion of the British explorer and agent Alexander Burnes, came across a merchant involved in India's north-western transregional trade also identified as Darya Khan Lohani. Mohan Lal reported that Lohani and Shikarpuri merchants (the latter identity will be discussed below) dominated the mediatory trade between Bukhara and Multan and that, were it not for these merchants, Multan 'would not become the rival of the markets of Hindusthan, the Panjab, and Khorasan' (Mohan Lal I97I: 39I-6). Focusing his attention on Afghanistan, Alexander Burnes also recognised that the Lohani dominated the movement of goods in and out of India's north-west frontier. According to Burnes:

the merchants, who carry on the trade from India to Cabool, are principally Lohanee Afghans, whose country lies westward of the river, between Dera Ismael Khan and Cabool; and they now make an annual journey to and from these places, bringing with them the productions of Afghanistan, and taking back those of India and Europe. Being a pastoral race, they are their own carriers; and being brave, they require no protection but their own arms... Lohanees pass into India, and even to Calcutta and Bombay (Burnes I843: 284-5).

Indo-Afghan Powinda tribesmen clearly played an important role in Indo-Central Asian transregional trade, although this was generally limited to the buying, selling and transportation of goods (Montgomery I862: 43). In I75I, for example, a Tatar from Astrakhan visited Khiva, Bukhara and Balkh and reported that Afghan Powindas were active in transporting bulk goods to these areas from as far away as Calcutta (Shamansurova I966: III-2). However, neither Lohani Afghans, nor any other Muslim group, comprised an ethnic component of primary importance in the diaspora. The overwhelming majority of the diaspora was comprised of Hindu merchants who belonged to any of a number of mercantile-oriented castes engaged in transregional trade, brokering or moneylending, and who, in some accounts, are collectively referred to as 'Banias' (or 'Banians'), a designation derived from the Sanskrit word vanija, 'a merchant', or vanijya, meaning 'trade' (Ibbetson igi6: 242; Russell i969, II: II2).

Although in some nineteenth-century literature the term 'Bania' refers to a specific caste affiliation, in earlier literature it is more generally used to refer to individuals, or groups of individuals, whose economic activities focused on commerce. ${ }^{16}$ Bania communities operated trading networks from several commercial centres throughout Gujarat, Sind, Punjab, Rajasthan and the Indus basin, but Multan was the primary focal point in their north-western trade. Thus, in the I66os, the 
French traveller and geographer Jean de Thevenot observed that, although the political elite and the majority of the population of Multan were Muslims, 'it contains a great many Banians also, for Multan is their chief rendezvous for trading into Persia, where they do what the Jews do in other places; but they are far more cunning, for nothing escapes them, and they let slip no occasion of getting the penny, how small soever it be' (Sen I949: 77). In I676, Tavernier similarly reported that 'Multân is the place from whence all the Banians migrate who come to trade in Persia, where they follow the same occupation as the Jews...and they surpass them in their usury' (Tavernier I995, I: 74). ${ }^{\text {I7 }}$ As noted by Dale, at this early date, Europeans were still ill-informed about the complexities of the Indian social system and their widespread use of the occupational term 'Bania' to refer to the members of the Indian diaspora suggests little more than that the individuals in question were probably non-Muslim Indian merchants.

Thevenot provides a rare exception to this rule in his careful observation that 'at Multan there is another sort of gentiles whom they call Catry. That town is properly their country and from thence they spread all over the Indies' (Sen I949: 78). Here, Thevenot is referring to the Hin$\mathrm{du}$ Khatri caste, long considered to be among the most important merchant communities of early modern India. Because of the Khatris' increasingly important role in India's transregional trade under the Mughal Empire, partly a result of Mughal patronage, it seems reasonable to suggest that many of the Multanis and Banias referred to in the historical sources can more specifically be categorised as Khatris. ${ }^{\text {I8 }}$ Dale locates Khatris in Astrakhan during the late seventeenth century and, in the I830s, the British imperial proconsul and past governor of Bombay, Mountstuart Elphinstone, was informed that Khatris were still highly involved in north-west India's transregional commerce and that they maintained communities throughout Afghanistan and as far away as Astrakhan (Elphinstone I839, I: 4I3-4; Dale I994: 58-9). In the early twentieth century, the economic historian L.C. Jain noted that the Aroras, a sub-caste of the Khatris, were known to 'control the finance of much of the commerce of India with central Asia, Afghanistan and Tibet' (Jain I929: 32). The British ethnographer Ibbetson likewise observed that the Arora-Khatris were centred in Multan and Derajat and were involved in business throughout Afghanistan and Central Asia (Ibbetson I9I6: 250-52). George Campbell's mid-nineteenth-century Ethnology of India provides an even more impressive image of the Khatris' role in the diaspora:

besides monopolising the trade of the Punjab and the greater part of Afghanistan, and doing a good deal beyond those limits, they [Khatris] are in the Punjab the chief civil administrators, 
and have almost all literate work in their hands... Even under Mahomedan rulers in the west they have risen to high administrative posts... No village can get on without the Khatri who keeps the accounts, does the banking business, and buys and sells the grain. They seem, too, to get on with the people better than most traders and usurers of this kind... I do not know the exact limits of Khatri occupation to the West, but certainly in all Eastern Afghanistan they seem to be just as much a part of the established community as they are in the Punjab. They find their way far into Central Asia... They are the only Hindus known in Central Asia. In the Punjab they are so numerous that they cannot all be rich and mercantile; and many of them hold land, cultivate, take service, and follow various avocations (cited in Russell i969, III: 458-9). ${ }^{\text {I9 }}$

It is clear that Khatris were an important element in the ethnic composition of the diaspora. Regardless of Campbell's claim, however, Khatris were not the only Hindu community to establish themselves in Central Asia. Despite their participation in occupations similar to those of the Bania communities, Khatris were considered to be Kshatriyas, the second-highest varna in the Indian social hierarchy, below only the Brahmans. Banias, however, were generally associated with either the Vaishya (merchant) class, the third-highest position, or with communities affiliated with the commercially oriented Jain or Sikh religions.

Based on research in the Russian colonial archives and the Office of the Bukharan Khushbegi, the Russian historian G.L. Dmitriev suggests that the majority of the Indians present in Central Asia in the colonial period were Bhatias, a merchant caste associated with Sind, especially the area around Multan, since the seventh century (Dmitriev I972: 235). ${ }^{20}$ In the nineteenth century, many Bhatia caste members were located in the north-west frontier town of Dera Ismail Khan and were known to have travelled to Kabul, Bukhara and even as far as Arabia (Russell I969, I: 350). Their centralisation in Dera Ismail Khan is most certainly related to that city's position as the renowned winter headquarters of Powinda nomads and its convenient location on the west bank of the Indus river, approximately roo kilometres north-west of Multan, near the Gumal Pass. Also known to have been active in IndoCentral Asian commerce are Muslim Khojas and members of the mixed Hindu-Muslim trading caste from Gujarat, the Bohras (Levi 2002: III). The Bohra communities in the Punjab, those most likely to be involved in Indo-Central Asian commerce in the early modern and colonial eras, were predominantly, if not entirely, Hindu. Another Muslim commercial caste engaged in Indo-Central Asian commerce were the Parachas, a name derived from the word pârcha, Persian for 'cloth', 
the principal commodity in which they traded. According to Ibbetson, in the nineteenth century, Paracha communities inhabited the area around the north-western town of Rawalpindi, and there were also large communities further to the north-west in Atak (Attock) and Peshawar, from where they conducted 'an extensive trade with the cities of Central Asia, chiefly in cloth, silk, indigo, and tea' (Ibbetson I9ı6: 252-4). Nineteenth-century Russian archival documents record that Indian merchants in Central Asia originated from throughout north-western India, including Multan, Shikarpur, Peshawar, Lahore, Haripur, Ludhiana, Amritsar, and the urban centres of Kashmir, as well as from the more distant cities of Delhi, Allahabad, and Bombay (Dmitriev I972: 234). ${ }^{21}$

Whereas Banias and Khatris were both commonly identified as 'Multanis' because of their commercial centralisation in that city, another component of the Indian diaspora was identified as 'Marwari'. This designation indicates these merchants' relationship to the urban centres of Marwar and, considering the predominance of Jain merchants in that region, suggests that many of the 'Marwari' merchants are likely to have been adherents to the Jain religion. ${ }^{22}$ The Marwaris were probably active in the diaspora from the late seventeenth century, prior to which Marwari family firms seem to have restricted their commercial interests to domestic markets. They began to appear in Astrakhan only from the early eighteenth century, and probably arrived in Central Asia at roughly the same time. It is interesting that the classic paradigm of the Indian family firm, the Jagatseth ('World Banker') house, originated in Marwar and operated under the direction of the acknowledged leader of the Jain Oswal caste. This firm was founded in the second half of the seventeenth century and, following its move to Bengal (first to Murshidabad and then to Dhaka), rose to commercial prominence at the beginning of the eighteenth century, roughly at the same time that an individual identified as 'Marwar Baraev' ('Great Marwari'), appears in archival documents from Astrakhan. ${ }^{23}$ This individual was most certainly the leader of the Jain merchants in that diaspora community at the time, a conclusion equally applicable to another individual similarly identified as 'Marwari Baraev' who lived in Khojand, near the Farghana Valley, some I50 years later. ${ }^{24}$

Marwaris in Astrakhan are known to have participated in diverse commercial activities, focusing especially on moneylending ventures and long-distance trade. As was common among all of the Indian merchants in Astrakhan, much of their transregional trade was conducted by means of commenda partnerships (various types of trade agreements between partners supplying capital investment and labour) and other arrangements with their colleagues, Marwaris and others. ${ }^{25}$ Their partners were most commonly located in a number of Iranian cities dot- 
ting the shores of the Caspian Sea, situated on the trade routes connecting Astrakhan with Bandar 'Abbas (also referred to in historical sources as Gombroon). The presence of Marwaris in Iran is further suggested by George Forster's late eighteenth-century statement that, in the Iranian town Tarshish (Turshiz/Kashmar, located some 300 kilometres south-west of Meshed), he came across approximately one hundred families of Indian merchants identified as being from Multan and Jaisalmer, the latter of which was an important Marwari Jain outpost in western Rajasthan (Forster I970, II: I86). Devendra Kaushik's research into nineteenth-century Russian colonial documents confirms the presence of a significant number of Marwari merchants in the Indian diaspora communities in Central Asia. Thus, in addition to Hindus and Muslims, the Indian diaspora in Central Asia probably also included Jain communities, although it must be acknowledged that this is to some degree conjectural as the Marwari merchants' religion is not specifically mentioned in Kaushik's sources (Kaushik I985: 3I).

The presence in the diaspora of adherents to another Indian religion, Sikhism, is less surprising considering that a significant percentage of the Sikh community has roots in the Khatri caste and, like the Khatris, the Sikh tradition places a great emphasis on commerce. The participation of Sikh communities in Indo-Central Asian trade was facilitated by the location of the Sikh capital at Amritsar, a Punjabi city situated some thirty kilometres east of Lahore on trade routes leading through the Khyber Pass to Central Asia.

It is difficult to definitively establish for how long each of these communities was involved in the Indian diaspora in Central Asia, but Khatris and Banias, especially of the Bhatia, Bohra and Lohani castes, are known to have emerged as important merchant communities prior to the seventeenth century and probably participated in the diaspora from its inception. $^{26}$ The Marwari Oswals (almost certainly adherents to the Jain religion) seem to have achieved great commercial prosperity during the seventeenth century and to have spread throughout the diaspora in the eighteenth and nineteenth centuries (Sharma I984: I86-7; Dale I994: 60). References to Sikhs do not appear in the sources until the nineteenth century. During the early modern and colonial periods, agents of these various communities dispersed throughout the subcontinent and beyond, establishing an impressive trade and moneylending network that extended across Afghanistan, Central Asia, and eventually reached even beyond the Arabian Peninsula and East Africa to the Caribbean islands in the west, and to Southeast Asia and China in the east (Ray I984: 252-4). 


\section{Modus Operandi and Relations with Host Societies}

By the time the diaspora emerged in the mid-sixteenth century, the Multani firms had a well-developed system to enlist agents and prepare them to be dispatched to work in distant locations. Agents were exclusively male, and they underwent rigorous training that encompassed complex accounting techniques, mathematical formulas for computing various types of interest, moneylending procedures, instructions for issuing and cashing hundis (bills of exchange), secret codes for recording commercial transactions, a variety of issues related to their own legal traditions and those of other legal systems, and a lengthy period of apprenticeship. This system of training is not in and of itself unique in Indian business history, but the operation of the Indian diaspora differed from earlier practices in some important ways. ${ }^{27}$

Prior to being dispatched into the diaspora, the Multani agents were loaned a certain amount of capital, generally in the form of a commodity for export. The commodity most often advanced seems to have been cotton textiles - produced in abundance in India and one of India's largest export commodities since antiquity. Furthermore, because of the Multani agents' long-established role as creditors to cotton farmers and weavers, to whom they advanced raw cotton in exchange for a portion of the finished cloth, cotton textiles were available to the Multanis in large quantities at below-market prices. Perhaps for this reason, whereas most observations of the Multanis focus on their moneylending activities, they are also not infrequently referred to as textile traders. In the I66os, Raphaël du Mans described the totality of Multani merchants in Isfahan as 'cloth merchants' (bazzaze) and, already in I558, Anthony Jenkinson observed that Indian merchants in Bukhara were also traders in textiles (du Mans I890: I80-8I; Jenkinson I886, I: $87-8)$.

Jenkinson's account is the earliest concrete citation of the Indian diaspora merchants in Central Asia, and it provides some insight into the Indians' commercial operation. It is interesting, although somewhat misleading, that Jenkinson described Bukharan trade at that time as 'beggerly and poore' because he was astonished that it took the Indian merchants who came there two to three years to sell their merchandise before returning home, and they refused to bargain with him for his English wool.

The Indians doe bring fine whites, which the Tartars [Turks] doe roll about their heads, and all other kinds of whites, which serve for apparell made of cotton wooll and crasko, but golde, silver, pretious stones, and spices they bring none ... I offered to barter with Marchants of those Countreis, which came from the furth- 
est parts of India...to give them carseis [kersey, an English woolen cloth] for their commodities, but they would not barter for such commoditie as cloth (Jenkinson ı886, I: 87-8).

At first glance, Jenkinson's disappointment in the Bukharan market seems to suggest that Bukhara's commercial climate was impoverished and devoid of opportunity. Reconsidering Jenkinson's conclusions in the context of the Indian diaspora merchants' commercial techniques, it is apparent that the Indians he encountered were already operating in accordance with the standard diaspora model that was to become so familiar in later years.

The first order of business for Indian agents travelling to locations in Afghanistan, Central Asia, and Iran was to arrange for their commodities to be transported by Afghan Powindas, or otherwise by caravan, across the inhospitable intermediary lands. This was an arduous journey and also an expensive one as, in addition to standard transportation expenses, they would be required to pay customs duties at each political boundary. After several months of travel the caravan would arrive at its destination and Indian agents would take up residence in a caravanserai, commonly one owned and operated by their firm and placed under the direction of their firm's senior representative. This individual - known in Central Asia as the aqsaqal and in Iran as the kalantar - was responsible for supervising the local Indian community and mediating their relationship with the host state. At this point, the Indians would begin selling their merchandise. However, considering that every caravan that brought Indian merchants to distant markets also brought hundreds - or even thousands - of camel loads of cotton textiles, the Indians would have been inclined to sell only a small percentage of the total. The rest would be hoarded for sale over an extended period of time in order to keep the market from saturating and driving down the price of their merchandise, and, by extension, the value of their capital wealth.

Thus, rather than demonstrating the destitute nature of the Bukharan market at the time of his visit, Jenkinson's inability to purchase Indian cloth at a discounted price seems more likely to have represented the Bukharan market's saturation with Indian textiles and the Indians' efforts to keep the price of their merchandise as high as possible. Furthermore, whereas Jenkinson was shocked that the Indians he encountered commonly spent two to three years in Bukhara before returning home, later observers report that it was typical for Indian merchants to spend several years working in the diaspora before returning home. Calculations of available information place the Indians' average tenure abroad at between six and seven years, although some indivi- 
duals are known to have stayed in particularly lucrative posts for several decades (Dale I994: I05; Levi 2002: I4I).

The Indian communities were therefore almost exclusively comprised of a rotating population of men. While these men were living in distant communities in control of considerable amounts of the firm's capital, the firm directors back in Multan were responsible for watching over the agents' families. This arrangement served the dual purpose of reassuring the agents of their families' well being in their absence, while simultaneously ensuring that the agents themselves remained loyal and conducted themselves responsibly. Should an agent prove untrustworthy by absconding with the firm's capital, his reputation - and credit - would be ruined, and his family would be held responsible for any resulting losses. Archival records suggest that such situations only rarely occurred. In any event, during their extended periods abroad, the Indian agents generally lived a monastic lifestyle as they actively participated in numerous commercial ventures, only one facet of which was the sale of their merchandise.

As the Multani merchants gradually sold off their textiles, they did not allow the cash they earned to remain idle as they prepared for their return to India. Rather, they were trained to put their capital to work by reinvesting it in other, very profitable commercial activities, most commonly in reasonably secure, interest-earning moneylending ventures. The Multanis in Afghanistan, Central Asia, and Iran specialised in several types of loans, divisible into short-term cash loans, on the one hand, and agricultural loans, on the other. Because many farmers depended on credit to get their crops planted, agricultural loans constituted an especially important and very lucrative venture for the Multanis. Prior to the planting season, even those Indians who resided in cities across the diaspora are known to have ventured into the countryside where they advanced loans to farmers, in cash or in kind, with the cumulative principal and interest collected at harvest time (it was a common arrangement for the Indian to receive one-half of the harvest). Although the risk involved in agricultural loans was greater than that of a loan against collateral, it is easy to understand why the Indian moneylenders were attracted to rural markets: the interest earned was correspondingly higher and the term of an agricultural loan was usually six months or less, depending on the length of the growing season. To the Indians, this meant that the capital retrieved was available for other investments the rest of the year.

The Indian diaspora merchants therefore operated at a critical juncture between urban and rural markets, serving their host societies by providing investment capital to facilitate agricultural production even when local peoples could not afford the initial investment in seeds for planting or other necessary materials. It is deceptively tempting to attri- 
bute the Indians' success in these markets to the prohibition of riba' (collecting interest from loans) in Islamic law. Muslim merchants across the Islamic world devised numerous techniques to circumvent this restriction; they were quite capable of providing credit for profit, and they regularly did so. Instead, the Indians' dominance of the moneylending trade should be attributed to their access to their firms' vast reserves of capital wealth and their training, which emphasised moneylending for profit.

It is also important to note that, in addition to the Indians' role as rural credit agents, they commonly purchased the remainder of the harvest for cash and arranged for its sale in urban markets. In this capacity, the Indians served their hosts by extending a monetised economy into the countryside, facilitating the collection of taxes in cash. They also served their host societies by importing necessary goods, purchasing and arranging for the export of local production, and supplying a considerable tax income for the treasury. The combination of these factors at least partly explains the motivation of Muslim administrators to protect the Indian merchants and ensure that they could conduct their business in a safe, predictable and reasonably agreeable social climate.

In some locations Indian merchants congregated in urban neighbourhoods, but the vast majority of references are to Hindu merchants living in specifically 'Indian caravanserais'. These structures conformed to the standard architectural styles of the region and era, and the exteriors gave no indication of the inhabitants' cultural and religious uniqueness. The interior of the caravanserais, however, represented a Hindu microcosm within their Islamic host societies. Indian merchants were, of course, the primary residents of the Indian caravanserais, but the caravanserais are also known to have housed Indian cooks, barbers, jewellers, tailors, servants and retail shops where the Indians purchased many of the goods necessary for their day-to-day lives, including religious paraphernalia, from other Indians. Furthermore, within these caravanserais, Indians were exempt from many legal restrictions that applied to the general Muslim populace. For example, visitors to the Indian caravanserais of Bukhara commonly noted that, whereas alcohol and tobacco were prohibited in that religiously conservative city, inside of their caravanserais, Indians smoked and drank alcohol freely (Likoshin 1896 ).

Hindus were generally permitted to celebrate their religious festivals, even in Central Asia's rather conservative religious climate. For example, several nineteenth-century sources describe the Hindus' celebrations of Diwali, a festival in honour of the goddess Lakshmi, and another celebration that appears to have been Holi, a festival celebrating the approach of spring. According to one Russian observer of a Diwali 
celebration in Tashkent in 1895 , the Hindus celebrated this holiday by abstaining from drinking alcohol, maintaining a strictly vegetarian diet of ceremonial Indian cuisine, illuminating the caravanserai with hundreds of petroleum lamps, and enlisting musicians, singers and dancers to perform devotional songs. This same visitor returned the following year for the celebration of the festival of Holi, which he referred to as a festival 'with alcohol'. This affair drew large numbers of indigenous spectators to the roof of the caravanserai, some of whom reportedly even joined the celebration (Likoshin 1896 ).

The celebration of these festivals was not restricted to Russian colonial Central Asia. In Bukhara as well, the Muslim population had a tradition of allowing, and even participating in, Hindu religious celebrations. For example, prior to the commencement of some festival activities in Bukhara, farmers are reported to have brought their cows to Indian caravanserais so that the Hindus could sprinkle them with dry red dye and pray near them. In return, the Indians fed the cows cottonseed, an unusual delicacy for the animals (Dmitriev I972: 242). Diwali was also documented as having been celebrated in an Indian caravanserai in Bukhara, where the holiday was popularly referred to as 'Id-i Charaghan' ('Festival of Lights') (Dmitriev I972: 242).

Because of the limited number of years individual Indian merchants generally spent abroad, there are only a few accounts of Indians who died while in the diaspora. On occasion, however, this did happen and it invariably produced a source of potential conflict: the Hindu tradition of cremating the dead. While cremation ceremonies were common in India, Muslims in Afghanistan, Central Asia, and Iran commonly considered it to be abhorrent. Still, Hindus placed a great spiritual importance on this tradition and whenever a comrade died, the survivors went to great lengths to acquire permission from the relevant administration to conduct a ritual cremation. Permission was necessary largely in order to secure military protection for the duration of the ceremony, thereby discouraging any local troublemakers from disturbing the funeral pyre. Following cremation, the ashes of the deceased were collected and returned to India.

Throughout the diaspora, it was common practice for the Multani firm directors to send Brahmans to supervise religious ceremonies and service the other religious needs of their agents. This was achieved by contracting individual Brahmans to live in a specific diaspora community for a stipulated period of time, following which they were replaced by other recruits. While the directors of the family firm ensured the financial security of the Brahmans' families back in India, the Brahmans themselves were dependent upon the Indian merchants for their livelihood; there is no indication that they, at any time, participated in commercial activities. 
Although the Indians enjoyed great cultural autonomy within the confines of their caravanserais, Hindus (and other non-Muslim minorities) were required to obey certain social restrictions. Hindus were generally forbidden to own Muslim slaves and to ride on horseback in towns, and they commonly had to dress in a distinctive manner so that they could easily be distinguished from Muslims. For example, Hindus in nineteenth-century Bukhara were required to wear short, tight-fitting, single-coloured (usually black) chapans (a long, flowing outer robe) with minimal pattern and, whereas the fashion was to fasten one's chapan with a sash, Hindus and Jews were only allowed to tie their clothes with a hemp rope, probably to ensure that they did not carry concealed weapons in their sashes. Hindus were also instructed to wear distinctive square hats, tight shalwar (pants), leather shoes, and even a distinctive hair style so that they could be easily distinguished from Muslim men who, at that time, generally shaved their entire head. ${ }^{28}$ Alexander Burnes observed:

They are not permitted to build temples, nor set up idols, nor walk in procession: they do not ride within the walls of the city, and must wear a peculiar dress. They pay the 'jizyu,' or poll-tax, which varies from four to eight rupees a year; but this they only render in common with others, not Mahommedans. They must never abuse or ill-use a Mahommedan. When the king passes their quarter of the city, they must draw up, and wish him health and prosperity; when on horseback outside the city, they must dismount if they meet his majesty or the Cazee. They are not permitted to purchase female slaves, as an infidel would defile a believer; nor do any of them bring their families beyond the Oxus. For these sacrifices the Hindoos in Bokhara live unmolested, and, in all trials and suits, have equal justice with the Mahommedans. I could hear of no forcible instance of conversion to Islam, though three or four individuals had changed their creed in as many years. The deportment of these people is most sober and orderly;-one would imagine that the tribe had renounced laughter, if he judged by the gravity of their countenances. They themselves, however, speak highly of their privileges, and are satisfied at the celerity with which they can realise money, though it be at the sacrifice of their prejudices (Burnes I834, I: $285-6$ ).

In only a few locations across the diaspora were Hindus allowed to construct free-standing temples. In Central Asia, as in most diaspora locations, Hindus dedicated rooms in their caravanserais to function as religious libraries and places of worship. These rooms were generally 
equipped with a small altar surrounded by stone figures or, in later years, portrait images of Hindu deities. The temple room of a rather old Hindu caravanserai in Tashkent reportedly housed an icon of Kali that had at some point in time been brought from Banaras, although the Indians who lived in that caravanserai in the late nineteenth century could not say when (Dmitriev I972: 240).

Available sources indicate that Hindu communities in Iran were, occasionally, allowed to build temples outside of their caravanserais. At the end of the seventeenth century, John Fryer recorded the existence of two temples in the village of Naoband, a short distance north-east of Bandar 'Abbas, where the large number of Hindus living in that busy port city celebrated their festivals (Fryer I9I2, II: 336-7). There are also numerous accounts of a remarkable Hindu temple in Baku (in modern Azerbaijan), an important commercial centre on the Russo-Iranian trade routes traversing both the Caucasus Mountains and the Caspian Sea (Forster I970, II: 256-9, 262; Keppel I827: 29I-4). This temple, situated some twenty-five kilometres to the north-east of the city, was located in the vicinity of a wealth of liquid petroleum deposits, or naphtha, the flammable gases from which were incorporated into the Hindus' religious rituals. The temple was properly known by the Sanskrit name juala mukhi ('flame-mouthed'), one of the less-common names of the Hindu goddess Durga. In addition to servicing the needs of the local Multani merchants, the juala mukhi temple of Baku attracted pilgrims from across India.

\section{From Multan to Shikarpur}

During the late eighteenth century, the popular identification of the majority of the Indian diaspora merchants changed from 'Multani' to 'Shikarpuri'. It has been suggested that the designations 'Multani' and 'Shikarpuri' referred to Indian merchants who operated two distinct merchant diaspora networks (Markovits 2000: 29-30, 37-8, 60-69). A contrary thesis, put forth here, argues that the merchants referred to by the designations in question were of the same extraction. The change in terminology was precipitated not by the emergence of one diaspora over the ashes of another, but by a combination of factors which contributed to the decline of Multan as the financial capital of north-west India and the corresponding rise of Shikarpur as, for reasons to be detailed below, many of the Multani firms relocated their centres of operation to that city.

It was observed above that Multan (Mulastana) was an important frontier commercial centre already during the ancient period, and this importance increased under Delhi Sultanate and Mughal patronage. 
That the province of Multan was regularly granted to Delhi Sultanate and Mughal heirs apparent is indicative its political, strategic and economic stature (Dasti I998). ${ }^{29}$ During the Mughal era, Multan was also a mint town and an important centre of agricultural production and manufacturing. Cotton textiles enjoyed an especially prominent position among the region's products; the outlying towns and villages supplied the Multani commercial houses with finished materials that were destined to be exported to any of a number of distant markets.

Even during the Mughal era, however, Multan's prosperity was occasionally threatened. In the second half of the seventeenth century, the commercial advantage of Multan was diminished by the silting and shifting of the Indus, a development which denied merchants access to the important riverine routes of commerce customarily used to transport merchandise from Multan to the Arabian Sea ports of Thatta and Lahori Bandar (Tavernier I7I2: 62; Singh I99I: I87-9I). The city's importance as a frontier-trading centre was also somewhat challenged during the periods when the Mughals occupied Qandahar, a coveted military outpost and the most important commercial centre on the Indo-Iranian caravan routes. Qandahar, however, suffered from a chronically turbulent political climate. Throughout the Mughal era, Qandahar was the object of a nearly perpetual contest between the Mughals and the Safavids, and this resulted in the city being placed under siege some fifteen times and changing hands on a dozen separate occasions. Thus, even during the Mughals' extended periods of occupation of Qandahar (such as I595-1622 and 1638-49), Indian family firms chose to keep their central offices in the more predictable markets of Multan.

Multan continued to function as north-west India's primary commercial centre throughout most of the eighteenth century, remaining largely unaffected even by Nadir Shah's I739 invasion of the Mughal Empire and sack of Delhi. However, as the Mughals weakened and lost their ability to maintain control of their territories, the protracted process of Mughal decentralisation sent the city into a century-long period of crisis. Between I749 and I849 Multan suffered from a series of Afghan, Maratha, Sikh and finally British invasions and occupations, reducing it from a position among the greatest early modern international money markets and commercial centres to a regional trading town (Khan I983: III-66).

As the commercial climate in Multan worsened during these invasions, many Multani financial houses chose to relocate to Shikarpur, a smaller city in the neighbouring province of Sind. Of paramount importance to this decision was Shikarpur's location in Durrani Afghan territory and the need of the Multani financial houses to maintain their close relationship with the Durrani ruling elite and Afghan Powinda 
nomads, the primary carriers of bulk commodities from India to Central Asia and eastern Iran. ${ }^{30}$ Compared to Multan, Shikarpur was a young urban centre of minor importance (it was founded in ca. I6I6 as a hunting retreat). The merchant households, however, found the city's location agreeable as it was situated south-west of Multan, near the Indus river, and therefore offered access to the Indian Ocean ports as well as a convenient proximity to the Bolan Pass route to Qandahar, the first capital of Durrani Afghanistan, from where caravan traffic could continue westward to Iran or northward to Central Asia. Furthermore, the region was heavily populated by the Lohani, some of whom participated in this trade as sedentary commercialists operating financial houses while others carried on commerce as transporters of bulk commodities between India and Central Asia. The decision of the Multanis to move to Shikarpur was greatly encouraged by the achievements and patronage of the Afghan leader Ahmad Shah Abdali, founder of the Durrani dynasty (reigned I747-73), who, by I768, had assumed control over much of north-west India and extended his northern border as far as the Amu Darya. Multanis had been active in Afghan territory for centuries, and following their move to Shikarpur their commercial interests appear to have increased markedly. Shikarpuri merchants were nearly ubiquitous in urban and rural Afghanistan, and they are even reported to have played a dominant role in the financial administration of Durrani Afghanistan.

Noting his impressions of north-west India during his travels in the I820s and I830s, Charles Masson reported that Shikarpur was a very wealthy city and that its principal citizens were Hindu bankers and moneylenders who maintained close commercial connections with their agents, dispersed throughout Iran and Central Asia. Summarising the Multani firms' migration to Shikarpur, Masson suggested that:

as the city [Shikarpur] is not understood to be one of great antiquity, it is possible that the influx of Hindús to it is not of very distant date, and that it was occasioned by the fluctuations of political power. As the existence of some great centre of monetary transactions, in this part of the world, was always indispensable for the facilities of the commerce carried on in it, it is not unlikely, looking at the facts within our knowledge connected with the condition of the adjacent country during the last two centuries, that Múltân preceded Shikárpúr as the great money mart, and that from it the Hindús removed, converting the insignificant village of the chace [hinterland] into a city of the first rate and consequence (Masson I844, I: 353). 
Masson goes on to refer to Shikarpur as 'the great money-mart of Central Asia' and, from the beginning of the nineteenth century, sources repeatedly refer to Shikarpuri merchants as the dominant agents in the Indian diaspora (Masson I844, I: 354, 360). In I83I, Alexander Burnes observed that Shikarpuris even had agents in Multan, and he reported meeting in that city 'forty Shroffs, (money changers) chiefly natives of Shikarpoor' (Burnes I834, III: III).

In an effort to distinguish the Shikarpuris of his study from the earlier Multani merchants, Markovits endeavours to cast doubt upon Masson's assertion that the two designations were at different times applied to individuals of the same extraction. Instead, he suggests that the Multani network had largely atrophied by the second half of the eighteenth century, when the Shikarpuri diaspora emerged sui generis in response to developments in Durrani Afghanistan..$^{3 \mathrm{I}}$ However, there seems to be no compelling reason to contest the conclusion advanced by Masson that the position of Shikarpur as the 'great money mart' of that time was a product of the migrations of Multani merchants who, during the late eighteenth century, relocated their firms to Shikarpur in order to benefit from a more stable political environment and take advantage of new opportunities under Durrani patronage. In terms of the decline of the Multani network, while it is certainly the case, as observed by Markovits, that the Multani communities in Iran underwent a period of decline in the eighteenth century, it should also be stressed that this was largely due to the draconian and predatory policies of Nadir Shah, discussed below. There is no available evidence suggesting any disruption in the continuity of the Multani communities in eighteenth-century Central Asia. Furthermore, there is no clear ethnic distinction between the Shikarpuris and Multanis. Markovits recognises that the term 'Shikarpuri' was applied to merchants who came to Shikarpur from many different regions (he fittingly describes the city as a kind of late-eighteenth-century Bania 'melting pot'). As noted above, the designation 'Multani' also was not a static ethnonym. Both of these terms referred to a diverse, dynamic conglomeration of merchant communities that incorporated Khatris, as well as Bhatias, Bohras Lohanis and various other castes associated with the designation 'Bania'. Considering the available evidence, it seems more convincing that the vast majority of the Indian merchants attracted to Shikarpur came from Multan, either directly or via their posts in the diaspora. ${ }^{32}$

It should also be noted that, while many Multanis migrated to Shikarpur in the late eighteenth and early nineteenth centuries, those Multanis whose commercial interests in the diaspora would not have benefited by relocating to Shikarpur and associating with the Durrani administration stayed in Multan. This explains why, as considerable numbers of merchants identified as Shikarpuris took advantage of 
commercial opportunities in locations in and adjacent to Durrani territory in Afghanistan, far eastern Iran and Central Asia, reports of 'Multanis' conducting commercial operations focused outside of the Durrani sphere of influence, primarily in western Iran, the Caucasus and Russia, continued well into the nineteenth century. Considering this, Markovits concludes that the Multani network in nineteenth-century Russia 'was apparently distinct from the Shikarpuri network operating in the Central Asian khanates' (Markovits 2000: 62). The degree to which this was actually the case is open to question. It should not be overlooked, for example, that while Alexander Burnes was in the office of an Indian firm in Kabul in the I830s, he was offered the opportunity to purchase bills of exchange (hundis) cashable at branch offices in Nizhny Novgorod, Astrakhan and Bukhara (Burnes I834, I: I69-70). Thus, while diaspora communities in various locations differed considerably in terms of their commercial specialisations and the social conditions in which they lived, there is insufficient evidence to support any argument for a qualitative dichotomy in the Shikarpuri-Multani merchant diaspora; it existed as a singular phenomenon.

It is generally agreed upon that Shikarpur emerged as the financial capital of north-western India during the late eighteenth and early nineteenth centuries. Still, first-hand accounts report that Multan, Lahore, Amritsar, and other large cities continued to function as the premier centres for the transportation of commodities from north-west India. Masson observed that, 'Multan is said to have decreased in trade since it fell into the hands of the Sikhs, yet its bazaars continued well and reasonably supplied with articles of traffic and consumption. There are still numerous bankers, and manufacturers of silk and cotton goods, and...[Multan] has an extensive foreign trade with the regions west of the Indus' (Masson I844, I: 395). The trade of Multan did indeed undergo a decline following the Sikh conquest, but this recession was temporary and Multan quickly reclaimed its role as a commercial centre, although without the distinction of being the north-western centre of India's great family firms. ${ }^{33}$ Mohan Lal confirms this, reporting that 'Shikarpur cannot rival Bahawalpur, Multan, and Dera Ghazi Khan in commerce, but it is inhabited by a race of people who conduct a prosperous trade in Afghanistan, Turkistan, Khorasan, and part of Persia. It has no manufacture of any description, but derives its distinction solely from its situation in the midst of the commercial routes' (Mohan Lal I97I: 4II). Relating his impressions of Shikarpur, Mohan Lal described a commercial climate so tense and competitive that he was unable to find an informant willing to provide him with details on the nature of the commerce in that city. Still, his visit to Shikarpur's bazaar evoked a marvel unsurpassed in this experienced traveller's numerous accounts of Indian, Afghan and Central Asian markets: 
I feasted my eyes with the beauty of the bazaar at Shikarpur. After passing through lanes closely peopled, I stepped into the large bazaar, and found it full. There was no shop in which I did not observe half a dozen Khatri merchants, who appeared to me to have no time to speak to the purchasers. Such was the briskness of trade going on in the bazaar... It occurred to me that the reason why Shikarpur surpasses Amritsar in wealth is, that its inhabitants, who are for the most part Khatris, have spread themselves in almost all the regions of Central Asia, whence they return loaded with gains to their families at Shikarpur. There is not so much commerce carried on at Shikarpur, I believe, as in Multan and Amritsar, but you will see all the shopkeepers writing Hoondees, or bills of exchange, which you can take in the name of their agents at Bombay, Sindh, the Panjab, Khorasan, Afghanistan, part of Persia, and Russia (Mohan Lal I97I: 438).

This account is corroborated by the observation of Alexander Burnes that Shikarpur's 'importance to the trade of the Indus...does not result from any superiority in its home manufactures, but from its extensive money transactions, which establish a commercial connection between it and many remote marts' (Burnes I843: 54).

\section{Challenges, Decline and Adaptation}

The second quarter of the eighteenth century was arguably the most traumatic period in the history of the Multani diaspora. Iran had occupied a central position in the Multanis' diaspora commerce from the beginning, but the Indian merchant communities in Iran suffered severely during the I722 Ghilzai Afghan invasion of Isfahan and occupation of much of Iran. According to the chronicle of one Armenian observer, the invading Afghan forces decimated the Hindu community of Isfahan. The Afghans reportedly demanded 25,000 tomans (a considerable sum) from the Hindus as their 'indemnity' but, because the Hindus' capital was engaged in investments, they were able to raise only 20,000 on such short notice. The Afghans responded violently and, fearing for their lives, many Hindus fled to safer places or returned home, while others are reported as having been so distraught at their financial ruin that they drank poison or simply died of grief. According to one Armenian observer:

Only a few Indians were left in the town; these people had advanced money to the Muhammadans against promissory notes 
(sanad) and jewels, gold, silver and house ornaments (zinat). Mahmud took all these valuables from them without payment, not even regarding them as forming part of their indemnity. The shops of those Multanis who had died or had fled were consequently closed, but Mahmud had them opened and seized all their contents (Gilanentz I959: 36).

Anti-Hindu activities continued in the wake of the Afghans' ejection from Iran by Nadir Shah Afshar (reigned I736-47). Information regarding Nadir Shah's specific policies toward the Indian merchant communities is scant, although reports from the Indian communities of later years suggest that Nadir Shah used their unprotected status (by Islamic law, Hindus, unlike Jews or Christians, were not considered dhimmis, 'people of the book', and were therefore not required to be protected) as a pretence for confiscating much of their wealth and property. This traumatic experience remained in the Hindus' collective memory even as late as I824, when the community of Indian merchants in Baku reported to George Keppel that, although they had no complaints about their treatment in Iran at that time, 'Nadir Shah treated their predecessors with great cruelty; impaling them, and putting them to several kinds of tortures' (Keppel I827: 294).

Prosperity returned to Indian merchants in Iran in the decades following Nadir Shah's assassination in I747. The founder of the Zand dynasty, Muhammad Karim Khan (reigned I75I-79), effectively seized power in southern Iran and reinstated a policy of tolerance toward foreign merchant communities, especially notable in the encouragement of British commercial activity in the Persian Gulf port of Bushahr and in the return of significant numbers of Indian merchants to Iranian markets. Government-sponsored anti-Hindu activity in Iran had long since come to an end by I802, when Edward Waring reported that, in Bushahr, 'the Hindoos live unmolested by the Persians, and are neither insulted nor oppressed by the government' (Waring I807: 3-4). The Hindus' welcomed return to Iranian markets was likewise observed by George Forster who, in the late eighteenth century, encountered some one hundred Indian families living in their own private quarter in the eastern Iranian town of Tarshish, where 'they conducted business without molestation or insult' (Forster I970, II: I86). Forster also observed significant Hindu merchant communities in the Iranian towns of Meshed, Yazd, Kashan and Qazvin, and he reported that, although there were a number of Indian communities active in Iranian towns on the shores of the Caspian Sea, there were larger Indian communities in the numerous Iranian ports on the Persian Gulf engaged in maritime commerce. Indian firms, especially Shikarpuris and Sikhs, continued to send agents to Iran throughout the nineteenth and twen- 
tieth centuries, and they exhibited an impressive ability to adapt to changing circumstances by taking advantage of their position as British subject and engaging in a wide variety of commercial activities.

The Indian diaspora communities in Central Asia also suffered a disruption in their commercial activities, although not until the late nineteenth century, and without reprieve or return. This was largely a result of Russian colonial expansion into sedentary Central Asia, which began in I865 with the conquest of Tashkent, soon to be the colonial capital of Russian Turkestan. Already in April I866, the Russian colonial administration turned its attention to the several thousand Indian merchants in its territory. Whereas their Muslim predecessors had viewed the Indian moneylenders as a necessary, even desirable contribution to society, the Russian colonial administration viewed the Indians as an undesirable threat whose usurious activities were contrary to the best interests of the Russian colonial population.

Considering the 'Great Game' political rivalry between Russia and Great Britain in the nineteenth century, one might expect to find the Russian colonial authorities troubled by the presence of several thousand Indian merchants - British subjects and potential spies - widely dispersed throughout Russian colonial territories. The British did, in fact, enlist some Indians as spies, and on occasion some of these spies are known to have posed as merchants in order to gain entry to Russian Turkestan. But, at least in terms of the policies he directed toward the Indian merchant communities in his newly acquired territory, the Governor General of Russian Turkestan, Konstantin von Kaufman, was not overly concerned with British espionage. Russian archival records indicate that Kaufman even rejected numerous proposals advanced by his subordinates suggesting that the Russians evict the Indians from their territory. ${ }^{34}$

To be sure, Kaufman did consider the Indians' moneylending activities to be exploitative and he was particularly concerned with the Indians' ownership of an increasing amount of agricultural land - farmland that had been used as collateral for loans that had defaulted. Thus, for Kaufman, the threat of a British invasion of Central Asia must have seemed much less pressing than the Indians' moneylending operations, which, one plot of land at a time, were effectively transferring ownership over large portions of Russian colonial territory into Indian hands! Still, Kaufman was sensitive to the Indians' contribution to the Central Asian economy in their role as transregional traders, and he recognised that their rural credit interests were crucial to the well being of his subjects. The abrupt removal of the Indians from Central Asia was therefore not desirable: to do so without first establishing institutions that could take their place would wreak havoc upon his region's 
agrarian economy and ultimately lead to economic collapse and famine.

Rather than evict the Indians, in 1877 , Kaufman published a circular that outlined a series of policies strategically designed to undermine the Indians' moneylending operations. ${ }^{35}$ The most important of these was prohibiting the Indians from foreclosing on loans that had been made using agricultural property as collateral. The publication of this circular sent shock waves through the Indian communities: Central Asian farmers refused to repay even the principle on their debts, and the Russian administration refused to respond to the Indians' complaints. It is conceivable that the Indians might have been able to adapt to the restrictions imposed upon them and shift their emphasis to urban moneylending and long distance trade. But the Indians' long-term commercial prospects in Central Asia were terminated by Kaufman's concomitant implementation of a state-sponsored Russian colonial banking system, rapidly expanded throughout the region. This measure effectively ended the Indians' ability to continue in their unique role as Central Asia's premier financiers and removed Indian moneylenders from their intermediary position between agricultural producers and the market. Ultimately, Kaufman's policies brought about the Indians' rapid withdrawal from Central Asia in favour of emerging opportunities elsewhere.

\section{Conclusion}

For millennia there has been a regular movement of people and commodities between India and the lands to the north and west. This grew considerably after the eleventh-century Ghaznavid invasions of India and their establishment of the first in a series of Turko-Afghan dynasties that ruled in north India for over seven centuries. Throughout this period, Multan functioned as north-western India's premier commercial centre for international trade and, in the years that followed, the economic opportunities offered by this frontier town fostered the development of a number of great merchant family firms, the agents of which were collectively identified in historical literature as 'Multanis'. These heavily capitalised, caste-based family firms enjoyed several centuries of economic prosperity during the Delhi Sultanate and Mughal eras, one result of which was the extension of the Multanis' commercial activities beyond the boundaries of the subcontinent. By the middle of the sixteenth century, they had established diaspora communities in a number of locations in Central Asia and Iran and, within just one century, the population of Multanis living abroad grew to number in the tens of thousands. 
At first glance, the ability of Indian merchants to maintain thriving communities in Afghanistan, Central Asia, and Iran appears to be a historical aberration, as they represent a significant Hindu population in Muslim states: individuals technically unprotected by Islamic law. However, with only a few notable exceptions, residents of the Indian diaspora communities enjoyed the steadfast protection of their Muslim hosts. This can be attributed to several important factors. Most obviously, the Indian merchants were widely respected as large-scale transregional traders whose fortitude, technical knowledge, and commercial connections were valuable resources for the state. They supplied their host societies with necessary commodities and a commercial outlet for their own products, and they provided an important source of tax income for the state treasury. But more important than their transregional trade was the Indians' penchant for interest-oriented moneylending ventures, including the operation of elaborate rural credit systems. This promoted the expansion of their host states' agricultural tax bases and, by extending a monetised economy into the countryside, also facilitated the states' collection of tax revenues in cash. In this way, Indians in the diaspora served as a bond that connected the economies of their host societies with the vast resources of India's agrarian economy, which they expertly employed as an engine for investment in foreign markets.

In an effort to illuminate the numerous caste and religious identities of the groups that comprised the diaspora, the discussion above has deconstructed such vague terms as 'Multani', 'Shikarpuri' and 'Bania' as used by early modern authors. It has also been argued that the Indian diaspora exhibited a remarkable historical continuity for nearly four centuries. Variations in political and economic climates prompted the Indians to extend their diaspora in search of new commercial opportunities, and to evacuate problem regions and re-establish themselves elsewhere when necessary. Still, whether they were designated 'Multani' or 'Shikarpuri', the Indian merchants involved in diaspora commerce were a part of a unique, unified entity.

In the I870s, Konstantin von Kaufman, the Governor General of Russian colonial Central Asia, implemented a series of revolutionary policies that strategically targeted the Indian merchants in his territory, undermined their business interests, and, by the end of the nineteenth century, effectively brought an end to the Indian communities in Central Asia. In Afghanistan, Indians maintained an active commercial presence right up to I947. In Iran, notwithstanding the disruptions of the second quarter of the eighteenth century, Indian commercial activities have continued on into the twenty-first century. Indeed, the celebrated Indian Hinduja family, operators of one of the wealthiest com- 
mercial firms in the world, began as a modest Shikarpuri firm in early twentieth-century Iran.

In the end, the socio-political trauma associated with Partition provoked the mass migration of the Shikarpuri-Multani firms from Pakistan, largely to Bombay. From this new centre, the Indian firms directed their attention away from Afghanistan and Central Asia in favour of emerging commercial opportunities literally across the globe. By the beginning of the twenty-first century, large numbers of ShikarpuriMultani merchants had established a vast network of communities that stretched from Hong Kong, Manila, and Singapore in the east - across much of Africa and Europe - to the Caribbean islands, Central America, Canada, and the United States in the west.

\section{Notes}

I For further discussion, see Tölölyan I996.

2 R. Cohen I997: ix; Wink I987: 35I; Tölölyan I996: II.

3 For further discussion, see Safran r99ז: 83-4.

4 A remarkable exception to this rule can be found in S.D. Goitein's study of the social and economic operation of a medieval Jewish merchant diaspora communities operating out of Fustat, modern Cairo. Goiten i967-88.

5 See Map 4B in Habib I986.

6 Wink I990: I66-89; Durrani I991: II-2; Dasti I990: 247-8.

7 Zia ud-Din Barani I860-62: 310-I2. See also Raychaudhuri and Habib I984: 85; Jain I929: I0; Dasti I990: 249; Jackson I999: 245-9.

8 English translations of these documents can be found in Levi 2002: $267-9$.

9 Cited in Druhe I970: 95.

Io For discussion of these records, see Mukminova I985: 6I-8; Gopal I992: II-3; Dale I994: 63-4, 75-6; Levi 2002: IOI-2, 267-9.

II Based on his patronym, the cloth-printer identified as 'Lahori Chitgar ibn Lalu' was most likely a Hindu. 'Gujar' was the name of a predominantly pastoral Panjabi tribe subject to a policy of sedentarisation by emperor Akbar in the late sixteenth century. Singh I991: II2, I32, 259, 265, 29.

I2 Alam also suggests that Multanis had to take legal recourse in the local qâdî. In addition to establishing an Indo-Muslim commercial presence in the muhallas (neighborhoods) of sixteenth-century Central Asia, however, the preponderance of references to Muslim Indians in Central Asian legal records seems to suggest that, unlike their non-Muslim counterparts, Muslim Indians in Central Asia were expected to conduct their business within the parameters allowed by the sharîat as interpreted by the local legal administration. The social distinction between non-Muslim Indians on one hand, and Muslims on the other, should not be interpreted to suggest that these communities did not interrelate. For example, commercialists such as Darya Khan are known to have employed non-Muslim Indian artisans, such as 'Lahori Chitgar ibn Lalu'. See also the case of the Muslim Indian Hamid who had partnerships with two Hindus, Ardas and Banda Minkab, in Astrakhan and Moscow. Antonova I958: 24I-8.

I3 Della Valle I972: 39; Kemp I959: 36; Olearius I667: 299.

I4 Durrani I990: I03; Wink I990: I66-9; Wink I997: II5-9; Dale I994: 62-4. 
I5 See especially Markovits 2000: 46-7, 25I-2. See also Russell I969, II: 44I-2; Burton I851: 310-17; Pandey 1992: I29-30; Ray I984: 244.

I6 In the Central Provinces alone, Russell identified twenty 'sub-castes' of Banias, both Hindu and Jain, the most important being Agarwala, Oswal and Parwar. Despite Russell's identification of the Banias as a distinct caste, he acknowledges the possibility that it is 'merely an occupational term applied to a number of distinct castes.' (Russell I969, II: III-6I). According to Ibbetson, 'the word Banya is generally used for "shop-keeper" all over the Panjáb, not excepting even the frontier where Kirár is the more usual term; and it is just possible that in some cases other mercantile castes have been included in this figure... It is sometimes said that Banya is no true caste at all, but merely an occupation term equivalent to "shop-keeper," and that the great divisions of the Banyas, the Aggarwáls, Oswáls, and the like, really occupy the position of castes; and this is in a sense true.' Ibbetson I9I6: 242-3. Timberg also argues that it was much more likely that, based on their similar occupations, the term was applied to a variety of castes, the members of which, over time, acknowledged a common identity as Banias despite their various endogamous caste affiliations. Timberg 1978: $148-60$.

I7 For the original citation, see Tavernier I7I2, I: 62. This is echoed in Della Valle I972: 39 .

I8 Muzaffar Alam observes that the extraordinary strong Khatri participation in this trade, it should be noted, seems to have coincided with the rise and growth of Mughal power in India'. Alam I994: 2II.

I9 This is confirmed by Elphinstone who reported that, in Afghanistan, Hindus 'are often employed about the court in offices connected with money or accounts; the duty of steward and treasurer about every great man, is exercised either by a Hindoo or a Persian. There have even been Hindoo governors of provinces, and at this moment the great government of Peshawer has been put into the hands of a person of that religion'. Elphinstone I839, I: 414-5.

20 Ibbetson reported that, in the nineteenth century, the Bhatias were numerous in Sind and Gujarat, but that their region of origin appears to have been Bhatner, Jaisalmer and Rajputana. Wink also notes that, 'there was a close connection between the Bhattîs or Bhâtîs of Mâda (modern Jaisalmer district) and the Caulukyas of Gujarat in the mid-twelfth century.' In an effort to locat the Bhatia homeland, Anthony O'Brien establishes the presence of the Bhatia as a community 'in or adjacent to Sindh from the 7th century onwards.' This is supported by a reference in the Chachnamah to the king of Batiah in eighth-century Sind. According to Ibbetson, they were distinctly below the Khatris in social status but, like the Khatris, the Bhatia had a long tradition of maintaining widely dispersed commercial communities to the northwest. Ibbetson I9I6: 250; Wink 1997: 23I-2; O’Brien I996: 30-58; Mirza Kalichbeg Fredunbeg I979: 43.

2I Ludhiana, east of Amritsar, was the Khatris' primary centre of activity in nineteenthcentury Punjab. Ibbetson I9i6: 248.

22 Russell I969, III: 456-63; Dale I994: 58; Sharma I984: 185-207. Sharma notes that 'the term Marwari dates back to the establishment of Marwari business houses outside Rajasthan, particularly in Bengal, Bihar and Orissa, since the time of Akbar and Shahjahan'. It has been argued by Max Weber that, due to the strict restrictions of their faith, Jain merchants' commercial activities focused on banking and moneylending and they rarely ventured far from their home. Dale, however, locates members of the Marwari Jain Oswal caste in seventeenth-century Astrakhan. Furthermore, Sharma and L. C. Jain both note that business ventures did, in fact, frequently take Jain merchants to distant markets. Thus, although L.C. Jain notes that the designation 'Marwari' could refer to either Jains or Hindus, specifically Vaishnavites, at least 
some of the Marwaris who constituted a minority of the population of the Indian merchant diaspora were most certainly adherents to the Jain religion. Sharma I984: I85-6; Weber I992: 200; Jain I929: 29-30; Dale I994: 58-60.

23 Antonova I965: 56-7, 6I-2, 65-7, 82-4, II3-4, II4-5, I28-33, I35. See also Gopal i988: 7-8; Dale I994: 59-60.

24 Although Marwaris were likely to have been present in Central Asia long before then, the earliest documents available specifically referring to Marwaris in Central Asia date to the nineteenth century. Levi 2002: I09-IO.

25 It should be noted that the term 'commenda' refers to such business partnerships as practiced in medieval Europe. Murat Çizakça, principally drawing on materials from the Ottoman archives, has demonstrated that medieval European merchants learned such techniques from their Muslim counterparts, who generally referred to the partnership system as 'mudaraba', from the word mudarib (Turk.), meaning 'an agent' (Ar., mudâraba). Çizakça I996: 4-62; Udovitch I970: I70-248; Udovitch I979: 25574 .

26 As noted above, the Bhatias were established in Sind even prior to the thirteenth century, when many of them converted to Islam under Firuz Shah Tughluq. Wink I997: 23I-2. According to Russell, however, in the nineteenth century, those Bhatia merchants whose commercial interests led them abroad were exclusively Hindu. Russell I969, I: 350. Markovits suggests that the term 'Lohana' was actually used as a sort of general designation for all merchants of Sind, except Khatris and Bhatias. Markovits 2000: $25 \mathrm{I}$.

27 The discussion below summarizes a number of conclusions advanced in Levi 2002.

28 Sadr al-Din 'Aini I959: 73-5; Mohan Lal I97ı: I0I; Olufsen I9II: 296-7; Dmitriev I972: 239 .

29 The tradition of granting Multan to the heir apparent was common among the Delhi Sultans and Mughal emperors alike. In addition to its commercial value, these rulers attached a great strategic value to the province in terms of protecting their territory in India from foreign invasions.

30 For further discussion, see Levi forthcoming.

3I In his own words, Markovits suggests that 'Shikarpur was the centre of a financial network which developed in the second half of the eighteenth century in direct relation to the rise of the Durrani Empire.' He apparently contradicts this by elsewhere stating that 'Hindu merchants who lived in dispersed colonies in the Islamic lands of Central Asia who had been known as Multanis...gradually became known as Shikarpuris'. Markovits 2000: 29-30, 60-62.

32 Jain's mutual identification of these merchants as 'Shikarpuri Multanis' further suggests that the former is derived from the latter. Jain I929: 33 .

33 The re-emergence of the designation 'Multani' among Indians in Bukhara at the end of the nineteenth century suggests that some of the Shikarpuri firms may have moved their central offices back to Multan. See Olufsen i9ı1: 297; Curzon I889: I72. Alam has uncovered a few 'Multani' financial houses that maintained their identification with that city even after having moved the center of their commercial activity to Shikarpur. Alam I994: 223-4. See also Ray i984: 253-5.

34 The discussion between Kaufman and his subordinates can be found in the Central State Historical Archive of the Republic of Uzbekistan, fond I-I, opis' II, delo 39. See Levi 2002: 250-58.

35 Central State Historical Archive of the Republic of Uzbekistan, fond I-I, opis' II, delo 39: I6-I7b. 



\title{
3 'We Lost our Gift of Expression'
}

\author{
Loss of the Mother Tongue among South Asians in East \\ Africa, $1880-2000$
}

\author{
Gijsbert Oonk
}

\section{Introduction'}

Contact between Asians, Africans, and Europeans in East Africa has a long history and was largely influenced by the economics and politics of colonisation and the emergence of nation-states. ${ }^{2}$ This long-standing relationship resulted in a particular 'East African Asian culture' in which Gujarati (Indian), Swahili (East African) and European cultures were adapted, transformed, and re-invented. The migration of Asians from one continent to another, where they became a minority, resulted in the development of various strategies of adaptation, with the group adopting new socio-cultural values while maintaining some of their original values. Despite the information we have on the number of migrants, their religious backgrounds and their reasons for migration, we know very little about the 'cultural baggage' of these migrants and even less about how and why this changed after their migration. ${ }^{3}$ This cultural change was not a natural, harmonious process; rather there were many conflicts, which required painful decisions to be made.

One such decision was the exchange of the Gujarati language in favour of the Swahili and English languages. The first generation of $\mathrm{Gu}$ jaratis in East Africa knew how to read, write, and speak Gujarati, whereas the third-generation migrants may speak Gujarati with their parents but prefer to use English among themselves and they also do not know how to read or write Gujarati. This exchange of Gujarati in favour of English was the result of individual and community-based decisions. It should not be seen as a simplified process of a minority community adapting to 'globalisation', or 'westernisation' by instrumentally choosing the more 'global' language, the language of the business elite. On the contrary, as we will see, the colonial state promoted English and German education in a period when the Gujaratis successfully supported and sponsored their own Indian schools, using Gujarati as the vernacular language. The Germans in Tanganyika and the British 
in Uganda and Kenya were not able to implement their education systems because Gujaratis refused to support the interests of colonial states. They followed their own cultural and economical agenda. Interestingly, the Gujaratis themselves promoted the English language when the independent East African nations started to promote Swahili, the vernacular East African language. This was the consequence of intended and unintended Government policies and the realisation by $\mathrm{Gu}$ jaratis that their future did not lay in India but in Africa and the West.

This struggle over the 'teaching language' is one of the most important variables of ethnic identity. Together with religion, food and dress habits, and a shared history [real or imagined], 'language' is among the key variables of most definitions and descriptions of 'ethnicity'. The maintenance of aspects of Indian culture(s), in the form of the reproduction of language, is seen as a key element in many definitions of diaspora. ${ }^{4}$ In the book's introduction, I have shown that there is a tendency to 'unify' the South Asian diaspora in the diaspora debate. In this article, I emphasise that migrants make their own adaptations to local circumstances. The consequence may well be that they do not identify with their ancestors' culture 'back home'. It is therefore intriguing to see how the shift in identity and the choice of language occurred among the Gujarati businessmen of East Africa. The choice of the 'teaching language' was instrumentally made. The Indian/Gujarati community had an active and successful lobby in this matter.

In this article, I use the image of 'three generations' of Hindu Lohanas in Tanzania:5 (I) the pioneers (born I880-I920), who decided to settle with their families in East Africa; (2) the Asian East Africans (born I920-I960), who made East Africa their home; and (3) the internationalists (born I960-2000), whose 'roots' are as Asian East Africans, but who are economically oriented towards the west and culturally towards both west and east. This typology reflects the change in identity from one oriented towards the Gujarat region to an international' orientation. The Lohanas lost a part of their primary 'Gujarati' identity and gained an 'international' identity. This change was, however, not welcomed by all of the community's members. Some expressed their concern about the loss of 'the gift of expression'.

In this article, I focus solely on Hindu Lohana families. ${ }^{6}$ The research was based on the history of twenty Hindu Lohana families who have lived in East Africa for three or more generations. ${ }^{7}$ The results of this research are particularly accurate for Dar es Salaam and the Coastal Region, where most of the interviews were conducted. ${ }^{8}$ Wherever relevant, I discuss the variation among and within the various families and relate these families to the more ideal type of family. ${ }^{9}$ Furthermore, archival material has been added, especially data related to the educational and language policies of the German [in German Tanganyi- 
ka] and British colonial governments. In general, the development of Indian education in East Africa is a much-neglected area of research. At best, it is hinted at in general histories on Asians in East Africa. Moreover, the use of sometimes very valuable German sources in the Tanganyika National Archives (TNA) is rare because of the language problems faced by many English- and/or Swahili-speaking scholars. This article is the first attempt to fill this gap.

I also argue that there is a need to study language adaptation as a local 'bottom-up' process; local, in the sense of a well-defined geographical and historical area and 'bottom-up' in the sense that we choose to take the perspective of the 'agent', the one who accepts, refuses or mixes new language opportunities. By pursuing this perspective, we may gather a view of how the 'range of choices' is defined by the actors of change themselves. This may provide us with insights into the economic and cultural agendas of individuals as well as groups in a fastchanging economic and cultural environment.

My argumentation is divided into five sections. First, we introduce the general migration history of South Asians in East Africa. Here the main focus will be on the absence of Hindu women in East Africa. The second section looks at the life histories of early Lohana migrants who settled in East Africa between I880 and I920. Here, the main aim is to show the emphasis on their knowledge of reading and writing Gujarati. The third section highlights the second-generation Lohanas' efforts to establish 'Indian Schools' that would teach Indian languages. The fourth section coincides with a dramatic shift in the colonial history of East Africa, when the East African colonies became the independent countries of Uganda, Tanzania, and Kenya. These countries no longer subsidised Indian schools, so this option was no longer available. Hin$\mathrm{du}$ Lohanas opted for English-language education, and the third generation eventually 'forgot' how to read and write Gujarati. In the fifth and final section, I emphasise the consequences of these findings in relation to the discourses around the diaspora concept.

\section{Migration and Settlement of South Asians in East Africa}

In the nineteenth century, trade between South Asia and East Africa was constrained by the rhythm of the monsoons. From November to March, the famous, beautiful dhows sailed from West India to East Africa and between April and October, they made the return journey. The trade in cotton textiles, ivory, and spices was profitable but dangerous. Many traders did not return home safely. Rough seas, pirates, and various diseases took the lives of many traders and early adventurers. 
It was only in the late nineteenth century that some South Asian traders started to settle in Zanzibar and on the East African coast. These early South Asian settlers are nowadays seen as the pioneers of many South Asian family business houses in East Africa, such as that of Nanji Damordas, who at the age of ten, accompanied by his father, came to look after some business in Zanzibar. Most of these early migrants were asked to join the flourishing family businesses or to assist in the businesses of community members. Initially, they travelled back and forth to India, but slowly they settled in East Africa and invited their brothers and sisters, wives, and children to join them.

The general migration history of Asian East Africans is well documented. Long before East Africa was 'discovered' by Europeans, Zanzibar and the East African coast were well-known trading destinations for Arabs and South Asians. Trading relations were strengthened with the establishment of the British Empire in East Africa. In the period between 1880 and 1920 , the number of South Asians in East Africa grew from about 6,000 to 54,000. These included Hindus (among them well-known business communities like Patels, Lohanas, and Shahs), Muslims (especially Ithnasheries, Bohras, Ismailis), Sikhs, Goans, and others. ${ }^{\text {IO }}$

The various Asian business communities that arrived in the late nineteenth century developed far more intimate social and economic relationships with each other than they did in India. These linkages resulted in new business habits, marriage policies and forms of capital accumulation. Their shared knowledge of the Gujarati language and their minority status (never more than 2 per cent of the total population in East Africa, somewhat higher in the main trading ports) in a new society played an important role in this process. Despite the development of intimate social economic links, inter-caste marriages and marriages between Hindus and Muslims were still uncommon. ${ }^{\text {II }}$

The Muslims settled earlier with their families than Hindus owing to the Hindu taboo on travel overseas. ${ }^{\text {I2 }}$ Upper-caste Hindu men considered Africa to be 'alien' and 'unsafe' for women, and believed that women would be better off if they stayed behind in their own extended households in India. Owing to economic and social uncertainty in East Africa, Hindu women often remained behind in India to look after their parents-in-law, children and property, and to take care of their children's education. ${ }^{13}$ The unmarried Hindu men generally went back to India to marry, and their wives stayed behind from the outset, with the men making frequent trips back and forth. In other cases, the women came to the East African coast for a few years, returning to India to give birth, where they then generally remained for the next io to 20 years, until their children finished their educations. ${ }^{\mathrm{I}}$ 
The sultan of Zanzibar, Seyyid Bargash, must have been aware of this, as he encouraged Hindus to bring their wives to Zanzibar. He sent his private vessel to welcome the first Hindu woman to Zanzibar and gave her a reward of Shillings 250/-. Moreover, he promised to turn Zanzibar's Old Fort into a residence for the wives of merchants and offered to equip it with water pipes fitted with silver taps to ensure that Hindu women need never appear in public. ${ }^{15}$ Around the same time, the Hindu community in Gujarat revolted successfully against Brahmin priests and religious customs which were cramping their mercantile activities and making commerce overseas difficult. ${ }^{\text {I6 }}$ All these activities paved the way for Hindu migrants and settlers in the late nineteenth and early twentieth centuries. A new (in fact, very old) world was there to be discovered.

\section{The First Generation: Reading, Writing, and Speaking Gujarati}

The first generation of Hindu Lohanas in East Africa were born between I880 and I920 in Gujarat, western India. Most of them received at least their primary educations in their homeland. They were able to read, write, and speak Gujarati and some had a little knowledge of English when they arrived in East Africa. Others travelled as young boys with their fathers and received some primary education in East Africa. An example is Sunderjibhai Damordas, a ninety-nine year old Hindu Lohana. ${ }^{17}$ The migration history of Sunderjibhai follows the familiar pattern of his community to East Africa. ${ }^{18}$ In I9i6, at the age of ten, he arrived in Zanzibar together with his father, Nanjibhai Damordar. They were asked to look after the shop of a relative, Kesawji Dewanji, whose sons didn't want to settle in East Africa and returned to India. ${ }^{\text {I9 }}$

Formal and informal education played an important role in the lives of the pioneers. Most respondents recalled their primary and secondary schools. As might be expected, some received part of their education in India, whereas others were educated in East Africa exclusively. Sunderjibhai recalls that he had just finished King Readers II when he left school in Mombassa, i.e., his English was very poor at that time. However, he already knew how to read and write Gujarati, having learned it in Gujarat.

The Christian missionaries in East Africa had little interest in South Asians. Nevertheless, they could not afford to let them remain uneducated. They were middlemen between the economy of the West and the Swahili farmers. They therefore took a great interest in educating their children and started their own schools from the moment Gujaratis settled in East Africa. ${ }^{20}$ During the colonial period, Sunderji and most other South Asians in East Africa went to so-called 'Indian 
schools', where they were taught to read and write their 'own' languages. Though many schools were intended for certain communities or founded by religious institutions, others served a wide range of students of various backgrounds. ${ }^{2 \mathrm{I}}$ Most of my respondents remembered that they had attended 'Indian schools' where Hindus and Muslims sat together. Many of these schools were (partly) financed by the prosperous South Asian business community and colonial governments. The colonial governments welcomed such initiatives by South Asians wholeheartedly.

One may here record a tribute of appreciation to the voluntary efforts that the Indian community have made throughout the Territory to provide some form of education, however poor, for its children. It is a tribute to their sense of responsibility towards the rising generation. In India people are well accustomed to the principle of providing at their own cost some kind of education for their children.... ${ }^{22}$

However, the colonial governments wanted the South Asian communities to be taught in English and/or Swahili (in Kenya and Uganda) or German and/or Swahili (in German East Africa, DOA). In the first place, those who could read, write, and speak the language of the ruler might find a job in the colonial civil service. Secondly, the governments wanted to control native trade and produce, especially the account books of South Asian traders, in order to levy taxes and to avoid 'illegal' Indian competition.

It is difficult to judge the accusations of irregularities and illegal business practices, because most of the evidence comes from colonial officials who, generally, supported European interests. For example,

It is the opinion of the Europeans entrusted with Indian business relations that 30 per cent of the Indians of Kilwa and Mohorro become bankrupt as soon as accounting becomes obligatory (...). They always receive new credit from their fellow believers. Scarcely a month passes when Indians do not come forth to declare themselves bankrupt in one or other city of our colony. They gladly pay 200 rupees of the establishment tax. ${ }^{23}$

Whether this is true or not, these accusations played a major role in the development of colonial policies towards the use of Gujarati account books and the teaching of Gujarati, English, and German in primary and secondary schools.

Thus, in 1906, the German colonial government tried to force South Asians to do their accounting in either German or Swahili (in Latin 
script, and not in Gujarati or Arabic script). ${ }^{24}$ This was not backed with any initiative to encourage Swahili or German education for Indians. On the contrary, Indian education was deliberately hindered at first: 'The Indians who, by their high intelligence and endeavour, get the most out of education without being useful to the Government will be held back and segregated. ${ }^{, 5}$ Nevertheless, government education for Indians was introduced after I9I2, when the Germans claimed that accounting done in Gujarati made it difficult to levy the profit tax and led to fraudulent bankruptcy claims. They admitted that the 'big Indian firms' were not the targets of the legislation as their books 'were very well kept, even by European standards'. ${ }^{26}$ The main aim was to challenge the 'big mob of retailers', and 'Blutsauger' [cheats or bloodsuckers, G.O.], i.e., the small shop owners and so called duka wallas. ${ }^{27}$

However, it was soon realised that it would be impossible to force the 'old men', the Indian family patrons, to learn German or any other European language in a short period of time. The Germans proposed that the South Asians should demand that the young men in their firms learn a European language. The reasoning was twofold. Firstly, the young men would eventually be able to present their accounting in German or English and secondly, after one generation the language problem would be solved. Nevertheless, the Germans themselves were unable to provide the necessary funding for this education. In addition, they realised that the compulsory learning of European languages might lead to the migration of South Asian businessmen to Mombassa or Nairobi, where learning a European language was not yet an issue.

Meanwhile, the new Indian Association had taken up the 'language matter'. The secretary of the Indian Association reminded the British Chief Secretary in Dar es Salaam, Tanganyika, that,

my Association has also taken the trouble of making enquiries in Uganda regarding the matter and we are informed that even there it is permissible to keep such books in Gujarati amongst other languages. ${ }^{28}$

In Kenya and Uganda it had since the early I920s been accepted that the account books of Indians could be kept in English, Gujarati, or Urdu. $^{29}$ The British Colonial Government hired South Asians to check the account books of South Asian firms. Except for a minor debate concerning the expenses of these colonial clerks, the language problem never came up. The Indian Association successfully made its point and the proposed language legislation in Tanganyika was never passed and the Tanganyika colonial government appointed South Asian accountants to check the Gujarati books. However, even this was effectively challenged by the South Asians because they didn't want their books to 
be open to 'outsiders', because of the importance of company secrets. Several older informants readily explained to me that they kept their business records in Gujarati even though they were able to read and write in English; the main reason was to keep them secret, and not necessarily to avoid paying taxes either. Interestingly, complaints by South Asians regarding tax rates were written in English in Kenya and Ugan$\mathrm{da}$, and in Swahili and German Tanganyika. In everyday practice, language did not seem to be a problem. ${ }^{\circ}$

In my view, the South Asian businessmen used the 'language' argument instrumentally in order to minimise colonial government interference. Tax avoidance and the misuse of trading licenses were just a small part of this. More importantly, I assume, was the desire to keep the 'social distance' between the legislators and the traders at a level that would allow them to outplay the legislators. Most of my informants in Dar es Salaam do not hesitate to state that they made 'fair deals' with the South Asian clerks regarding taxes without ever showing any of their accounting books. At the same time, raising taxes and checking accounting books was only an excuse by the colonial government to defend the interests of European firms in the area. This seems to have been the major reason behind proposed legislation, particularly during the German colonial period in Tanganyika.

This is not to say that language is unimportant and merely a condition for understanding, exchange, and collaboration or competition. On the contrary, language is also an important part of primary identity. Members of the first generation, even those who read, write, and speak English fluently, still regard Gujarati as their mother tongue. It is an important part of their cultural background. This is reflected in the fact that I saw various Gujarati newspapers and magazines in the houses of these first generation people, including special women's magazines. Most first-generation Gujaratis in East Africa would have read Gujarati with more ease than English and thus they subscribed to magazines published in Gujarat.

The preference for Gujarati was also reflected in the fact that whenever a will had to be drawn up, it was written in Gujarati. I also came across English and German translations of wills in the colonial records that were originally written in Gujarati. The will of the well-known South Asian trader Sewji Hadji of Bagamoyo has its own entry in the Archives. It has been translated into German and English as well. ${ }^{3 \mathrm{I}}$ This evidently shows that there was a clear preference for Gujarati in personal correspondence.

In short, and as expected, the first generation of Hindu Lohana Gujarati businessmen could already read, write, and speak Gujarati when they arrived in East Africa. They kept their business records in Gujarati, except for a few larger firms, which kept them in English. The first- 
generation South Asians started to build educational institutions where the vernacular language would be Gujarati. Nevertheless, this was challenged in the following period by the colonial rulers who succeeded in making English the most important subject in the curriculum.

\section{The Second Generation: Speaking and Reading Gujarati}

The second-generation Hindu Lohanas in East Africa were born in East Africa in the period between I920 and I960. Manilal Sunderji Damordar is the third son of Sunderjibhai. He speaks fluent Gujarati, is able to read Gujarati but has difficulties in writing it. He was born in Dar es Salaam and had his primary and secondary educations there. $\mathrm{He}$ went to London in the I96os to study for his university degree in commerce. He is fluent in English. Most of this generation learned to read and write Gujarati and English in the colony's 'Indian schools'.

As the British could not provide the education they wished to in the territories, they were happy with South Asian initiatives to build schools throughout the country. In general, the level of Indian education was sufficient and could easily bear comparison with most missionary schools. However, the colonial government was unhappy with the fact that in most Indian schools, the vernacular language remained Gujarat, while English was only treated as a subject. While the government was willing to promote the education of Indians in the colony, one important condition was that the vernacular language be English as well. In the words of R. Smith, the Director of Education in Dar es Salaam,

The medium of elementary education is the language of the country, but as the Indian Communities wish to maintain their identity by continuing to encourage the use of Gujarati for commercial purposes I warned them that it is not improbable that Government will decide to assist only in schools where English is taught. ${ }^{32}$

In I925, the Colonial Government was still arguing that the Gujarati language was mainly used for commercial purposes among South Asian traders and that the government therefore should not support Indian education unconditionally. Nevertheless, this reasoning lost out in favour of a new argument. The Colonial Government started to emphasise that their main interest was the development of the country, especially the Africans. Therefore, the education of Indians was not at the top of their agendas. Nevertheless, they were willing to support other groups as well. A remarkable conflict of interests between the co- 
lonial government and the South Asian settlers emerged. The colonial government demanded that education to be either in English or Swahili (or even in German, in German Tanganyika), whereas the settlers again opted for their own language. This conflict of interests was particularly intense during periods when there was a shortage of funds on both sides.

The Indian Educational Society represented the various sections of the Asian community in East Africa. They used every argument they could think of to convince the colonial government to support more 'Indian schools'. This is clear when we look at the example of the 'Indian Public School' in Dar es Salaam in the period I925-I940. The Indian Educational Society, for example, pointed out that Dar es Salaam had an Indian public school in I9I7. It was closed during the First World War and re-opened in I92I as the Lok Tilak Memorial Indian School. As the number of pupils (boys and girls) grew faster than its ability to fund them, the Indian Educational Society organised a meeting at which the South Asian business community pledged Shillings I4,000, or about Io per cent of the total operating costs for one year. The Society also asked the British Government to provide a substantial grant arguing that Indians were 'your loyal subjects and taxpayers and are entitled to such concessions'. ${ }^{33}$ At this point, they were also referring to the Indian contribution, both physical and financial, during the First World War.

However, before this request could be granted, the British colonial officials had to develop their own educational priorities, conditions for funding, and legislation. The following topics and questions appeared in formal and informal correspondence: (I) whether special education for Indians was desirable at all. Were not large numbers of South Asians returning to India anyway? In other words, 'African' tax money should not be wasted on temporary migrants; (2) legislation that accounting should be kept in Roman alphabet with Arabic numbers in other words, not in Gujarati; (3) whether the quality of the buildings, educational materials, and the teachers were adequate, and (4) whether the colonial government should support education in the Gujarati language and, if so, up to what level? ${ }^{34}$

The Lok Tilak Memorial School was lucky until the early I930s to receive some ad-hoc funding from the government. The grants never amounted to more than fifty per cent of the total operating costs, however. The main source of income came from the parents of the children and generous contributions from the South Asian business community. This period of financial uncertainty would not end until a definite education policy was developed in 1937.35

It was only during the period 1929-1937 that the foundations for a colonial education system for South Asians in East Africa were laid. In 
I929, a grant-in-aid code was promulgated which provided for the payment of staff grants, block grants and average attendance and capital grants for buildings and maintenance. A primary school syllabus in Gujarati (and Urdu) was also prescribed and schools were under the control of the Board of Indian Education. ${ }^{36}$ In addition, a separate tax for non-native education was raised among Indians, which provided a little more than 20 per cent of the total government expenditure on Indian education. ${ }^{37}$

On the question of language, the general feeling among colonial officials was well formulated by the General Governor of Tanganyika, Donald Cameron, in a confidential letter to L.C.N.C. Amery (Member of the British Parliament):

I am in favor of grants-in-aid being made to Indian schools under a grant-code when it is prepared, but only in respect of education imparted in English. The teaching of Gujarati to Indian children is not to the general benefit of Tanganyika and for that reason I consider that assistance to it from public funds is not justified. ${ }^{38}$

The Indian Association and the Indian Educational Society were well aware of the position of the Colonial Office. Both realised that the provision of instruction in the English language would improve their chances of obtaining a subsidy for the Indian schools. Therefore, they began writing applications for grants in which they guaranteed English education from standards four or five onwards. After the I930s, it was finally agreed that teaching in Indian public schools would be in Gujarati (or Urdu in Muslim schools) up to the fourth standard, with English thereafter. ${ }^{39}$ This means that South Asians were first taught Gujarati and received English only after the fourth year.

Nevertheless, teaching in Gujarati was an important issue for the Gujarati community. The language became an instrumental symbol for Gujarati culture in the case of the Kitui Indian School in Moshi. This school was so small that the Education Officer opted for amalgamation with the Arab School. The South Asians were furious and argued fiercely that the:

Kitui Indian School is a Gujarati Primary School, running up to standard V. Its main language is Gujarati and all the subjects is being taught in Gujarati.... The Indian Community is not willing at all to enrol Arab boys in their Gujarati Primary School and is also unwilling to have a combined school for there is a vast difference in Indians and Arabs culture and behaviour. ${ }^{40}$ 
From the correspondence it is not clear what is meant by the 'vast difference in South Asian and Arab culture', though some hints are made elsewhere that the differences are related to the unwillingness of South Asians to have combined classes (South Asians and Arabs), especially with regard to South Asian girls. ${ }^{4 \mathrm{I}}$

Gujarati language and culture played an important role for these second generation South Asians. The generation of Manilal Sunderji Damordar, those born and educated in East Africa, learned basic reading and writing in Gujarati, which - at that time - was still considered their mother tongue. This is confirmed by some figures, however sketchy, from the I93I census report, which stated that more than one-fifth of the Tanganyika South Asians were able to speak English, whereas more than 75 per cent stated that they could not (the remaining 5 per cent did not answer the question on language). Furthermore, the report stated that about half of the South Asian population was able to read and write Gujarati, whereas only 5 per cent could read and write English. ${ }^{42}$ However, competency in the English language grew rapidly in the years to come.

From the I950s onwards, many parents in the upper strata of the Lohana business community were unhappy with the quality of education in the colony, especially at higher levels. ${ }^{43}$ Thus they began sending their sons and daughters to India and - those who could afford it - to the UK. Most of them were still British subjects, so admission into British universities was relatively easy. ${ }^{44}$ Unfortunately, we do not have any figures about the numbers of Hindu Lohanas who obtained university degrees abroad. However, more than half of my male informants of this generation, like Manilal Sunderji Damordar, had at least two years of higher education in the UK [32 out of 59] and thus developed some fluency in the writing and speaking of English. ${ }^{45}$

In 2000, although Manilal Sunderji Damordar spoke and read Gujarati, he had difficulty with writing it. He did not show the same interest in Gujarati newspapers as his father had. He had not subscribed to any of the Gujarati newspapers or magazines. His English was fluent and he kept his business correspondence in English. Sometimes, however, when he wrote his father, he made an effort to formulate at least a few sentences in Gujarati. With other Gujarati businessmen of his generation he spoke Gujarati, sometimes mixing in a few English words. At home, he spoke Gujarati with his wife and children; and while his wife would respond in Gujarati, his children usually responded in English. 


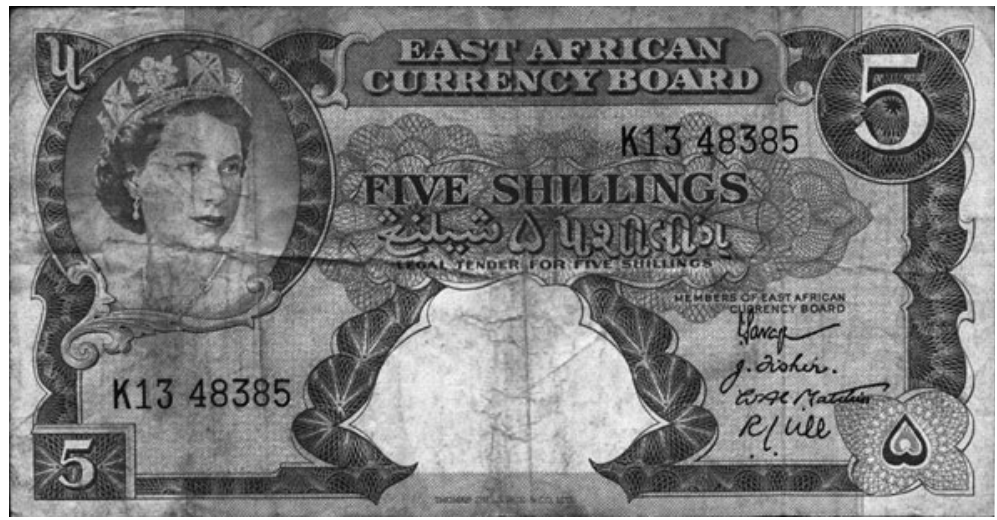

The struggle for the hegemony of language is 'work in progress' for the East African Currency Board. The languages of business were English, Arabic, and Gujarati, but not Swahili.

\section{The Third Generation: Speaking Gujarati}

Third-generation Hindu Lohanas were raised in East Africa in the period I960-2000. One day, I was invited to a Gujarati dinner at the Damordar house. There I noticed that Gujarati was being spoken. Manilal Sunderji Damordar spoke Gujarati with his wife and his son, Jivraj (22 years old) and daughter Shrutti (20 years). They responded to their father in Gujarati; however, Jivraj and Shrutti spoke English with each other and immediately admitted that they could neither read nor write Gujarati. Jivraj even admitted that he was unable to follow Gujarati lectures at the temple. His mother was especially concerned about this. ${ }^{46}$

Jivraj and Shrutti were born after the independence of the East African nations (Uganda, Kenya and Tanganyika in I96I-I962). By this time, there were no longer any 'Indian schools' that could provide the basic knowledge required for writing and reading Gujarati. In Kenya and Uganda, they would have been taught in English; while in Tanzania, Swahili became the language used in schools. Interestingly, the South Asian business community did not attempt to provide their community with language classes. They must have realised that their economic outlook was 'international' and not 'South Asian'. This was a consequence of their economic re-orientation towards the UK and the West in general, and the political events of the early I96os (independence) and early I970s (expulsion of Asians by Idi Amin). ${ }^{47}$ These events made them realise that the English language had become a ne- 
cessity. However, some religious institutions advocated separate religious classes. In this context, most Hindu Lohanas chose to send their children to schools in which English was the chief language or - if they could afford it - to the International School in Dar es Salaam.

Jivraj and Shrutti attended the International School in Dar es Salaam. Their English was perfect and their pronunciation was almost 'Oxford English', without the typical 'Indian' accent. Both of them admitted that they only ever spoke Gujarati at home with their parents, grandparents, or other elderly relations. Sometimes they used it as a secret language on school playgrounds when they did not want others to overhear what they were talking about. For them, knowledge of $\mathrm{Gu}$ jarati was not an important part of their identity, although they did state that they felt 'Indian'. This feeling of being 'Indian' was reflected in their food and dress habits, but not in their language use. It is interesting to note that a part of this 'Indianness' was related to the Hindi language, because both of them liked to listen to Hindi Music and watch Hindi movies, which they could actually barely understand. ${ }^{48}$

After interviewing them several times, we started corresponding via e-mail. They were studying in the UK and I was interested in their choice of food and their dress habits while they were abroad. During this correspondence, they began thinking more about their identities and background. One day, I asked them about their dress habits in the UK, Shrutti wrote:

Turning to Indian wear ... i [sic] do wear a simple salwaar (don't know how to spell it!!! how shameful! [italics mine]) around the house. I find it comfortable and easy to wash and wear. The only time $i$ [sic] would wear Indian out of the house in uk [sic] is when there is a special Indian occasion or ball (which is about once-twice a year). ${ }^{49}$

Some interviews with various parents revealed a concern for the shrinking knowledge of Gujarati among third-generation South Asians. This was especially true for families who attended lectures at Hindu temples. Lectures were often in Hindi or Gujarati, but the active knowledge of these languages among the third- (but often also second-) generation Asians is so poor that they have difficulty in understanding them. Therefore, some of the local Brahmins have requested their guest lecturers from India to use English.

This has led to an interesting debate within the Lohana community on whether lecturing in English in the Hindu Temple should be encouraged or not. For some, the teaching of religion in Gujarati is an essential part of the culture and teaching in English should be discouraged. This is a more strongly held view among some of the visiting 
Hindu priests from Gujarat (supporters of the BJP [Hindu Nationalist Party in India]) and the Hindi Belt. They have emphasised their language by refusing to lecture in English. There seems to be no debate on the question of whether lecturing should be in Hindi or Gujarati. The question is whether it should be done in an 'Indian' language or not. $^{50}$

Many members of the Lohana community in East Africa realise that knowledge of Gujarati is fading. Therefore, they encourage Gujarati language lessons on temple premises. Some (grand)parents try to teach their (grand)children Gujarati by introducing private tutors and extra language lessons. Nevertheless, I did not come across a single person of this generation who was born and/or lived in East Africa who could read and write in Gujarati. The knowledge of Gujarati is fading fast and is being replaced by English.

Jivraj notes that:

My parents are proud of us when we know all the religious functions, despite the fact that we went to the International School. So we stayed in touch with our culture. They feel sorry that we are not able to read and write our language anymore. Because it would enable us to attend more lectures from the Gurus from India

Although the community may be divided on which language should be used to teach the religion, there is agreement that the Hindu faith plays an important role in the community. Even those who did not visit the temples or lectures agreed that their sons and daughters should marry a Hindu, for cultural and religious reasons. 'In the end, it is difficult for outsiders to understand our ways' as one informant put it. In other words, there is a division between those who support religious teaching in English and those who would like to see religion taught in Gujarati. At the same time, both sides agree that English is the most important language in current business affairs and for career opportunities. Therefore, they agree that English should be the language used in school. Despite of all this, however, Gujarati is still considered the mother tongue by this third generation, and it plays an important role in the construction of identity. The question remains how many more generations it will take before this language is lost and English is accepted as the 'mother tongue'. 


\section{Conclusion}

In this study, I have investigated the loss of the ability to read, write, and speak Gujarati among the Hindu Lohana community in East Africa and the increased importance of English among the various generations. The first generation of Hindu Lohanas in East Africa still speaks, writes, and reads Gujarati fluently; the second generation speaks and reads Gujarati ,while the third generation may speak Gujarati at home with the (grand)parents, they are unable to read or write it. This youngest generation has developed a preference for English. This development occurred despite massive state intervention. Colonial officials needed the Asians to read and write in English in order to present their accounting books. The Hindu Lohanas successfully refused to do so. Nevertheless, the Lohanas developed the habit of reading and writing English just prior to the independence of the East African nations, in the period when not English, but Swahili was being promoted. This shows that the Gujaratis have had control over their 'identity' creation. This 'identity' creation was not a desire to 'hold onto tradition' and 'maintain the traditional language', nor was it part of the 'assimilation' into the local - i.e., Swahili - culture. These Hindu Lohana businessmen chose to become 'international' and opted for the English language. Despite the concerns of elderly members of the community, Gujarati was replaced by English. One Hindu religious leader suggested that 'we may have lost our gift of expression', but many businessmen would reply 'but we gained a more international outlook'.

This shows that the South Asian Lohanas in East Africa have toyed with three language options: Gujarati, Swahili, and English. Notwithstanding the current emphasis in the mainstream diaspora literature, the outcome of the interplay of three languages is that they opted for the international outlook. Contrary to what is suggested in the literature, it has not been a linear change from 'Gujarati to English', it has to be viewed as a process. This process has not yet been completed the knowledge of a particular language is subject to change again; either in the direction of Gujarati, as Brahim Priests continue to do their utmost to teach in Gujurati or Hindi in the Hindu temples of Dar es Salaam.

Previously, I have described the development of an Asian African identity among Hindu Lohanas in East Africa, which was based on changing food and drinking habits in particular. ${ }^{5 \mathrm{I}}$ The conclusions of that article are confirmed here. After three generations, the Hindu Lohana community in East Africa has developed a unique, self-determined combination of Swahili, European, and South Asian elements. This community does not identify with the Indian diaspora nor with the culture of their ancestors in India. ${ }^{52}$ Their home is Africa and their 
outlook is 'international'. In other words, the diaspora concept, with its emphasis on 'rootedness, the homeland, the reproduction of Indian culture abroad,' cannot help us to understand the history of the Lohana community in East Africa. Therefore, I again emphasise there is a further need to study these communities from a 'local bottom-up' angle.

\section{Notes}

I The research was made possible by the Netherlands Foundation for the Advancement of Tropical Research (WOTRO) in collaboration with the History Department of the Erasmus University, Rotterdam. In addition, the Vereniging Trustfonds Erasmus Universiteit Rotterdam and the History Department of the same university made available the necessary funds for attendance at the AAS conference in March 2003.2 In this article, we use the terms 'South Asians' and 'Indians' synonymously. It would be more correct to use 'South Asians' throughout, because South Asia was split into India and West and East Pakistan in I947. Nevertheless, colonial sources refer to 'India' and 'Indians', and many 'South Asians' in East Africa refer to themselves as Indians, or recall that they went to 'Indian' schools.

3 By far the best account for the 'cultural baggage' of Asians in East Africa is: C. Salvadori, Through open Doors: A view of Asian Cultures in Kenya, Nairobi I983. However, this otherwise excellent book presents a rather static vision of the Asian Cultures in East Africa. See also R.G. Gregory, South Asians in East Africa: An Economic and Social History, 1890-1980. Boulder: Westview Press, I993; R. Gregory, Quest for Equality: Asian Politics in East Africa, 1900-1967.

4 See, for the importance of the Telugu language for Telugu migrants, the article by Chandrashekar Bhat in this book. A view similar to this article may be found in the article by Anjoom Mukadam and Sharmina Mawani in this book. Kim D. Butler, 'Defining Diaspora, Refining a Discourse', Diaspora Io (2) 200I, I89-2I9. R. Cohen, Global Diasporas: An introduction, Seattle: University of Washington Press I997; J. Clifford, 'Diasporas', Cultural Anthropology, (9) 3 I994, 302-338; W. Safran, 'Diasporas in modern societies: myths of homeland and return', Diasporas (I) I I991, 83-99. S. Vertovec, The Hindu Diaspora: Comparative Patterns, London: Routledge 2000.

5 The literature on this subject includes, Robert G. Gregory, India and East Africa: A History of Race Relations within the British Empire, 1890-1939, Oxford: Clarendon Press I97I; M. Mamdani, From citizen to refugee: Uganda Asians come to Britain. R.R. Ramchandani, Uganda Asians: The end of an Enterprise, Bombay: Bombay United Asians Publications I976. H. Tinker, Separate and Unequal: India and the Indians in the British Commonwealth 1920-1950. St. Lucia: University of Queensland Press 1976; H. Tinker, The Banyan Tree. Oxford: Oxford University Press, I977.

6 Hindu Lohanas in East Africa come from the rural districts of Cutch and Kathiawar (Gujarat, western India). They were traditionally laborers, masons, husbandmen, shopkeepers, and traders. Their history is related to that of one of the Kshatria (warrior) castes, which in ancient times was called Lavan. The plural form of this was Lavanam and, over a period of time, it changed first to Lavana and finally to Lohana. In the nineteenth century, many turned to weaving and textile trading. Those in Kathiawar were especially well established as maritime traders and many were doing business in Oman. When the Sultan of Oman moved his headquarters from Musquat to 
Zanzibar (1832), Lohana traders quickly followed him and set up shops there. From there, they spread to the mainland from 1885 onwards.

7 These families include more than 200 people, of whom 78 were interviewed. Information on occupation, knowledge of languages and, for example, nationality is available for almost all of the family members. Seven or eight key informants were interviewed three, four, or more times. In addition, informal meetings, dinner parties and celebrations of holidays were attended by the researcher.

8 Indians in Zanzibar may follow a different pattern, as the Swahili language is more accepted among 'Indians' there, especially among Ithnasheries and Khojas. Moreover, my interviews with members of Indian Muslim communities, especially the Ithnasheries, revealed that they speak more Swahili, even at home, than their Hindu counterparts. The lower class Indians in Kariakoo, Dar es Salaam also developed a preference for Swahili. These results are not included here.

9 The focus on (Lohana) Hindus is a consequence of my personal network of Asian businessmen. Nevertheless, they form the majority of Hindus in East Africa. See Robert G. Gregory, Quest for Equality: Asian Politics in East Africa, 1900-1967, New Delhi I993, p. I3. In I995, it was estimated that there were 3,000 Lohana Hindus among a total of Io,००० Hindus in Tanzania. Some of the other Hindu communities include Bhatias, Patels, Vanias, Brahmins and 'others'. None of these other Hindu jatis numbered more than 800 people. Furthermore, the number of South Asian Muslims was estimated at 26,000 in I995. See C. Voigt-Graf, Asian Communities in Tanzania: A Journey Through Past and Present Times, Hamburg 1998, p. 53.

Io R. Gregory, South Asians in East Africa; R. Gregory, Quest for Equality..

II Literature on this subject includes, Robert G. Gregory, India and East Africa; M. Mamdani, From citizen to refugee: Uganda Asians come to Britain. R.R. Ramchandani, Uganda Asians. H. Tinker, Separate and Unequal. India and the Indians in the British Commonwealth 1920 - 1950. St. Lucia: University of Queensland Press 1976; H. Tinker, The Banyan Tree. Oxford: Oxford University Press, I977.

I2 According to the I887 census, there were 4866 Muslims and I022 Hindus/Jains in Zanzibar.

I3 Diverging concepts of purity and impurity made it rare for Hindu merchants to bring their wives, while Muslim merchants generally travelled with their families, especially to Muslim lands. Little is known about the Hindu taboo on travelling over sea. There is evidence that Hindus have been crossing the seas without compunction for many centuries, but the kind of ritual penance they had to undergo upon their return is not generally known. In some communities, such as Gujarati Vanias of Porbandar during Gandhi's time, we know that these rituals took place, but we lack information on other communities. One hypothesis which seems plausible, however, is that the generalised taboo on voyages by women represented a kind of substitution. The fact that the woman of the household did not travel overseas seems to have been sufficient to ensure the continuing purity of the household. However, questions remain about what happened when Hindus decided to take their wives and children to East Africa. Claude Markovits, The Global World of Indian Merchants, 1750-1947. Traders of Sind from Bukhara to Panama. Cambridge University Press 2000, pp27. See, for the fact that the burden of maintaining religious and caste "purity" fell largely on Hindu women, R. Nagar, Communal Discourses, Marriage, and the Politics of Gendered Social Boundaries Among South Asian Immigrants in Tanzania, Gender, Place and Culture 19985 (2), 7-34.

I4 The interrelation between social ties and business is clearly evident from various family histories. The eminent Mohammedan general importer and export merchant firm of the Karimjis was established in Zanzibar in the early I80os. The founding father of the Karimji family was Jivanji Buddhaboy. He had three sons: Pirbhoy Jivan- 
jee; Karimji Jivanji and Esmailji Jivanji. They carried on their father's business under the name of Pirbhai Jivanji until I86r. By then, the brothers had gone their separate ways. Karimji Jivanji started his own business, while the other two brothers worked jointly. Karimji Jivanji was followed by Alibhai Karimji Jivanji. In the late I8oos, he went to India to attend the marriage of his only son, Alibhai. As he had left the family business and because of the considerable sum he had to pay for the marriage, he invested in buying goods in India to bring back to Zanzibar to trade. The sailing ship in which he was returning to Zanzibar after the marriage of his son encountered a storm and the entire cargo had to be jettisoned. Mr. Karimji Jivanji thus landed on the shores of Zanzibar with his investments lost, no capital of his own and debts to pay. Source: family archive.

I5 Contemporary sources on the position (and absence) of Hindu Women in East Africa include: Richard Burton, Zanzibar: City Island and Coast vol. I London I872, pp. 32935; F.B. Pearce, Zanzibar: The Island Metropolis of Eastern Africa, (Frank Cass I967) I920, 257. See also: M. Honey, A History of Indian Merchant Capital, unpublished Ph.D. thesis, Dar es Salaam i982, p. 74.

I6 A. Sheriff, The Rise of a Commercial Empire, unpublished Ph.D. thesis, London I97I, p. 354 .

I7 The names of the informants have been changed for reasons of privacy.

I8 The migration history of Asian East Africans is well documented. In general, it is suggested that there is a long history of trading relations between East Africa and South Asia. Long before East Africa was 'discovered' by Europeans, Zanzibar, Mombassa, and Kilwa were well-known trading ports for Arabs and South Asians. These trading relations were strengthened during the establishment of the British Empire in East Africa. A number of Indian indentured laborers supplemented the trading diaspora. In the period between I880 and I920, the number of South Asians in East Africa grew from about 6,000 to 54,000. These included Hindus (among them wellknown business communities like Patels, Lohanas, and Shahs), Muslims, Sikhs, Goans, and others. R. Gregory, South Asians in East Africa; R. Gregory, Quest for Equality.

I9 We know little about the families who returned to India. If we assume that their reasons for returning were business failure, bad management or the like, we can also assume that this may be the reason why the stories of those who settled in East Africa are (mainly) success stories. Another explanation of their return may be the fact that religious taboos made them unhappy and uncertain in East Africa.

20 See, for example, Director of Education to Honourable Chief Secretary, ${ } \sigma^{\text {th }}$ March I925, Tanzanian National Archives (hereafter TNA), AB I032, p. 4: 'Throughout the Territory, wherever there is an Indian community of any size, Indian parents have taken steps to provide that their children shall, at least, be taught to read and write in Gujarati, and at big centres like Dar es Salaam, Tanga and Tabora and elsewhere English is also taught, and girls as well as boys rightly, attend these schools....' In I886, John Kirk welcomed the initiative of Tharia Topan to open a school in Zanzibar: 'The educational standard of the rising Indian community here is undoubtedly far below the educational standard and business capacity of their fathers who came from Kutch ... a knowledge of English is essential if the rising generation is to hold its own in keen competition with English, Americans, French and Germans. So great, therefore, would be the benefit to be derived from good schools in Zanzibar for the rapidly increasing British Indian population (...)Kirk to Secretary of State, Zanzibar, May I, I886 FO 84/I773 PRO London. Regarding Zanzibar, we discovered from the Foreign Office archives that the leaders of the various Indian communities had for some time been concerned by the absence of any educational facilities for their children, and at a meeting convened by Euan-Smith in the previous July [1890] they had agreed to fi- 
nance a school which they decided to place under the management of a committee elected from members of all Indian communities, both Muslim and Hindu. A sum of 50,000 Rupees was subscribed at this meeting, and other donations quickly followed. When the school opened, two hundred pupils were enrolled with a staff of teachers recruited in India. Gujarati and English were to be the languages taught. FO 84, Euan-Smith to Salisbury, 30 July I89o; FO 84 ibid. I January I89I.

2I The Ismailis, in particular the followers of the Aga Khan, were quick to build their communal-based Ismaili schools, which were nevertheless also accessible to other Indians.

22 Ibid.

23 Memorandum Kilwa, I9 May I903, TNA G I/29/II. Translation mine.

24 At that time, Governor Von Goetzen was even attacked for trying to make Swahili the national language and was instead urged to make German the national language, Die Post 23 Aug. I9I3.

25 Dar es Salaam report cited in G. Hornsby, 'German Educational Achievement in East Africa', in Tanganyika Notes and Records (62) I964, p. 86.

26 German customs inspector to Government, 22 April I906 TNA G I/29/II. Translation mine.

27 Ibid. I3 May I906, TNA G I/29/II. In Kenya, the Fire Insurance Company requested that the Government require that accounting and books be kept in English or Swahili [and not Arabic or Gujarati] in order to be able to check the claims. Kenyan National Archives [hereafter, KNA], AG 30/53, pp. 3-6.

28 The Indian Association to Chief Secretary in Dar es Salaam, 5 April I933, TNA II. 660 p. 244.

29 Amendment to trading licenses I923 TNA 7092/I.

30 TNA G3-52. In the Zanzibar archives, we came across examples of books which were kept in Gujarati and English. Zanzibar Archives HC 2/49, trustee report I9O2.

3I The German Records section of the TNA contains several German as well as English translations of wills. See G3 35, where we find the names of Karim Ladha, Remtulla Meralji and Dayal Trikamdas; the most famous person had his own entry under G3 38. This was Sewji Hadji, who left a huge portion of his possessions to the Germans in order to build a hospital and a home for lepers.

32 R. Smith, Director of Education in Dar es Salaam, 24 March 1925, TNA, AB 1032, p. I4.

33 The Indian Educational Society to the Chief Secretary in Dar es Salaam I2 March I925, TNA AB I032, 9.

34 Educational Office, Dar es Salaam, various correspondence I925-1930, TNA AB I032.

35 Educational Office, ibid.

36 It is interesting to note that, in Mauritius, Hindi was promoted. This is despite the fact that the majority of Indians in Mauritius spoke Bojupari and not Hindi.

37 See the Annual Reports of the Educational Department, 'Indian Section', I933-I959.

38 Cameron to Amery, confidential letter, I5 October 1925, TNA AB I032, p. 54.

39 In some regions, Gujarati was the vernacular language until the fifth or sixth standards. The German colonial history was too short (until I9I9) and too scattered for the Germans to develop a common overall colonial education strategy. See, for the formal position on English as the medium of education, Annual Report of the Education Department I930, TNA II7I8.

40 KNA DC KT 2/6/I, p. 78. Underlined in original.

4I KNA, DC KT, 2/6/I/, p. I30. This may also refer to the notion of purity, the burden of which was laid on Indian (Hindu) women. See FN I2.

42 Report on the Non-Native Census I93I, pp. 50-5I. 
43 Report of the Special Committee on Indian Education, I95I, Dar es Salaam; Report of the Committee on the Integration of Education, I959, Dar es Salaam.

44 Several authors reveal that, in Britain, Gujaratis from East Africa (who arrived in the I960s and early I970s) were more educated than those who had migrated directly from Gujarat. This may be attributed to their class background and their access to better education. See T. Van der Avoird, Determining Language Vitality: The Language use of Hindu communities in the Netherlands and the United Kingdom, Tilburg 200I, p39.

45 A.Y. Lodhi, Oriental Influences in Swahili: A Study in Language and Cultural Contacts, Göteborg 2000, mentions Kassam's (I97I) unique survey of language among the Asians of Dar es Salaam in I970 which showed that the languages used at home included: Cutchi 52 percent, Gujarati I4.5 percent, Swahili 7.3 percent, and English 26 percent. Note that Cutchi was much more popular than Gujarati. However, Cutchi is solely a spoken language. Moreover, those who speak Cutchi are also able to speak Gujarati, which is - in general - considered to be a more 'sophisticated' language. Thirteen per cent of the Asians claimed that they spoke Swahili at home. Nevertheless, it is not clear which communities were meant here. Most likely they were Ithnaserius and Bohras (Muslim communities). Another small survey in Uganda in I954 showed that 92 per cent of the traders who had applied for a trader's license spoke Gujerati or Cutchi as their first language. H.S. Morris, The Indians in Uganda, London I968, p. I9.

46 The mother is generally seen as the gatekeeper of the community language at home. The inter-generational language shift in favour of the dominant language is also described in Van der Avoird, Determining Language Vitality, pp. 229-23I.

47 See, G. Oonk, 'After shaking his hand start counting your fingers', Itinerario XXVIII (3) $2004,70-88$.

48 Similarly, third-generation Hindus in the Netherlands like and watch Hindi movies, but have established a preference for the Dutch language. Avoird, Determining language, p. 162.

49 Personal e-mail correspondence October 2002.

50 The leaders of the Ithnaseri community have dealt with this since the I96os. They tried to introduce a religious instruction book in Gujarati with Roman script: Elements of Islamic Studies. In I988, they agreed to use an English religious instruction book. Because of the steady migration of Ithnasheries to the West they feel that there has been an uncontrolled Anglicisation of the community, in a environment where there is strong anti-Muslim sentiment. In Dar es Salaam, some of the community members emphasised that in losing the language, Ithnasheries would lose their umbilical cord with their roots. See also: R. Nagar, Making and Breaking Boundaries: Identity Politics Among South Asians in Post-Colonial Dar es Salaam, unpublished Ph.D. Dissertation, University of Minnesota, I995, pp. 280-285.

5I G. Oonk, 'The Changing Culture of the Hindu Lohana community in East Africa,' Contemporary South Asia I3 (I) 2004, 7-23.

52 G. Oonk, 'After Shaking his Hand Start Counting Your Fingers.' Trust and Images in Indian Business Networks, East Africa I900-2000, Itinerario XXVIII (3) 2004, 70 88. 



\title{
4 Contextualising Diasporic Identity
}

\author{
Implications of Time and Space on Telugu Immigrants
}

\author{
Chandrashekhar Bhat and T.L.S.Bhaskar
}

\section{Introduction}

Any diasporic community is uniquely situated owing to its multi-polarity, defined by the continuity/discontinuity of the cultural baggage from the place of origin, the dynamics of the host society and the influence of the motherland or ancestral land. This uniqueness is carried further by temporal and spatial dimensions besides the location of the emigrants in the society of their origin. Some sections of a society are more prone to emigration than others and the causes and consequence of such emigration have their implication for the diaspora formed. For instance, the Indian diaspora is not a homogeneous entity without diversity, though there is an overriding common identity as 'Indians' despite the 'differences' on account of regions from which they have migrated, when they migrated, where they have migrated to, including the socio-cultural and demographic environment in the receiving society. More often than not, these differences become significant at some stage or the other in the process of settlement and identity formation. A close look at the formation of Indian diasporas, since the mass emigration of indentured labour during the early nineteenth century to the emigration of highly skilled software engineers during the last decade of the twentieth century reveals that there is greater fractured Indian diasporic identity (Verma, and Sheshan: 2003) than has been thus far imagined.

Indian society is distinctively known for its diversity and the Indian immigrants worldwide are no exception to such practices of differentiation on the basis of religion, region, language, and caste. Such differentiation is of course less pronounced in the case of fourth- or fifth-generation descendants of Indian indentured labour employed in European sugar cane plantations of the Caribbean, Africa, South Pacific and Southeast Asia. Long ship journeys that the indenture labour had 
to undertake to arrive in plantation colonies gave rise to bonds of brotherhood, commonly called 'jahaji bhai'. Despite the continuities in religious and regional identities, they exhibit a certain homogeneity that is conspicuously absent from among the later emigrants especially after India's Independence.

\section{Towards a Concept of an Old and New Diaspora}

Indian diaspora today comprises broadly of four streams following the diverse situations under which they emigrated. The first stream includes third- to fifth-generation descendants of the early emigrants during the mid-nineteenth century, to the British and European colonies in Africa, Southeast Asia, Fiji, and the Caribbean as plantation labour and railway workers under the indenture system. As Clarke et al. (I990) points out, under this system some I.5 million persons migrated to the above destinations. Robin Cohen (I997) has classified them as 'labour diaspora'. Many of them lost contact with their 'motherland' including their mother tongue. They may be called 'old diaspora' for lack of a better term.

In the course of their long journeys by ship to distant destinations, the unknown co-passengers became 'jahaji bhai' (literally meaning 'ship brother', an assumed brotherly affinity due to travelling together) and this bond continued thereafter among their descendants till this very day. The Indian diaspora communities that were established during the colonial era were isolated from one another and the plantation owners under the new system of slavery called the 'indentured labour' (Tinker I973) totally denied the indentured labourers employed by them any access even to their own kith and kin employed by other planters, let alone any access to the then existing means of transportation and communication to engage with the motherland. A significant outcome of the 'ship brotherhood' was reflected in the gradual erosion of caste boundaries, almost forging towards a two-fold division of the Hindu community into Pundits (Brahmin priests, strictly following the tradition of vegetarianism and teetotalism) and the rest, including the Chamars (the untouchable castes) during life in the plantation barracks. However, the caste distinctions gradually reappeared in the course of their settlement in rural Trinidad, which, according to Vertovec (I992), are quite pervasive.

The second stream consists of professionally trained and skilled emigrants to the developed countries of the West since the mid-twentieth century till this day. They continue to maintain their religious and caste practices through the vibrant interaction with places of their origin. Since they have been away from India for some five decades now and 
as the process of immigration continues, they are referred here as 'new diaspora'.

Any analysis of Indian diaspora cannot ignore the distinction between the old and the new Indian diaspora. Not only do they vary in the contexts of their emigration and destinations but also in terms of their socio-economic background and the degree of interaction with the motherland. They have undergone migration experiences so varied that their cultural practices in the host environment reflected greater differences than similarities, representing almost two very distinct 'diaspora communities' bearing the common noun Indian. These differences are strikingly apparent between the descendants of the indentured and the new Indian immigrants, when they meet in a place like New York or London. With a view to bringing such a distinction between these two streams of Indian immigrants to the fore, the concept of old and new Indian diaspora has been employed in the diasporic discourse (Bhat 1998, 2003; Jain 2004). While the new diaspora has retained a close relationship with family, locality, caste, region, and religion in India, the majority of the old diaspora has lost contact with the motherland, including the familiarity with the mother tongue.

The consequences of the two streams of emigrations described above are strikingly diverse, not merely due to the distinct temporal contexts in which they have occurred but also the attributes of the population that emigrated and their destinations. While it is poverty and despair that compelled emigration under conditions of indenture to work in British and other European colonies, the emigration of predominantly urban middle class, English-educated professionals and highly skilled personnel to the industrially developed countries of the West has been occurring to avail the emerging employment opportunities following World War II. The social position of the two streams of emigrants from India too has been widely varied; the indenture labour largely came from deprived sections among the lower castes whereas the professionally trained and skilled emigrants belonged not only to the upper classes but also to the upper castes.

The post-colonial emigrants not only enjoyed the advantage of being professionally trained, middle class, Anglophone Indians, but also earned adequate income that could facilitate visits and frequent communication with the place of their origin. The recent advancement in technologies of travel, transport, communication, information, and the Internet has contributed immensely to the growth of transnational networks and virtual communities. A few hours of air travel, compared to the month-long ship journeys of the colonial era, has facilitated the new emigrants to maintain close ties with their places of origin. There is a revival of the 'local' at the global context, with the shrinking of space and time. 
The migrant labour force, semi-skilled and unskilled, which emigrated to the countries of West Asia and the Gulf following the oil boom during the nineteen sixties and seventies form the third stream. Many of them left their families behind in India and remitted savings towards family maintenance and investments. They form the majority of the Non-Resident Indians (NRIs) or the expatriate Indians and most of them hail from the states of Kerala and Andhra Pradesh in particular. They are denied any citizenship rights in the countries where they work and, therefore, cannot permanently be deterritorialised from the motherland. They cannot be called a diaspora since they are denied membership in the host society. At best they are a 'transitory' diaspora.

The migration of software engineers and information technicians over the past two decades may be considered as the fourth wave, the 'IT wave' as it is popularly called, and has its own distinctive features. Most of the emigrants are young graduates from leading institutes of engineering and technology, whose expertise is in great demand in the US, Europe, and other developed countries. Though they are drawn from all over the country, Andhra Pradesh and Tamil Nadu have a major share in the export of computer professionals. Unlike the earlier waves of emigration, the software professionals often move to multiple destinations, operating across several nation-states in a transnational space.

Despite certain similarities, each stream of emigrants varies from the other in so far as the socio-economic and educational background from which they emigrated from India and also their location in the host societies.

\section{Telugu Diaspora: A Brief History}

Telugu is a South Indian language spoken by approximately 60 million people residing predominantly in the present state of Andhra Pradesh and the neighbouring states of Tamil Nadu and Karnataka. Following the linguistic reorganisation of Indian states in 1956, Andhra Pradesh has not only emerged as the largest state in South India but Telugu has also become the second large language next to only Hindi. A considerable number of Telugu-speaking people in particular emigrated from the east coast of Southern India during the colonial period (I83os to I920s) to destinations such as Fiji, Malaysia, Mauritius, Singapore, and South Africa. After India's independence, a significant number of urban middle-class Telugus, professionally trained and skilled, emigrated to developed countries such as Australia, Canada, Germany, New Zealand, the UK and the US. 
Today, Telugus form the largest South Indian community to have emigrated to different parts of the world, if the decedents of the nineteenth- and early twentieth-century immigrants and the post-Independence emigrants, including the software professionals to the Americas and Europe are taken together.

The emigration of Telugus from different parts of South India has occurred in basically three phases:

- the colonial emigration as indenture and kangani labour to the British and French colonies during the nineteenth and early part of twentieth century,

- the emigration of professionals such as doctors, engineers, scientists, and students to the developed countries such as US, UK, Canada, Australia and New Zealand, and more recently,

- the software professionals to Europe and especially the US and Canada.

There are several push and pull factors that were responsible for the emigration of Telugus during the colonial period. Firstly, the Zamindari system introduced by the British rule worsened the plight of the poor peasants because of high taxes; secondly, frequent famines and the lack of any irrigation facilities caused untold misery among the peasants (Rao I983). Furthermore, natural calamities like famines and floods, shrinking of the cottage and handicraft industries owing to the introduction of European factory products, and the lack of employment opportunities were instrumental in pushing many Telugus to emigrate. There were also opportunities for employment in plantation labour in the British and French colonies that pulled many Telugus to immigrate to countries such as Fiji, Malaya, Burma, Natal (South Africa) and Mauritius in order to escape starvation and death.

Presently, Telugus are found on almost every continent. They form a considerable segment of the population of some of countries such as Fiji, Mauritius, Myanmar, South Africa, Europe, US and United Arab Emirates. They have also immigrated to Canada, New Zealand, Australia and Singapore, but their presence in these countries is almost negligible.

\section{Old Telugu Diaspora}

Telugus form the third largest regional and linguistic diaspora to emigrate from India as indentured or kangani labour during the colonial era, next only to the Bhojpuri and Tamil diasporas. They were recruited mostly to replace the emancipated African slaves in the sugarcane plantations of Mauritius, Fiji and South Africa, and the rubber plantations in Malaysia. Though they were also taken to Burma in large numbers, there is little data available on the Telugu presence today owing to 
their forced assimilation into Burmese society (Phyu 200I). The earliest Telugu emigration may be traced to their journey via the ship the Ganges to Mauritius in I836. The next important emigration destination was Natal in South Africa in I860. The first Telugus arrived on the vessel Elbe in Fiji's Nakulau Depot in I903 along with other South Indians as indentured labourers (Bal Govinda I981: ı84). The Telugu immigrants in Fiji had striven to preserve their language and culture. Language is one of the distinctive features that separated Telugus from Tamils and other Indian communities. However, Telugus were so closely associated with the Tamils during the course of their settlement in Fiji, South Africa, and Malaysia that they followed the fairs and festivals of the numerically predominant Tamils, retaining their identities through Telugu names and festivals. The birth of the Andhra Sangha$\mathrm{mu}$ in Fiji in I94I provided much needed forum for articulating the problems faced by Telugu labourers on the island besides the promotion of Telugu language and culture.

Telugu emigration to Natal, South Africa happened from I86o until I9II as part of the indenture system of the Madras Presidency. The indentured labourers worked on the sugar and tea plantations, collieries, railways, wattle plantations, etc. Apart from a few Naidoos and Reddies (the agricultural castes), the Telugu immigrants in South Africa included farm labourers from the lower castes, including the untouchables. There were also some free passage migrants such as clerical staff, teachers, komatis (Traders), kamsala (Blacksmiths) and kumara (Potters), many of whom lost their identities in course of their settlement.

Until the formation of the Andhra Maha Sabha of South Africa (AMSSA) in I93I, there was little attempt made to unify Telugus on a sub-ethnic or linguistic basis. Currently, the Sabha has more than 30 branches, and promotes the teaching of Telugu at school and undergraduate levels. For instance, the University of Durban, Westville offers courses in the Telugu language and teaching.

Telugus formed part of the kangani labour ${ }^{\mathrm{I}}$ that migrated along with Tamilians and Malayalees to the Malay Peninsula. The main centre for their recruitment during those days were located at Vizagapatnam and Nagapatnam. The contract in the kangani form of labour recruitment was for three years, compared to five years in the indentured system. Most of the labourers worked on rubber plantations, oil palm cultivation and in the coconut fields. There were also a few Telugus who worked on road construction, drainage, sanitation, the electricity board and the railways. Most of the Telugus who migrated to Malaysia as kangani labour during the colonial period were from the coastal regions of Srikakulam, Vizianagaram and Visakhapatnam and a few others from East Godavari and Chittor regions. Most of the kangani emigrants 
came from castes such as Gavara, Kapu (sometimes called as Telaga) and Velama (the richer section among them are called Velama dora). The rest were from chakali (washer man), mangali (barber) and other functionary castes.

Telugus in Malaysia were a less visible group until the early I900s due to the substantial presence and predominance of the Tamil population. The planters had paid almost no attention to the Telugus as a distinct group among the Indian coolies. But the birth of the Malaysia Andhra Sanghamu in I955 provided the Telugus a forum for redressing the problems faced by Telugus in Malaysia other than the fostering of their culture. Apart from organising cultural activities, the association has persuaded its members to learn and speak Telugu at home and community gatherings.

\section{New Telugu Diaspora}

Immigration of Telugus to various destinations in developed countries, following India's independence constitutes the new Telugu diaspora. Unlike the colonial migration, the bulk of them are professionally trained, English educated, urban middle classes from upper castes. Some of the immigrants initially arrived in their host countries for the purpose of higher education and then continued to stay on securing employment while the others immigrated to the host countries directly to join the expanding job market in manufacturing and service sectors.

The stream of new Telugu diaspora comprised of educated youth from the important cities of Andhra Pradesh, such as Hyderabad, Vijayawada and Visakapattanam, besides a few from the well to do farming families of West and East Godavari region. Countries like the US, United Kingdom, Canada, Australia and New Zealand have significant presence of this new Telugu diaspora.

The most recent trend since the I990s is the wave of emigration of software professionals, especially to the US, following the demand for professionally skilled personnel in the high growth area of computer and information technology industry. It will not be an exaggeration to mention here that every young Telugu pursuing undergraduate education, especially in engineering and other technical fields, dreams of destination US for higher studies or employment.

\section{Telugu Diaspora in Mauritius and United States}

For a detailed analysis of the Old and New Telugu Diasporas, Telugus in two locations are selected with the view to illustrate the similarities and differences following the diverse migration experiences. Telugus in Mauritius are the earliest to immigrate in large numbers during the co- 
lonial period and had remained with least interaction with the motherland for more than a century and a half. They form a significant section of old Telugu diaspora. Though they have lost touch with their mother tongue, they have carefully preserved the Telugu culture and identity. Compared to the Telugus in Mauritius, Telugus in the US represent a large cluster of the new Telugu diaspora, a vibrant community pursuing very close interaction with their kith and kin in Andhra Pradesh.

\section{Telugu Diaspora in Mauritius}

Telugus migrated to Mauritius as part of indentured labour during the nineteenth century. It is believed that the first batch of Telugus who arrived in Mauritius was from the Coringa (Koringa) on board ship Ganges in the year 1836 from areas surrounding Vizianagaram. During the period I837-I880s nearly 20,000 Telugus have migrated to Mauritius as indentured labour (coolie) to work on the sugar plantations. Most of them hailed from the areas of Ganjam, Vizag, and Rajamundry.

From the data available through various records, most of the Telugus in Mauritius were originally from the places like Bimli or Bimlipatam (Bheemunipatnam), Vizagapatam (Visakhapatnam), Thoonee (Tuni), Uncole (Ongole), Oopada (Uppada), Alleepuram (Alleepuram), Nabobpettah (Nawabpeta), Ganzam (Ganjam), Vizianagaram (Vizianagaram), Alamunda (Alamanda), Cocanada (Kakinada), Berhampur, Chicacole (Srikakulam), Rajahmundry, Guntur, Masulipatnam, Nellore, Cuddapah, Anantapur, Chittor and Hyderabad (the current names are given in brackets).

Presently Telugu population in Mauritius is claimed to be more than 60,000 (discussion with Sanjeeva Appadoo, Telugu teacher from Mahatma Gandhi Institute, Mauritius) and have become a visible part of Mauritian society. According to the Mauritius Census Publication of I990, there were $2 \mathrm{I}, 027(2.05 \%$ of the Mauritius total population of I,O22,456). They have a considerable population in Quatre Bornes, St. Pierre, Riviere Du Rempart, Chemin Grenier, Flacq, Mahebourg, Casis (Port Louis), L'Escaillier, Goodlands, and Tayak.

According to the early Mauritian census records, maintained by the Colonial Offices in India and Mauritius, Telugus formed a part the two broader categories of Indian immigrants, namely Indo-Mauritians and Other Indians. The category of 'Indo-Mauritians' referred to the persons of Indian origin born in Mauritius, belonging to the second or later generation of Indian immigrants while the category of 'other Indians' referred to the first generation Indian immigrants 'born outside Mauritius'. It was only in the I96I census (published in I962), that the Indo- 
Mauritian category was further classified into Hindoos, Tamils, Telugus and Marathis on the basis of their sub-ethnic identities with the view to ascertain the magnitude of culturally exclusive groups among the Indians in Mauritius. By I96os, Mauritius had already emerged as multilingual and multicultural society, with a demand for state support from diverse ethnic groups to promote their ancestral languages and cultures. Thus, the Telugus were enumerated separately, for the first time, as a distinct group, on the basis of linguistic, cultural and religious criteria.

The census data on Telugus and their religious affiliation during the past five decades, from I962 to 200I, reveals some of the changes that they have undergone over the years. From the statistical data it may be observed that Mauritian Hindu society experienced a religious sectarian shift when the followers of Arya Samaj gradually chose Sanatana Dharma (Bhaskar 2003: 9I). During this process the Telugus as well as the other regional groups formed on the basis of their ancestral languages, such as Hindoos (the descendants of Bihari and other North Indian people speaking Hindi), Tamils (the descendants of Tamil speaking people from South India) and Marathis (the descendants of Marathi speaking people from Bombay Presidency), employed 'ancestral language' as the basis for cultural and religious differentiation. For instance, today Mauritius has Telugu temples, Tamil Temples and Hindoo Temples to promote respectively Telugu religion and festivals, Tamil religion and festivals, and Hindoo religion and festivals. The descendants of Indian Muslim immigrants in Mauritius consider Urdu as their 'ancestral language' as well as 'current language', though their ancestors spoke Hindi, Tamil, Telugu, Marathi or Gujarathi.

\section{Telugu Identity}

As mentioned earlier, Indian diaspora in Mauritius comprises of the descendants early immigrants from at least five linguistic regions, if not more, and continue to nurture their distinct identities and regional cultures over the years. In some respects, they resemble Indian castes, especially in terms of endogamy and exclusive ritual practises, although free from commensal restrictions and a ritual hierarchy based on 'pure' and 'impure'. These identities have economic and political implications in the representative democracy of Mauritius, which promotes multi-culturalism as a state policy. 'Language and religion are the most tangible markers of cultural identity' in Mauritius today according to Hookoomsing (2003a:I69) and 'Linguistic Groups' based on the ancestral language of their forefathers have assumed great significance in political and cultural identity. The Mauritian Government considers all ancestral languages as national heritage and bestows equal rights to all these languages. 
The Telugu people are proud of their cultural heritage and consider the Telugu language, temples, and festivals as significant constituents of Mauritian Telugu identity. The cultural practices, traditions, festivals, and language of the Mauritian Telugus have their roots in the traditional customs and folk culture of the rural Andhra region.

\section{Telugu Language}

Mauritian Telugus consider Telugu as their ancestral language and hence worthy of veneration. They speak French Creole at home and use it as a common medium of communication with the members of their own Telugu community as well as others they encounter in their daily lives.

While Telugus share many aspects of culture and tradition with the followers of Sanatana Dharma (Vedic Hindu Dharma), Telugu language is considered as the distinctive feature that makes the Telugu community unique from other people of Indian origin in Mauritius. Telugus in Mauritius believe that their ancestors spoke Telugu and observed Telugu culture, which differentiated them from the rest of the Indian communities in Mauritius. There have been concerted efforts by various Telugu organisations, both cultural and religious, to promote their language as it forms one of the significant indices of Telugu identity on the island. Ancestral language, culture and religion reinforce each other in Mauritius society to provide distinct identities to 'linguistic groups' that play a significant role in socio-economic and political contexts. Resources for articulating these identities are generated by respective groups, that supplement the state support these groups receive for promoting their linguistic cultural heritage.

From the very beginning, Telugus have tried to promote and protect their mother tongue. For instance, during the initial days of their settlement in Mauritius, Telugus taught their children through writing on palm leaves or beach sand, apart from the oral teaching through folk songs, bhajana (devotional songs) and theatre performances (naata$\mathrm{kam}$ ). It is believed that the labourers gathered in the evening and sang songs in praise of the God, like Ramadasu keertana and Nrusimha sata$\mathrm{kam}$, overcoming the strain of the day's hard work on the plantation. It was a particular drama called Ramaleelalu in the areas of the Vale and Mapou that inspired plantation labour to take pride in the Telugu language and culture.

Telugus have always worked on the plantations along side Tamils and Hindi-speaking labourers. Apart from the influence of these languages, French was decreed the lingua franca for all Mauritians. Telugus as well the others gradually gave up speaking their mother tongues in favour of French and Creole. 
In the I880s, the institution of baithkas began to strengthen the Hin$\mathrm{du}$ religion in opposition to the dominance of Christianity. Indians began to gather and participate singing bhajans, folksongs, prayers, etc., displaying unity in times of adversity. During that time, Bhojpuri was the lingua franca for Indians. But in later years, Telugus and Tamils felt the need to have their own festivals such as the Ammoru Panduga, and Cavadi. The arrival of the Arya Samaj on the island created a split in the Hindu community dividing them into Sanatanists and the Arya Samajists. According to Rao (1983: 36), 'this had shaken the faith of many Hindus for whom idol worship was the greatest symbol of their religious identity and further Arya Samaj introduced Hindi (khari boli) as the language of discourse'. This estranged the Telugu people from Baithkas, giving rise to the formation of Mauritius Andhra Maha Sabha (MAMS) in I946 with following objectives: a) to strengthen the Telugu solidarity and distinct identity; b) to popularise Telugu teaching; c) to organise Telugu festivals; and d) to construct temples for Telugu gods like Narasimha, Anjanai Swami (Hanuman), etc. MAMS made all-out efforts to promote the Telugu language by building Telugu vernacular schools, training teachers, etc. ${ }^{2}$ Two prominent persons who strove to promote the use of Telugu language on the island were Pandit Ramamurthi and Pandit Gunnayya Ottoo.

The teaching of oriental languages was officially recognised as early as I925 and the then Mauritian Government gave due importance to the teaching of these languages at the school level (Murugaiyan 2003: I9I). The teaching of Telugu has seen many changes over the years since independence because both governmental agencies and non-government organisations were actively involved in the promotion of the Telugu language. Use of Telugu in the public sphere is almost nonexistent except for a few people who speak the language on special occasions like during festivals, in temples, during programmes, etc. In general, it is spoken with some difficulty. The teaching of Telugu was formally initiated in the schools on I August 1958. Later on, the existing Hindi syllabus was translated into Telugu (written in English/French script).

Almost all branches of the MAMS now runs evening schools to teach Telugu with active co-operation from the Telugu Teachers' Association (TTA). The teaching ends with MAMS conducting Annual Telugu Language Examinations (ATLE) for standard I to V. Students learn Telugu at three different levels - primary, secondary and tertiary. MAMS also conducts exams for students at the first two levels. Apart from MAMS, the Telugu Cultural Centre Trust has recently started promoting the language on the island.

Efforts are also being made by other organisations such as Telugu temples, Mauritian Broadcasting Corporation (MBC), Mauritian Col- 
lege of Air (MCA), Ministry of Education and Scientific Research (MESR) and the Drama Section of the Ministry of Arts and Culture (MAC) to promote the Telugu language. The above-mentioned institutions and departments have been effective in encouraging children and adults to learn and speak Telugu.

\section{Telugu Temples}

Telugu temples play a very significant role in the promotion of Telugu identity. All Telugu temples in Mauritius have regular Friday Telugu bhajan. Photocopies of the songs (written in Roman script) are distributed to the devotees to facilitate singing. The Pravachanam (in Telugu language) follows the Bhajan by the local Aacharya (purohit). A local bilingual expert subsequently translates the contents into Creole for easy comprehension of the devotees. They are mostly attended by elderly men and women, children, and a few women from the neighbourhood. On some of the festival days or special occasions, like somebody's birthday or wedding anniversary, the entire Telugu community will assemble at the temples for the celebration and a festive meal.

According to Appadoo (I990), there are some 80 Telugu temples on the island, and most of them are located in villages. These temples are often registered with the Mauritius Andhra Maha Sabha (MAMS) which is also involved in the construction of temples, mostly the Vishnu Mandirams, Venkateshwara temples, Ram mandirams and a few Krishna mandirams. The two earliest temples that deserve mention are the Simhadri Appanah Mandiram in Beau Vallon in the south and the Vishnu Mandiram in St. Pierre. A large portion of Telugus are devotees of Puttaparthi Sri Satya Sai Baba in Andhra Pradesh and Ganapathi Sachidananda Swamy (a Telugu ascetic) in Mysore.

It is interesting to note that many Mauritian Telugus still opt for a local acharya for family related puja or occasion (pujas occur at home, at birth- and death-related rites, etc). They think the local acharya can communicate better in Creole, which allows them to better understand the essence of the puja. The acharya from India sometimes learns Creole and communicates in broken Creole with the devotees. Weekly visits to the temple is compulsory to emphasise the fact that they are a close-knit community and consider the temple as a platform for the promotion of culture and solidarity.

\section{Telugu Festivals}

Celebration of festivals formed a part of the cultural life of the Mauritian Telugus. They celebrate festivals like Simhadri Appanna Puja, Rama Bhajanamu, Ammoru Panduga, Sankranti, Deepawali, Ugadi, Sri Narasimha Jayanti (Kollala Pandaga), Govinda Puja (Sri Venkateshwara Puja vratam), and Andhra Avatarana Dinotsavam (Andhra Forma- 
tion Day). According to Appadoo (I994: 252), the Telugus being mainly vaishnavities perform Rama bhajanamu and Simhadri Appanna pooja. Although there is a mixture of local customs, the original Telugu culture are preserved and passed on with care. One can observe the distinct Telugu culture in celebration festivals such as Ugadi ${ }^{3}$ and Rama bhajanamu.

The wedding ceremony is a very special event and weddings are generally arranged during the weekends, especially on Sundays, to allow friends and relatives to attend the celebration. Weddings are usually celebrated for four days beginning with pasupu and ending with enaalu. The pasupu is celebrated on Friday and the actual marriage which lasts for an hour or little more, takes place on Sunday. But, with the passage of time, people became too busy with their professions, as a result, there have been changes in terms of celebrating the wedding.

\section{Telugu Broadcasting}

Though very few Mauritian Telugus understand Telugu, recently acquired, they have institutionalised the broadcasting of Telugu programs for an hour every evening. The older generation of Telugus consider it an important event of the day, which allows them to take the images of the motherland into their drawing rooms. They also have a weekly telecast of Telugu films and other events of interest to the Telugus.

\section{Markers of Mauritian Telugu Identity}

What makes the Mauritian Telugus so distinctive from other overseas Telugu communities is their consistent commitment towards protecting Telugu culture over the generations, despite their integration into the westernised Mauritian society with Creole as the lingua franca. Two centuries, beginning with the suppressive regime of indenture and kangani employment in isolated barracks, away from their ancestral land and culture have not alienated them from their attachment and devotion towards their Telugu origins and they have religiously guarded their Telugu identity to this day. Needless to emphasise that Mauritian Telugus feel privileged to observe the Telugu traditions, festivals and fairs with utmost dedication. They take pride in maintaining the Telugu culture over the generations, despite the significant loss of 'Telugu language', arranged marriages (cross-cousin or uncle-niece), and joint families that continue to be 'essentials' of Telugu identity in Andhra Pradesh.

It is worthy to note that the Telugus, despite being demographically lesser in number compared to both the dominant Bhojpuri Hindispeaking community and the Tamils, who have enjoyed special favoured treatment from the French owing to their colonial past, have continued to passionately preserve their distinctive identity. The Tamils, 
for instance, celebrate Tamil New Year Pongal, Bharadhiyar Centenary and several other festivals unique to Tamil culture and 'Tamil religion' to preserve and promote Tamil identity (Murugaayan 2003: 197). The common experiences of migration, during the ship's journey, life in plantation barracks and coercion by the colonial rulers led to homogenisation, to a certain degree, in the Indian diaspora in the Caribbean, Fiji and the French territories. But the Indo-Mauritians have maintained their linguistic and regional boundaries, if not the languages, owing to their substantial presence to retain such diversity.

\section{Telugu Diaspora in the United States}

The emergence of a Telugu diaspora in the US is a post-independence phenomenon. Many Telugus have migrated to the US initially as postdoctoral fellows and scientists utilising various scholarships. In more recent years, they migrated as professionals - such as engineers, doctors, and software engineers.

Apart from changes in the educational system, the post-I960 period witnessed advancements in science, technological applications, communication and print media, which facilitated the educational system in terms of providing the infrastructure. The secondary and higher education systems were made available in all major towns and cities of Andhra Pradesh. Many of these educational institutions began to introduce courses that offered better employment opportunities. On the other hand, the parents and students began to take note of professions that were in great demand such as engineering and medicine. The parents are increasingly prepared, even at prohibitive costs to send their children to professional colleges and get them trained. Therefore, many students opted to pursue these courses of study. The liberalisation of the Indian economy after I990 further provided impetus by opening up of overseas opportunities. During this period it was observed that, many Telugus utilised the available opportunities in the west, and migrated as students, scientists, engineers, doctors and software professionals and made the US their homeland.

The present day Telugu population in the US can be categorised as follows:

- People who have entered the US as professionals;

- Students who are pursuing higher education, and;

- Families of the immigrant professionals.

Apart from merely keeping in touch with families, the Telugu immigrants in US have always maintained consistent cultural and economic links to their land of origin. Most of the early immigrants were depen- 
dent upon telephones and land mail, while present-day immigrants are able to communicate via communication technologies such as Internet, e-mail, messengers and Webcams.

\section{Telugu Identity in the United States}

For any Indian or person of South Asian origin, cultural identity forms the core of socio-economic, political and religious life whether they are located in India or in the diaspora elsewhere. Articulation of cultural identity is essentially political in nature and varies with context, from religious or regional to linguistic or caste. Telugu identity in the US not only expresses the ideology of Telugu language but also of Telugu region (the state of Andhra Pradesh) and Telugu culture. When in Andhra Pradesh the Telugu identity is dormant, as it is commonly shared by all except the immigrants, such identity assumes significance in all other parts of India where Telugus form a minority. It is more so in the overseas context where Telugu identity offers comfort, security, support and, above all, the feeling of a home away from the homeland. Thus, the Telugu identity has political implications in their immigrant context in the US besides providing for the economic and cultural needs of the Telugu community. Resources are pooled by the Telugus themselves through membership, donations, and other forms fund rising to promote the interest of Telugus and towards maintaining Telugu culture and identity in the US.

The Telugu language is considered as the most significant marker of Telugu identity, along with its distinctive traditional practices and festivals. Many of the Telugus in the US believe that they are more Telugu culturally than those back home in Andhra Pradesh. They strive to pass on their language and culture to the successive generations in the US. Besides the language, its movies, literature, radio and its associations provide essential inputs helping to make Telugus feel at home in the US.

\section{Telugu Language}

Language is considered the most important carrier of culture and identity. In contrast to the situation in the old diaspora, there are no government or private schools in the US that teach Telugu language. Teaching the language in the diaspora is done by establishing Telugu schools. Many Telugu associations have started weekend schools for the second- and third-generation Telugus who were born in the US. The classes are usually conducted at an association building, a temple, or a school whose space is used for conducting weekend classes. Sometimes, summer schools are established to teach the language during holidays at the primary or secondary level. At the initiative of Professor Velcheru Narayana Rao, the University of Wisconsin at Madison has 
been offering a course on Telugu for nearly a decade. Of late, because of the efforts of Professor Rao, the Telugu Association of North America and the Detroit Telugu Association, the University of Michigan in Ann Arbor has also commenced teaching Telugu as part of its South Asian Studies programme.

Many families that have settled permanently in the US have sponsored parents to join them under the 'preference system' that fosters family reunions, because parents and grandparents play an important role in teaching language and tradition to children at home. In fact, some of Telugus have even sent their children to their parents in India, to train them in the Telugu language, culture, and classical dance and music performances. These visits not only familiarise the new generation with the knowledge of language and culture but also help motivate them to appreciate their Telugu heritage.

The second generation immigrants are currently in a dilemma as they are being pressured by their parents to learn Telugu, which in their view is not useful living in the US.

\section{Telugu Movies}

Telugu movies have thus far played an invaluable role in the Telugu diaspora in the early years of Telugu emigration to the US. The early immigrants in the I950s and the I960s had to strive hard to get the movies to the US. Those Telugus who were successful in obtaining them were approached by Telugus in other states in the US, to rent the movie, and then send it back. It is important to note that the Telugus in the US initially came together to see Telugu movies. As Telugus began to meet more regularly, the ideas of establishing Telugu associations took shape with a view to promoting Telugu culture and identity. Some Telugu movie producers have shown interest in making movies depicting the Telugu way of life in the US. For example, Padamati Sandhyaragam, America Abbayi, America Alludu, Paradesi, Atu America Itu India, and Doller Dreams deal with diasporic themes familiar to Telugus. Apart from showing the benefits of being in an advanced nation, these movies also raised certain issues that Telugus encounter in their daily lives, such as the initial culture shock, the adjustment to the American lifestyle and the Telugu relationship with white Americans.

Over the years, the marketing of Telugu movies in the US has increased by leaps and bounds. The emerging networks between local Telugu film producers and American film distributors have accelerated this process. Local film distributors in Andhra Pradesh often distribute the films with the help of American representatives. The business has encouraged the entry of non-resident Telugus into the Telugu movie industry via collaborations with local producers on a partnership basis or helping them establish their offices. One of the prominent characteris- 
tics in the process has been the establishment of many Telugu websites, which focus on the movie business. ${ }^{4}$ Telugu movies from the I960s and the I970s have always been a source of true Teluguness for people in the diaspora. These movies have not only emphasised and highlighted social issues of inter-caste and inter-religious marriages (i. e., Malleswari, Shankarabharanam and Missamma) but have also reflected Telugu pride (Alluri Sitarama Raju, who fought against British rulers). In general, these movies, which are often referred to as Pata Cinemalu, have become just as popular as more recent movies. Contemporary Telugu movies are very much in demand in the US and it is a very lucrative business in the diaspora to market the films of, for instance, megastar Chirangivi (Shankardada MBBS) and superstars like Nagarjuna (Annamauiah, Sri Ramadasu), Venkatesh (Sankranthi), Balakrishna (son of the renowned film star turned politician N.T. Rama Rao; Veerabhadrudu), Sridevi (Kshanam Kshanam) and Jayaprada (Siri Siri Muvva).

\section{Telugu Literature}

The First Telugu Literary Symposium of America (America Telugu Sahiti Sadassu) was organised on May 23-24, I998 in Atlanta, Georgia by the Vanguri Foundation of America, Inc. The Symposium was the first of its kind in North America. Panel discussions included subjects such as the literary aspects of Telugu, sweeya kavitha ganam, ${ }^{5}$ short stories, discussions on teaching Telugu in North America, presentations on computer technologies related to the development of Telugu language and communications. Subsequent Telugu Literary symposiums were held in Chicago and Detroit. They were funded by the Vanguri Foundation and the local Telugu literary bodies associated with the local Telugu associations organised the event (Detroit Literary Club of the Detroit Telugu Association).

Apart from the nation-wide Sadassu (membership) as described above, almost all Telugu associations in the US have their literary bodies encouraging the literary expressions from the diasporic Telugus. There are also independent organisations such as the Telugu Fine Arts Society in New York that have been actively promoting Telugu literary interests in US Literary magazines like Rachana (www.rachana.net), webzines like www.sahiti.org, www.eemata.org, www.eevaram.org and other popular literary sites like www.kaburlu.com, which have been publishing diasporic Telugu literature.

Silicon Andhra (www.siliconandhra.com) is an upcoming literary body, which is associated with many cultural and literary programmes that promote the Telugu Identity, culture, literature, and traditions. It conducts the annual Andhra Cultural Festival in California. 


\section{Telugu Radio}

The first Telugu radio broadcast in the US, Ganasudha, was established by the Telugu Association of North Texas (TANTEX) on 23 September I998. Ganasudha is the only Telugu Radio Programme that has been effectively broadcast by a group of volunteers led by the main hosts Ramam Devaraju and Padma Devaraju and others like Prasad Thotakura, Nageswara Rao Chintapanta, and Santha Puligandla. Sheer interest in the promotion of Tellugu language and culture and his obsession with film music, encouraged Ramam Devaraju to establish this weekly programme. It is broadcast from Dallas, Texas every Sunday from Io:०० a.m. to II:०० a.m. on Ir:50 AM. Its programmes include:

- Interviews with Telugu cinema actors and noted Telugu singers such as S.P. Balasubramanyam

- Five minutes of news in Telugu covering the events in Andhra Pradesh and India

- Telugu movie songs dominate the programme and a combination of old and new songs are broadcast. The songs are the best collection of Telugu songs imaginable

- Games, quizzes and contests such as the following:

- Anthyakshari: Live game played by listeners is presented the second Sunday of every month.

- Cheppukondi Chooddaam: Another live game involves playing a small musical bit by the host. Listeners must then identify the song and sing the song. Presented the fourth Sunday of every month.

- Quizzes and Contests: Every broadcast includes some contests where listeners have to identify the movie name, lyrics, writer, producer, etc. The winner receives a prize from a local sponsor.

- Special programs such as those that celebrate the festivals of Depaavali, Dasara, Sankranthi.

\section{Telugu Associations}

Telugu associations in the US basically originated as cultural organisations with a view to preserving and promoting their ethnic minority culture and passing it on to subsequent generations. There are certain aspects of culture, which conflict with the dominant host culture that cannot be easily inculcated among those born and brought up in the US. But the pursuit of cultural preservation continues with various kinds of activities organised by Telugu associations. Over the years, many Telugu associations have sprung up in response to increased numbers of Telugus residing in the US. The majority of these are the contemporary software migrants. The associations have also expanded their activities beyond socio-cultural programs to developing links with the homeland in terms of emerging political and economic networks. 
Telugu associations are all non-profit organisations that aim to bring the Telugu-speaking population a common platform. These cultural bodies are often associated with the following major activities:

- Bringing Telugus from the region ${ }^{6}$ or state together on a common platform

- Promoting the language (among the relevant generations) and preserving Telugu identity (which is expressed in various ways such as the celebrating of festivals in local Hindu temples, the organising of literary activities, etc.)

- Offering financial support to various individuals or associations involved in the promotion of Telugu identity (this is evident in how many Telugu associations have established their own foundations in this regard, such as the Telugu Association of North America (TANA) Foundation, and the American Telugu Association (ATA) Foundation

- Encouraging second-generations socio- cultural programmes

- Facilitating political and economic networks with the homeland. In some cases, the association can act as a mediator between the diaspora and the homeland.

The Telugu Association of Greater Chicago was established in I971, which led to the emergence of many other Telugu associations. By the mid-I980s, almost every state in the US had some Telugu associations at the regional and local levels. While some of them sought affiliation with TANA and ATA, others maintained their own identities and agendas. Literary Foundations like Vanguri Foundation, and Vishnubhotla Foundation are also involved in the promotion of literary interests. Meanwhile, each Telugu association also has its own literary wing, which encourages activities related to Telugu poetry, literature, story writing, etc. These literary bodies have organised many nation-wide Telugu literary symposiums with funding coming from said the aforementioned foundations.

There has been an obvious increase in the activities of Telugu associations, especially those pertaining to homeland, following the recent developments in transport and communication technologies. Telugus are able to keep in contact with people back home more rapidly than ever before via e-mail, the Internet, video, and Telugu TV channels.

Most of the Telugu associations in the US generate a sense of 'home away from home' and offer support, especially to newcomers, helping them cope with their alien environment. However, some of these associations have become platforms for Telugus segregation and division based on caste, region, or religion. For instance, the Telugu Association of North America (TANA) is dominated by members of the Kamma caste. To counter this trend, Reddy caste members found it necessary 
to found a separate association called the American Telugu Association (ATA) to protect and promote their sentiments and political affiliations with Andhra Pradesh. Although ATA is identified with the Reddy caste and TANA with the Kamma caste, both have often accommodated members from other castes and regions. Being the dominant castes, both castes play a significant role in the politics of Andhra Pradesh. This has also led to the establishment of extensive caste networks between the diaspora and their places of origin. These networks have a considerable impact on Andhra Pradesh politics through party funding and electioneering. Some of the 'green card' holders from the US have even succeeded in becoming members of Indian Parliament and the Andhra Pradesh Legislature by running for office in elections.

Maintenance of Telugu identity and participation in Telugu associations have provided the Telugus with opportunities to seek mutual support and advancement in practically every sphere of life including housing, education, employment, healthcare and the promotion of Telugu culture.

\section{Transnational Networks}

Transnational networks among the Telugus may be examined from the aspect of their involvement in socio-cultural, economic, and political spheres among Telugu community members dispersed in a number of countries. Of course, these networks depend on the community's density and distance, which are central to individual and group interactions. But the major stakes concerning the transnational networks or physical links between Telugus, involve economic, political, religion, as well as social and cultural factors.

\section{Socio-cultural Networks}

Advancements in transport and communication technologies and the process of globalisation have had a profound impact on the socio-cultural networks of Telugus in the contemporary world. In the past, kinship and community networks were maintained via remittances, letters, and occasional visits to the homeland whereas today, these networks have been further strengthened with the development of instant communication networks and faster transport. Today, it is not surprising to find in the US one member, if not more, of each family among the people of coastal districts of Andhra Pradesh, enhancing the intensity of networks among the Telugus in the US and Andhra Pradesh.

The basis for formation of any family is marriage, and in Andhra, the preference is given for marriages between cross-cousins, i.e., between ego and his mother's brother's daughter. Such a marriage be- 
tween cross-cousins is popularly known as 'Menarikamu'. Close kin networks reinforced by these kinds of marriages have also facilitated the chain-migration of relatives to foreign destinations. One of the major concerns of all parents in the diaspora is finding a suitable spouse from one's own caste if no suitable match is available among the preferred relatives. Today matrimonial advertisements on the Internet have made it easier to search for suitable brides or grooms on the basis of caste.

Culturally, Andhra Pradesh has a distinctive tradition, which is easily identifiable from other major Indian cultural strands. Some of the cultural symbols of Andhra Pradesh include the Kuchipudi dance, Pochampally handlooms, and Kalamkari paintings, all of which are still maintained by the Telugus. The Kuchipudi dance, known for its grace and charm, is performed at almost every gathering and festivity in the Telugu diaspora. Some of the important Kuchipudi dance dramas that are performed transnationally, including the Srinivasa Kalyanam, Rukmini Kalyanam, Sakuntalam Bhamakalpam, Hara Vilasam, and Ardhanareeswaram which were preserved by such renowned performers as Dr. Vempati Chinna Satyam, Sobha Natarajan, Shantala Shivalingappa, Lakshmi Narayana Shastri, and Chinta Krishna Murti among others. Similarly, the Perini Thandavam, is a male dance that is popular among the Telugu diaspora.

Festivals serves as another cultural basis for the transnational networks. The major Telugu festivals includes Ugadi (Telugu New Year's day), Makar Sankranti, Dasara, Diwali, Siva-Ratri, and Ganesh Chaturthi. These are celebrated not only in Andhra Pradesh but also among the Telugus in the diaspora. These festivals are celebrated in both individual homes and outside collectively, which helps bring all of the Telugus together. Visiting cultural guests like Sai Baba, Ganapati Sachidananda Swami, classical dancers and other performing artists, film stars, singers as well as the visiting elite from Andhra Pradesh offer yet another form of transnational cultural network among the Telugus.

\section{Economic Networks}

Although the initial links between Telugus and Telugu diasporas appear to be personal and family networks, there are certain economic implications as well. A considerable amount of expenditure is now spent on emigrant education and travel, which includes gifts and other favours. Eventually, these obligations lead to regular remittances to the parents or other relatives back home. As the migration flow increases, the financial networks between the homeland, diaspora community and host society also become more intense. These economic transactions are both personalised and institutionalised in, for example, ex- 
port-import businesses that deal in cultural products and consumer goods.

There are several two-way economic transactions articulated between the homeland and the diaspora. First, there are the 'non-entrepreneurial channels' of economic links, in the sense that, Telugus visit their places of origin with bags full of novelties and valuable items not readily available on the Indian market, that are offered as gifts to relatives and friends or sold for profit. This flow peaks during the festival and holiday seasons such as the Ugadi, Navaratri, Dasahra, Diwali and New Year's Day. Second, the 'entrepreneurial channel' links the homeland and the diaspora in a more formal manner. Several Telugus abroad send a significant portion of their savings back home in the form of remittances in order to invest in real estate, industrial establishments, small businesses, educational institutions, and/or to contribute to welfare organisations such as charities, old age homes, famine and flood victim relief, etc. Corporate hospitals such as the Apollo Hospitals, Medwin Hospitals, C.D.R. Hospitals and L.V. Prasad Eye Institute in Andhra Pradesh have contributed to the healthcare sector via the NRI Telugus.

\section{Religious Networks}

Andhra Pradesh is not only the home of several important religions but also the origin of several religious and sectarian movements. From Hinduism to Islam and from Buddhism, Jainism to the sectarian and cultic movements of more recent times such as Araya Samaj, Divya Jnana Samaj, Radha-Saomi Satsang, Meher Baba and Sai Baba, it reveals certain basic underlying facts regarding the faith and social structure which have persisted over time despite various ups and downs. These Telugu religious faiths and spiritual movements - which are observed both in Andhra Pradesh (motherland) and in the diaspora - indeed forms the basis for strengthening the links between the Telugu diaspora and the motherland, on the one hand, while constituting an important Telugu identity marker in the diaspora, on the other.

One of several important channels that articulate these Telugu religious links entails pilgrimages to the birthplaces of spiritual teachers or gurus (i.e., Puttaparthi, the birthplace of Sri Sathya Sai Baba) and important cultic temples (Shri Venkateswara Temple in Tirupati, the wealthiest temple in India and second wealthiest in the world after the Vatican is visited by thousands of pilgrims from around the world annually). This kind of personal pilgrimage has two important consequences. On the one hand, it strengthens the link between Telugus and the Telugu diaspora through religion, and on the other, it provides a better environment for regional development. For instance, Sri Sathya Sai Baba's organisations - spread over I37 countries world-wide 
in over one thousand centres - not only promote the spiritual needs of the people but also the practical needs of society in general such as providing higher education and water, specialised medical care and so on to the masses.

\section{Caste and Association Networks}

While language and religion bind Telugus in both India and in the diaspora, caste and sub-caste identities provide them an additional forum for closer interaction. Telugus are divided into several caste groups; the most important being the Brahmin, Komati, Reddy, Kamma, Kapu, Naidu, Mala, Madiga, Yeraka, and Yanadi. If we look at Telugu migration history, most of the post-colonial migrants are drawn from the upper classes and castes, where as the migrants during the colonial period generally belonged to the lower caste groups. These caste differences have made their presence known in the various socio-economic and political interactions among the Telugus in the diaspora. For example, Telugus are divided along the lines of caste in the US, where the Kamma caste dominates the Telugu Association of North America (TANA) and the Reddy caste dominates the American Telugu Association (ATA).

One of the important channels of articulation of common interest among the migrants is their ethnic associations. The Telugus have formed their associations in order to maintain their cultural identity and to promote their socio-economic and political interests in the host country. They have also maintained close networks with community members in the place of their origin. Through their active participation in the activities of the association, Telugus in the diaspora strive to preserve their cultural heritage. The associations further serve two basic functions; i) raising funds for specific purposes especially during times of crisis, and ii) as a means of reinforcing the community networks by bringing together people who are dispersed throughout the world.

The associations also organise conferences and observe festivals to essentially cater to the Telugu community located in different parts of the world. Almost all of the associations abroad are formed on the basis of caste, religious, regional, and/or pan-Telugu identities in one way or another. There are local as well as global associations based on Telugu identity. While the local associations play a crucial role in preserving Telugu culture in a local context, the global associations provide a forum for Telugu participation world-wide. The local associations cater to a particular diasporic community and operate in the country of settlement, whereas the global associations are transnational in nature, cutting across the national boundaries.

Differences between the 'local' and the 'transnational' associations can be illustrated with the example of the 'Telugu Association of North 
Texas' (TANTEX) and the 'World Telugu Federation' (WTF) in terms of their objectives and the nature of their activities.

The mains of objectives of TANTEX are:

I. to maintain, preserve and perpetuate the cultural heritage of the Telugu-speaking people of North Texas;

2. to assist and promote cultural, educational, social and community affairs of the Telugu-speaking people in North Texas, and;

3. to foster understanding between the Telugu-speaking people and others in the community.

Whereas the objectives of WTF are:

I. to organise periodical Telugu literary, educational and cultural conferences and seminars throughout the world and;

2. to promote understanding of the Telugu language, literature, arts, culture, music, dance, and drama, particularly among Telugu children world-wide.

Networking between these associations facilitates the relations between the Telugu diaspora and the home country. From the motherland's perspective, when we look at the diasporic Telugus (or Non-Resident Telugus), we have to look at both their contribution to the motherland and the motherland's contribution to the expatriate Telugus. It is true that expatriate Telugus play an important role in the all-round development of Andhra Pradesh. The former Chief Minister of the State, Sri Chandra Babu Naidu has tried to involve the Telugu diaspora in the developmental schemes of Andhra Pradesh. The diaspora has made valuable contributions not only in the fields of science and technology but also in industry, healthcare, quality educational institutions such as the Indian School of Business (ISB) and the International Institute of Information technology (IIIT), as well as various other gainful ventures. For instance, 'Naandi', a trust formed by the Telugu diaspora and the Andhra Pradesh government, calls for increased involvement by the Telugu diaspora in the development of Andhra Pradesh.

\section{Political Networks}

Besides their networks through associations, Telugus have also maintained close networks with the homeland on a political level as well. Their networks are discernible through their participation in the political life of Andhra Pradesh, by mobilising support for specific political parties. Furthermore, whenever prominent members of the Telugu diaspora visit their places of origin, the Telugu political elite and administrators make a special effort in welcoming them. This has resulted in a further development of networks and links between the diaspora and 
the homeland. There are several instances where collaborative projects that include joint ventures were initiated for the benefit of Telugus in general.

Today, the Telugus have emerged as a distinctive transnational community, bringing the 'local' and 'global' together. This is manifested in the socio-economic, cultural, and political networks between Telugu communities, their homeland, and their kith and kin world-wide. During the last two decades, these contacts have been further facilitated through the encouragement and intervention of the Andhra Pradesh government in various political as well as economic matters. It is obvious that, although the Telugus are separated by great distances, they remain linked to one another through ties of kinship, shared resources, and cultural exchanges. They preserve and recreate their culture in new homes across the globe.

\section{Virtual Networks}

Of late, the Telugu diaspora - especially the new Telugu diaspora - has been very active on the Internet in terms of emerging e-groups. People with similar interests form an e-group online and share their views with the rest of the members in the group. As mentioned earlier, The Internet is providing a constructive platform for the Telugu diaspora, to interact, not only among themselves and with other migrants in other parts of the world, but also with the Telugus back home. It is this interaction between the Telugu diaspora and the Telugus that has given rise to a virtual community ${ }^{7}$ of Telugus.

The presence of the Telugu diaspora online is seen in terms of Telugu association web pages as well as personal, literary, media, and popular entertainment web pages. Many of these websites have discussion forums, thread messages, list forums, and Usenet ${ }^{8}$ groups. Some of the sites even provide free e-mail addresses and space for personal homepages. Many Telugus in the diaspora are kept informed of developments back in the motherland via these sites - from politics to popular music. All of these websites act as global and online platforms where the participating members exchange and express their views on various issues concerning not only the Telugu culture and life but also politics, economics, entertainment etc.

Physical interaction is slowly being replaced by virtual interaction online and a visible shift towards online interaction is noticed in the networks between the Telugu diaspora and the Telugus elsewhere, with the latest CMC advancements such as web cams, video and tele-conferencing. Presently, most Telugu associations have their own websites informing the public of their activities. Though they focus on a particular group in the Diaspora, the pages are open to anyone who visits the site. 
Telugu websites vary: there are general, political, economic, literary, matrimonial and other sites as well.

There are also developments such as a kind of sub-nationalism among the Telugu diaspora based on regional sentiments that are facilitated by Internet communications. But the virtual communities and the interactions have both internal and external constraints. Factors such as reliability, security, infrastructure, and government policy act as controls and constraints, which finally determine the nature and magnitude of emerging networks within the diaspora.

\section{Contextualising Identity}

The latter half of the twentieth century saw the world-wide rise of ethnicity issues based on race, religion, region, language, caste, or tribe. The Indian subcontinent experienced ethnic revivals and mobilisations based on religion, region, language and caste identities in particular that facilitated the usurping of political, economic and social interests. In Mauritius, there has been a trend toward a complex game of ethnopolitics (Hookoomsing 2003b: I9) and an “...ethnic evolution from Indian to separate Hindu and Muslim identities, with a further perspective of a potential Hindu fragmentation to make room for a Tamil entity .... evoking a familiar reality of perpetuating the religious and provincial divisions inherited from the subcontinent." It is not just the Hindi-speaking Hindoos and Tamils but the Telugus and Marathis have also secured their own territories in the ethno-politics of Mauritius. The state offers support for the teaching, propagation and celebration of these ancestral languages among the People of Indian Origin in Mauritius. The Mauritian state thus lends legitimacy and official approval to communities and identities based on the notion of 'ancestral languages' (Esenlohr 2002: 103).

Telugus in Malaysia experience a different situation from those in Mauritius, says Sanjeeva Appadoo, a Telugu teacher at the Mahatma Gandhi Institute in Mauritius. In Malaysia they speak Telugu at home while in Mauritius they have been facing the trauma of dwindling use of the mother tongue. Although the Telugus in Mauritius speak Creole or French at home as a consequence of the loss of the 'mother tongue' over a century ago, Telugu is still everything to them - their 'religion', 'culture', and way of life. They worship Telugu in the form of a 'mother goddess' and address her by Telugu thalli (meaning 'Telugu mother'). Telugu thalli idols have found their way into the altar of Telugu homes where she is worshipped along with other deities. In fact, some of them keep the soil ('mother earth') collected from their places of origin as a sacred representation of the Telugu thalli in the altar. Mauritian 
Telugus consider themselves Telugu bhaktas (devotees of Telugu goddess), because Telugu is worthy of worship. Telugu is not just a language, it's an entire way of life.

The above-mentioned conceptualisation of Telugu as their 'religion' is also reflected in the perception of the other 'Ancestral Language' groups such as Hindi-speaking 'Hindoos', Tamil-speaking 'Tamils' and Marathi-speaking 'Marathis'. Though most of the People of Indian Origin are Hindus, the various ancestral language groups have built their own temples; those who spoke Hindi and Telugu maintained 'Hindoo' and 'Telugu' religions and temples. Similarly, the Tamil- and Marathispeaking communities maintain 'Tamil' and 'Marathi' religions and temples. Thus the Hindu religion, as practised by most of the Indian immigrants in Mauritius, was gradually appropriated by different 'ancestral language' groups into Hindoo, Tamil and Telugu religions during the processes of their immigration. Thus, Telugu for the Telugu community in Mauritius is not just the 'ancestral language' but represents a very distinct culture and religion to which all Telugus belong and a primordial ethnic identity they can articulate in the socio-economic and political arena.

This means that the migration and immigration experiences of the Telugu-speaking people from the erstwhile British state of Madras have led to the formation of endogamous caste-like structures, based on the 'assumed' linguistic identity (they believe that they are descendants of the Telugu-speaking immigrants from Andhra Desha (Telugu Country), an assumed abode of people pursuing Telugu culture and language). It is primarily a linguistic identity that has been transformed into a cultural and - more significantly - a religious identity in the context of Mauritius. Similar kinds of migration and immigration experiences are reflected in the formation of Marathis, the descendants of the Marathispeaking indentured or kangani labourers from the former British province of Bombay, as well as Tamils and Hindoos.

Mauritius has seen the emergence of unique caste-like structures over the past century and a half from the regional clusters of linguistic identities. They have also assumed a unique religious dimension, fragmenting the pan-Indian religious ideology of Hinduism, despite the fact that all of these newly emerging groups have similar deities in their temples.

Eisenlohr (2004:8I) argues that the ideologies of ancestral languages in Mauritius 'are involved in the processes of group identification, by projecting notions of Hindu community through a particular regime of temporalization'. In Mauritius, the meaning of 'Hinduness' is associated with 'ancestral time', combining the ideas of language with ritual performance, evoking an ancestral homeland in India. It is a matter of common knowledge and practice that Hindi is officially recog- 
nised as the ancestral language of Hindoos in Mauritius, though Hindi is never used in everyday life and remains fairly unknown to the very people claiming it as their ancestral language.

The experience of the Telugus in the US is very different from those in Mauritius. Temporally, the bulk of Telugu migration to the US occurred after India's Independence, especially since the I950s. Most of these immigrants hailed from well-educated, urban, upper- or middleclass and caste backgrounds. Besides promoting unique cultural practices, Telugu identity offers the immigrants - especially those from Andhra Pradesh - a significant community base, which allows them to feel at home in the alien environment of the host society. For instance, several Telugu associations located in different states offer employment or educational support to the newly arrived Telugus in an unfamiliar environment.

The new Telugu diaspora in the US experienced the smallest challenge to their identity because they continued to maintain close ties with the people and places of their origin. They pursued maintenance of Telugu identity, especially its promotion among the younger generations with the help of various associations, though there is no threat of its being assimilated or forced to follow socio-cultural practices other than their own. In fact, Telugus are presently in a position to replicate their caste and regional identities and networks with their counterparts in Andhra Pradesh, using advanced transport and communication technologies. Moreover, the Telugus have moved to a country, which is already advanced compared to Mauritius where the immigrants had to help develop the country where they began at the lowest rungs in society. Unlike Mauritius, Telugu identity in the US has a limited role in the identity politics of the host society or in the sharing of power with other immigrants of Indian origin.

Following the formation of the World Telugu Federation, people from Andhra Pradesh, the old and new Telugu diaspora world-wide participated in various conventions organised periodically in different venues where the Telugus have had a considerable presence, both in India and the diasporic countries. These conventions also provide opportunities to promote collaboration involving trade, commerce, industry, and other avenues of business. The Andhra Pradesh government has, since the I990s, initiated several programs (through the Andhra Pradesh Non-Resident Industrial Corporation) to involve Telugu diaspora as a partner in the overall development of the state. Today, Telugus in India and in the diaspora, both old and new, have established close socio-economic, political, and cultural links that span the globe and transcend the borders of nation-states for their mutual advancement. 


\section{Notes}

I In the kangani system, the recruitment of labourers was generally carried out by a known person from the same village who was already employed on the same plantation as a kangani or overseer.

2 MAMS presently has 84 branches across the island and actively promotes the Telugu culture and identity.

3 Ugadi, often spelt as Ougadi signifies the onset of the new Telugu year. During this festival, special food like pacchadi, toranalu, muggu (or alipona) are prepared. The pacchadi tastes sweet, sour, salty, bitter and hot symbolising an individual's life as a combination of all kinds of emotions. According to Appadoo (I990), the festival includes a Samouhika (group) puja, panchanga sravanam, a gathering at the beach and watching a Telugu movie on TV.

4 The prominent ones are www.telugcinema.com and www.idlebrian.com although there are other websites such as www.southindianmusic.com, www.raaga.com, www. tharangani.com, www.ragalahari.com etc which market Telugu movies and audio to the diaspora Telugus.

5 Recitation of original poetic works by the Telugus in the US.

6 The Tri-State Telugu Association (1984) represents three American states Illinois, Indiana, and Wisconsin (www.telugu.org).

7 Rheingold defines virtual community as 'social aggregations that emerge from the net when enough people carry on those public discussions long enough, with sufficient human feeling, to form webs of personal relationships in cyberspace' (www.rheingold.com/vc/book/)

8 Rheingold defines a Usenet as a 'way of passing information and communication around a network as a distributed resource with no central control manifested in the rapid growth of the anarchic global conversation' (www.rheingold.com/vc/book/). 



\title{
5 Separated by the Partition?
}

\author{
Muslims of British Indian Descent in Mauritius and \\ Suriname
}

\author{
Ellen Bal and Kathinka Sinha-Kerkhoff
}

\section{Introduction}

If we were to start this introduction by stating that India is the ancestral home of those who call themselves Hindus, we would expect our audience to concur without ado. If we added, however, that India is also the ancestral home of many Muslims, people would probably look up and ask: 'you mean Pakistan?' And surely our audience would gasp if we were to convince them that Pakistan is the ancestral home of Hindus. Clearly, the I947 partition of British India (hereafter the Partition) has had an impact on the way scholars look at the Indian diaspora. As a result, many studies on the Indian diaspora become analyses of the 'Hindu diaspora' (Vertovec 2000) with Muslims sometimes even delegated to Pakistan (Khan I995: 96). Others prefer to speak of 'Indian diasporas' and yet others, having failed to accommodate the Muslims within the Indian diaspora, have proposed abandoning the term and speak instead of the 'South Asian Diaspora' (Van der Veer I995; Clarke et al. I990). In other words, scholars do not automatically include so-called overseas Muslims - even if (offspring of) pre-Partition migrants - as part and parcel of the Indian diaspora. Religion does seem to divide.

In this article, we analyse the relation between religion, identity formation, and place, which will explain the causes for such above-mentioned, anticipated bewilderment. We not only argue that the Partition along religious lines has made it difficult for scholars since 1947 to link Hindus to Pakistan and Muslims to India, but we also address more fundamental questions concerning communities, ethnicity, religion and homeland. Such questions have gained all the more relevance since the II September 200I terrorist attacks, which seriously induced processes of stereotyping and articulating Muslim identities all over 
the world. The loyalties of Muslims towards their countries of residence, especially of Muslim immigrants, are addressed with suspicion, and the question has been raised whether 'true Muslims' do not consider themselves first and foremost members of a transnational Muslim community or a de-centred Muslim diaspora.

Our focus is on indentured labourers and their descendants in Suriname and Mauritius. We ask how Muslims among them have related to their land of origin, presently known as India. During the nineteenth and early twentieth century, approximately I.5 million people emigrated under the indenture system from British India to several European colonies in various parts of the world. Despite the dire conditions under which they worked, the large majority of migrants opted to stay on. These indentured labourers did not constitute separate, unified and homogenous groups, nor were they the only migrants. Here, we dismiss the a priori arguments that: I) there is a natural relation between these indentured labourers and their homeland and 2) that since this homeland was divided on religious grounds, (descendants of) these labourers were divided along religious lines as well, with Hindus identifying with India as their land of origin and Muslims therefore rejecting it. Instead, we question the nature of the relation between the (offspring of) indentured workers and their homeland, religious affiliations and community identities, and look at the consequences of religion for the diasporic nature of these British Indian migrants and their descendants, while focusing on the Muslim members.

\section{Defining Diaspora}

'The Indian Diaspora', was defined in 2002 by the Government of India (GoI), as 'a generic term to describe the people who migrated from territories that are currently within the borders of the Republic of India. It also refers to their descendants'. Furthermore, the GoI added that all these people, 'residing in distant lands', 'have retained their emotional, cultural and spiritual links with the country of their origin'. This official definition therefore does not, formally, exclude any (religious) group of Indian origin from membership of the 'Indian diaspora'. Yet, at the same time, it also signifies a narrow view of diaspora that scholars have debated, expanded, and reworked over a long period of time. Central to these debates is the connection between the migrants, their descendants, and their 'homeland'. Related to this is the fundamental question of whether all those migrants, or their ancestors, want or should be called the 'Indian diaspora'.

Some scholars, in line with the GoI definition, have shown the relevance of an imaginary Indian homeland (that is partly invented), even 
at times when there was no relationship between the migrants or their descendants and the present-day Indian nation (e.g., Appadurai I996: 49). Others, however, have questioned the importance of a real or symbolic homeland for diasporas and prefer to emphasise 'transnational connections linking diasporas'(Clifford I994: 306). However, most scholars feel that it is hard to speak about diaspora without implicating the concept of either a physical or psychic homeland (Gupta and Ferguson I992: II). Yet, they have convincingly shown that the 'homeland' can be de-centred, multi-centred and/or deterritorialised and they urge us to move away from the theology of origin/return and towards the de-centring of the homeland, and its incorporation as one of the sites in a diaspora.

Others propose treating the diaspora not as a bounded entity but to speak of 'diasporic stances, projects, claims, idioms, practices and so on' (Brubaker 2005: I3). Rather than starting from the premise that a bounded entity called diaspora exists, these scholars call for studies into its genesis, and 'the degree and form of support for a diasporic project among members of its putative constituency’ (ibid). In line with this we should ask questions such as which, why and when people started identifying as an Indian diaspora, and/or when they stopped doing so.

Vertovec (2000a: I) rightly argues that while over the last ten years there has been a proliferation of literature and a mushrooming of interest among academics - and among members of ethnic minority groups - surrounding the notion of 'diaspora', '[s]urprisingly, religion has been the focus of relatively little attention within this growing field'. He therefore sets out to analyse the religious aspects of diasporic experience, which, he feels, can 'give us insights into general patterns of religious transformation'(2000a: 8). We share Vertovec's interest in the study of the connection between religion and diaspora but we have a slightly different approach. We agree that ' $[D]$ iasporas arise from some form of migration, but not all migration involves diasporic consciousness'(ibid.: I2), yet deviate from his thoughts when he connects his concept of diaspora with religion and argues that it is possible to talk of a 'Hindu diaspora', 'especially because, no matter where in the world they live most Hindus tend to sacralise India and therefore have a special kind of relationship to a spiritual homeland' (ibid.: Io).

We feel that such an analysis overlooks religious (Hindu) communities that consider their religion universal and thus do not attribute a central role to India, and more importantly, we fear that such an approach equates the 'Indian' with the 'Hindu diaspora' and tends to exclude other religious communities from this Indian diaspora. Therefore, we propose that like Hindus, Indian migrants identifying as nonHindus and in particular as Muslims, should be studied in a fashion si- 
milar to that of Hindu migrants from India. This would allow for the inclusion of Muslims with Indian ancestors in the diaspora (as these Muslims might also have 'a special kind of relationship' to India, spiritually or otherwise) or exclusion of Hindus or others, if they wish to.

In this article, we therefore proceed along from new insights and examine the political, social, and cultural struggles, which have encouraged certain people to identify themselves as a diaspora and others to exclude themselves. In this way we are careful not to homogenise diasporic identifications or experiences and are sensitive to the influences of local experiences with the understanding that the local is always already permeated by the trans-local, including the happenings in the homeland. We also investigate the nature of the diaspora (and its relation with the homeland) and analyse the role of religion in the processes of diasporic community construction.

\section{Muslims from Indian Origin Compared}

Today the number of the Indian diaspora is estimated at over 20 million, including the so-called 'old diaspora'(especially those who left under the indenture system). The latter, also referred to as People of Indian Origin or PIOs, are believed to have continued nurturing close socio-cultural links with their so-called motherland ever since their departure (Bhat, in this volume, Narayan and Sahoo 2003). The Indian 'origin' of these people is taken as the primary indicator that they are part of the Indian diaspora. Whether or not PIOs actually identify as members of the diaspora is not taken into consideration (see also Sinha-Kerkhoff and Bal 2003).

In this article we compare Muslims in Mauritius and Suriname and the kind of communities they constitute. We ask whether or not they can be defined as a diaspora. In order to accomplish these tasks, we had to analyse the historical struggles of these Muslims in both Suriname and Mauritius, which have until the present day led to a bounded diasporic group of Hindustanis in Suriname, comprised of Muslims and Hindus, while in Mauritius they gave birth to a distinct ethnic group with religion as its qualifying factor. Therefore, while Suriname and Mauritius are similar in many ways, this different outcome regarding Muslim notions of belonging makes these countries interesting case studies for comparison. Both countries are proud of and known for their heterogeneous populations and the relatively peaceful co-existence among its various ethnic groups. Both nations have large populations of PIOs, i.e., people whose ancestors can historically be traced to the South Asian region and to the place that now comprises the Indian Republic. The other major population segment in both societies is of African descent. Yet, whereas in Suriname PIOs currently - although some more heartily than others - identify themselves as a 
separate ethnic group comprised of both Hindus and Muslims, Muslims in Mauritius have grouped themselves as a separate ethnic community. By juxtaposing these two cases, we show that we, as scholars, should not a priori, exclude or include Muslims in the 'Indian diaspora'. We should instead detail the local and historical case studies that show that the effects of the partition of the Indian Subcontinent on populations that left the region before 1947 are varied and forbid a simple exclusion of Muslims in the analysis of the Indian diaspora, or their delegation to a Pakistani, South Asian, Arab diaspora, or a transnational Muslim diaspora without a homeland.

\section{Mauritius and its People of (British) Indian Origin}

Until the Dutch arrived in the seventeenth century and named the island after its Prince Maurits van Nassau, Mauritius had no human population at all. The French succeeded the Dutch and the British (who had followed the Dutch). During these various periods of rule there was influx of settlers, soldiers, traders, convicts, workers, and slaves (cf. Carter I995). The British, who ruled from I8Io to I968, retained the French civil code but abolished the African slave trade and in order to satisfy the demand of plantation owners for cheap labour, they organised the migration of workers from the British colony of India. Along with these contract workers, Chinese and Indian traders and businessmen also settled in the colony. Mauritius ${ }^{2}$ now has a population of approximately I.2 million people ${ }^{3}$, and it is - like Suriname - still characterised by ethnic, religious, racial, and linguistic groups living in relative 'harmonious separatism' with each other. ${ }^{4}$

In I952, the population of Mauritius was officially categorised into three groups: the 'General Population', which included 'whites, coloureds and Creoles', 'the Indo-Mauritians' and 'the Sino-Mauritians' (Nave 200I: 98). The category of 'Indo-Mauritians' included all 'Hindus' and 'Muslims' who had come from British India as indentured labourers, as well as so-called free passengers. The number of indentured labourers was always much higher than the free migrants, and since many of them had arrived from the port of Calcutta they were received as Calcuttyas (see also Carter 2000). Most of them originated from the populous districts of Bihar and the eastern United Provinces (U.P.), though a small minority came from South India and the Bombay Presidency. Along with them, free traders from Gujarat arrived (Allen 200I). Muslims formed a conspicuous minority among these immigrants. ${ }^{5}$

In 1834, the governments of Mauritius and British India agreed upon the importation of indentured labourers, although between I 834 
and I838 immigration remained largely a private affair (Jha I987: I37). Later on, the whole enterprise became state regulated and officially the system was abolished in I924. During this period, which thus comprised ninety years, over 450,000 men and women were brought in as indentured labourers from British India. Although around one third returned, the majority decided to stay in Mauritius after the expiry of their contracts. They were given land - a bonus from the British Government - and special loans to help them get started as farmers in their own right. Thus, from the I89os onwards, the former indentured workers gradually became small farmers and, subsequently, citizens of Mauritius (Ramdin 200I: 3).

These Calcuttyas did not constitute a homogeneous group. First of all, there were those who identified themselves as 'Muslims' and those who called themselves 'Hindus'. Among the 'Hindus', internal variety based on regional, linguistic, religious, class and caste differences existed. There were those who spoke Bhojpuri, Tamil, Telugu and Marathi 'at home' and Hindus were divided between those who had started calling themselves Arya Samajees and those who opposed them, identifying instead with the Sanatan Dharma. A similar variety was discernible among the 'Muslims'. Nevertheless, a common culture developed among them that included practices such as the celebration of Muhar$a m$ and Holi. Hindus and Muslims on the plantations also shared food habits, dress codes and used mehendi during weddings. Also important was the darga (tomb of a saint, pir) where both Hindus and Muslims went to offer prayers to gain boons from Allah and returned for thanksgiving using incense, money, and garlands. A 'Mauritian Bhojpuri' (Gambhir I986) developed with Arab, Pharsi, tribal, Sanskrit, French, Chinese, Portuguese, English, French and even Turkish vocabulary and later matured into a Bhojpurised Creole which became the lingua franca of Muslims as well as Hindus.

Till the Ig6os, these various groups of Muslims and Hindus were officially grouped together in the category of 'Indo-Mauritians'. In I962, however, this category was subdivided into 'Hindus' and 'Muslims' and hence the Mauritian population was officially divided into four main categories. Scholars, though referring to the change, have never given much thought to this division of the Indo-Mauritian category. In fact, they seem to take it for granted, as a rather natural and logic decision reflecting territorial realities. Many scholars refer to the impact of the I947 division of British India and conclude that it was the strained conditions associated with the setting up of Pakistan that drove a wedge between Muslims and Hindus in Mauritius (Dinan I986: 22; see also Biltoo 200I). We do not deny that this present 'dichotomization within the Indo-Mauritians' (Hollup I996: 299) may have been influenced by the Partition, but feel that this 'wedge between Muslims 
and Hindus' needs much more attention because, till the late I940s at least, Indo-Mauritians seem to have been much more united by their common ancestry than divided by religion. We have therefore analysed the period from around I9Io onwards in order to explain why in I962 certain Muslims claimed a separate identity based on religion rather than region of origin ${ }^{6}$ and we conclude that the split in the IndoMauritian community on the basis of religion was the result of the interaction between local processes in Mauritius and the 1947 partition of British India, perceived as a process with no clear beginning or end. ${ }^{7}$

\section{Hinduisation as Indianisation among Hindu Indo-Mauritians}

By the time Mauritius became an independent dominion in I968, Hindus dominated the government and they have done so ever since. ${ }^{8}$ They in fact have been able to retain political control since I948 when adult suffrage was introduced. In circa ı9ı0, however, Manilall Doctor was sent from India to Mauritius by Mohandas K. Gandhi, who, after having visited the island for three weeks in I90I, wanted to inspire the so-called downtrodden 'Indians'. Manilall, an Indian barrister-at-law, came to Mauritius to defend these Indians in the courts, and ended up founding the Arya Samaj, 'to bring social justice and human progress among the Hindus' [emphasis ours] (Ramdin 200I: 7). He was concerned with the fate of Hinduism in Mauritius and wanted to 'check mass conversions of Hindus to Christianity in Mauritius'(Ramdin 200I: 7). At the same time, the Arya Samaj wanted to purify 'orthodox Hinduism' by reviving Vedic and Sanskritic Hinduism and did so by launching aggressive campaigns against 'superstition' and practices such as ojhai, jhad-phunk and exorcism, some of which were also common among Muslim Indo-Mauritians (Bahadur 2000: 137). It also favoured (female) education and fought for the uplifting of the 'illiterate masses'. The ensuing discussions between the two groups resulted in the division of these Hindus into the 'Arya Samajees' and the 'Sanatans' with both groups building new temples and educational institutions.

Although there were fundamental differences in the religious outlook of the two groups, the general focus on education stimulated the growth of an articulated middle class, which started participating in trade unions and political activities. Moreover, both the Arya Samajees and Sanatans invited missionaries from (British) India to come over to Mauritius and they went to India for further studies and religious education. In tough competition with in particular the Franco-Mauritian population in the political field, this newly educated Hindu middleclass emphasised the need for a 'united Hindu front'. They propagated a 'unifying Indian consciousness' fuelled by 'reformist' Indo-Mauritian 
leaders who were in close touch with India (Mulloo 2004: II2-II3), and during the I930s, a kind of Indian nationalism developed among this elite. This 'nationalism' was initially based on 'collaboration and compromise', both with the colonial power and 'with the Franco-Mauritian bourgeoisie, which controlled the Mauritian economy and society' (Hookoomsing 2003: 2I). Among these educated Hindus, English, French, and in particular the standardised form of Hindi (khadi boli), which by that time had developed in India, were presented as the 'cultured languages' of Hindus. Moreover, while this Hindu elite faced efforts of an 'ethno-linguistic purification' among the French-speaking population in Mauritius, they started rallying for Hindi 'to promote the "Hindu cause" in Mauritius' (Eisenlohr 2000: 13). This was made possible by identifying standard Hindi as the 'language of our ancestors' regardless of the fact that the vast majority of the Hindu population, like the Muslims among them, were illiterate Mauritian-Bhojpuri speakers (e.g., Eisenlohr 2002:2). The low status of Bhojpuri, which lacked standardisation and a recognised literary tradition, made it unattractive to the Hindu organisations in their efforts to gain supremacy over the French-speaking elites in the British colony (Eisenlohr 2002: 6). Furthermore, this Hindi-speaking Hindu elite started evoking the idea(l) of 'Chota Bharat' during the I920s in reaction to the old established Franco-Mauritian colonial elite's view of Mauritius as a 'Little France' (Hookoomsing 2003: I8). A process was initiated that is described by scholars such as Benedict (I96I: I4I) as the 'sanskritisation of Hinduism in Mauritius', which made 'the symbol of India the symbol of a new uniform Hinduism in Mauritius'.

These educated Hindus thus preferred 'pure Hindi' as an ancestral language over Bhojpuri, which was called a junglee (backward) language (Boodhoo I999: 39). Efforts were also made to do away with Pharsi (Persian) words, that had been part of the Bhojpuri spoken tradition and many aspects of the common Bhojpuri culture were denounced by Hindus who urged others to discover 'the real Indian culture'. Interestingly, in this process Bhojpuri, which had been the spoken language of both Muslim and Hindu Indo-Mauritians, became represented as 'Hindu property' (Eisenlohr 2002: I3). This resulted in a transformation of the social relations between Hindus and Muslims in Mauritius and seriously influenced the basis on which Muslims started to assert their claims of political authority in Mauritius (Eisenlohr 2000: 15).

\section{Islamisation as De-Indianisation among Muslim Indo-Mauritians}

The seed of Islam was sown by a group of Indian merchants who started coming to the island from 1758 onwards and did a thriving business there (e.g., Emrith I994; Jumeer I999). African slaves might 
also have been Muslims, yet as original names had been exchanged for Christian names, it is difficult to present figures. The bulk of Muslims came to India as indentured labourers and were identified, along with Hindus, as Calcuttyas (Jahangeer-Chojoo 2000: II9). Moreover, another group of British Indian Muslims came to Mauritius from the Surat and Kutch regions of Gujarat as well as from Bombay. Their number greatly increased after World War I but never surpassed that of the Calcuttyas and they remained a small, though elite, minority in Mauritius. Clearly, during the nineteenth- and early twentieth century, these Muslims did not constitute a homogeneous group, although the vast majority was Sunni, ${ }^{9}$ which in Mauritius was considered as 'orthodox'. Class differences among Muslims were significant and there was a huge gap between the economic position of most Muslims and the small but economically powerful and socially influential group of Muslim traders. These Gujarati-speaking Muslim traders were again divided into two principal groups, the Kutchi Memons and the Sunni Surtis, plus a small number of Shias. ${ }^{\text {IO }}$ These Muslim migrants came with a certain amount of capital and were not bounded by any contract. They were concentrated in the capital and engaged almost exclusively in commerce. They were also known as 'white Muslims' because of their fair complexion (Boodhoo I999: 2). They established firms and stores and became the leading dealers in foodstuffs and textiles. At a certain time, they also became the owners of sugar estates and factories. Although today there are many Muslims who own large sugar plantations, none of them are involved in owning or managing a sugar factory (Emrith I994:37-38). Nevertheless, the importing of grains, jute bags, and textiles became more or less their monopoly. They also invested in the university education of Muslim students in Mauritius and abroad. By the end of the I $9{ }^{\text {II }}$ century, these white Muslims had emerged as major economic agents. For them, the most important factor that enhanced the trade between British India and Mauritius was no doubt the 'Coolie Trade' or the organised migration of indentured labourers from India. The need for the transport, clothing and food for these labourers gave an impetus to commercial transactions with India. These Muslims were, in fact, more active than the colonial government. Through Indian middlemen or commercial houses they supplied the immigration stream (Carter I995: 53) and used the empty returning ships for the exporting of sugar and other national and international products. They truly were an Indian trade diaspora. ${ }^{\mathrm{I}}$

These Muslim Indo-Mauritians started functioning as the Indian elite on the island even before the arrival of the Arya Samaj missionaries in Mauritius and the subsequent birth of an educated Hindu elite. They visited India at regular intervals, they tried to find spouses in the villages of Gujarat and a number of them maintained two homes, one 
in Mauritius and one in British India. They played important roles in both the religious and educational fields. For example, they maintained the Jummah Mosque, one of the most important religious centres in Port Louis. They were very much in touch with (British) India and when Mohandas K. Gandhi made a brief stop in Mauritius on his way from South Africa to India in the beginning of the twentieth century, he was welcomed and celebrated by these Muslims in the name of all Indo-Mauritians. However, a process described by Benedict (I96I: I42) as the 'sunnification of Islam' started among them that would, ironically, pull Muslims away from 'India'.

Among these elite Muslims, as it was among Hindus, there was an intense power struggle and they experienced feelings of humiliation under the dominance of the Franco-Mauritians. Consequently, these Muslims emphasised the importance of a Muslim identity through Islamic revivalism. Local (read Bhojpuri) and sectarian practices were denounced in favour of a uniform orthodox practice. This, for instance, united into a strong movement against the celebration of Muharram, known in Mauritius as the Yamsé or the fête des Ghouns (Jumeer i999: II2). Religious leaders like the mullas also increasingly denounced 'unIslamic practices' such as prayers for pirs and the dispensing of attention and cures through prayers and taviz (amulets) (Jahnageer-Chojoo 2002: I2I). They also propagated the 'de-hinduization' of Muslim marriage celebrations (Benedict I96r: I42). Although this kind of 'islamisation' certainly divided the Indo-Mauritians on the basis of religion, the religious reform did not necessarily urge them to distance themselves from India. In fact, missionaries from British India such as those related to the Tablighi Jamaat (International Brotherhood of Muslims), were invited to Mauritius, to further the 'sunnification of Islam in Mauritius' (Benedict I965: 39). ${ }^{\text {I3 }}$

Furthermore, even though standard Hindi and Urdu were in fact two forms of the same language while Urdu uses a form of Arabic script and draws heavily from Persian and Arabic for its formal literary vocabulary and standard Hindi is written in the devanagari alphabet, turning to Sanskrit for 'learned and elegant words'- the elite Muslims increasingly preferred Urdu over Bhojpuri as their ancestral language. Consequently, language, like religion, no longer functioned as a marker of ethnic unity among the Muslim and Hindu Indo-Mauritians.

These processes, which indeed divided the Indo-Mauritians into two separate communities with different religious-linguistic identities, were also reflected in politics. The first proposal for a new constitution was made in 1946 and elections on a limited electoral roll were held in I948 and I953, with some Muslims demanding different electoral rolls (Singh 2005: 66). By the time elections came around in 1959, the Indo-Mauritians were divided into two parties: the Independent For- 
ward Bloc (IFB) and the Mauritius Committee of Action (MCA). Muslims had furthermore formed the Comité d'Action Muselan (CAM). Sookdeo Bissoondoyal had established a party supported by rural Hindus, the Independent Forward Bloc (IFB), which wanted the revival of Indian culture and values. Muslims increasingly began voting for "nonHindu parties', favouring the Creole struggle against 'Hindu hegemony'. However, there were Hindus who did vote for Muslim candidates and Muslims who voted for Hindu candidates (Dubey I997: 5859).

After the partition of British India in I947, people's relation to the idealised ancestral motherland (British India) as well as to post-partition India also changed. Hindus emphasised their Hindu/Indian backgrounds even more (Nave 200I: 98) while a number of Muslims began referring to Pakistan as their 'homeland' (Sharma I986: 9). ${ }^{\mathrm{I}}$ Increased communal rivalry between Hindi-speaking Hindus and Creoles also drove away the Muslims who feared the 'peril of Hindu majority' (Dubey I997: 64). Thus, by the early i96os, politics had become completely 'communalised' even though the Muslim vote at that time was still divided (Dubey I997: 66). By that time, not all Muslims were voting 'against' Hindus or for the CAM, but the pro-Indian approach of certain Hindu leaders was certainly not adhered to either. This process culminated in I962, when 'a group of Muslims' reacted strongly against the Government's decision to group Muslims together with Hindus under the common ethnic denomination of Indo-Mauritians for the population census (Emrith I994: II9).

\section{'Calcuttya' Muslims between Re-Diasporisation and De-Diasporisation}

In I93I, almost one hundred years after the first indentured labourers arrived in Mauritius, the Muslim population was 50,592 out of a total Indo-Mauritian population of 268,649. The bulk of these Muslims were (the descendants of) these indentured labourers known as the Calcuttyas. It is not clear whether the educated elite actually helped these Calcuttyas in their economic development. Some Muslims even argue that the tendency of Gujaratis to favour family and group members has in fact hindered the progress of Calcuttyas, especially in the commercial sector (Jahangeer-Chojoo 2000: I27). Nevertheless, these 'white Muslims' financed the building of several mosques and madrassas (schools) and greatly stimulated the birth of an educated elite among the Calcuttyas who became wedged in between these processes of re-diasporisation among Hindus and de-diasporisation among Muslims.

A review of the socio-economic and religious-cultural development of these Calcuttyas in the period from I860 to I904 shows an increase in the mosques they managed (with the financial assistance of Gujarati 
Muslim social organisations). Later on, when the Hindu elite started gaining political power, there was an increased emphasis on orthodoxy and concern with non-Islamic practices among the educated Calcuttyas as well. This affected local religious practices, as seen in changes in dress styles, for instance, with the indentured labourers abandoning the traditional clothing whenever they began to climb up the class ladder. Moreover, sometimes purdah would be introduced among Calcuttya Muslim women (Jahangeer-Chojoo 2002: II6). There was also a gradual disappearance of the Muharram festival among these Muslims in Port Louis and a decline of the 'Indian' way of celebrating Ramadan (Hollup I996). Muslims also participated less in Hindu festivals such as the Holi celebrations, in which they had previously played djal (small cymbals).

Nevertheless, for many Calcuttyas, mostly Sunni Hanafees, some 'Indian' traditions remained unchanged, such as the (Sufi) ritual of offering incense, money, and lengths of cloth to famous pirs. The HinduMuslim divide of the Indian subcontinent was therefore not fully replicated in Mauritius (cf. Hookoomsing 2003: I6). Moreover, 'communal violence' in Mauritius was more common between Hindus and (Christian) Creoles than between Hindus and Muslims. However, when during the 1948 Mauritius elections no Muslim candidates were elected, they decided that the future demanded a separate platform for Muslims and a strategy of political and economic alliances (Hookoomsing 2003: I9). Moreover, the small group of Muslim merchants and traders began favouring the use of Urdu and Arabic over Gujarati and merged with many of these 'Muslim coolies' who had dropped Bhojpuri for Urdu and Arabic as common languages of Islamic reference (Hookoomsing 2003: I7). Subsequently, as in post-partition India and among the Calcuttya Muslims as well, linguistic and regional features started functioning as markers of social and class distinction.

Muslims represent I7 per cent of the current Mauritian population, among which the descendants of indentured labourers form the largest group (Rajah-Carrim 2003). ${ }^{15}$ Our interviews with these Calcuttya Muslims indeed confirm that they do no longer share a common (Bhojpuri) culture with the Hindu Calcuttyas in Mauritius. ${ }^{16}$ However, these Calcuttya Muslims are not at the same level as the Muslim Gujaratis, even though some of them felt that these richer and better-educated fellow Muslims had helped them (Carroll 2000: 37). Others felt discriminated against in the public sector and subsequently set up small businesses themselves and have become quite successful (Carroll and Carroll 2000: I4). ${ }^{\mathrm{I}}$ In the countryside, the Calcuttyas are either self-employed workers, traders, or banyans (middlemen) in the fishing trade. In the urban areas they are employed as skilled workers or self-employed technicians (Mehta 2004: I94) and only very few of them are doctors, 
barristers, or engineers. ${ }^{18}$ There is thus 'uneven inclusion' of these Calcuttyas into the rest of the Muslim population, or rather the other way around, and economic differences between the groups have remained.

Among Hindus, Hindi replaced Bhojpuri as the Ancestral Language (AL) and the Language currently spoken at home (CL), but Gujarati Muslims still support Urdu as their AL. However, we found that the Calcuttya Muslims seem to have abandoned the idea of 'ancestral language' altogether (Edun 2003: I67-I7I). Moreover, our interviews with Hindu and Muslim Calcuttyas also demonstrate that the (re-) discovery of a 'homeland' among many Hindu Indo-Mauritians - aided by the Government of India ${ }^{19}$ and the subsequent reactivated social, economic, cultural, religious and educational ties with present-day India - has motivated these Muslims not only to abandon a common Indo-Mauritian identity (Hookoomsingh 2003: I7) but also to abandon (British-) India as their homeland. Indeed, some of them seem to have replaced this homeland for Pakistan or the 'Arab world'. ${ }^{20}$ Or they were influenced by more recent voices of 'fundamentalism' (Hollup I996) and post-September II global world changes, and now support 'the idea of belonging to the ummah' either as a safety valve in an increasingly tense local political environment ${ }^{2 \mathrm{I}}$ or as a 'tool to locally get material and political gains' (Jahangeer-Chojoo 2002: I24-I25). ${ }^{22}$

However, we feel that, in general, these Muslim Calcuttyas no longer constitute a diaspora. Clearly a process of de-diasporisation has set in among them, away from Hindu Calcuttyas and their India, which has in fact been replaced by Mauritius as the 'homeland'. In their cultural and research centres they now study the contributions of Muslim IndoMauritians to the development of Mauritius as they try to create a kind of Mauritian Islam. Questions about roots or origins do not seem to play a role. However, the possibility of the creation of new groups remains open and these (other diasporic) identities lie 'dormant' and can be 'reactivated' at any time, depending on the interaction between local and global circumstances in Mauritius (cf. Jahangeer-Chojoo 2002: II7II8).

\section{Muslim Indentured Labourers in Suriname}

Suriname offers another textbook example of a so-called poly-ethnic or plural society. Notwithstanding significant co-operation and identity formation along non-ethnic lines, the articulation of ethnic identities has left its mark on the organisation of Surinamese society. Ever since the Dutch arrived in 1667 , ethnic (typically referred to as racial) distinctions have marked interpersonal relations, initially between the colonial planters and slaves of African descent, but since the abolition of slavery 
in 1863 and the subsequent importing of labour from other colonies also with people of Asian descent (from British India, Dutch Indies, China). Today Suriname also has immigrants from British Guyana, Haiti, Brazil, as well as 'new' migrants from China. The two dominant communities, however, are the Afro-Surinamese, also known as Creoles, and the People of Indian origin or PIOs, in Suriname commonly known as Hindustanis. Notwithstanding ethnic differentiation or even antagonism, the country has never witnessed inter-ethnic violence in any way comparable to countries like neighbouring British Guyana. Approximately half of all of the Hindustanis, some 160,000 people, are currently living in the Netherlands. The others have remained in Suriname. Here we concentrate on the Surinamese Hindustanis, in particular, the Muslims amongst them.

Preliminary figures from the last population census in Suriname (Algemeen Bureau voor de Statistiek 2004) show that the country now has 487,024 inhabitants, of whom almost seventy per cent reside in the capital Paramaribo and its bordering district Wanica. The report, however, makes no reference to either religion or ethnicity. In I99I, Hindustanis formed the largest community (37.0 per cent), followed by the Afro-Surinamese (3I.3 per cent), the Javanese (I4.2 per cent), the Maroons or inland Creoles (8.5 per cent), Amerindians (3.I per cent) and I.7 per cent 'other' (Brinkerhoff and Jacob I994: 637-638).

In this last section, we will analyse the process of community construction, identity politics and the construction of notions of belonging among the Surinamese Hindustanis, with a particular focus on Mus$\lim$ Hindustanis. Although the Hindustanis by no means constitute a homogeneous community - they are comprised of Hindus, Muslims, and Christians of various denominations - and their history has been marked by occasional periods of conflict and estrangement, until the present day there has been no ethnic bifurcation akin to the Mauritian case. Here we will try to explain why in Suriname, unlike in Mauritius, religious differences have not led to the construction of distinct ethnoreligious communities and a process of diasporisation among Hindus and of 'de-diasporisation' among Muslims, but instead resulted in the formation of one Hindustani diasporic community.

British Indian migration to Suriname was mostly restricted to labourers who left under the indenture system and whose arrival was closely connected to the prohibition of African slavery in 1863. In search of alternative labour on the plantations, the Dutch signed a convention with the British government in 1870 that allowed them to contract Indian labour. Between I873 and I9I7, approximately 34,000 British Indian contract workers migrated to the Dutch colony. Their early history shows much resemblance to the indentured workers in Mauritius. Historical sources (e.g., Grierson I883) demonstrate that they too 
came mostly from the Bhojpuri area of British India, now covering the western part of Bihar and eastern Uttar Pradesh. Upon their arrival in Suriname, they started working on various plantations under 5-year contracts. And although they could make use of a 'free passage' to return to Calcutta after the completion of their contracts, by I9I5, only an estimated one third had made use of this opportunity (Ramdin 2000:152).

These British Indians in Suriname were similar to the indentured workers in Mauritius in that they constituted a varied lot with differences based on language, religion, regional background, class, gender and so forth. Here too they were initially referred to as Calcuttyas (Kalkattiya's) or Calcutta-soema (negro-English for 'human'), as well as coolies, British Indians, and Hindustanis (named after the region that the Muslim rulers had designed as Hindustan). ${ }^{23}$ The first generation of migrants came with dissimilar ambitions and personal histories, and they were variously equipped physically as well as mentally, to face the long journey and the new circumstances in which they had to live and work (cf. Vertovec 2000: 48-49). Furthermore, men and women had enlisted as singles, and family migration was rare. These migrants gave various reasons for migrating. Often it was a combination of poverty, personal and localised difficulties, coupled with a spirit of enterprise that brought people to one of the depots.

Most migrants stated that they were Hindu, often from the so-called depressed classes. Brahmins made up only 5 per cent, though according to the census of India of I93I, they constituted II per cent of the Hindu population in the United Provinces. The percentage of Muslims among the British Indian migrants was approximately I7.5 per cent while the percentage of Muslims in the U.P. was approximately I2 per cent at the time of migration (ibid.: II2). Thus the proportion of Muslims among the emigrants was relatively large. ${ }^{24}$ Neither Muslims nor Hindus constituted homogeneous categories of believers. The widely heterogeneous caste composition of the Hindus also accounted for religious heterogeneity. However, 'out of such profusion common forms were forged' (Vertovec 2000: 46-47). Similarly, Muslims were a heterogeneous collection of believers and sects. They comprised saiyads, sheikhs, pathans, mughals, julahas, fakirs, ghosis and hajams. Most Muslims were from the Sunni Hanafi mazhab. They celebrated the Eids as well as Muharram and Milad-un Nabi, and they were also influenced by the Shia and Sufis of North India (Chickrie 2002: 385).

While Hindi has typically become associated with Hindus and Urdu with Muslims in Mauritius, and, for that matter, in India itself; in Suriname a lingua franca now known as Sarnami or Sarnami-Hindustani developed, based largely on Bhojpuri and Avadhi, and blended with non-Indian languages (e.g., Vertovec 2000: 48). Despite the fact that 
both Hindi and Urdu were taught in local schools for Hindustani children (the so-called koelie schools), madrassas, etc., and both Hindi and Urdu have always been considered higher languages, which were used as religious languages, neither one of them developed into a first language, or a language spoken at home (CL). ${ }^{25}$

Notwithstanding the initial heterogeneity of the British Indians in Suriname, it was already evident that during their stay in the depots in Calcutta or the long journey which lasted for months, some 'singles' became 'couples', friends became 'brothers', ${ }^{26}$ and many friendships and marriages (including inter-religious ones) were long lasting. And while some considered themselves 'transients' and not 'settlers', subsequent generations came to realise that they were in a "position of no return' and abandoned the idea of going back to India. Suriname had become their country of 'permanent abode' and a process of community building had begun. By 1947, when India was divided into India and Pakistan, the British Indian contract labourers had evolved as a distinct ethnic and linguistic community whose members identified themselves as Hindustanis.

\section{Muslim in Suriname}

Scholars have argued that the history of Islam and Muslims in the Caribbean can be traced to long before the voyages of Columbus in the fifteenth century. ${ }^{27}$ They provide evidence that many of the slaves who were transported from West Africa to work in the Caribbean were in fact Muslims. Yet these scholars also agree that 'all these Muslim groups have submerged almost without trace'. With the arrival of Muslim 'East Indians' (as they were called in English) in Guyana, Trinidad, Guadeloupe, Martinique, Jamaica, St. Lucia, St. Vincent, Grenada and Suriname, Islam (or rather various Islamic syncretised traditions) was, however, reintroduced in the Caribbean. In Suriname today, Muslims of various ethnic backgrounds make up approximately twenty per cent of the total population. Unlike the Hindus (who now constitute 27 per cent of the population and who are generally of Indian descent), the Muslims are comprised of people from various (diasporic) backgrounds (including Javanese who came under a similar indenture system from the Indonesian Archipelago between I890 and I940, and also a growing number of Afro-Surinamese Muslims). Most Muslims in Suriname, however, are of Indian descent. Every one of the sixty-four boats that brought indentured labourers to Suriname also included some who identified themselves as Muslims. According to the personal database of these indentured labourers, the first boat, the Lalla Rukha, counted at least 35 Muslims among the 4IO people who had embarked (De Klerk 1998 (1953): 48-49). ${ }^{28}$ All in all, an estimated one fifth of all 
British Indian indentured labourers were Muslim (e.g., Karsten I930; De Klerk I963: 6r; Ramsoedh and Bloemberg 200I: I23-165).

Unity among Muslims in Suriname during certain periods and in particular fields - like the foundation of the country's first political party, the Muslim Party ${ }^{29}$ - never led to the construction of a separate Surinamese Muslim diaspora without 'homeland(s)', or an ethnic Muslim community rooted in Suriname. Muslims of Indian descent and those from Java rarely developed common Islamic programmes and institutions and the history of religious institutionalisation is based on intra-ethnic rather than inter-ethnic religious co-operation. They never set themselves apart from other Surinamese people as one single community.

Some scholars have argued that 'the Hindustani competition with Creoles for scarce socio-economic and political resources' produced a strong tendency, 'within the Hindustani group to neglect the internal socio-religious differences and to stress the fact that Hindustanis were a group originating in India, having a common history and therefore a common identity' (Brinkerhoff and Jacob I994: 636-662). Although we agree with the argument that animosity toward the Creoles possibly led to a lack of communication regarding internal differences, we would also argue that religion was 'a significant symbol system of identification, demarcation and support' (Bauman I999), without causing a permanent breach between Hindus and Muslim Hindustanis. We believe that it was precisely the localised (British Indian or South Asian) culture of Islam that these Muslim Hindustanis highlighted and linked them to countries of origin different from those of the other Muslims. ${ }^{30}$ Moreover, they were united by Urdu (as their religious language), which separated them from the Javanese Muslims and from those who were more influenced by the process of 'arabization' (Chickrie (200I and 2002: 38I-399). ${ }^{3 \mathrm{I}}$ Hence, Hindustani Muslims in Suriname preferred links with Lahore and did not seem to have much interest in 'pilgrimages to Mekka' (Karsten I930: 20). This orientation continued after I947, when India was partitioned and Lahore became part of Pakistan. Rather than resenting the 'Indianisation' of Muslim cultural practices, the Hindustani Muslims in Suriname sought its preservation and invited maulanas from India and Pakistan for this purpose.

Though language and religious South Asian affinities therefore united these Hindustanis, the Muslims, like their Hindu counterparts (who, similar to Mauritian Hindus, became divided into Arya Samajees and Sanatans), were affected by internal fragmentation and institutionalisation. This process started soon after the contract labourers settled as free immigrants in Suriname. They broke up into several organisations and are now divided over many mosques. The first and most pro- 
found division among the Muslims was between the Sunnis and Ahmadis. This separation goes back to the early twentieth century when Surinamese Muslim leaders were looking for scholars from (British) India to teach them about Islam. The Surinamese Islamic Association (SIV) approached Himayal Ill Islam in India for assistance, and he encouraged them to contact Moulvi Ameer Ali of Trinidad. Ameer Ali came to visit Suriname and preached the ideology of Ahmadiyyaism. ${ }^{32}$ Here, like in Trinidad, the introduction of the new ideology caused a schism among the Muslims. Soon, the SIV came to be dominated by the Ahmadiyya doctrine causing many Sunni Muslims to leave and form several orthodox groups (Kassim I999: 176-77).

Further fragmentation of the Hindustani Muslims in Suriname continued in the course of the twentieth century, although the real rupture between the Sunnis and Ahmadis only occurred after World War II. Many of our informants believe that the moulvis and maulanas from Pakistan, who then started arriving in Suriname, were primarily responsible for stirring up the differences between local Sunnis and Ahmadis. This was particularly so after I974, when the Ahmadis were officially declared non-Muslims in Pakistan. ${ }^{33}$ These conflicts have remained unresolved until today.

The Boycott: Communal Conflicts in Suriname of the 1920 s and 1930 s

Unlike Mauritius, Suriname is situated at a considerable distance from India. This has certainly had an impact on the minds of the migrants and their descendants. Of those contract workers who stayed in Suriname, only a few were able or willing to maintain their contacts with India. After the first generation of migrants passed away, most of the contacts with relatives in British India were also discontinued. By I9I6, when ships stopped bringing new migrants from India, British Indian immigrants increasingly saw India as the land of their ancestors rather than as their own. Moreover, in 1927 these British Indian aliens formally became recognised as Dutch subjects ('onderdanen') in colonial Suriname and the Netherlands also became the official motherland for many of these Hindustanis. ${ }^{34}$ Nevertheless, the route to India was not totally forgotten (cf. Rajasingham-Senanayake 2003).

For instance, their religious orientation with regard to British India was maintained and Hindu as well as Muslim religious leaders from India and other regions where British Indians had settled (e.g., Trinidad and neighbouring Guyana) visited Suriname on a regular basis. Not only was their arrival intimately linked to religious fragmentation amongst Hindus and Muslims, it also affected internal cohesion amongst the Hindustanis. In the late I920s and I930s, Hindu-Muslim relations deteriorated and Suriname witnessed a period of communal antagonism, which is generally known as the Boycott (e.g., De Klerk 
I998 [I953]: I97). Suriname was spared the bitter clashes between Hindus and Muslims that took place in India, but many Hindustanis nevertheless recollect this period as a dark page in their history. Although the movement was not very widespread, did not encompass all of the members of the two religious groups, and the altercations were mainly verbal, our elderly informants still remember how, from I929 till at least I943, in a number of places, Hindus started boycotting Muslims by cutting all socio-cultural and economic links that had previously existed between the two communities. Most of our informants refer to a cow slaughter or sacrifice (kurbani) as the immediate cause of the conflicts. While Muslims had always refrained from kurba$n i$, since the late I920s relations between Hindus and Muslims had become disturbed to the extent that some people no longer cared. Like in India, here too 'holy cows' had become central symbols of the HinduMuslim conflict.

The most extensive written account of the Boycott comes from the hand of Munshi Rahman Khan, a Muslim indentured labourer with a vast knowledge of the Ramayana and other Hindu scriptures (SinhaKerkhoff, Bal and Singh (eds.) 2005). ${ }^{35}$ Rahman Khan penned his memoirs, producing a unique account of the British Indian migration story. Rahman Khan thought that the introduction of the Arya Samaj in Suriname (in 1929$)^{36}$ was responsible for the social unrest. While their initial quest for 'purification' of Hinduism caused discord between the Samajees and Sanatans, tensions between them were ultimately resolved at the expense of Hindu-Muslim relations, when Hindus united under one banner and 'rallied around the cow', but which completely alienated them from the Muslims.

While Rahman Khan's version of the Boycott is clearly favourable to the Muslim Hindustanis, other informants presented different accounts. The District Commissioner of the time for example held Muslims had not wanted to listen to him when he, one day before the slaughtering, had tried his best to persuade them to refrain from claughtering a cow. He had also pointed out that the parties should not forget that they were one race. ${ }^{37}$

In I943, more then ten years later, the Boycott officially came to an end in a meeting between Hindus, Muslims and representatives of the colonial government. Unlike in India, where Hindu-Muslim animosities have continued to impact Hindu-Muslim relations and politics, in Suriname, Hindustanis were able to restore communal harmony.

Contextualising Hindu-Muslim Antagonism in Suriname ${ }^{38}$

Considering the similarities between the communal strife in India and Suriname, it seems logical to link the happenings in the two countries and to search for explicit interlinkages. However, all of our informants 
denied such translational connections and emphasised that local factors had been responsible for the Boycott. Hence, the two very different outcomes in India and Suriname can only be understood by contextualising of the events.

During the period of indenture, a strong and common identity had developed among the labourers who had migrated from British India; an identity that united them but also set them apart from other migrant groups and the Dutch colonial rulers. As a community, the British Indians were looked down upon. Their religious views were portrayed as pagan by the dominant elites, and Christians were accorded a higher status. British-Indian traditions, languages, culture, and religions were not perceived as part of the local Surinamese society and, while in India caste and class had to a great extent been linked, in Suriname they were not institutionalised and the classification system was often altered.

It was the abandonment of the indenture system in I9I6 that led to the end of the colonial politics of segregation and to the acceleration of integration. ${ }^{39}$ And when, by 1927, the Hindustanis had officially stopped being British-Indians and became Dutch citizens ('Nederlandsche onderdanen'), they needed to invent new identities to help them to attain and maintain their legitimate place in Dutch-Suriname vis-à-vis other local migrant groups and Dutch colonial power. ${ }^{4 \circ}$ At the same time, agriculture did not provide a secure basis, because it is so labour intensive and so minimally profitable, to compete with Suriname's other citizens; plus they had no formal education, making social mobility almost impossible. 'The urge for a better social standing, to belong to the intellectual elite, to acquire possessions and social respect, formed the basis for the breakthrough in Hindustani attempts to emancipate themselves in our country' (Ramsundersingh I998: 93, translated from Dutch). In the late-I920s Suriname, education, employment, and religion (and gender) seemed the primary directives for the enhancement of the socio-economic status of Hindustanis.

This process of emancipation and becoming rooted in Suriname caused the apparent harmony within the community to begin to crumble. By the end of the I920s, relatively harmonious relations amongst Hindustanis became increasingly disturbed. For example, the differences between the 'educated' and 'uneducated' caused great schisms, and the peaceful cohabitation between the various religious groups began to erode. Some Hindus, who had previously disguised or changed their ancestors' caste identities, now claimed the respect they felt they deserved because of their high-caste status. Meanwhile, other Hindus contested the relevance of caste and felt that education should determine one's position. In this context, the so-called reformers who had come from India to the Caribbean became quite successful in their ef- 
forts to introduce new religious, socio-cultural outlooks, and lifestyles to both Hindu and Muslim Hindustanis. Some chose religion as the main source of identification and either rallied for or against the holy cows' imported from India.

In the end, however, Hindustanis united under the banner of a shared ethnic identity vis-à-vis other ethnic communities, and when in I947 the British left India, independence was celebrated, although the division of British India on religious lines was not welcomed, let alone imitated. On the contrary, people seemed rather disappointed with these developments in 'their Hindustan'. ${ }^{4 \mathrm{I}}$ Hence, peace returned in the course of the I940s, and in I949, many Hindus and Muslims formed a united political party, the VHP (United Hindustani Party) to run for office. Notwithstanding the occasional friction, distrust and inter-religious tensions, ethnic identity has proved to be stronger (and more instrumental) than religion until this very day. This is not to say that the future might not bring different (diasporic) orientations and identifications. Among Hindustanis in the Netherlands, for instance, we see how religion does seem to play a different and more significant role in the way Hindustanis construct identities and notions of belonging.

\section{Hindustani Muslims: Part of a Hindustani Diaspora}

The Indian indentured labourers left British India at a time when neither nationalist nor communal (religious) identities had yet crystallised. They left when there was still not much of a national identity or a 'common bond of unity and fellow feeling'. People generally considered themselves Bengali, Sikh, Rajput, Maratha or Hindustani, but not Indian (cf. Nag 2001: 47-54). We have contended that in Suriname most Muslim and Hindu Hindustanis, no matter how fragmented and how many conflicts they may engage in, give preference to ethnic unitiy over religious division. This, however, does not say much about Muslims' attitudes towards divided India and a newly established Pakistan. Some scholars propose that Pakistan has replaced India as the point of cultural and religious reference for the Muslim descendants of the emigrants. ${ }^{42}$

Our own research does not provide evidence that the two-nation ideology has in any simple way been incorporated in Muslim Hindustani ideas of rootedness and their sense of belonging. Today, both Ahmadiyya and Sunni religious and cultural traditions can still only be properly understood in relation to the local context, the traditions of the colonial regime in British India, the history of Islam in South Asia, and the influence of Christianity and transnational networks. In other words, the religious loyalties of these Muslims are related to various geographical spaces. They have neither merely exchanged (British) In- 
dia for Pakistan as their religious and cultural point of reference, nor have they exchanged their old ethnic identifications for a new postmodern, or 'post-Westphalian' (Sayyid: 2002) Muslim identity. At the same time, they realise that they have lost their 'Hindustan' homeland as a result of the catastrophe known as Partition. Instead, they maintain a diasporic memory of 'Hindustan' as the undivided homeland in which Muslims and Hindus mostly shared cultural and even religious traditions. For these reasons, we feel that these Muslims, along with the Hindus, should be conceptualised as part of an Indian, or rather, a Hindustani diaspora.

None of the Muslims we interviewed in Suriname had any desire 'to return to the homeland', although, during an Indian Diaspora conference in Delhi in January 2003 where one of us was present, for example, people often expressed a keen interest in their (territorially defined) roots and some of them had even (tried to) find their ancestral homes. These informants clearly did not identify with present-day India very much. One even stated that: 'Hindustanis have nothing to do with India. This is all a creation of the media'. Another noted: 'No, I am not a member of the Indian family. I am Surinamese and not proud of being part of the so-called Indian family'. The majority of Muslims do not consider present-day India or Pakistan as their homeland identifying themselves instead as Hindustani and recognising Hindustan as their 'homeland'. It is precisely because religion is seen as a symbol of identification, demarcation, and support for both Hindu and Muslim Hindustanis, that these two groups are tied together as a diaspora united in their perception of the common homeland known as Hindustan. At the same time, Muslim Hindustanis have been provided with a number of alternative 'homelands' such as Pakistan and other countries with whom they share the religious traditions that are prevalent on the Indian subcontinent ${ }^{43}$ such as Trinidad, Guyana, the United Kingdom, Mauritius and the Netherlands. These links to other nation-territories other than India should, however, not be used as an argument against inclusion of these Hindustani Muslims in the (Indian) diaspora, as their unanimity with other Hindustanis is found exactly in this belief of a common homeland. However, since Hindustan no longer has a territorial base, these Hindustani Muslims have taken it upon themselves, with the help of trans-local relations, to rebuild their homeland in the country of residence with an Islam that is firmly rooted in Hindustan. 


\section{Conclusions}

Islam is India's largest minority religion, with Muslims officially comprising I2.I percent of the country's population, or I2 8 million people as of 2004. This is more than the number of Muslims in Pakistan. Nevertheless, some find it difficult to think of these Muslims in India as 'Indians'. Similarly, when these Muslims leave the country, they are often excluded from the Indian diaspora category. One has to wonder about self-identification.

In this article, we have empirically shown that Muslims with ancestry in what is currently known as India, have identified in different ways over time and geographical location. They do not necessarily become part of the 'Indian diaspora', the 'Asian diaspora', or the 'Pakistani' or 'Muslim diaspora'. Instead, as we have shown in the case of Mauritius and Suriname, what we need is in-depth and historical case studies that explain why in certain instances Muslims of British-Indian descent feel part of a diaspora while in other cases, they do not identify themselves with a diaspora at all.

Scholars among others seem to have been influenced by two historical processes that have caused them to jump to conclusions that are not warranted when local conditions are thoroughly analysed. The break-up of British India in 1947 and the incidents that took place before and after 'September II', within and beyond various Muslim communities globally, have certainly had an impact on the discussions about the 'Indian diaspora'. We have shown that these two processes during which 'Hindus' became disconnected from 'Muslims' and 'Muslims' from 'the rest' have encouraged scholars (and also non-Muslims) to better see how 'Muslims' define themselves. Nevertheless, the processes of labelling and self-identification of Muslims of British-Indian descent did not lead to a uniform and static category of diaspora Muslims. They faced a variety of changing local and global challenges. In Suriname they long for an undivided homeland called Hindustan along with their fellow Hindus, while the Muslims of British-Indian descent in Mauritius prefer local inclusion as a separate ethnic community. Thus, we do not deny the influence of the Partition and September II on diaspora formation and the role religion has begun to play herein. However, we emphasise that this role has varied over time and space and can only be properly understood when the interaction between the transnational and national is taken into account as reflected in the localised and changing group identities of Muslims of British-Indian origin. 


\section{Notes}

I http://www.indiandiaspora.nic.in (accessed on 5 June 2007).

2 Mauritius, situated in the Indian Ocean, has been a republic since I992, and is comprised of several dependencies: Rodrigues Island, the Agalega Islands and Cargados Carajos Sholas. It also claims sovereignty over the Chagos Archipelago. However, we only focus on the main island here.

3 http://www.internetworldstats.com/africa.htm (accessed on 5 June 2007).

$4 \mathrm{http} / /$ infocountries.com/mauritius/Io.htm. Tensions between ethnic groups (in Mauritius known as 'communalism') are not absent, however, and are mainly between so-called North Indian Hindus and Christian Creoles (e.g., Carroll 2000).

5 About I7 per cent of the immigrant population who came to Mauritius under contract between 1830 and 1920 was Muslim. By I 846 , there were already approximately 7,500 Muslims working on the sugar plantations (Dinan I986: 22).

6 This section about Mauritius is based on existing scholarly work as well as on findings collected during a field trip by our research assistant, Alok Deo Singh, who visited Mauritius in September 2002 to collect archive material as well as secondary sources. He also interviewed some $40 \mathrm{Hindu}$ and Muslim Indo-Mauritians during his stay. We also carried out fieldwork in Gujarat in January 2003 among the socalled Muslim 'Maurice-walas'.

7 See also Bal and Sinha-Kerkhoff (2004) for similar approaches to the I947 partition of British India.

8 Since 1968, all of the Prime Ministers of Mauritius have been Hindus of Indian Origin: Sir Seewoosagur Ramgoolam also known as the Father of the Nation (1968I982), Sir Anerood Jugnauth (I982-I995 and 2000-2003) and Dr. Navin Ramgoolam (1995-2000). In 2003, however, Prime Minster Jugnauth transferred power to Paul Berenger, the first (non-Hindu) Franco-Mauritian Prime Minister since Mauritius' independence.

9 Both Sunni Hanafis as well as Sunni Shafis who comprised 95\% of the Mauritian Muslims (Dinan I986: 60).

Io Including the 'Cocknies', the 'Kodjas', the 'Bohras' and the 'Aga Khanites'. The latter arrived in Mauritius much later from East Africa. There were also Ahmadis who came to Mauritius in the I9Ios through Sufi Ghulam Mahammad. They soon faced opposition from the 'orthodox' Sunni Muslims and many among the latter do not recognise Ahmadis as Muslims (Dinan I986: 6I-62).

II Yet, during our fieldwork in Gujarat in 2003, we realised that many Gujarati Muslims in Mauritius still maintain ties with relatives in Gujarat and frequently travel back and forth between the two nations. The so-called 'Maurice-walas' who have settled in Gujarat even speak Creole among themselves.

I2 In 1958, the Islamic Circle religious group was established. They revived Tawheed ideology, which preached against the imams from India who had introduced Indian customs in Mauritius. They claimed that these customs had no place in Islam (Hollup I996).

I3 However, this changed during the I970s when there was a growing attraction among Muslims to the Arab (oil rich) world. Consequently, some Muslims even claimed Arab ancestry and in the 1983 Census, when for the first time informants were allowed to include their language of choice, Arabic, which had until then not been on the Census list, showed larger figures than Urdu as the ancestral language of the 'Mauritian Muslims' (Hookoomsingh 2003: I7).

I4 In an effort to discourage ethnic communalism, however, the Central Statistics Office of Mauritius, which conducts the national census, has not collected data on ethnicity since 1983 . The percentages reported by scholars seem to be based on estimates cited 
in a number of sources (see also Hollop I993; Carroll and Carroll 2000; Eriksen 2002).

I5 Our interviews with Hindu Indo-Mauritians also confirm that most 'Hindus' feel that they share neither a common cultural background with Muslims nor an 'ancestral homeland'. These Hindus identify 'India' as their ancestral homeland and they often delegate Muslims to Pakistan. When we interviewed Anand, a journalist and historian from Port Louis, he noted that 'When Amartya Sen got the Nobel prize, it was a matter of pride for us Indians in Mauritius. But one of my Muslim friends said that even had he been from Pakistan that it would have still been of great pride for us. So you can perceive the way Muslims think about India'.

I6 This article was obtained through HighBeam Research at http://www.highbeam.com

I7 http://www.islamfortoday.com/mauritius.htm.

I8 Since I948, the Government of India (GoI) has assisted in the establishment of several cultural institutions in Mauritius such as the Mahatma Gandhi Institute, the Indira Gandhi Centre for Indian Culture and the Rajiv Gandhi Science Museum. The GoI has also supported all kinds of cultural revivalist movements in Mauritius that 'promote pride in Hindi' and the cultural heritage of Hindus (cf. Dubey 2003: I32). Moreover, Hindu fundamentalist parties and organisations in India also 'assist' Hindus in Mauritius in their efforts to ensure that the 'Indian [read: Hindu] culture' is 'secure in Mauritius' (cf. Dhanilal: 2003). Several Arabic countries have helped Muslim Indo-Mauritians retain their 'Islamic heritage' and have promoted Arabic among them.

I9 There are several socio-cultural institutions in Mauritius that are supported by the state and designed to foster a sense of belonging to a cultural heritage among Muslims and some of them have indeed tried to make Muslims feel closer to Pakistan (or the Arab World).

20 That the political environment in Mauritius has changed of late, was evident during a murder trial involving Cehl Fakeer Meeah, the leader of the local chapter of the Mauritian Muslim party, Hezbullah, and three others for the 1996 murder of three rival Muslim political activists. This shocked the Hindu-Christian duopoly in Mauritian politics and revealed the anger of Muslims in Mauritius who feel that since September II the GoM has been targeting Muslims and Islam and political parties such as Hezbullah (www.Muslimmedia.com, 2002, internet edition of Crescent International, newsmagazine of the Islamic Movement, I6-31 October).

2I After the partition of I947, British Hindustani became the common designation for the so-called PIOs in Suriname (De Klerk I998 [1953]: 43-54). It should be realised, however, that what is considered 'India' on present-day maps, is quite different from pre-partition British-India. Moreover, while pre-independent India was geographically larger, it was not a single entity politically but part of the larger British Empire, while some 600 native states were quasi-independent.

22 The reasons could have been that many recruiters were Muslims and that Muslims, unlike Hindus, faced no religious sanctions when they travelled overseas. Besides, Muslims were not only over-represented in urban areas from where recruitment was easier (De Klerk I998 [I953]:II2-II3), they also faced severe hardships and a decrease in status during that period. See, for instance, Robinson (I993) for further reading on the socio-economic status decline among Muslims in the United Provinces.

23 People initially referred to Sarnami or Sarnami-Hindustani as Hindustani (not to be confused with the Hindustani spoken in India), but in 1964, Jnan Adhin successfully introduced the name Sarnami (referring to Sarnam as in Suriname), underlining the local embedding of the language. Though widely spoken among Hindustanis, Sarnami has never acquired a status similar to that of Hindi or Urdu, even though at- 
tempts to introduce these languages (especially Hindi) were never really successful (Marhé n.d.).

24 Known as 'ship brotherhood' (jahazia bhai) and 'depot brotherhood' (dipua bhai). (Gautam I995:. 3).

25 http://www.shef.ac.uk/usic/whatis/articles/carib.htm (downloaded on 2I October 2004):I-5.

26 The 35 people mentioned here were considered Muslim or Mussalman. There might have been more Muslims, such as the Pathans and the Afghans who were, however, not always categorised as Muslims by the Dutch administrators. See also http://www. nationaalarchief.nl/Suriname/base_hindo/introductie.html and "The Lalla Rookh: Arrival of the First Hindustani Muslims to Suriname”, posted on I9 May, 2002 and available at: www.Guyana.org/features/LallaRukh.pdf.

27 www.Guyana.org/features/LallaRukh.pdf.

28 Ibid. So-called Javanese Muslims from the Dutch East Indies (now Indonesia) in Suriname are kejawen, following the syncretic practices and beliefs of Java, which incorporates old Javanese beliefs, including Hindu-Buddhist elements.

29 Karsten, for example, pointed out that these Muslims were more oriented towards (British) India than towards Cairo or Mecca and quoted one of these Muslims as having said: 'We could have written to Kairo or Mekka as well but the problem is that they publish in Arabic and never in Urdu or Persian'. Besides, Urdu has also linked them to the cultural-religious traditions of the Indian subcontinent (Karsten I930: 20).

30 The Ahmadiyya movement was founded by Mirza Ghulam Ahmad in I889 as a reaction to the influence of Christian missionaries and the Hindu Arya Samaj reform movement in northern British India. After the death of Ghulam Ahmad, the movement split into two: the Quadianis and the Lahoris. Among Hindustanis we find almost only the latter. See, for instance, Landman (I992: 24 and I95-230.

3I In Pakistan, the opposition against these Ahmadis has always been very strong and in I974, it even precipitated the Non-Muslim declaration in Pakistan, which declared that the Ahmadis were non-Muslims and forbade them to perform Haj in Mecca.

32 Gouvernementsblad van Suriname (8 Augustus I927, no. 60). See also Choenni (2003).

33 The first full translation appeared in 2003 in Dutch (Hira).

34 Representatives of the Arya Samaj have been active in Suriname since I9I2. The Arya Samaj mainly wanted to reconstruct the Vedic traditions and strongly protested the contemporary social practices in India such as the practice of widow burning (sati), child marriages, the hierarchical caste system, women's oppression, idol-worship, and the social veneration of myths.

35 Report from the District Commissioner of the meeting between Hindus and Muslims in the public school in Livorno. Gouvernements-Secretaris Suriname, Immigratie en Kolonisatie, Landsarchief Suriname, no. N: 33/20.333, dated i9 April I933.

36 For this section we have used, apart from archive material found in the National Archives in Delhi, the West Bengal State Archives (Kolkata) and the Archives in Paramaribo: Grierson (I883); McNeill (I9I5); Karsten (I930); Hajary (I937: I-3); De Klerk (I942: 97-II7); De Klerk (I963); Malik (I993: 204-8); De Klerk (I998); Mitrasingh and Harpal (eds.) (I998); Orna (I999: I20-24); Nandoe (2000: 235-43); Ramdin (2000); Baumann (200I: 59-8I); Gautam (200I); Ramsoedh and Bloemberg (200I).

37 De Klerk refers to the first decade of the twentieth century as the start of Hindustani participation in civil society. In I9Io and I9II, the first two British (competing) associations, to represent the British Indians in Suriname, were founded. In I9Io: De Surinaamsche Immigranten-Vereeniging. In I9II: the Surinaamsche Britsch-Indiërs-Bond: Ikhtiyãr aur Hak. See De Klerk (I998: I73-74). 
38 Gautam writes that the implementation of the new law (1927) imposed Dutch citizenship on all newly born children and encouraged the assimilation of Indians in Suriname (Gautam I995: 15).

39 For example, in July I947, a group of young Hindustani intellectuals wrote in their monthly newsletter Vikaash the following about India's independence and subsequent Partition: 'The moment has arrived... Freedom that has taken many years of furious fighting has finally been regained. It has already been determined that the remaining I5,000 British troops will have left Hindustan by I5 August. Energetic men who have given everything for the good cause can now look back on what they have reached for Hindustan. But alas! It could not be what they would have wanted so much: their ideal of a United Hindustan has been destroyed, their hope has gone up in smoke... Yet! There is hope for the future! Especially the circumstance that Hindus and Muslims are not strictly separated gives reason for hope. One expects that both states will co-operate intimately, as they share so many interests' ('Liga van Hindostani's', Vikaash (Evolutie), vol. I2, no. 2, I4 July I947. Translated from Dutch).

40 Van der Burg and Van der Veer, for example, wrote that: 'The distance between Muslims and Hindus that existed in India was brought to Suriname by the contract labourers and now exists in the Netherlands as well. Inter-religious marriages are rare and participation in each other's ceremonies is limited. (..) From that moment [of the Partition] on, two cultural points of reference have existed: India for the Hindus and Pakistan for the Muslims' (I986: 23-36). Similarly, Vernooy and Van der Burg refer to a 1955 Surinamese almanac in which the flag of Pakistan (green and white) is called the official flag of the orthodox Muslim Organization, the Ahle Sunnat Wal Jamaat-Hanafi (SMA) and that these Muslims are oriented towards Pakistan. This SMA, which was founded in 1932, is still one of the largest Hindustani Sunni organisations (Vernooy and Van der Burg 1986: 47; Van der Burg and Van der Veer I986: 23-36).

4I These trans-local links that help retain and rebuild cultural and religious beliefs and practices from the homeland are not new. The Ahmadiyya link between British Guyana, Suriname, and Trinidad was already established in July-August 1934, by Moulvi Ameer Ali. Furthermore, the Ahmaddiya movement tended to maintain strong links with its centre, Lahore (now in Pakistan). See Kassim (1999: 156-I85). Kassim also refers to 'an Inter-Colonial Muslim Conference' in August 1950, during which delegates from Barbados, British Guyana, Dutch Guyana (Suriname)and the host territory, Trinidad, met to consider the educational, social, economic, moral, and religious problems of Muslims in the Caribbean, with the aim of establishing 'a closer relationship and forging co-operation among the Muslim community of those territories through a regional Muslim organisation' (Ibid.: I77). 

PART 2

CRITICAL SOCIOLOGICAL AND ANTHROPOLOGICAL PERSPECTIVES 



\title{
6 A Chance Diaspora
}

\author{
British Gujarati Hindus
}

\author{
John Mattausch
}

\section{Introduction}

In a recently published article, the editor of this collection, Gijsbert Oonk (2006), persuasively argued that there has been an unfortunate tendency of sociologists, economists, and anthropologists to ignore South Asian entrepreneurial failures in East Africa, to concentrate only upon the successful, and then to infer from these successes commonly held qualities such as 'hard work' or superior business acumen that are meant to explain the achievements of the South Asians and the comparative poor performance of the Africans. Contesting this unfortunate analytical orthodoxy, Oonk argues that we need to understand the success of South Asians, many of whom were Gujaratis, 'from a historical point of view', that the early South Asian migrants 'started with a far more favourable socio-economic position than their African counterparts', and that we should recognise not all South Asians were successful, the less successful and the failed returning to India. That the South Asian migrants started from a 'far more favourable socio-economic position', that they, unlike the vast majority of Africans, 'were accustomed to a money economy and the concept of interest', that many of them could read and write, was simply down to their good fortune, to coincidence, the coincidence of economic opportunities becoming open to South Asians pre-favoured with socio-economic capital. This is but one example of how chance has knitted the pattern for four centuries of British-Gujarati history, a history spanning three continents.

From the outset, when the East India Company's ship The Hector dropped anchor at Swally Hole in August I608, this mutual history has been periodically swept up by the currents of chance, which carried some Gujaratis along trade routes re-paved with colonialism to Africa and then to Britain where they have now, in a remarkably short period, built a notably prosperous, culturally strong community that exhibits many of the chief features that are currently fashionable when labelling 
a 'diasporic' social group. In this article, I try to extend the hand of friendship to what the French sociologist, Professor Boudon (I986: I73) has called the 'very unwelcome guest, ubiquitous but studiously concealed, ignored and even denied the right to exist by virtually everyone', an analytical welcome to chance as it has been manifested in contingency, coincidence, and character. I begin by surveying the progress of British Gujarati Hindus, highlighting the diversity of their achievements and their parallel development as both successful capitalistic citizens and as members of the international Hindu community. I then suggest that these 'twin trajectories' are partly chance outcomes and that understanding this uncharacteristic British 'ethnic' community requires us to welcome chance back into the analytical fold. This analytical tack is not taken at the expense of recognising the salience of structural features of capitalist development, nor is it forgetful of those features of the British Gujarati Hindu community that have helped or hindered their socio-economic progress: these structural considerations, which I will consider in this article, are of indubitable significance and have been routinely flagged up in the research literature. Instead, my chief concern in this article is to bring to the fore the chancy elements in our mutual history that have been routinely overlooked but which, as I will try to show, cannot and should not be simply swept under the analytical carpet.

\section{Dharma ane Dandho - Duty and Work}

If it would be right to label something as 'gratuitously symbolic', then Britain's first public Sanatan Sandesh (ecumenical) Hindu mandir (temple) in Leicester would surely qualify. Founded in 1970, before the arrival of the expelees from Uganda, the mandir caters primarily to the British East Midlands city's Gujarati Hindu community and, in common with many another British mandir, is housed in a large, Victorian former Christian church: just as they revived Leicester's inner-city economy, so too have the migrants and refugees breathed new life back into her deserted places of worship. Serving as a community centre as well as a religious mandir, offering classes of religious instruction for the city's Hindu children, support for the elderly and various other social services, it is a thriving resource for Hindus throughout the U.K., as well as for Leicester's own, overwhelmingly Gujarati, Hindu population. At Divali time, businessmen and shopkeepers attend to have their yearly accounts blessed by Lakshmi, some of whom will have placed an advertisement in the mandir's glossy Divali commemorative magazine. Turn to the back of the magazine and you find a handy 'List of Advertisers', a list paying tribute to the now well-recognised commercial achievements of this small British 'ethnic' group which, in just three decades, sometimes in the face of hostility, racism, as well as, for some, 
the trauma of expulsion from Uganda, now stands on an equal footing with the wider community, and in some cases and in some areas, has overtaken it.

What, I think, is striking about this list of advertisers, an oft-overlooked feature of the public face of British Gujaratis, is the wide variety of businesses offering the magazine's readers their Divali greetings. In addition to the more specialised shops selling Gujarati vegetarian foods, clothes, jewellery, wedding paraphernalia, and the cliched CTNs (Confectioner-Tobacconist-Newsagent), there are also travel agents, driving instructors, immigration consultants, camera shops, furniture stores, tailors, carpet shops, accountants, pharmacists, opticians, vacuum cleaner salesmen, car showrooms, florists, etc. - and this list of advertisers is by no means fully representative. In the arts, in politics, in the professions, Gujaratis are also to be found, often prominently. From their restricted class location in East Africa, confined to what Mahmood Mamdani had argued (I976: 108) was a narrow 'commercial bourgeois' niche, the African emigrants, refugees, the British-born generations and those arriving directly from India have in a short time occupied a huge diversity of largely middle-class or self-employed positions in modern Britain along with a wide spread of working-class jobs.

Whatever else we can and cannot say with confidence about them, we can at least be certain that the religious traditions of Gujarati Hindus have not impeded their progress and that Hinduism has proved highly adaptable. A telling example of this adaptability came in the political stance taken by Asian women workers during the industrial disputes of the I970s, at Thorn Lighting, Walkers and other Leicester factories, and most famously at the London Grunwick photo-processing plant when Mrs. Jayabhen Desai became the spokeswoman for the predominantly East African Asian female workforce resisting the Company's racist discrimination, Dickensian work practices and exploitative rates of pay (at that time the lowest in the industry, $£_{2} 8$ per week compared to the national average of $£ 72$ ). As Avtar Brah argued (1987), the simplistic stereotype of docile, submissive Asian women hidebound by traditional Hindu patriarchy needed to be scrapped. Today, while British Asian women do not figure strongly in the annual British 'Asian Rich List' (of which, in 2005, some ı०\% have an African background), nonetheless there are a small number of businesses headed by Gujarati women, ${ }^{\text {I }}$ and they too have gained impressive educational qualifications with the diversity of their achievements mirroring that of their menfolk. ${ }^{2}$ This diversity, the rapid successes, have come from a numerically and proportionately small community. Britain's total Hindu population, according to responses to the self-declared 'religious question' in the 200I Census, numbers some 559,000 of whom 4I,248 live 
in Leicester, the English city with the highest proportion of 'ethnic minorities', with Hindus, not all of whom are Gujarati, comprising I $4.7 \%$ of Leicester's total population. ${ }^{3}$ Only $37 \%$ of British Hindus were born in Britain, 39\% in Asia (30\% in India, 6\% in Sri Lanka), 21\% in Africa. A further feature of British Hinduism, not usually noted by commentators or researchers, is its overwhelmingly upper-caste composition; a feature distinguishing it from the Indian patterning of caste groupings, a social composition that obscures the corollary of ascribed disadvantage suffered by over 9.2 million Scheduled Castes and Tribes in present-day Gujarat (Das 2000: 2). This, then is a comparatively small British community dispersed throughout the country, most of whom were not born in the UK: Leicester's Hindus are the country's third highest demographic concentration but nonetheless numerically, at just over 40,000, still not a large group. If we follow Steven Vertovec's (I996: 78) proportionate national estimates of Britain's Hindus, then some $70 \%$ are Gujarati, just 391,300, of whom some 246,519 may be classified as 'East African Asian' or 'African Asian', the latter nomenclature used in the much-cited 4th PSI Survey. This reworked PSI classification is something of a catch-all category:

Those who said that their families had originated in the South Asian subcontinent were also asked whether their parents of grandparents had lived in Africa for any length of time, or whether they themselves had been born there (Madoodi997: 15).

Respondents to the survey located in this broad category could for example include a person born in Britain with grandparents who had lived for a couple of years in Malawi in the I950s, someone born in Uganda in the I920s forced to flee Amin's ogreish polity, or a woman who had migrated from Bombay to Kenya to join her new husband's family only to find that because of the worsening position of Asian teachers in Nairobi in the mid-I96os they were soon to leave for England. Similarly, it is not clear what is meant by 'Gujarati' given that some British Gujaratis may not hold Indian citizenship, may never have visited the State, may not be fluent or even speak the language, nor know little of the State's history. For Gujarati Hindus, however, the ascribed character of their religion does give them a traceable lineage and the foundation for Gujarati self-identification - a point which I will expand upon later.

How are we to explain and gauge the rapid, diverse successes of Britain's small Gujarati Hindu community? A key obstacle to answering these questions is the absence of longitudinal research, a common failing of British social science, highlighted by Vaughan Robinson (I990 \& I993), and to which Valerie Marrett's study (I989 and I993) of 68 
Ugandan Asian refugee families, some 200 individuals who settled in Leicester, interviewed throughout I972-82, stands as a rare exception. Despite the city's notorious efforts to dissuade the refugees from settling in the city, spearheaded by the local paper The Leicester Mercury (a campaign critically scrutinised by Marrett), the Ugandan Asians have thrived, a tribute, in Marrett's judgement, to 'The outstanding characteristic of the Ugandan Asians' since settling in the unwelcoming city, their 'striving toward self-determination: the right to choose a life style unrestricted by formal barriers to progress.' (I993: 267) This striving has been a family affair. Marrett outlines the main commercial trajectories, the diverse occupational and business routes taken by the refugee families but, nonetheless, exactly how much of their progress is by way of re-establishing previous African successes and patterns, and how much has been innovative, is difficult to judge in the absence of detailed longitudinal research data stretching back to their positions in Africa. Marrett notes (I993: 25I) that:

The majority of the Ugandan Asians who came to Leicester were previously in some form of commercial enterprise. Not all were shopkeepers and there was a sizeable representation of civil servants, bank employees, teachers, accountants and blue-collar employees, particularly mechanics and craftsmen.

Unfortunately, however, it is not possible to say with any precision just what proportion of the city's refugees re-established businesses, how many innovated, or how those who innovated fared compared to those who re-established - and, of course, not all of the refugees were Hindus, not all were Gujaratis, and those having this background also came from other African countries.

Vaughan Robinson's own, retrospective analysis of national data illustrated 'East African Asians' 'marching', in Vaughan's words, into the middle class in the I970s and I980s, although given the speed of their advancement, perhaps 'galloping' would be more accurate. In his earlier study, Robinson had:

... argued that because of their backgrounds, their previous social position in East Africa, the absence of a myth of return, and their experience of having been refugees, the East African Asians in Britain would be far less encapsulated within their culture and community than their sub-continental counterparts (I993: 236).

In this earlier study (1986) Robinson had reasoned that their willingness to compete 'with whites for scarce resources' would make them 
more aware of 'racist exclusionary barriers' and would emphasise for them that, despite their economic achievements, they 'would still remain socially marginal to white society' (1993: 236). While the East African Asians' economic advancement that Robinson traced in the Seventies and Eighties has continued, his hypotheses over racism and social marginality now seem less plausible. As East African Asians reskilled, re-qualified, as their children went to make their ways in Thatcher's, then Blair's, Britain, some may well have become sensitive to 'racist exclusionary barriers', but there is no evidence I know of that they found these barriers uniformly high or indeed uniform, nor that they attributed racism to the whole of 'white' society. By the I99os, such explanations, which identified racism as the chief cause of discrimination and disadvantage, were being supplanted by an emphasis upon the interplay of 'opportunity structures' and ethnic cultures. In the opinion of Modood, Virdee and Metcalf (1995: 128):

While this is a theoretical advance, it does not take the idea of 'interaction' far enough. It still assumes that 'opportunity structures' can be culturally neutral and can be defined independently of ethnic group norms and attitudes - an assumption challenged by our study.

If we focus upon one key aspect of British Asian economic prowess, ${ }^{4}$ on self-employment, then the findings of Modood, Metcalf, and Virdee's study (I995), which included an inter-ethnic comparison of selfemployed British Asians, showed that while British Pakistanis were drawn to self-employment to escape 'from poor employment prospects and racism in the labour market', this was much less the case for 'African Asians', the majority of whom were motivated to pursue self-employment by the 'business orientation' also shared by the 'Indians' in the study's sample. All three ethnic groups associated self-employment with prestige, but not all three groups enjoyed the same advantages when they started off in business. Just as Oonk noted that Gujaratis moving to Africa had been favoured, by chance, with the capital and skills that gave them an advantage over the Africans, so too 'African Asians' ${ }^{\text {'5 }}$ were better placed to succeed in Britain, having often arrived as intact families with business experience, with no cultural proscription against their women working, and with variable but far better educational levels. ${ }^{6}$ That British Pakistanis and 'African Asians' were in markedly different positions when they arrived in Britain and when they began to set-up businesses this was due to simple coincidence, to chance. The arrival of single Pakistani men with limited labour-market skills and education who went to work in the textile mills of northern England and in the factories of the West Midlands would not necessa- 
rily have led down the road to their community's current socio-economic woes. If Britain's textile factories, along with her other manufacturing industries, had not gone into steep decline just a few years after Pakistani men first clocked-on then these features of their community may have counted for little, but of course as it actually turned out, chance coincidence assured their lasting salience. It is not sufficient, as Modood et al., argued merely to consider the interaction of culture and 'opportunity structures'; chance too must be included for just as Modood et al. argued that 'opportunity structures' are not immune from cultural influence, so too they are not immune from the influence of chance.

One further omission in the research might be worth mentioning: there is no sustained treatment, barely a mention, of the kindness and help given by some white Britishers to the migrants from Kenya and Tanzania, and more acutely to the refugees from Uganda. Most usually, such support is referenced to the family of migrants/refugees already living in this country before the new arrivals came or to the wider British South Asian community. It may be worth recalling the 'unremembered acts' by members of other British 'ethnic communities', some tangible, for example, the voluntary workers who manned the Uganda Resettlement Boards' stalls. The less tangible but perhaps equally important shows of political sympathy and decency, for instance, Edward Heath's expulsion of Enoch Powell from the Conservative Party (Humphrey and Ward I974: 35), and many other unrecorded instances, such as the remarkable Englishwoman, Lenore Reynell, who responded to the Uganda Asian Crisis by learning, on her own initiative and at her own expense, Gujarati to a level of proficiency whereby she was able to record audio tapes for blind Gujaratis, give Gujarati children lessons in reading and writing their parents' mother-tongue, could translate into English Bhanubhen Kotecha's autobiography, On The Threshold Of Afri$c a$ and give 'unstinting help' with the translation and preparation of the manuscript for Balwant Naik's autobiographical novel Passage From Uganda. Academics, more used to investigating racism and disadvantage, caught on the hop by an uncharacteristic 'ethnic' immigrant community that succeeded rapidly, neglected to record these moments of help and support and the positive effects they may have wrought. Just as the adaptations made by Gujarati migrants have been diverse, so too the responses of Britishers to the new arrivals were varied; in 1972 when the Uganda Asian refugees arrived, a year in which much else of note also occurred, it is probable that most Britishers were simply indifferent, with only a tiny minority responding with either racist hostility or sympathetic kindness.

In so many ways, the progress of Gujarati Hindus in Britain mirrors their history in the African countries. As I and others have noted (Mat- 
tausch 1998: 123; Twaddle I990: I5I), the Africa to which Gujaratis migrated was largely novel, new artificial countries recently forged by colonialism, with new commercial opportunities that the migrants successfully exploited, as had some of their forefathers back in Mughal Gujarat. They may, as Tambs-Lyche argued (1975) have been spurred on by a 'trading ethic', but there was no long-standing caste tradition informing the migrants' commercial enterprises: neither Lohanas nor Patidars (the two chief castes) had any history as shopkeepers, ginnery owners, civil servants, etc., any more than they had a tradition of working as doctors, dentists, engineers or accountants, the so-named 'Dead Society', the professional occupations favoured by younger British $\mathrm{Gu}$ jaratis. In Britain, as in Africa, they succeeded commercially by adapting to novel circumstances in diverse ways, evident, for example, in the variety of Gujarati shops on Leicester's Melton and Belgrave Roads, a wider variety than that found on other British Asian shopping streets (Hardhill I999: 9). In both of these very different, largely novel settings, the migrants not only succeeded in the secular, commercial field; they were also equally successful in sustaining a religious identity. Whereas the commercial successes were often innovative, and highly diverse, in the religious sphere they were imitative and traditional, albeit with slight variances brought on by the exigencies of migration, for example the absence of Brahmins and the importation of sampradya (guru-led sects) to Africa and then Britain. Which brings us to a key feature of the internationalisation, the international expansion, of Gujarati Hinduism as it emerged first in Africa and then in Britain, a curious two-piece outfit, a vibrant diverse innovative adaptation to imperialistic, now contemporary capitalism, and then a return to a noncapitalistic Hinduistic domestic way of life, after work. Both dharma, religious duty, and dandho, work. It has been customary to examine the 'religious' side to this duality with reference to ideas, values, feelings and beliefs, or to its institutional establishment. But in this article I would like, instead, to examine this twin trajectory in terms of sociological mechanisms of inheritance, how Gujarati Hindus sustain both their secular capitalistic and religious identities. Cultural patterns, including innovations, count for nothing if they are not passed on; they have, in Steven Vertovec's phrase, to be reproduced.7 In both secular and religious dimensions of reproduction, marriage is central.

Every Saturday and Sunday, the latter popular with shopkeepers, seemingly without fail, the hall in Leicester's Sanatan Sandesh mandir is booked for a wedding. In the hundreds of sister British mandira, as well as in all sorts of other suitably large venues, British Hindu weddings are celebrated. These weddings are overwhelmingly between individuals from the same 'ethnic' group, as are nearly all British marriages (98\%). Data from the 200 I U.K. Census showed that of the pal- 
try $2 \%$ of inter-ethnic marriages, 2 I9, 000 , then nearly all of them, I98,000, included a 'white' person, and that people from South Asian backgrounds were the least likely to be married to someone from a different ethnic group. Only $6 \%$ of British Indians, a category that includes Sikhs as well as Hindus, had married outside of their own 'ethnic' group. ${ }^{8}$ For Hindus, marriages are inter-caste, rather than 'interethnic' unions. Unfortunately, the topic of British Asian weddings has pushed issues of 'arranged marriage' to the foreground and it was concerns over the second generation, 'between-two-cultures', that have predominated with most research focusing upon young Asian women at the expense of the men's experiences (a gender bias found in other areas of research on British South Asians as well). 'Arranged marriages' is often nowadays seen as an item drawn from an outdated academic stereotype, or a rather old-fashioned non-progressive practice, but there is no gainsaying the importance of marriage in today's British Gujarati Hindu community, nor for that matter the centrality of marriage and the preoccupation with nubile women in major Hindu texts. 9 These marriages are presented by some as a means of maintaining 'ethnic boundaries', and in the case of Britain's Hindus they serve to sub-divide this small community into discrete family networks. Whether or not the incidence of British Hindu arranged marriages if rising or falling is not known, but attitudinal findings from the 4th PSI Survey suggests that British African Asians' attitudes toward 'mixed marriages' are no different from those held by the wider community and that, as the generations grow, fewer and fewer are having their spouses chosen by their parents. However, in terms of their self-reported attitudes, the $4^{\text {th }}$ PSI Survey actually shows that those whom they classified as 'African Asian' held views and opinions virtually indistinguishable from the rest of population, and certainly not sufficiently discrete to distinguish them as a separate 'ethnic' group (Mattausch 2000). Moreover, what people say and do are often, as Nina Hutnik (I99I) revealed, very different. African Asians were decrying arranged marriages in the I950s (Bharati I970:49), and, in any case, what is sociologically interesting about Hindu marriages is not the anthropological minutiae of how they are arranged, but rather who they are arranged between, how caste is perpetuated in modern British capitalistic society, how genes and property are passed on, how a caste identity is bequeathed by parents to their children.

Although Leicester's Sanatan Sandesh mandir may lay claim to being the first proper public ecumenical British Hindu temple, there are rivals for the title of the UK's first ever mandir, including one founded in London in 1962; other early examples include the mandir founded by Kenyan Asians in Coventry in I967 (Tambs-Lyche I975), and the Sai Baba mandir founded in a private home in Golders Green, London in 
I969, still maintained by the same family, and in any case, every Hin$\mathrm{du}$ home has its own domestic shrine, maintained by the women of the family. The hundreds of public mandira built in Britain in the last thirty years are tangible tokens of permanent settlement ${ }^{\mathrm{IO}}$ reflecting the wide, caste-steered, diversity of British Hinduism, predominantly Gujarati and bearing the imprint of the African chapter. In Africa, Gujarati Hindus adopted the sampradaya which now enjoy strong support in this country with their own dedicated mandira as outposts in the internationalisation of Hinduism. Marriage is within this internationalised community. One reason for the popularity of sampradaya in Africa was the simple absence of Brahmin priests, part of a larger problem caused by the selective migration patterns with the two Lohana and Patidar castes predominating, thus not allowing authentic caste patterns to be reproduced under African skies. As Steven Vertovec notes (2000: 92), in East Africa:

... a caste system could no longer govern social, economic, ritual or other relationships, caste identities among Gujaratis have continued to be of considerable importance with regard to status, marriage, social networks and formal institutions.

It is this newly internationalised caste identity that is being reproduced in British Hindu marriages, an identity which may, via the factious Swaminarayan sampradayek, include poisonous Hinduvta elements as rivalries, hatreds and fanaticisms originating in the sub-continent. These are spread amongst the world-wide community (Dwyer I994: I85-I86; Mukta 2000) - a disturbing aspect of British 'ethnic' identity also infecting other British South Asian communities. ${ }^{\text {II }}$

In order for Gujarati Hinduism to persist, to have been successfully sustained in Africa and now in Britain, inessential practices, rituals, and the like have been pragmatically abandoned in the light of changing circumstances, a shedding of inessential features illustrated by Gijsbert Oonk's study of Lohanas in East Africa (2004). Prohibitions against meat eating, smoking, drinking alcohol, cultural prescriptions over the roles of women, joint family set-ups (Morris I970) and other inessential customs and traditions, can all be sloughed off. Criteria of spouse eligibility can be changed (Michaelson I979; Oonk 2004), young British Gujaratis can ignore their parents' choices of spouse, but nonetheless caste marriages, the mechanism of Hindu reproduction, must be continued. Very soon after the topic of arranged marriages had attracted attention from British social scientists there was a critical backlash against the emerging 'between-two-cultures' stereotype and in this discursive context Catherine Ballard tried to 'seek some kind of order in the reality of [South Asian] marriage'. Her I978 paper, in addi- 
tion to reminding us that 'arranged marriages' were not just an Indian speciality, also explained the underlying rationale behind the traditional Indian model, 'the inheritance of land, property, and ascribed occupational status' achieved through the rules of exogamy and endogamy, rules as they apply to the chief British Gujarati castes elaborated by Michaelson (I979) and myself (I993). Leaving aside the cultural niceties, Hindu caste marriages are the means for distributing genes and property to future generations, with men staying put and inheriting property and women leaving their natal village to spread their genes. ${ }^{12}$ This is the mechanism for reproducing babies with a ready-made ascribed Hindu identity and property rights. The authority for the proper conduct of marriages and weddings is not merely religious, it is sited geographically back in India: to my knowledge, the Gujarati migrations have not spawned any religious leaders or new sects and all religious authority flows from India to the international caste communities, placing those in Britain and elsewhere outside India, on an inferior footing. Furthermore, the endogamous criteria of some British caste marriages ties Hindus to their ancestral villages back in India, geographical identities written in religious fiction as each village's unique kuldevi.

Although Hindus have been living in Britain for some four centuries (Visram 2002), it has only been in the last thirty or forty years that they have settled in any number and could as a community adapt Hinduism to the British context. It is thus too soon, I feel, to discern many real long-lasting trends or to make sweeping generalisations, especially in view of the troubled passage from Africa, and the fact that currently most British Hindus were not born in the UK (while British-born Hindus overwhelmingly describe themselves as 'British', 91\%, this figure falls to $69 \%$ for the community as a whole). ${ }^{13}$ One trend that is discernible is the, as I have noted in this article, twin trajectory of contemporary British Gujarati Hindu social life: on the one hand, the public, innovative, highly varied, strikingly successful, capitalistic achievements; on the other hand and simultaneously, the less public, traditionally orientated non-innovative, equally impressive establishment of the British branch of international Hinduism. It is these twin parallel trajectories that I want to concentrate upon in the remainder of this article. I wish to suggest that these twin trajectories arose in historical circumstances that were sometimes chance outcomes and that the diversity of public Gujarati Hindu practices signals the influence of chance-given individual characters.

Part of the reason for the continuing superior authority of Indian Hindu religious practices and spokesmen rests with the nature of authority in Hinduism. Lacking the proper authority, Gujarati settlers in Britain are in a poor position to diverge or innovate. Traditional authority in Hinduism came from a time when Indian authors were a 
rarity, largely because books were scarce and most people illiterate. Even today, the effective literacy rate for the State of Gujarat is only $69 \%$ (revised 200I Indian Census) with wide differences between the figures for men and women, urbanites and villagers, and with Scheduled Castes and Tribes lagging far behind the State average. In the recent past, nearly all Indians were illiterate, the I90 Census for (undivided) India gives a dismally low 5.4\% (crude) literacy rate whereas in comparison, already by the seventeenth century a measure of literacy was enjoyed by some $30 \%$ of the English population. The chief reason for these long-standing comparative differences is the slow adoption of the modern movable-type printing press in India; whereas Britain and the rest of Europe had presses sited in most major cities fifty years after Gutenberg's pioneering experiment, the first Indian-owned presses in Gujarat were only established in the early nineteenth century. In I996, I published an article examining the reasons behind the sluggish adoption of printing technology by Gujaratis and its social implications. I had reasoned that, although all the technical, material and craft prerequisites were present in Gujarat, the socio-religious milieu was unfavourable. Consequently, the caste patterning of literacy, the near universal illiteracy, and the high status of the elites' languages persisted for centuries longer than they had in Europe where literacy rapidly grew, vernacular languages displaced Latin and the authority of religious elites declined thanks to the millions of printed texts in circulation (some 20,000,000 by I500). Further, the press promoted English nationalism, along the lines of Benedikt Anderson's 'imagined communities', it promoted democracy and it preserved new, innovative knowledge. Moreover, as Gopal has noted (1969: 53), in Gujarat, illiterate craftsmen, confined to a lowly caste status, were obliged to rely upon inherited and acquired skills which they jealously guarded, they were unable to read about new techniques, and knowledge was routinely squandered rather than preserved. There had been one recorded attempt to establish a printing press in seventeenth-century Mughal Gujarat by the wealthy, enterprising Bhimjee Parekh, but his efforts were dogged by ill luck. Parekh requested a competent caster of metal type (the only technically demanding element of the modern press), be sent at his expense by the East India Company from England, but when the man arrived he was found to be incompetent and conditions in Gujarat were worsening as Maratha raiders were ransacking and besieging Surat. There were no further recorded attempts to establish a press in Gujarat, and given the turmoil attendant upon the collapse of Mughal rule this is not so surprising.

Since publishing this 1996 article, I have come to reconsider the reasons I gave for the Gujaratis' slow adoption of the press and I would now place greater emphasis upon purely chance factors. As is well re- 
cognised, the technical achievements of Gutenberg were modest, easily copied, as evidenced by the rapid adoption of the technology throughout Western Europe. Bhimjee Parekh was just unlucky. That Mr. Hill, the printer sent from England, was so unsatisfactory was just down to chance, as was the coincidental timing of Parekh's efforts with the decline of Surat. If Parekh had been dealt a better hand by chance, then perhaps the press would have spread as rapidly throughout Gujarat as it had in Europe. If this had happened, then oral authority might well have given way to the new textual authority that triumphed in England thanks to the autonomous authority of textual knowledge that could be corrected, printed in authoritative editions, and which existed autonomously and outlived it authors. In Gujarat, in contrast, authority remained personal, vested by tradition in individuals, in particular, held by male Brahmins and other minority elite castes. Perhaps too, Hindus would, like seventeenth-century Englishmen, have been able to interpret, question and challenge religious texts without relying upon literate Brahmins and then, rather than the reformist sects that emerged in nineteenth-century India, there would instead have been the growth of secular alternatives to religious philosophy. But, thanks to the 'bludgeonings of chance', none of these changes occurred, personal authority wrapped in religion persisted, and still today when British Gujarati Hindus need guidance over how they should worship and conduct themselves, they are obliged to seek answers from personal authorities back in India. Predictably, this unlucky outcome has meant that Hinduism is a moribund religious culture with tradition, the unchanging Dharma, holding sway (hence, the standard reply to inquisitive outsiders, "Because that's how we've always done it"). Furthermore, the perpetuation of personal authority may account for a feature of sampradaya: heterodoxical Hindu movements demand a guru with appropriate personal authority to lead them.

Printing technology is just one, albeit striking, example of the huge technological advantages enjoyed by the British that, by the time they rose to paramountcy in Gujarat, had become a technological chasm. Clearly, the lack of gutsy rivers in Gujarat pre-empted factories powered by water wheels, the English predecessor to steam power; steam engines were the next key technological step that had to be taken to retain a competitive edge. Steam engines, the force that powered the industrial revolution, had to be imported by Indians, by, for example, Gujarati mill-owners living on Bombay in the nineteenth century, some 50 years after Gujarat had been subsumed by the Bombay Presidency. Similarly, steam trains, along with thousands of miles of rail and other infrastructure, had to be shipped over, like giant children's construction sets, with obvious commercial benefits for the British. Although it is far more technically difficult to build and copy than printing presses, 
steam engine technology often advanced in incremental steps spurred by contingent needs, first from the need to ventilate and keep dry the increasingly deep shafts sunk to mine coal or tin in England (Newcomen's Engine), through improved stationary engines (Watts'), followed by the development of engines to power trains, ships, and turbines. That these contingent needs were felt in England, rather than in Gujarat, was simply down to chance. So too was the uneven geographical distribution of indigo, opium, cotton, pepper and the like which lured Europeans to India, rather than vice versa, as well as the lack of reliable rivers in Gujarat which could have been dammed to drive waterwheels (Mattausch 2003).

The distributions of plants, spices, and other resources, are examples of contingency, of chance, as too is the instance of Bhimjee's ill-luck in paying for the unsatisfactory printer Mr. Hill to be sent from England, and the coincidental intensification of Maratha raids on Surat which stymied speculative ventures such as establishing newfangled printing presses. Coincidental chance also played a hand in promoting migration from Gujarat to East Africa, in both the reasons for migration and in the selection of which groups migrated. Plagues and famines besetting Gujarat from I896 until I9II, the champianno, bringing cholera, dysentery, mass starvation, and other horrors were the chance impetuses encouraging young men to migrate from one British colonial territory, Gujarat, to another, East Africa, where the wholly coincidental growth of trade and the opening up of the hinterlands by the railway offered some hope of betterment (Mattausch 2003: I27). One caste well-placed to exploit this chance opportunity was the Patel, the Lewa Patidar, a prosperous, ambitious, upwardly mobile community. Owning enviably fertile land under the eponymous patidari lineage system brought the wealth necessary to fund migration, while the practice of dividing land equally between sons weakened the position of families over time while giving a further spur to the migration of younger heirs. The Patels' system of land inheritance also promoted hypergamous marriages, female infanticide, and the formation of hierarchical marriage circles, gols, (Mattausch 2001: 62-64) that are nowadays studiously maintained in Britain and throughout this international caste community which is known for its highly competitive intra-caste, status-conscious character. When the early migrants became established in East Africa they brought brides over from their gols, and more Patel men also migrated through 'permit lagna' marriages, marriages arranged with suitable daughters of Africawala families which allowed the boys to obtain travel permits (Patel and Rutten I999/2000: 7).

Chance needs no passport and it accompanied the migrants and refugees to Britain. The stagnant, declining British economy of the I970 coincidentally favoured the ambitions of Leicester's Ugandan 
Asian refugees. Facing a need for homes large enough to accommodate their intact families, facing hostile, sometimes racist, landlords, and a lack of suitable council housing, the refugees initially moved in with relatives, often in the Highfields area, and then very quickly bought into the then booming Leicester housing market, buying homes in the run-down, hence cheaper Belgrave area of the city (Marrett I989). Enterprising, Marett's 'self-determining', Patels found disused industrial premises standing empty, a useful opportunity offered by the coincidental decline of traditional city companies and the general economic slow-down, just as they also found abandoned churches suitable for their mandira. Similarly, in the I970s British small shopkeepers, struggling to keep going in the gloomy economic climate, meeting new competition from supermarkets, were willing to sell their businesses, their CTNs, their post offices, to enterprising Patels - another coincidental stroke of good fortune exploited with astonishing vigour to the point where by the I990s, 67\% of London's CTNs were owned by British Asians, especially Patels (Lyons and West I995).

Neither Hinduism nor social science recognises chance: these few examples of coincidence and contingency that have had a role in the history of British Gujaratis are, I hope, sufficient to convince sceptics that chance is not an ignorable, nor an insignificant factor. If we do not give chance its due then we may end up explaining outcomes in terms of mysterious deities or equally mythical entities such as 'national character', the latter an explanatory candidate favoured by Raj historians. There was, of course, no such thing as a, biological, 'British character' turning the map pink; but there is, I believe, such a thing as an individual's character, which is inherited. By 'character' I simply mean the inherited differences of degree marking each person as a unique individual, in the Wittgensteinian sense as partly similar and partly different from other people. A person's character is partly a chance inheritance which, as evolutionary psychologists are keen to emphasise, helps explain why you and your sibling, though both of you share the same parentage, are nonetheless discrete individuals. Sympathetic to Schopenhauer, ${ }^{\mathrm{I} 4}$ I consider character to be what you are, and thus not a possible cause of behaviour, precluding any notion of determinism (you cannot sensibly be said to determine yourself). Characteristics flavour how we do things, but they are not a cause or motive. Analogously, characteristics are like the phenotypic expression of a person's inherited genotype which gives them a certain height. Obviously, we are all of a certain height, we can only know our own height by comparison with other people's, what will most influence our adult height is the environment in which we grow, but our potential height, and the rates at which we grow are genetically inherited (your brother, fed the same food, will not grow at the same rate, nor 
end up as tall or short as you). Examples of characteristics include your sense of humour, tastes in music, patience, vanity - all existing on a range, just like a continuum of stature with most of us clustering around the arithmetic mean average. Whether or not we come to recognise our own character, whether a characteristic is exercised, may be down to chance; for example, being a gifted storyteller may be far more appreciated if you happened to have been born into an oral culture. $^{\mathrm{IS}}$

I am analytically comfortable with the notion that Gujarati Hindus, just like everyone else, have individual characters. How characters become expressed is steered by the person's environment, which since the arrival of capitalism has become an increasingly artificial, social environment, an environment which, like character, is open to chance influences. What is noteworthy about British Gujarati Hinduism is the combination of the twin trajectories; both the maintenance of a traditional Hinduistic way of life alongside vibrant capitalistic roles. This marriage of identities suggests that the classical sociological picture of how societies change and how people come to think of themselves and act is in need of a little revision.

Starting with the Scottish School, classical social theory of all persuasions embraced the notion that societies develop through historically discernible stages, stages that became, in the nineteenth century, evolutionary progressions with positivism supplanting the metaphysical, capitalism supplanting feudalism, modernity supplanting ancien regimes, and the orient supplanting the occidental. I have argued elsewhere (Mattausch 2003) that societal evolution is logically impossible and that rather than a history of one form of society supplanting a predecessor, societal change is better seen as a process of accumulation. If this argument is correct, then instead of traditional Hinduism being replaced by capitalism, we can expect Hinduism to be added to capitalism instead, and vice versa, as the old imperialistic, racialist barriers become breached by increasing capitalistic internationalism (aka 'globalisation'). Thus, it is not the case that individual identities are simply transformed, rather, individuals may add further cultural dimensions in much the same way as Roger Ballard analogously argued (1994: 30-33) younger British South Asians can happily switch between cultures like bilingualists can happily switch between two languages. Ballard developed this linguistic analogy to counter the presumption that younger British South Asians would necessarily suffer from 'culture conflict', arguing that the upcoming generation were better viewed as 'skilled cultural navigators, with a sophisticated capacity to manoeuvre their way to their own advantage both inside and outside the ethnic colony' (I994: 3I). But perhaps an extension to his linguistic analogy suggests that just as much as bilingual individuals do not translate from one 
language to another, so too British Gujarati Hindu cultural bilingualists are inured to possible conflicts between western capitalism and traditional Hinduism, hence facilitating the conjoining of two, at root, incompatible cultures.

The degree to which individuals are linguistically, or culturally, fluent is of course a reflection of their own characters and the circumstances in which they live, a reflection of sometimes chance-given opportunities. The twin trajectories of the community's advancement, both diversely capitalistic and traditionally Hinduistic, requires us as social scientists to grant chance a decent analytical role in explaining how the parallel developments occurred, how they may change in the future and how they knit the community's web of internationalised castes. Admitting chance back into the analytical fold does not diminish the salience of well-known structural factors any more than it trivialises the struggles and achievements of British Gujaratis. Instead, recognising the roles played by chance allows for a more authentic explanation of the ways in which this community has fared in the course of international capitalistic development, an historical process for which the arrival of the East India Company's ship, The Hector, in Gujarat sounded a starting pistol.

\section{Notes}

I For a study and discussion of Gujarati female entrepreneurs in the male-dominated Asian garment business, see: Irene Hardhill I999.

2 See the 'Britain's Leading South Asian Women' listing compiled annually by the Website Redhotcurry Ltd for British Asian women's impressive achievements and striking diversity.

3 Figures taken from the Government's National Statistics Online: www.statistics.gov. uk. Just over half of British Hindus live in London, a further $22 \%$ live in the East and West Midlands. It should be noted that only $92 \%$ completed the Census's self-declared religious question, the wording of which - 'What is your religion?' - may have been appropriate for ascribed religions such as Hinduism, far less so for religions of conversion and choice, such as Islam and Christianity. (This Census question was worded differently in both the Scottish and Northern Ireland Censuses)

4 For a broad overview of established British Asian businesses and their disproportionately rapid growth, especially since the very late I990s, see Dhaliwal and Adcroft 2005 .

5 Modood, Virdee and Metcalf's I995 study drew upon the samples for the $4^{\text {th }}$ PSI Survey and employed the same worrisome categorisation of 'African Asians'.

6 The absence of British Pakistani women from the paid labour force and this community's very low educational levels are the chief reasons for their comparatively poor economic standing, a weakness of the wider British Muslim community. For an excellent analysis of British Muslims founded upon the 200I Census see Ceri and Peach 2006.

7 Steven Vertovec discusses what he terms 'facets of reproduction', facets divided between 'cultural transmission between generations' and institutionalisation and routi- 
nisation, in the most useful fourth chapter surveying the 'growth of Hinduism in Britain' of his book The Hindu Diaspora (2000).

8 All statistics are from the British Government's National Statistics Website.

9 For example, Draupadi's shaming and redemption in the Mahabharatta; the kidnapping, rescue and marriage of Sita in the Ramyana; and the discussions of marriage and the stories of unlawful abduction in the Srimad Bhagavata Purana, Book X.

Io The rapid construction of public places of worship by Hindus has also been matched by the rest of the other British South Asian communities: in 1964, there were only I3 officially certified sites of worship for British South Asians, by 1998 there were 6I4 certified Muslim mosques -the oldest, the Woking mosque, dating from the I880s - Io9 Hindu temples, and I93 Sikh gurudwara. Today, there are at least 150 British mandira. For a discussion of Hindu temple building in the U.K., see R. Gale and S. Naylor 2002.

II As is usually the case, published but non-quantified discussions do not allow any reliable estimation of the influence of groups such as the VHP or the BJP, upon British Hindus. My postgraduate supervisee Alex Dean's unpublished research shows that British Muslims also import so-called 'communal' hatreds and that for the British Pakistani Muslim community, suppurating old bitternesses over Partition and Kashmir fester away, informing young male Muslim/Sikh gang rivalries, some of which have resulted in murders.

I2 Two unreplicated studies by population geneticists illustrate the gendered patterning of gene transmission in Hindu societies: Majmuder 1999 and Bramshad 1999.

I3 Labour Force Survey, June 2003 to May 2004. The percentages are for all British Hindus, not just the majority British Gujarati component.

I4 For Schopenhauer's epigrammatic remarks on character see Essays and Aphorisms, 1970: I66-180. For the neglected importance and influences of Schopenhauer, see Brian Magee 1997.

I5 I have sketched some evidence from genetic science, particularly from Behaviour Genetics, for chance affecting behaviour in Mattausch 2003: 518-520. Chance and character are the topics of a book I am currently writing. 


\title{
7 Contested Family Relations and Government Policy
}

\author{
Links between Patel Migrants in Britain and India
}

\author{
Mario Rutten and Pravin J. Patel
}

This paper discusses the social links between Indian migrants in Britain and their family members in India. It is based on fieldwork among members of the Patidar community in rural central Gujarat and among their relatives in London. Members of this community have a long history of national and international migration. Many of them migrated to East Africa in the early part of the 2oth century and from there to Britain (and the US) in the I960s and I970s.

The aim of this paper is to show the differences in perspective on the social links 'from below' between the Patidar migrants in London and their relatives in Gujarat. ${ }^{\mathrm{I}}$ Both the migrants in London and their relatives in Gujarat acknowledge the notion of an Indian diaspora as a significant category, but they frame and discuss this notion in very different and contradictory ways. The Patidar community in London is a transnational community that maintains frequent long-distance family links with their home region in India. There are, however, differences within the community that are related to their patterns of migration. The links between family members India and Britain are neither static nor without problems. Over time, the orientation towards India has become more ambivalent. Moreover, there are differences of opinion between the Indian migrants in London and their relatives in Gujarat on the nature of their relationship and on the type of help rendered. Furthermore, the migrants in London challenge the government perspective on the diaspora concept. This paper thus shows the complex process of appropriation of notions of 'the Indian diaspora' among those who describe themselves as members of that diaspora, and among their relatives at home. 


\section{Introduction}

By the end of the twentieth century, about 2 million people of South Asian origin were residing in Europe, the US and Canada. The majority of them, about I.26 million, live in Britain (Jain I993: 34-35). Geographically, the Indian migrants in Britain are concentrated in the urban counties of England, from Kent in the south east to Lancashire in the north west. The largest number, about 36 per cent of the total Indian population, live in Greater London, while 22 per cent have settled in the Midlands area (Ram I989: IOI-02). With regard to their region of origin in India, the Gujarati and Punjabi communities are by far the largest Indian communities in Britain (Jain I993: 36 ).

Gujarat is one of the prosperous states of India. Being a coastal state it has a long tradition of overseas trade. Gujarati business houses have existed in Africa since the thirteenth century and Gujarati businessmen, particularly the Ismaili Muslims, have been bankers and moneylenders of high reputation (Dobbin I996:109-30). Among the Hindus of Gujarat, the members of the Patidar caste from central Gujarat have emigrated to East Africa in large numbers since the late nineteenth and early twentieth century.

The Patidar community is an upwardly mobile, middle-ranking peasant caste which can be found in several regions of Gujarat, but has its main concentration in the Charotar tract of Kheda and Anand districts in central Gujarat (Pocock I972). With about fifteen to twenty per cent of the district population, the Patidars form a substantial minority that have been able to acquire economic, social, and political dominance since the early part of the twentieth century, both at the regional and state level (Hardiman i981; Rutten I995).

Participation of the Patidars from central Gujarat in the process of migration abroad has a long history. From the late nineteenth and early twentieth century onwards, family members of Patidar businessmen had already started migrating to Madhya Pradesh, Orissa, West Bengal, Andhra Pradesh and other states of India, to trade in the locally produced biddy tobacco. This form of migration was mainly confined to the upper stratum of the business community in central Gujarat. A more spectacular form of migration, which was one of the first streams of migration among the middle-class Patidars in central Gujarat, was the migration to foreign countries, especially to East African countries such as Kenya, Uganda and Tanzania. This pattern of migration started during the period of economic deterioration around the turn of the century and accelerated during the I920s and I930s. Many Patidars who had never travelled any further than Ahmedabad or Baroda began to pick up the trade connection which had existed for two thousand 
years between Gujarat and Africa (Pocock I972: 63; Desai I948: I8/I4I; Tambs-Lyche I980: 35-40).

This early migration abroad from the Charotar tract was closely related to the job opportunities offered by British colonial rule in East Africa. During the first decades of the twentieth century especially, many Patidars from middle-class and lower middle-class peasant backgrounds migrated as passage or free migrants to countries like Kenya, Tanzania, and Uganda. Colonial rule and the completion of the East African railways offered these educated middle-class Patidars white-collar clerical occupations, and initiated a new era of economic opportunities to be exploited by the members of this peasant caste who took up a variety of commercial and professional activities. Most of these Patidar migrants went to East Africa on the basis of a work permit provided by fellow villagers who had gone earlier, or on the basis of a marriage with a Patidar girl or boy living in an East African country. These marriages were known as permitian lagn (marriage arranged with a view to get a permit to go to Africa), because the main purpose for the Patidar family in the village was to provide one of their sons or daughters with an opportunity to migrate to East Africa. It was usually through the help and support of their new family-in-law, along with that of other relatives and fellow villagers, that these young migrants who had never travelled beyond their own regional towns, were able to settle down in their new environment.

The colonial period in the I950s saw only a very small trickle of Patidars to Britain. From the mid-I96os onwards, however, the pattern of migration of the Patidar households changed very quickly from East Africa to Britain. As a result of radical Africanisation programmes in these countries and the fear that immigration restrictions would soon be implemented by the British government, many of these East African Indians left for Britain in a relatively short time span. Between September I967 and March I968 alone, I2,000 South Asians from Kenya entered Britain, while 29,000 Asians arrived in I972 after being expelled from Uganda (Michaelson I978/79: 35I). Although a relatively prosperous minority of these so-called 'twice migrants' (Bhachu i985) had already begun to invest in Britain in the I950s and early I960s mainly through the purchase of houses where young relatives could stay whilst studying (Michaelson I978/79: 350) - most of those who migrated from Africa to Britain at the end of the I960s, early I970s, arrived practically empty handed and were usually fully dependent on friends and relatives (Tambs-Lyche I980: 4I).

As a result of these patterns of migration, the Patels constitute one of the largest groups among the Gujarati Hindus in Britain. Not surprisingly 'Patel' is one of the most popular Indian surnames abroad along with the 'Singh' surname. According to a conservative estimate 
of the membership of associations of all the marriage circles in Britain, there were about 30,000 Patels from central Gujarat living in Britain in the early I990s, of which 90 per cent reside in London (Lyon and West I995: 407).

The main part of the findings presented in this paper are based on fieldwork conducted in 1998 among members of the Patidar community in rural central Gujarat and among their relatives in London in I999, followed by subsequent visits since then. In order to study the links between the Patidars of India and Britain we collected information through a survey from 313 households in six villages in central Gujarat who have relatives in Britain, out of which 157 were selected for in-depth interviews. This was followed by a survey among 159 Patidar households in Greater London, of which 80 were selected for in-depth interviews. Members of the Patidar households in Greater London originated from these same six villages in central Gujarat. ${ }^{2}$ The reason for selecting six different villages is related to the fact that the Patidars of central Gujarat are not a homogenous group but an internally differentiated one with several hierarchically organised subgroups having a unique preoccupation with the competitive display of social status. In their selection of marriage partners the Patidars confine themselves to their own subdivision within a specific group of villages, based on an extended hierarchical system of endogamous marriage circles (Pocock I972; Hardiman I98I). These marriage circles (ekada or gol) have retained their social significance for the Patidars living in Britain, where they have established associations which organise social and cultural activities for its members (Lyon and West 1995: 407; Michaelson I97979: 355).

In order to have a fairly representative picture of the socio-economiccultural links among the Patidars in central Gujarat and their relatives in Britain, we decided to select villages of both high ranking marriage circles and medium-ranking marriage circles. For this purpose, we divided the villages of central Gujarat into two major strata which are recognised as socially significant: Mota Gam (big villages) and Nana Gam (small villages). The six villages belonging to the marriage circle known as Chha Gam (six villages) are considered Mota Gam, while almost all the other villages are generally known as Nana Gam. From Mota Gam we selected two villages from the Chha Gam marriage circle. The big villages are actually rural towns compared to the smaller villages. However, this distinction does not only reflect the difference in size but also the social status. The Patidars of the big villages are considered to be of the highest social status among all the hypergamously organised marriage circles of villages in central Gujarat (Pocock I972; and Hardiman 198I). 
Except for the Panch Gam (five villages) marriage circle, whose status is ambiguous, all the other marriage circles belong to the Nana Gam category. From these marriage circles we selected four villages from two medium-status marriage circles: Sattavis Gam (27 villages) and Bavis Gam (22 villages). ${ }^{3}$

The selected stratified sample of villages within both Mota Gam and Nana Gam marriage circles allows for comparison between Patidars from high-status and medium-status villages. This difference between high-status and medium-status villages is an important aspect within the Patidar community with its strong sense of hierarchy and practice of hypergamy. An important reason for selecting these three specific marriage circles is that members of these circles make up the largest share of the Central Gujarat Patidar migrants in Britain. Based on information provided by Lyon and West on the number of Patidars in London, it turns out that seventy per cent of the 30,000 Patidars from central Gujarat in London belong to the Chha Gam, Sattavis Gam, and Bavis Gam marriage circles (1995: 406-07).

Within the Patel community in Britain, there are differences that are related to their patterns of migration. First of all, there are those who belong to so-called twice-migrant families. These Patels entered Britain from East Africa, especially from Kenya, Uganda and Tanzania. In our sample of 159 households in Greater London they make up threefourths of the total number of household members who were not born in Britain. This figure includes those who came to Britain after a temporary stay in India following their departure from East Africa. The remaining one-fourth of the household members consists of those who migrated directly from India to Britain without having any previous migration history.

In his overview of differentiation among the British Gujarati, Steven Vertovec extensively discusses the difference between these 'East African' Gujaratis and the 'Indian' Gujarati. In general, he emphasises, 'East African' Gujarati are viewed as having a higher educational and occupational background and being more wealthy and of higher status compared to those who had directly migrated from India.

East Africans' are usually associated with higher educational and occupational backgrounds than Indians (Modood et al. I997). This trait has been subsequently equated with greater status and wealth. The East African Asians' supposed longer and deeper acquaintance with the English language and with urban, middleclass 'European' (albeit colonial) lifestyles has connoted a better preparation for successful living in Britain. Though it would be difficult to prove the validity of all such traits, they remain com- 
mon stereotypes that determine much by way of attitudes and social formations (Vertovec 2000: 90-9I).

Our analysis of the migration history of the Patels from central Gujarat points to the fact that there are also social differences among East African Gujarati in Britain that belong to the same caste group. Most of the East African Patels settled in Britain came from Kenya and Uganda. There are slight social differences between those Patels who came to Britain from Kenya and those who came from Uganda. One of the reasons for this process of social differentiation within the Patidar community seems to be partly related to a difference in their patterns of migration.

It appears that due to an earlier process of urbanisation and education, and a subsequent greater exposure to the outside world, the Patels of the Mota Gam villages started emigrating to East Africa earlier than their counterparts from the Nana Gam villages. Perhaps the fear of losing status by their inability to marry their daughters and sisters in equal or higher status families within their own marriage circle, due to a combination of higher dowries and an increasing scarcity of land, may also have compelled them to look for better opportunities outside India. As a result, most of those Patels who emigrated to East Africa at an early stage originated from one of the Mota Gam villages that belong to the Chha Gam marriage circle. Since Mombassa was the port or arrival in those days, the large majority of the Mota Gam Patels settled down in Kenya.

After they had established themselves, these migrants started to encourage and help those relatives who were interested in migrating to East Africa. This applied especially to those who were in need of assistants and other junior staff members to help them run their businesses. Due to the prevailing system of hypergamy among the Patidars of central Gujarat, some of these relatives, particularly on the in-law side of their family, originated from Nana Gam villages that belonged to other marriage circles. As a result, an increasing number of Nana Gam Patels started to emigrate to East Africa. Being latecomers and relatively less educated compared to the Mota Gam Patels, many of them encountered difficulties in finding employment in Kenya. In search of new opportunities, these Nana Gam Patels started moving further inland and settled down in large numbers in British protectorate Uganda.

Thus, it seems that the majority of Patels who settled down in Kenya originated from the Mota Gam villages, while among those who settled down in Uganda the proportion of Patels from Nana Gam villages is higher. This difference in geographical pattern of migration reflects a relatively invisible but nevertheless significant difference of status with- 
in the Patidar community of central Gujarat. In general, the Patels that belong to the Mota Gam villages are usually associated with higher status and greater wealth as compared to those who originate from the Nana Gam villages. Therefore, most of those who came from Kenya to Britain were relatively better-off and higher status Patels than many of those who came from Uganda. Moreover, the Patels of the Mota Gam villages who had migrated earlier to Kenya also had a stronger tradition of retaining links back home than those who came later and settled in Uganda due to various socio-historical reasons. This different tradition of maintaining links back home in India seems to be reflected in these two groups even in Britain.

Another reason for the social differentiation between those Patels in Britain who came from Kenya and those who came from Uganda is in the manner in which they migrated to Britain. Those Patels who migrated from East Africa to Britain came to Britain in two waves. Those who came from Kenya arrived mainly in the mid- and late ig6os, while those who were settled in Uganda entered Britain in the early I970s. Those Patels who came from Kenya could usually plan their migration in advance. Due to the continuing Africanisation programs in Kenya, they could anticipate their departure and were able to transfer part of their wealth to Britain relatively easily. This was much less so for those Patels who had settled in Uganda. Their departure from Uganda was the result of a sudden and unexpected expulsion by Idi Amin. Being forced to leave the country at very short notice, they arrived in Britain as political refugees with very little personal property left over.

\section{Social Links}

Regardless of whether they migrated from East Africa or India, and whether they belonged to the Mota Gam or Nana Gam villages, the characteristic feature of the Patel community that we studied in London is that they remained attached to Indian culture and to their Gujarati background in terms of their social relations. Most of the older generation have retained their Patidar identity by organising themselves on the basis of their village of origin and marriage-circle (gol). These village-based associations and organisations of village circles in Britain bring out directories giving details of all the Patidar family members concerned. These directories are mostly used to help to arrange marriages. For this purpose, the associations also organise marriage-melas, in which young boys and girls publicly introduce themselves and try to find out suitable life-partners. Besides, the village associations and marriage-circle associations of Patidars in Britain organise meetings to 
celebrate Nav Ratri, Diwali and other important Indian festivals, and have functions like dinner-and-dance parties, where they eat, drink, and dance to Hindi songs till late into the night and early morning hours on weekends. Moreover, many Patels participate in religious activities, for which the Swaminarayan temple in North London is often a focal point (see also Williams i984). Although most of the active members in these associations belong to the older generations of Patidar migrants, many organisations also have youth committees in which youngsters are involved and encouraged to organise and participate in various activities.

Along with organising social and religious events, members of the Patidar community in London have started making organised efforts to teach Gujarati to the younger generation. Children belonging to the second and third generation of migrants are mostly able to understand functional Gujarati, but they find it difficult to speak, and are often unable to read and write the Gujarati script. This problem, of course, is not confined to the Patel community in Britain. The Gujarati community as a whole has become more conscious about teaching Gujarati to their children. There are about 500 classes that teach Gujarati throughout the UK, often for two hours a week on Saturdays and Sundays. By the end of the I99os, about one thousand to fifteen hundred students were taking Gujarati language examinations annually.

On the whole, village life in Gujarat still has a profound effect on the first generation of Patidar migrants. They grew up in the villages during their formative years, where they studied and spent their childhoods. Moreover, many of them grew up during the patriotic period of the national independence movement, which made them even prouder of their Indian culture and heritage. The social, religious and cultural bonds with their home village and with other Patidar migrants from the same region, when they first lived in East Africa and later on in Britain, further cemented those ties with their villages of origin. Therefore, the social identity of the first generation of Patidar migrants is deeply embedded in village life. Meanwhile, their ties with their places of origin and with their relatives and friends in Gujarat are still quite strong.

One of the indicators of social links between the Patidar migrants in Britain and their relatives in the villages in Gujarat are the various types of intense contacts that exist between the members of both groups. Writing letters is still the major form of communication used by households in Gujarat to contact relatives in Britain, although phone calls are also an important way of keeping in touch. Because the costs of long-distance telephone calls from India to Britain are high they are usually kept very short and are often only made in emergency situations or for very specific purposes. Patels in Britain make phone 
calls more often to their families in the village; some even call on a weekly basis for a few minutes. These calls are used to exchange information about the well being of relatives on both sides.

Another important form of contact between the households in Gujarat and their family members in Britain are visits by relatives from Britain to their home villages. More than ninety per cent of the selected 3I3 households in the six villages have been visited by relatives in Britain in the period between 1993 and I998. In total, 768 relatives visited India which means an average of 2.7 relatives per household of which a substantial number visited India more than once during this five-year period. Most of these visits were of relatively long duration. Almost fifty per cent of them stayed one to three months, while the visits of nine per cent of British relatives lasted four to six months. About forty per cent of the relatives who visited their home villages stayed in India for less than a month.

In recent years, when many of the older migrants retired from active employment, a movement from Britain back to India during winter has emerged. Among the older generation of Patidar migrants in Britain, there are quite a few who could be called international commuters'. These are Patidars from Britain who travel to India every winter for stays of one to five months. In most cases, they live in Gujarat in their own apartment or bungalow in one of the nearby towns or on the outskirts of their home village. Some of them have actually for all practical purposes re-emigrated to India as they spend more time in their country of origin than in Britain. Although most of these people did return to spend their retirement in India, some returned because they no longer wanted to live with their families in Britain. Having returned to their village of origin, some of them realised, however, that they are no longer at home there either, as is shown in the following case study. ${ }^{4}$

Shamalbhai is 72 years old and since 1994 he lives again in the village in which he was born in I925. In I953, at the age of 27 , Shamalbhai left his native village when he was already married. He was invited to come to Tanzania by his father's eldest brother's son whose family had been living there since the I930s.

In 1956 , Shamalbhai came back to his village to collect his wife and three children. The highly unstable political situation around I963 made them decide to bring their children back to Charotar and to leave them with Shamalbhai's nearest relatives in his native village where they could attend the local schools. Although his wife stayed with their children for some months, she again joined her husband in Tanzania in 1964. Together, they lived and worked in Tanzania until I973 with only one visit to their children in Charotar in I969. 
After their visit in 1973, his wife remained behind in the village, while Shamalbhai returned again to Tanzania in 1974. From there he applied and was allowed to enter the UK in I979. Within one year after his arrival in London, Shamalbhai called his wife and their three children to join him in Britain. But Shamalbhai and his family were only able to get unskilled work during the early period in Britain. 'I could only get a job in a factory', Shamalbhai mentioned to us. 'In Tanzania I had a big shop with assistants and drove around in a Jaguar car, but I had to leave almost all my property behind when I migrated to the UK and had to start again from scratch.

'I was not really happy in London. It was hard work that my wife and I had to perform in those factories for very low pay, but we did it for our children. By migrating to the UK, we wanted to give them a better future, because they would not have these opportunities in India, being relatively low educated and without much property in the village. After my retirement in I990, however, my wife and I started to visit India very regularly. In fact, we used to often stay several months per year in India. In I994, we even returned and took up permanent residence again in my native village, because after my father's brother's daughter had left for the US, there was no one left in the village to take care of my old father. We then built a new house on the outskirts of the village and since then we live here the whole year around, and only occasionally visit the UK.'

Although at first, Shamalbhai returned to the village only because of his father, he visibly enjoys being part of the village life. Every day he makes his rounds of the village and on various evenings one can meet him in the village square, talking to old friends. On the other hand, however, he occupies a marginal position in his home village. 'Although I was born and brought up here, even after four years of my permanent return, I still do not feel that I am really part of village society. We participate in various activities, but somehow we have difficulties really mixing with our relatives in the village and force ourselves to attend their gatherings. But to be honest, we used to have the same feeling when we were living in the UK, because I arrived there at the age of 55 and only worked there for about ten years'. After Shamalbhai left the room for a short while, his wife also started to express her views. 'Yes, we were also not at home in London, but at least we had our children and grandchildren nearby. I don't like it here at all and hardly leave our house. My whole life I have been able to live and adjust in different countries. I have lived in Charotar, in Tanzania and in London, but now that we 
are old, I sometimes feel that we no longer feel at home anywhere and therefore it is better keep to ourselves inside our own house'.

As is to be expected, there are less visits by Indian relatives to Britain compared to the number of visits from Patidar migrants to India. However, members of more than twenty per cent of the selected households visited Britain between 1993 and I998. In total, I28 members visited Britain in this five-years period, which comes to an average of I. 6 relatives per household. This clearly indicates that there are substantial numbers of household members from the villages who have visited Britain. These visits are often of a longer duration. Only eight per cent of the household members who visited Britain stayed there for less than a month. About 45 per cent of them stayed between one to three months, while the visits of 33 per cent lasted four to six months, with the remaining $\mathrm{I} 4$ per cent remaining in Britain for a period of more than half a year.

The 313 households in the six selected villages with relatives in Britain have a total of 3,624 relatives in Britain, which is an average of II.6 relatives per household. Although the selection of households in the six villages was done on the basis of the existence of relatives in Britain, it turns out that I33 of the I57 selected families for in-depth interviews do not only have relatives in Britain, but also outside Britain. In total, this comes to an extra 1,469 relatives with an average of 9.4 per household. With the rigorous immigration restrictions imposed, emigration to Britain decreased rapidly from the late I970s, early I980s onwards. Since then, the US and Canada have become the most popular destinations for Patidar migrants (Jain I993; Helweg I987/I990). This is confirmed by the findings of our study. Almost 75 per cent of the 1,469 relatives of the selected families in central Gujarat live in the US, while almost 16 per cent live in East Africa.

One of the consequences of this widespread migration pattern of the Patidar community is the emergence of a category of people that we would describe as 'world citizens'. They are usually older people who, although they have a residence in one country, often travel between the UK, India, the US, and East Africa throughout the year, staying in each destination for a few months at a time. These people sometimes meet each other in different countries where they exchange information about relatives. There are even some cases of transnational holidays in which Patidar relatives from different parts of the world come together to spend their vacation by travelling to several countries. 


\section{Mirror Image of a Family Relationship}

The above brief account indicates that members of the Patidar community in London frequently maintain long-distance family links with their home region in India. Regular visits and frequent contacts keep many of the Patidar migrants in London well-linked to the villages in Gujarat and vice versa. However, these visits and contacts are not without their problems. The following examples will show in more detail that there are sometimes differences of opinion between the Indian migrants in London and their relatives in Gujarat on the nature of their relationships and on the types of help rendered.

In many instances, the visits of the Patidar migrants to India and of their Indian relatives to Britain are related to the marriages of one of their family members in Britain or India, mostly with a marriage partner from the other country. During the visits of the Patidar migrants to India, activities related to religion are also very common. Because of the substantial donations they make to local temples, they are often given special treatment in terms of comfortable and prominent positions. This emphasis on religion by the relatives from Britain, and the special 'VIP' treatment they receive in the temples in central Gujarat is viewed by some local Patels with jealousy and ridiculed in private conversations.

In 1988, Mohanbhai retired from his clerical job in London, while his wife Vimlaben retired in 1991. Since then, the two of them have been visiting Gujarat every year during the winter season for a period of two to three months. In 1994, they bought their own apartment in the nearby city of Baroda.

During their stay in Gujarat, Mohanbhai and Vimlaben spend most of their time in Baroda and from there they also make trips to Charotar to visit friends and relatives in their native village. Alongside these social visits, they take the opportunity during their stay to visit temples in Gujarat and usually also make a tour of a few days to other religious places in India. Mohanbhai emphasises his religious nature, and indicates that he regularly makes donations to local temples. 'Also, when I am in London', he told us, 'I very often make visits to the temple. In London, I am a member of the temple of Akshar Pursottam. Whenever we stay in Gujarat, we make it a point of going to the big temple of Akshar Pursottam in Gandhinagar'.

During one of their trips to their native village, Mohanbhai and Vimlaben showed some relatives the photographs of the Yagna ritual in which they had participated in the village temple a few weeks earlier. While showing the photographs, Vimlaben 
pointed out several of her relatives and friends from the UK and US. They were in fact easily recognisable, because Vimlaben and the other women from the UK and US were in the first row in the group photo, sitting in chairs with their plates on a table in front of them, while the women from the village sat on the floor behind them. Mohanbhai explained that Vimlaben and the other women from the UK and US had been the honoured guests at the Yagna ritual in the village temple. While explaining this, he took a letter from his wallet that he showed to us and his local relatives with some pride. It was a letter of recommendation from the Swaminarayan Mandir in London in which Mohanbhai is mentioned as a member of the Mandir in London and was allowed to stay in any of their temples in Gujarat for two days with a maximum group of 8 persons. 'In this letter, the temples in Gujarat are requested to provide me with boarding and lodging, and to enable me to pray and to have conversations with the priests', Mohanbhai told us. 'About two years ago, the Swaminarayan Mandir in London started to issue these letters in order to ensure that only genuine and honest people can make use of the facilities of the temples in Gujarat. And because of this letter, I will get special treatment during my stay in the temple', Mohanbhai added. 'We will be given a clean private room furnished with a table and a chair, and air conditioning if available. They will prepare food that is not too spicy and give us mineral water. This "VIP treatment" is usually given to every NRI (Non-Resident Indian) who visits a temple in Gujarat', Mohanbhai told us before he and Vimlaben left the house to visit some of Mohanbhai's old school friends in the village.

Shortly after Mohanbhai and Vimlaben left, local relatives started to make some critical remarks about the earlier discussions. One of Mohanbhai's cousin's brothers remarked: 'This VIP treatment is given to the NRIs only because they donate in pounds or dollars instead of Indian rupees. Many of them were never very religious when they were in Africa or went to Britain. But now that they are retired, they suddenly have a need for Indian culture and to rediscover religion. However, many of them have already become too westernised. They are not even able to sit cross-legged on the floor for a long time and their stomachs can no longer stand our drinking water'. The other relatives agreed with him in their mild attempt to ridicule the NRIs emphasis on religion, but could at the same time also not hide their jealousy regarding the special treatment the NRIs receive in the local temples. 
Another characteristic feature of the behaviour of the Patel migrants in London is the absence of productive investments in India. This lack of enthusiasm regarding the maintaining of financial links and investments in Gujarat by the Patel migrants in London are part of lively discussions both in India and Britain. Among the Patel migrants in London there are those who emphasise that they consider the lukewarm response accorded them by the Indian government in the early I970s a more shocking experience than their sudden and unexpected expulsion from Uganda by Idi Amin. In those days, the Indian government did not realise the importance of the Non-Resident Indians. Therefore, many of those who settled in the UK, after being expelled from Ugan$\mathrm{da}$, ironically translate 'NRI', the much trumpeted term by the Indian government, as "Non-Required Indians", and their bitterness is also reflected in their lack of enthusiasm in maintaining links back home in the form of investments in India.

It is partly due to these feelings that there are no strong developmental links between the villages in Charotar and the Patel community in Britain, despite the size and frequency of monetary help and financial transfers of the Patel relatives from Britain. Many Patels in the villages express their negative views about the fact that migrants from Britain do not contribute as much to the development of their home village as they used to in the past. Although they seem to understand the economic problems faced by the Patels in Britain today, they strongly believe that they avoid their responsibilities by not contributing to the welfare of their home villages.

Sureshbhai's family belongs to one of the economically most well-to-do families in the village. They own about 20 acres of land and have a large cold storage building and a tile factory and several other undertakings. Sureshbhai's younger brother Mahendrabhai is a regional politician who is also quite active at the local level. Among other things, he is the chairman of the educational board and secretary of the village co-operative bank.

On various occasions, Sureshbhai and Mahendrabhai criticised the large-scale migrations of the Patel community to the UK and US of members. 'Not one of our direct relatives has migrated abroad', Sureshbhai used to say with some pride. 'We are happy to live here and are not like all those Patels who do will anything to be able to go abroad'. Mahendrabhai adds: "And when they leave, they forget all about their native place. In the past few years, there has hardly been any financial support of our village from the Patels who live in the UK. Until the Ig6os, Patels who migrated to East Africa from our village used to make regular donations to the educational board and village pan- 
chayat. It was because of these donations that our village was among the first in the area to have a high school. Since they migrated from East Africa to the UK, however, we have hardly received any donations from our fellow villagers abroad. Even though they established a samaj from our village in London, this has not resulted in substantial support for the development of our village. "We realise that it is expensive to live in London, but compared to Gujarat, the Patels in Britain have hardly any social obligations and therefore less expenses in this regard. I personally feel that Patels in the UK are only after money and obsessed with saving as much money as they can. They hardly care about their relatives back home, and seem to have become misers who do not want to spend money on their social obligations.

When they are in the UK, they don't think about the welfare or development of their native village, but when they visit their village, they start to emphasise that we are all part of the same village and samaj. They even expect us to treat them with the highest respect because they have come from abroad. But to be honest, I don't think the Patels in Britain from our village are part of our community anymore, they have become strangers to us, strangers who are no longer really concerned about the welfare of their native village.

Family property issues in the village are also not without their problems. In several cases, relations between relatives in Britain and family members in the Gujarat village have become severely strained due to property conflicts. Members of the households in the village often believe that they are entitled to the total amount of ancestral property, because they looked after the family's property and often after their parents and other elder relatives in the village as well. The relatives in Britain, however, are sometimes of the opinion that they have a right to an equal share of the family's property, which they then will try to sell off.

Thus, at the beginning of the twenty-first century the Patel community in India and Britain seem to be on the crossroads in every aspect of life. On the one hand, the relationships are becoming more transnational and extending their links into different countries from India to Britain and to the US. On the other hand, it is struggling to maintain its traditional culture in Britain by reclaiming the younger generation and by redefining its links with the relatives in the home region of central Gujarat. This continuing process of both closeness and antagonism between the two sides of the transnational family, and the way in which they interact and influence each other, is not a new phenomenon for most of the Patel migrants in London. This has been part of 
their daily existence as migrants who maintain intense and frequent links with relatives in their home villages, especially for those who migrated to the UK from East Africa.

A man from overseas was not able to convert his success into prestige in Gujerat without the local knowledge and cooperation of people who had stayed behind. ...

The villages in Gujerat were sounding boards for gossip and anecdotes about emigrants in all parts of the world, and in East Africa the strongest sanctions compelling a Patidar to regulate his life according to the standards and values prevalent in his home district were the opinions of other Patidars in India. Every aeroplane flying to and from Bombay was loaded with gossip and comment (Morris I968: 96 and 99).

\section{Government Policy}

Ever since the beginning of the large-scale migrations of indentured labourers from the Indian subcontinent there has been governmental ambivalence towards the Indians abroad. During the first period of indentured migration, there was little government control. As the number of Indians increased in the various colonies, problems arose with regard to their rights and duties as inhabitants and citizens of the colonies in question. As a result, the Indian government gradually began to pay more attention to what at that time was called the Indian problem abroad' (Davis I968: I03). With this large-scale settlement abroad the issue was no longer simply one of regulating migration but of protecting an affiliated ethnic group. This matter has always been a very delicate one in terms of international relations. It was even more complicated because of the ambivalent position of the Indian government within the British Empire. 'The Indians, in contrast to the Negroes had a nation that could plead their case. Yet their own government was European in ultimate control, and hence had divided sympathies as between the migrants and their European masters' (Davis I968: I03).

Although they were ambivalent, early government policy towards the Indian populations abroad had a profound affect on future emigration policy. After I900, the indenture system became increasingly unpopular in India. Especially in view of the rising political awareness and growing strength of the independence movement, the treatment of the Indian indentured labourers abroad was considered an insult to the newly emerging Indian nation. During those years, public opinion in India therefore contributed to increasing the government's sensitivity to the adverse treatment of Indians abroad. This sometimes resulted in 
specific regulations of the flow of migration with respect to particular areas, while in the end it speeded up the tendency towards the abolition of the indenture system. Of course, 'it is a matter of speculation as to whether this step came after the demand for indentured labour had already subsided anyway, but the government's action was strongly supported by Indian opinion' (Davis I968: Io6).

After Independence, the Indian government continued its ambivalence towards the people of Indian origin abroad. During those years, the bureaucracy dealing with foreign policy inside and outside of India was strongly influenced by Nehru's belief that Indians abroad should not look to India to solve their problems but should fully integrate into the societies in their adopted countries. Therefore, for a long time 'Indian diplomats did not concern themselves with the diaspora's woes. Things, however, changed with the second and third generation Indians who were educated and had acquired greater economic muscle, especially after the arrival in Britain of the people of Indian origin from East and West Africa' (Malik I997: 136).

By the end of the I970s, the Indian government increasingly felt the need to develop a policy framework for forging closer ties with the Indian diaspora. This attention by the government for the Indian diaspora in part had to do with India's need for more external funding to deal with its economic problems. It also had to do with fact that the Indian diaspora had become wealthier over the years. In the I980s, in particular, soft loans and development aid to India by multilateral institutions declined considerably, forcing the government to turn to commercial borrowing at market interest rates with less favourable conditions. At the same time, there was a strong need for the renewal of Indian industry in order to increase the competitiveness of their exports in a globalised world. These changes in industry and the restructuring of the Indian economy required large inputs of capital, new technology and machinery, something which increased the need for foreign investment and aid.

This period of financial problems coincided with a growing visibility in economic terms of the Indian diaspora in the UK, US, Canada, and the Gulf states. The Indian government increasingly began to notice the achievements of their fellow countrymen in foreign countries, be it in business, industry, science, technology or education. As a result, it began to see the Non-Resident Indians as a potential resource for India. The aim was to turn the wealth of the Indian diaspora into future financial and industrial investments. The Indian government was therefore eager to quickly point out that the recent changes in the Indian economy also offered enormous opportunities for the Indian diaspora. It subsequently increased its efforts to attract expatriate scientists, technocrats, industrialists and businessmen of Indian origin who 
were working in western countries such as UK, US, Canada, or Australia. 'Whereas previously it tried to persuade Indians to return to India for good, now the government wanted them to act as catalysts while continuing to work abroad' (Malik I997: I22).

Over the past two decades, the Indian government has made efforts to evolve a policy that would benefit the Indian diaspora as well as Indian society. ${ }^{5}$ For this, it developed a large number of special schemes and fiscal incentives for NRIs. In I979, the Malhotra Committee, appointed by Department of Economic Affairs, had already made various recommendations to increase the level of NRI investment, several of which were partially implemented after I982. In the years thereafter, a large number of new schemes were introduced that provided incentives and concessions to those NRIs interested in making investments in their home country.

A special cell for NRI investment was constituted in I983 and a Joint Secretary in the Ministry of Economic Affairs was designated as the Commissioner for NRI investments. In the I980s, several special schemes were launched to attract NRI funds including: (a) various deposit schemes like the Non-Resident (External) Rupee Accounts - NR(E)A - scheme, the Foreign Currency (Non-Resident) Accounts - FCNRA - scheme, the Non-Resident (Non-Repatriable) Rupee Deposit - NR(NR)RD - scheme and Foreign Currency (Ordinary Non-Repatriable) - FCON Deposit scheme; (b) direct equity participation under various schemes; and (c) portfolio investment. Many of these schemes carried interests which were much higher than those available in the countries where affluent NRSs lived.... (Malik I997: I23-I26).

\section{Ambivalent Responses}

Notwithstanding the large number of incentives and concessions, there was not a corresponding increase in direct foreign investments by NRIs in India. Most of them preferred to invest their money in savings accounts or in commercial projects such as housing schemes. This was also the case among our sample of Patel families, as is shown by the following statement by one of them.

Most of the investments in India by the Patels from London that I know of come in only two forms. One, as NRI bank accounts and two, as real estate. This is because when we go to India we can use some of this money during our visits there, while we are getting higher interest rates at the same time. Quite a few of us have bought property in the form of flats or houses, mostly in cities like Anand, Vidyanagar, Baroda, and Ahmedabad. These 
flats and houses are useful during our stay during the winter season. I also have a flat in Baroda which gives me the opportunity to stay in Gujarat without being at the mercy of my relatives. The rising prices of real estate over the past few years have also made it an attractive investment because the value of our property has appreciated very fast over a relatively short period of time. I have never invested in any form of business or industry and I only know of two people who have done so in the past. Both stopped after a few years, one because of problems with his local partners, the other because he got fed up with the Indian bureaucracy. Almost all Patels are only interested in making investments in the UK. Investments in London are more remunerative and more important for the future of our children and grandchildren.

This lack of productive investment by NRIs is confirmed in K.N. Malik's study. He states that:

In the case of Gujaratis, the annual inflow was estimated at $£ 49.3$ million in the late i970s. Most of the remittances went into savings, maintenance, land, jewellery, consumer goods and better lifestyle. Little investment was made in trade and business.... Most NRIs have preferred to put their money in Foreign Currency Non-Resident (FCNR) deposits rather than invest in new projects (Malik I997: I29).

It is often argued that this low level of total investment, especially of direct investment, has mainly been caused by the India's restrictive foreign investment policies until 1992. Although the impact of government policies on NRI investment did indeed improve after the Indian government embarked upon its economic reform programme in the I990s, the reluctance or even unwillingness by Indians abroad to invest in their home region is also closely related to their view that other changes are necessary in order to improve these conditions.

Despite various concessions and incentives given to NRIs like tax exemptions in specific cases, easier norms for investment, changes in the Foreign Exchange Regulation Act (FERA) in favour of NRIs, permission to retain their property and accounts abroad, NRIs are still awaiting further facilities and more openness of the economy, including full convertibility of the rupee. An unfavourable response to their demands for dual citizenship, and some other benefits and the existence of red tape and an unsympathetic bureaucracy, have made them think that conge- 
nial conditions for NRI involvement in India do not exist as yet (Malik 1997: 132).

During our conversations with first-generation Patels in London, they regularly expressed negative views about Indian society. On many occasions, these migrants referred to bad experiences they had with the Indian government in the past, especially during their time in East Africa. One issue that came up several times in these discussions was the money they lost in the Indian government defence bonds scheme in I964.

During a discussion in the Barham Veterans Club on the lack of interest in investments in India, Mohan Patel referred to the 'Defence bonds scheme' of i964. According to him, the problems caused by this scheme are an example of the fact that for a long time, Indian government policies have been contrary to the best interests of the NRIs.

'In I964, the Indian government announced an investment scheme called the Defence bonds scheme'. Indians abroad could buy these bonds with British pounds while the value of the bonds was set in Indian rupees. The idea was that through these bonds the Indian government would be able to raise funds for their war efforts. These bonds could be sold as a kind of shares to importers who would then be able to receive foreign exchange, enabling them to make quite some money within the context of the so-called closed economy. In the first two weeks after the scheme was announced, the value of the bonds doubled and you could make quite some profits. You could not convert them back into pounds, but if you kept them they also provided you with interest.'

'Quite some Patels in Kenya invested in them. I also bought some bonds, while my father-in-law invested all his pension money in them. However, almost immediately after the closure date, the Indian government devaluated the rupee by 50 per cent and every one lost an enormous amount of money in terms of British pounds. This is how my father-in-law lost most of his pension as there was no opportunity to sell the bonds on the market for profit. This example shows that we Indians abroad have always been badly treated by the Indian government and that we therefore no longer trust the Indian government. Because of that, we are not interested in investing in India, despite the many schemes offered'.

Although political instability and corruption are part of the reasons why the Patels do not invest in India, such past experiences 
are also very important in understanding the present attitude and behaviour of the older generation of Patels in London.

Another incident that the Patels in London often referred to was the supposed indifference shown by the Indian authorities during the period of political problems in East Africa.

During one of our visits to Rameshbhai Patel's home, he told us about his experiences in Kenya in the I950s. In those days, he personally witnessed the arrival of Belgians who had to flee the Congo without any of their possessions. 'Our children's school was closed for a week because it housed these Belgian refugees. This experience of the Belgians made the Indian community in East Africa realise that there is a potential danger for us as well if we stay in these newly independent countries. We therefore decided to approach the Indian government.

'But when we approached the Indian government about what it would do if things got out of hand in Kenya, their representatives in Nairobi did not take our questions seriously. They had only come to Kenya to tell us clichéd stories and to emphasise that we had to stay in East Africa and contribute to the development of India by sending remittances and making investments back home. They did not take the problems of us Indians in East Africa seriously. They did not help us, but only came to teach us and to tell us to stay in East Africa, but in fact they let us down when we needed help from the Indian government at the time when things went completely wrong in Kenya and later in Uganda.

'To be honest, nothing has really changed since then. Now the representatives of the Indian government come to the UK and tell us the same kinds of stories. They emphasise that Indians in the UK should be proud of their Indian heritage and Indian culture, but when it comes to really understanding our problems and giving support to us, the Indian government does almost nothing'.

One of these more recent examples in which the NRIs felt to have been let down by the Indian government is the issue of the 'dual nationality'. This issue brought emotional sentiments to the fore as dual nationality was seen as the solution to many problems. Articles in newspapers and on websites discussed the advantages of dual citizenship. While migrants without Indian citizenship are restricted in the amount and type of property they can buy in India, the expectation was that dual citizenship would enable businessmen to buy land and property rights 
and thereby expand their businesses in India. On the whole, once citizenship was offered to Indian migrants abroad, they were supposed to be on a par with Indian citizens in terms of property and other legal rights. Moreover, Indian migrants with a dual nationality would not have to obtain a visa to enter India. Despite these advantages, doubts were being expressed among the Indian migrants about the implications of this new system of dual nationality (Verma 200I). This was also clearly shown during a seminar on 'Dual Nationality' in London in June I999, in which various Patels participated, as is shown in the following account from our fieldwork notes:

One of the issues raised during the seminar was the introduction of the PIO (People of Indian Origin) Card by the Indian government in 1998. The Deputy High Commissioner present at the seminar said that the PIO card is the closest approximation of dual nationality possible. The only difference is that PIO cardholders are not allowed to vote in elections, are not allowed to hold public office in India and cannot buy agricultural property. Other than that, PIO cardholders can enjoy the same benefits as other Indians (like access to education).

One of the main complaints from the NRI audience, many of whom were Patels from Gujarat, was the cost of the PIO card, which is $\$ \mathrm{I}, 000$ for 20 years per person. The Deputy High Commissioner emphasised that the NRI should not think in terms of costs, but should think in terms of its value.

Many of the elder Patels present indicated that they considered it to be very important that they are both British citizens and Indians and that they should be recognised as such by the Indian government. One of them stated: 'When we have a PIO card we are not considered foreigners in India (by customs officials and the stamps in our passports), but as Indians. Because of the (emotional) value attached to a PIO card, we are therefore so disappointed that the Indian government charges \$I, ০oo per person for these cards. We feel that the Indian government should be proud and happy that we NRIs are also Indians and they should therefore give the cards to us almost for free. We have the feeling that the Indian government is trying to make money off of these PIO cards and this adds to our negative opinions of the Indian government, which is only after the NRIs' money and nothing else.'

Although most of the stories narrated by the Patels in London concern their negative experiences with the Indian government, there are also several instances in which they emphasised the support the Indian 
community received from the Indian government. One of these incidents relates to their problems in Uganda during the late I96os and early i970s.

\begin{abstract}
After one of our meetings in the Barham Veterans Club, in which several Patels had expressed their negative views about the Indian government, Sureshbhai Patel presented us with a different view when we accompanied him. Sureshbhai emphasised that the Indian government had, in fact, helped the Ugandan Indians in the early I970s: 'Indira Gandhi negotiated with the British government and forced them to issue a stamp in the passports of those who first went to India. This stamp would give them the right to go to the UK whenever they wanted and the British government promised that they would always accept them. In that way, quite a few Indians were able to leave the problems in Uganda more quickly and return to India without the danger of losing their right to emigrate to the UK. As they had lost their jobs in Uganda, it was very difficult for them to live there. Their savings were running out quickly, while they had to wait for a long time to be allowed into the UK. Take my example. I only got permission after one-and-a-half years. To be able to go back to India has helped many Patels, because life in India was much cheaper than in Uganda'.
\end{abstract}

According to this Patel's view in London, the Indian government did indirectly help Overseas Indians in Africa by forcing the British government to state that they would always be allowed into the UK. At the same time, they could remain in India where life was much cheaper and less dangerous than in East Africa. He also indicated that several of his fellow Patels in London, who are in the forefront of expressing negative views on India, were among the strongest supporters of India at the time of their departure from East Africa.

'You must have noticed that Harishbhai Patel was expressing very negative views about the Indian government during our meeting. You can hardly believe that now, but he had been a staunch supporter of India in the I960s in East Africa. When the situation worsened in Kenya at the end of the I96os and many started to move to the UK, he told everyone that we should not go the UK but return to India, because there were many opportunities in India. He subsequently went to India, set up a business, but went to the UK after a few years. In fact, there were several others like him, who used to praise India, but quickly followed the majority to the UK and are now among the 
ones who are the most vehemently negative about Indian society and the Indian government'.

These NRIs who are tempted to invest in productive activities in India are often scared off by the many stories of bureaucracy and corruption, which make up a substantial part of the conversations among the NRIs in the UK. Many have stories, which can be considered hearsay that then become reality and scare off those who are considering investing. Some of them have told of concrete instances of corruption and mismanagement involving their own bank accounts. Their instructions to the banks regarding their investment plans, they claim, are not properly processed and thus they feel frustrated. At certain meetings there is even a kind of peer group pressure where one is only allowed to speak negatively about India. Those who do otherwise are often strongly ridiculed or contradicted.

\section{Conclusion}

Over the past few decades, social scientists have increasingly paid attention to the processes of 'globalisation' and 'transnationalism' (see, for example, Bamyeh 1993 and Nederveen-Pieterse I994). The rise of diaspora studies is one manifestation of this heightened debate. However, there is a lack of empirical studies that offer detailed insight into these processes. Empirical studies of international migrants - sometimes referred to as 'the exemplary communities of the transnational moment' (Tölölyan I99I: 5) - provide an opportunity to contribute to a deeper and concrete understanding of the various aspects and implications of the globalisation process.

Most of the earlier studies on international migration are characterised by a one-sided approach to the subject. They usually either focus on the effects of emigration for the home area or on the integration of the migrants in the host country. The research presented here has taken as its point of departure both the social environment of the locality of origin of the migrants and the social environment of the locality to which they have migrated. The focus has been on the changing social links between the migrants and their family members in the home area. It has also taken into account the changes over time in the government's perspective on these links. By combining these different perspectives, this research hopes to contribute to a better understanding of the existence of long-distance family relations and other networks beyond the nation-state and thereby to a new conceptualisation of the transnational society in the making. 
With world-wide improvements in communications, the ongoing inter-actional relationship between the migrant and the home community has grown more efficient and more evident. In contrast to the exindentured populations, Patidar migrants nowadays have been able to maintain extensive ties with India. Marriage arrangements, kinship networks, property, remittances, and religious affiliations keep many migrants well-linked to their places of origin. Contacts between earlier migrants in East Africa and their home regions were often maintained with the notion of the migrant possibly returning, as a result of which the home community acted as the focal point within this relationship.

However, this does not mean that all of the parties involved form a static and homogenous diaspora community. It is true that migrants in London and their relatives in India do view themselves as part of one and the same community. But at the same time, this transnational community is subject to deconstruction as its members disagree on the kinds of obligations they have towards each other. Relations are burdened with expectations that are not met, resulting in many frictions. From the perspective of the Patidars in the Indian villages, first of all, the NRI's have acquired a self-centred view over time. In the past, the migrants in East Africa had greater stake in maintaining strong ties with their relatives in India. According to many Patidar relatives in Gujarat, the migrants then thought that at some time in future they might return to India to settle there permanently. However, the subsequent migration from East Africa to Britain changed this orientation towards India. The local relatives seemed to think that earlier on, migrants considered India as their motherland (matru bhumi) and a permanent shelter to which they always return. After going to Britain, they began acting as if India had become like their wife's village (sasru) where they demand to be pampered and treated with extraordinary respect, and without reciprocity, as traditionally the Patidars have been expecting from their wife's family side. ${ }^{6}$ According to some local relatives, the term NRI should therefore not only be read as 'Non-Resident Indians' but also as 'Non-Resident Idiots'. From the perspective of the Patidars in London, however, NRI's stands for 'Non-Required Indians'. The migrants are not required by their relatives, who have taken over the agricultural land in the villages, but laugh at them behind their backs. The migrants are also not required by the Indian nation-state, that appeals to them with faint promises but has never treated them as true Indians in the past. The first-generation Patidar migrants in Britain seems to have an ambivalent attitude towards their home region and their relatives in the native villages. They are very much attached to Indian culture and emotionally depend upon their social links with their relatives and friends in Gujarat. They want to be respected by their relatives, and at the same time, they criticise them on numerous 
occasions and are not always willing to accept the social obligations that are part of these links, or only do so very hesitantly.

Apart from these two contradictory perspectives regarding the Indian diaspora among migrants and their relatives in India, we have highlighted the government's perspective, which has also changed over time. From a policy in the past of distance and ambivalence towards the Indians abroad, the Indian government has more recently made some efforts to develop a policy framework for forging closer ties with the Indian diaspora. The migrants who are hailed by the Indian government in this new manner have not yet, however, responded in the way that the government had hoped for. Instead, they look quite negatively on the Indian nation-state. They emphasise that the inclusion of 'NRI's' as true Indians is in fact hollow and hypocritical. Furthermore, many say that the government has never helped them in the past, which shows that it really doesn't care much about their fate and is actually not treating them as citizens of India at all.

To conclude, this article thus shows that notions of an 'Indian diaspora' are in line with the views expressed by both migrants and their relatives at home. Migrants in Britain and their relatives in Gujarat should therefore not be viewed as separate communities but should be considered in the same unit of analysis. At the same time, the findings of our study also indicate that they are also not considered as a homogenous transnational community (cf. Baumann I996: 23). Social links keep many of the Patidar migrants in London well-linked to their $\mathrm{Gu}$ jarat villages and have resulted in a two-way flow of people, capital, and ideas. These links are reinforced by frequent personal visits, continuous communication, and also by regular transfers of money and/or material goods. At the same time, however, these links between India and Britain are not without their problems. Several of the cases presented here show that there are substantial differences of opinion between the Indian migrants in London and their relatives in Gujarat on the nature of their relationships and on the types of help rendered. Moreover, the view of the government on the notion of diaspora has also been challenged. Therefore, this article shows the complex process of appropriation of 'Indian diaspora' notions among those who describe themselves as members of that diaspora and their relatives at home. 


\section{Notes}

I We would like to thank Sanderien Verstappen for her comments on an earlier draft of this paper.

2 This research was funded by the Indo-Dutch Programme on Alternatives in Development (IDPAD).

3 Viewing the differences in village size between the Mota Gam and Nana Gam villages, and in order to have a fairly evenly sized sample in both categories, we selected two Mota Gam villages and four Nana Gam villages.

4 All the names in the case studies presented in this paper are pseudonyms in an attempt to preserve some measure of anonymity.

5 For a recent overview of India's interface with its diaspora, see Sinha-Kerkhoff and Bal 2003 .

6 This feeling that has been expressed by our local informants in general, was articulated by Prof. Bhikhu Parekh at a public lecture delivered at the meeting of the Viswa Gujarati Samaj held in Baroda on 2-4 January I999. 



\title{
8 Diaspora Revisited
}

\section{Second-Generation Nizari Ismaili Muslims of Gujarati Ancestry}

\author{
Anjoom Mukadam and Sharmina Mawani
}

\section{Introduction}

The term diaspora seems to have migrated in a manner similar to those it intended to describe and beyond. It began as a way of describing the dispersal of Jews from their homeland (Connor: I986; Vertovec: 2000) and has subsequently flourished as a way of describing the relationship that individuals have with the so-called 'homeland' (Gupta and Ferguson: 1992). In searching the Internet one can find references to English, Australian, Indian, and African diaspora amongst others. The one factor that seems to be highlighted as a feature of all 'diasporas' is the relationship with a 'homeland' (original point of departure), real or imagined, as opposed to that of a 'hostland' (site of arrival). We propose that the association assigned by academics among others, may in fact simply be a relationship that these individuals have with their ancestral heritage (ethnicity). This paper aims to question the very nature of that link with a 'homeland' as it applies to the second generation and beyond. Mukadam (2003: 96) questions the use of terminology that is commonly used in discourse related to the second and third generation and proposes that the term post-diaspora be used to describe these individuals:

It appears that the word 'diaspora', like the word 'immigrant', is no longer being used to refer to the first generation and continues to be used when making reference to the second generation and beyond. If the word 'diaspora' refers to those whose cultural origins are in a different land, then how far back do these communities have to go before they are recognised as belonging to the new homeland or will academics and others always refer to them in relation to a past with which many, at best, have symbolic links?

In the introduction we have seen that there are five main features which are needed in order to define expatriate minority communities 
or diasporas: (I) Dispersal of individuals, communities or their ancestors from an original centre to at least two further locations; (2) Maintenance of a myth in relation to their homeland; (3) Alienation in the country to which they migrated; (4) Envisaging a return to their homeland at some future point in time and; (5) Dedicated to a relationship with this homeland (Safran I99I).

Although these criteria are useful when characterising first-generation migrants, for second-generation individuals and beyond there is a conflict of interest in labelling these individuals as members of a diaspora as it suggests loyalty to the land of their ancestors with which many have tenuous links. At a time when the issue of Britishness has taken centre stage it is imperative that the term diaspora be contested, deconstructed, and reformulated so as to be meaningful and not just a blanket term to be used ad infinitum. If these criteria are used to establish whether or not second-generation individuals born and brought up in the West are members of a 'diaspora' then, in our opinion, it is quite clear that they do not share these features. In fact, we would posit that by positioning them as members of a diasporic community academics are in fact jeopardising their full integration into their only homeland, the one in which they were born. Mukadam and Mawani (2006) have proposed five defining characteristics of post-diasporic individuals:

I. Have not participated in any form of voluntary or forced migration leading to permanent settlement outside country of birth

2. Consider country of birth as their homeland

3. Hold a conviction that they are full and equal citizens in their country of birth

4. Do not envisage migration to and permanent settlement in ancestral homeland

5. Show loyalty to and are active participants in their country of birth.

We will show through further discussion that the maintenance of aspects of Indian culture is in fact an appreciation of their rich heritage which does not amount to a diasporic imagination, rather the formation of a 'new ethnicity' that incorporates aspects of the culture of their ancestors combined with that of the land in which they were born - a hybrid culture and identity that is their defining characteristic.

\section{Patterns of Migration}

Prior to their migration to East Africa, the majority of Ismailis $^{\mathrm{I}}$ in India, primarily residents of Gujarat, were landowners and farmers, though a few were engaged in business, construction, and transportation. Deteriorating conditions in Gujarat in the late nineteenth century led some of the Ismailis to seek work in mills or on the railroads. The move of the capital of the Omani Sultanate from Muscat to Zanzibar 
was followed by a significant increase in the number of Ismailis, alongside other Gujaratis, in Zanzibar from the I840s to the I87os. The Gujaratis were fundamental to the development of the Omani Sultanate. In addition to providing assistance in the exportation of slaves and ivory from mainland Africa, they held prominent administrative positions (Melady and Melady I976; Gregory I993). The famine of I876 saw a dramatic decline in conditions in Gujarat and more Ismailis began leaving India for more prosperous parts. The economic opportunity awaiting the migrants in East Africa inspired the slogan 'Bas Chalo Afrika' (Let us go to Africa) (Walji I974). It is important to note, however, that not all Gujarati migrants went to East Africa, some moved to bigger cities on the subcontinent, such as Pune, Mumbai or Karachi (Gregory i993).

Having resettled in new lands, the Ismailis, like other Gujaratis, continued to practice their traditional ways of dress, food, rituals and language. Apart from religious differentiation, which perhaps was not so clearly visible, the Ismailis appeared to be like any other Gujarati community (Nanji I974; Mohamed I992). In order to distinguish them from other Gujarati groups and allow them to integrate with the indigenous population, for economic, political and perhaps even social reasons Aga Khan III took significant steps in an attempt to modernise the community (Williams I988). The successful modernisation of this community meant that the 'Ismailis evolved a culture which reflected their Indian heritage, their British colonial experience, and their African environment. What evolved was a completely new culture, different from their original Asian culture, which the immigrants had brought with them from their homeland' (Walji I995: II). An article in Africa Today describes the Ismaili community in East Africa as one which 'made this country their home and from the beginning had ceased looking backwards to the country of their origin. Due to this outlook, Ismailis had their marriages - most of them - in this country unlike other Indian communities. They seldom went to India for marriages' (Africa Today I959: 79). Even at this early stage, it is evident that the Ismaili community no longer looked to India as its homeland.

The decades after World War II, saw the end of British rule in East Africa and the Gujaratis in East Africa encountered major disruptions (Buchignani et al. I985: Israel I999). Africanisation and anti-Asian riots disrupted the lives of the Gujaratis. Kassamali, a first-generation Ismaili from Toronto, outlines his personal view relating to the situation in Tanzania after it gained independence in I96r:

After a couple of years in power [Julius] Nyerere [President of Tanzania] thought that 'we have an obstacle and they are the Asians.' So he tried to... frighten us. First, he took away all our 
properties. Number one blow. We didn't move an inch. Second blow, he took away all our businesses. The Asians didn't move. Very few, who had a lot of money, they thought, 'we better go to a safer place'. But the rest of the people remained there. And Nyerere thought these people are not moving. So the third ... tactic he applied was to arrest prominent people (Mawani 2006: $82)$.

It is said that Idi Amin, the President of Uganda, received a message from God during a dream, at which point he was determined to make Uganda 'a black man's country'. In I972, he expelled all South Asians from Uganda, most of whom were third-generation descendants of workers brought from India by the British colonial administration. They were given 90 days to leave the country and were only allowed to take what they could carry. This resulted in a mass exodus primarily to Britain, Canada, and the United States. Soon after Amin's decree, Aga Khan IV contacted Pierre Trudeau, the Prime Minister of Canada, and arranged for more than six thousand South Asians from Uganda, mostly Ismailis, to be accepted as refugees by Canada (Israel, I999). Prime Minister Trudeau issued the following statement:

We are prepared to offer an honourable place in Canadian life to those Ugandan Asians who come to Canada. Asian immigrants have already added to the cultural richness and variety of our country. And I am sure that those form Uganda will, by their abilities and industry, make an equally important contribution to Canadian society (Ismaili Canada I994: I6).

For the second time in their history, the Ismaili community had left behind homes, businesses, and other possessions, this time in search of safety, and were faced with the challenge of integrating into an alien society and re-creating new homes.

\section{Identity Construction in Contemporary Society}

The relationship between history and identity formation is crucial in bridging the past with the present, it is important both to our sense of who we are and how we relate this history to our lives today. In contemporary Western societies there is a clear shift away from assimilation towards a more inclusive and representative view of a multicultural and plural civil society. The process of forming identities and defining oneself involves identifying what one is as well as what one is not; it is an expression of similarities as well as differences. The construc- 
tion of identities is based on oppositions, primarily 'us' and 'them' (Woodward 1997; Pilkington 2003), and while the issue of identity is a fundamental concern of individuals during their lives, it becomes more of a concern 'when something assumed to be fixed, coherent and stable is displaced by the experience of doubt and uncertainty' (Mercer I990: 43). Individuals lack one fixed identity; and instead, identities are multiple and constantly shifting. Specific aspects of an individual's identity are salient in varying contexts and 'no one today is purely one thing. Labels like Indian, or woman, or Muslim, or American are no more than starting points' (Said I993: 407). An individual's identity is no longer restricted to a particular communal identity, such as kinship, community or class, but is based on a variety of sources, including marital status, age, gender, linguistic patterns and eating habits, so there is a greater 'proliferation of identities - of the number of yous on offer' (Bocock I992: I60). The post-structuralist notion of identity as fluid and ever-changing allows individuals to select the identity that suits their needs in a given context. For those from minority ethnic communities 'dominant versions of history and culture and the forms of identity that they encourage often function to exclude, silence, stereotype or render invisible those who do not fit within hegemonic narratives' (Weedon 2004: 24). It is clear that there has been a shift in relation to the terminology used to describe members of ethnic minority populations who have settled in the West. Several academics including Karim (I993), Parekh (200I), Modood (2005) and Mukadam and Mawani (2006) have addressed this issue of ethnocultural terminology and the way in which it needs to be constructed, deconstructed, and reconstructed in order to be meaningful in today's socio-political contexts.

The source of the term 'ethnic' can be traced back to the Greek word ethnikos, an adjective used to describe 'people living together, a company, a body of men, or a band of comrades' (Isajiw I999: 4I3). The word ethnikos 'described people who were not "like us", specifically, who were not Christian or Jewish but Gentile, pagan, or heathen' (Isajiw I999: 4I3). First used by the American sociologist David Riesman in I953, the term 'ethnic' did not appear in the Oxford English Dictionary until I972 (Glazer and Moynihan I975). The American Heritage Dictionary defines the term as

I. a. Of or relating to sizeable groups of people sharing a common and distinctive racial, national, religious, linguistic, or cultural heritage. b. Being a member of a particular ethnic group. c. Of, relating to, or distinctive of members of such a group: ethnic restaurants; ethnic art. 2. Relating to a people not Christian or Jewish; heathen. 
In present-day parlance the term 'ethnicity' purveys a sense of 'belonging to a particular group and sharing its conditions of existence' (Anthias and Yuval-Davies I992: 8).

Isajiw (I999) outlines four primary approaches to ethnicity. The primordial phenomenon approach is the oldest approach in sociology and anthropology, which states that ethnicity is assigned at birth and is fixed and permanent. In opposition to the primordial phenomenon approach, the epiphenomenon approach advocates that ethnicity emerges out of an unequal economy and only refers to minority groups working in marginal jobs on the periphery of the labour market. The situational phenomenon approach, most popular between the mid-I970s and the mid-I980s, acknowledges that the salience of ethnic identity varies depending on its relevance in a given context. In other words, 'individuals may choose to be regarded as members of an ethnic group if they find it to their advantage' (Isajiw I999: 4I4). The subjective phenomenon approach, inspired by the work of Barth (I969) on ethnic group boundaries, considers ethnicity as 'a socio-psychological reality or a matter of perception of "us" and "them" in contradistinction to something given, which exists objectively' (Isajiw I999: 4I4). Barth (I969: IO, I5-6) clarifies that, 'ethnic distinctions...are...often the very foundations on which embracing social systems are built [...and that] ethnic groups only persist as significant units if they imply marked difference in behaviour, i.e. persisting cultural differences.' Another theory within the subjective phenomenon approach is that of 'symbolic ethnicity' as proposed by Gans (I979), which suggests that ethnicity is 'a nostalgic allegiance to the culture of the immigrant generation, or that of the old country; a love for and a pride in a tradition that can be felt without having to be incorporated in everyday behavior' (Gans I979: 9). A more contemporary theory within the subjective phenomenon approach is constructionism, in which 'ethnicity is something being negotiated and constructed in everyday living' (Isajiw I999: 4I4).

While the term 'ethnicity' is an abstract concept that incorporates both the individual and the collective, 'ethnic group' focuses on the collective phenomenon of ethnicity and 'ethnic identity' concentrates on ethnicity as experienced by the individual (Isajiw I999). Both ethnic group and ethnic identity comprise of objective and subjective elements. The objective dimensions are notable details such as familial affinity, ancestry and observable characteristics of the group and its members. The subjective dimensions consist of 'attitudes, values, and preconceptions whose meaning must be interpreted in the context of communication' (Isajiw I999: 4I4). Yinger (I994: 3-4) provides a comprehensive definition of an ethnic group: 
an ethnic group is a segment of a larger society whose members are thought, by themselves or others, to have a common origin and to share important segments of a common culture and who, in addition, participate in shared activities in which the common origin and culture are significant ingredients.

The definition of an ethnic group I have suggested has three ingredients: (I) The group is perceived by others in the society to be different in some combination of the following traits: language, religion, race, and ancestral homeland with its related culture; (2) the members also perceive themselves as different, and (3) they participate in shared activities built around their (real or mythical) common origin and culture.

Fenton (2003: 23), in agreement with Yinger (I994), indicates that while ethnic group refers to groups with a shared descent and culture the phrase also denotes three additional aspects:

I. 'that the group is a kind of sub-set within a nation-state,

2. that the point of reference of difference is typically culture rather than physical appearance, and

3. often that the group referred to is "other" (foreign, exotic, minority) to some majority who are presumed not to be "ethnic".

Mukadam (2003: 74-5) has summarised six primary aspects exhibited by an ethnie (ethnic group or community) in varying degrees as outlined by Smith (1986):

I. 'A common proper name, to identify and express the "essence" of the community;

2. A myth of common ancestry, a myth rather than a fact, a myth that includes the idea of a common origin in time and place and that gives an ethnie a sense of fictive kinship;

3. Shared historical memories, or better, shared memories of a common past or pasts, including heroes, events, and their commemoration;

4. One or more elements of common culture, which need not be specified but normally include religion, customs, or language;

5. A link with a homeland, not necessarily its physical occupation by the ethnie, only its symbolic attachment to the ancestral land, as with diaspora peoples;

6. A sense of solidarity on the part of at least some sections of the ethnie's population'.

It appears that this fifth point, 'a link with the homeland', describing an aspect exhibited by an ethnic group is used incorrectly, in our opinion, by advocates of the term 'diaspora'. It would seem that individual ethnic and/or religious groups have varying degrees of ties with the 
'homeland' and that each needs to be considered individually rather than assuming this link and subsuming whole groups under banners such as the 'South Asian Diaspora' or 'East African Diaspora'. Butler (200I: 193) highlights the problematic nature of the term 'diaspora' in light of increased global migration of individuals and groups and the risk of essentialising the term as an 'ethnic label rather than a framework of analysis'. She does however state quite clearly that 'the construct of homeland is essential; it functions as the constituting basis of collective diasporan identity' (Butler 2001: 204). Does participation in cultural activities that have links with an ancestral home but which have evolved and hybridised in their new environment constitute a diasporic consciousness?

Contemporary Western societies are becoming increasingly multicultural and the question of a diasporic link features in one of the models (C) offered by Yinger (I994: 5) who proposes four models that illustrate the manner in which ethnic groups can exist in multi-ethnic societies:

A. 'A society can be built out of formally equal ethnic groups.

B. A major national cultural group, separated from one or more ethnic groups by a highly permeable boundary, can characterize a society.

C. One or more ethnic groups can be strongly oriented toward an outside mother society.

D. One or more ethnic groups can be "imprisoned" as disprivileged minorities within the larger society'.

It is important to recognise that these models are not mutually exclusive and a multi-ethnic society may consist of two or more models in varying degrees. It is these distinctions between and among ethnic groups that need to be understood more fully in order to analyse more adequately the notion of diaspora. In addition, the layers present within a multi-ethnic society are not permanent, but are constantly changing and shifting as boundaries become more or less permeable; equality among ethnic groups increases or decreases; orientation to outside societies grows stronger or weaker' (Yinger 1994: 5). Lall (200I: 104) questions the identification that many first-generation Indians have with their homeland due to government policy and how their identification with India is at best 'merely a symbolic one'. This statement leads one to infer that the twice-migrants may have even weaker links and that for the second generation these links may be questionable. By way of empirical research we will attempt to show that second-generation Nizari Ismaili Muslims of Gujarati ancestry born in either Britain or Canada are maintaining aspects of their Indian culture and have integrated into the mainstream societies in which they reside. 


\section{Making History - Post-Diasporic Identities}

The constructionist approach to ethnic identity opens a space for newly emerging and evolving hybrid and hyphenated identities, which no longer locates individuals 'between two cultures' (Anwar I975), but allows them to self-identify as Indian, Canadian, or Indo-Canadian, as circumstances necessitate (Cornell and Hartmann I998). To describe those, including herself, of Indian ancestry and British nationality $\mathrm{Mu}$ kadam (2003) coined the term Indobrit. Mukadam (2004) explains why she prefers to use the term Indobrit to identify herself and others like her:

Second-generation Indians born and/or brought up in the U.K. are products of the East and West and their lives combine both with ease. There is no conflict in terms of their identity, they are the fortunate ones who enjoy the best of both worlds as well as multiple identities that are fluid and dialogic. Never again to be defined as 'the halfway generation', 'between two cultures', 'immigrants' or members of a 'diaspora'. These individuals are the post-diasporic generation, creating their own world in the only homeland they have - Britain.

Hybrid terms, like Indobrit, offer the second and subsequent generation a holistic identity that is inclusive and does not result in an 'either/or' misrepresentation of the very complex multiple identities that they possess, yet situates them as belonging to the nation state while maintaining aspects of their ancestral culture. Contrary to expectations, studies have shown that individuals are striving to maintain their ethnic identities. ${ }^{2}$ Isajiw (I975: 132) outlines three patterns of the process of maintenance of ethnic identity: '(I) pattern of "transplantation" of the old culture, (2) the rebellion pattern, and (3) returning or rediscovery pattern'. The pattern of 'transplantation' refers to the efforts of primarily the first generation to replicate their ways of life prior to their arrival in the new country. This is often done by establishing ethnic ghettos or only associating with others from similar cultural backgrounds. The process of replication is not simply a continuation of earlier customs and traditions, as the ways of the new society are sure to infiltrate. Nevertheless, the 'transplantation' pattern of ethnic identity maintenance highlights the preservation of essential characteristics of the group's cultural heritage. The rebellion pattern, often exhibited by the second generation, occurs with growing involvement in the traditions and norms of the majority group. This often results in embarrassment and frustration with the customs of one's own cultural heritage, which causes individuals to consciously reject the practices of their cul- 
tural heritage or to over-identify with the majority group. The returning or rediscovery pattern, displayed by either first, second or subsequent generations, involves those who have been socialised in the dominant culture but whose identification with their ancestral culture has actually increased rather than decreased. This process of returning to one's ancestral culture is not the act of revisiting some forgotten past; in fact it is rediscovering aspects of that culture and bestowing it with new meaning (Isajiw I975).

An analysis of these patterns may distinguish 'transplantation' as that of dissociation, in which the individual maintains all aspects of the ethnic minority culture and does not integrate any aspects of the dominant culture; 'rebellion' as assimilation, in which the individual rejects all aspects of the ethnic minority culture and adopts all aspects of the dominant culture; and 'returning/rediscovery' as acculturation, in which the individual maintains certain aspects of the ethnic minority culture and adopts certain aspects of the dominant culture. In addition, one can also determine that that while some members of a minority ethnic community may move through all three patterns, Isajiw (I975) failed to recognise that others may never move on to the next pattern and in fact may remain static in the first or second pattern. Furthermore, the first generation is more likely to remain in the 'transplantation' or dissociation pattern, with a few moving on to the rediscovery or 'acculturation' pattern, and they may move back and forth depending on their personal circumstances. First-generation individuals can in our opinion be regarded as members of a 'diaspora' as they were actual participants in the migratory process. The second generation, having been born and/or brought up in the dominant society, can move through all three patterns, in any direction at any given time (Mukadam and Mawani 2005).

Based on the comment by Stephan and Stephan (2000: 544), 'If individuals can freely self-identify, their feelings regarding ethnicity will not be denied', Mukadam (2003) and Mawani (2006) incorporated the statement previously used by Phinney (I992) and Saeed et al. (I999), 'In terms of ethnic group, I consider myself to be....', into their questionnaires and then determined which strategy of self-categorisation the second-generation Nizari Ismaili Muslims of Gujarati ancestry born/brought up in London or Toronto have incorporated. Three possible choices exist:

I. Assimilative - identification with the majority group, e.g., Canadian or British;

2. Acculturative - identifying oneself with the use of a hybrid or hyphenated term, e.g., Indo-Canadian or Indobrit;

3. Dissociative - identification with the ethnic minority group, e.g., Indian or East African. 
Table I illustrates the strategy employed by Mukadam's (2003) London respondents and Mawani's (2006) Toronto respondents. Not surprisingly, the results from both the London and Toronto sample are very similar where the majority (London - 59\%; Toronto - 51\%) selected an acculturative hybrid ethnic identity strategy. While 4I percent of the respondents in London selected the popular term British Asian, the respondents in Toronto selected a variety of terms to describe their ethnic identity, which included variations of the terms Canadian, Indian and East African.

Table 1 Ethnic Identity Formation of Nizari Ismailis of Gujarati Ancestry in London and Toronto

\begin{tabular}{|c|c|c|c|}
\hline & $\begin{array}{l}\text { Assimilation } \\
(\text { London }=10 \%) \\
(\text { Toronto }=17 \%)\end{array}$ & $\begin{array}{l}\text { Acculturation } \\
\text { (London }=59 \%) \\
\text { (Toronto }=51 \% \text { ) }\end{array}$ & $\begin{array}{l}\text { Dissociation } \\
(\text { London }=31 \%) \\
(\text { Toronto }=32 \%)\end{array}$ \\
\hline London & British 10\% & $\begin{array}{l}\text { British Asian } 41 \% \\
\text { Indobrit 10\% } \\
\text { British East African Asian 4\% } \\
\text { British Indian } 4 \%\end{array}$ & $\begin{array}{l}\text { Indian } 23 \% \\
\text { African Asian } 4 \% \\
\text { Asian } 4 \%\end{array}$ \\
\hline Toronto & Canadian $17 \%$ & $\begin{array}{l}\text { Canadian Indian 24\% } \\
\text { Canadian East African 7\% } \\
\text { East African Canadian 7\% } \\
\text { East African Canadian Indian 5\% } \\
\text { East Indian Canadian 3\% } \\
\text { Indo-Canadian 3\% } \\
\text { Canadian African 3\% }\end{array}$ & $\begin{array}{l}\text { East African } 12 \% \\
\text { East African Indian 10\% } \\
\text { East Indian } 7 \% \\
\text { Indian 3\% }\end{array}$ \\
\hline
\end{tabular}

Source: Adapted from Mukadam and Mawani (2005).

Whilst second-generation Nizari Ismaili Muslims of Gujarati ancestry are trying hard to maintain certain aspects of their ethnicity, namely, language and religion, the harsh realities of life in an increasingly English dominated world, is that the home is almost the only place where the second and third generation can speak their mother tongue (Hinsliff 2002). Nevertheless, our results indicate that the majority of our respondents, regardless of gender, are choosing to predominantly speak English at home. Interestingly, a significant number of individuals are code-mixing and this is particularly noticeable amongst the Toronto male respondents, again an indication of increasing hybridity (table 2). 
Table 2 Language Use at Home

\begin{tabular}{lccl}
\hline & English & Gujarati/Kacchi & $\begin{array}{l}\text { Code-Mixing } \\
\text { English and } \\
\text { Gujarati/Kacchi }\end{array}$ \\
\hline London Females & $50 \%$ & $30 \%$ & $20 \%$ \\
London Males & $62 \%$ & $15 \%$ & $23 \%$ \\
Toronto Females & $71 \%$ & $14 \%$ & $15 \%$ \\
Toronto Males & $65 \%$ & $0 \%$ & $35 \%$ \\
\hline
\end{tabular}

Source: Adapted from Mukadam (2003) and Mawani (2006).

Alongside language loss is the concept of language shift, 'the process whereby a speech community, which traditionally uses language $\mathrm{B}$, gradually stops using it and turns to language A' (Grin, I993:378). Language shift occurs when 'a language with a greater political power, privilege and social prestige comes to replace the range and functions of a "minority" language. The inevitable result of this process is that speakers of the minority language "shift" over time to speaking the majority language' (May 2000: 366). A form of language shift is evident amongst the Ismaili community in Canada in terms of the publication of The Ismaili Canada magazine. The December 1976 issue of the magazine contained articles in both English and Gujarati. All issues after this one were printed wholly in English. However, the March 2004 issue contained two versions of certain articles, one in English and the other in French. The inclusion of French in the magazine may be a symbolic reflection of the acknowledgement of both of the official languages of Canada by Ismaili institutions, as well as an attempt to fulfil the linguistic requirements of the French-speaking Ismaili community, who are mainly based in the province of Quebec. While language shift in this case does not illustrate the total annihilation of Gujarati in the Ismaili community, it does highlight the gradual loss of proficiency in reading Gujarati, as well as an increase in English as the predominant language of literature within the community.

Interviews with Mukadam's (2003) respondents in London and Mawani's (2006) respondents in Toronto show how these individuals are negotiating the many facets of their identity in order to situate themselves firmly as British/Canadian citizens whilst showing pride in their ancestral culture. All of the respondents in London and Toronto used the terms British and Canadian, respectively, in reference to their nationality.

Rashida (Female Respondent, London):

...the term 'British' is more open. The term 'British' involves a huge range of ethnic groupings. The term 'British' is belonging to a country, irrespective of your colour, or your identity, or your 
cultural background... It's a question of nationality.

Shafik (Male Respondent, London):

It's nice for me to be able to speak to my parents in what is their mother tongue, it's nice for them for me to be able to do that ... it's not essential. And I think the more time you spend in a new environment the more you become acclimatised to it, the more your own identity is diluted by the influence of that environment, society which is good because it means you are obviously integrating...

\section{Culture as a Commodity}

The meeting of cultures often results in the adaptation of certain aspects of one group's cultural elements by another. While at first glance it may appear that it is the minority ethnic communities that are adapting aspects of the dominant culture, a more in-depth examination reveals that there is in fact a mutual exchange of cultural aspects. This is the phenomenon that is often referred to as globalisation. Britain, Canada, and the United States have recently seen an increased popularity in all things Indian and the year 2002 was dubbed an 'Indian Summer' in Britain. There was an explosion of plays and films addressing issues faced by second- and third-generation Indobrits, storefronts were decorated in an array of exotica including bindi, chappal (open-toe sandals) and kurti (short kaftans) and Hindi found its way onto clothing, handbags, and other accessories (Mukadam 2003). The fascination with India and Bollywood quickly made its way westward to Canada and the United States. While some events are a clear celebration of South Asian culture, there are others which are honing in on the South Asian market by incorporating South Asian themes to their advertising campaigns which, according to retail consultant Maureen Atkinson, is 'where the money is' (Yelaja 2004). The popularity of Indian culture and the subsequent increase in producing it as a commodity has met with mixed feelings. Some, like Manjinder Sihota, a shopper at Sears Canada, find the acceptance of Indian culture by the dominant society to be a pleasant surprise, "When you come up the escalator and see all the saris, it's like "Wow, it's really hip to be Indian"“ (Yelaja 2004). Shvetna Dhingra, a third-year sociology and South Asian studies student at the University of Toronto, feels that the promotion of Indian culture in the mainstream has helped her understand her own ethnic identity: 'Until recently, I don't think I actually knew what it meant to be South Asian. I always considered myself Canadian.... Now that I feel more connected to my roots, I'm proud to be a South Asian 
living in Toronto' (Haq 2004). Others, like S. Alladina, are sad that her South Asian peers had to wait for Indian culture to be in vogue before they felt proud of their cultural ancestry. Alladina also points out that with the hype for all things Indian, the significance of the merchandise is disregarded, thus reducing Indian culture to a mere commodity:

I resent the fact that as soon as some aspect of my culture became 'hot' in the mainstream, my Indian peers who usually ignore anything remotely 'Indian' quite suddenly display a seemingly superficial interest in their culture. However, perhaps this renaissance is needed in order for this[...]generation to give the South Asian part of their identity a chance to grow and flourish. We do after all have to deal with the pressures of 'fitting in' and not being typecast or singled out like an outcast. Yet I can't help but feel a pang of remorse[...]The downside to all of this popularity is that mainstream fails to adopt the cultural meaning behind the products they market' (Alladina 2004).

The trend towards all things Indian, from fashion to cuisine, has blurred the distinction between private and public displays of ethnicity amongst this generation. In recent years, there has been growing acceptance of plurality and diversity in Western contemporary societies leading to greater openness amongst those from the majority culture who now appreciate aspects of cultures other than their own. This in turn has led second-generation individuals to comfortably exhibit aspects of their Indian culture publicly as opposed to it being confined to the private domain.

\section{Conclusion}

We began this paper with an analysis of the term diaspora and the ways in which it has been used and continues to be used in society. It is the problematic nature of the term and the way in which it is conceptualised that needs to be redefined so that it can be used meaningfully. Clearly the fact that there are diasporic communities and diasporic studies is essential in understanding the continuing and more extensive movements of people in today's global society. However, as stated in the introduction to this volume, it is clear that there are several communities, such as the Ismailis, who, upon migration, have had little or no connection with their ancestral homeland. While the Ismailis reproduced aspects of their Gujarati culture, such as language, cuisine and dress, both in East Africa and the West, these aspects did not remain static; rather they adapted elements of the local majority cul- 
ture and sometimes merged the two together to create new hybrid forms. These hybrid forms are continually evolving and new forms are being produced by the second and subsequent generations. We posit that for the Ismaili community the maintenance of various aspects of Gujarati culture, in its multiple forms, is not the product of a diasporic imagination. This is the case because our respondents do not have any connection to their ancestral homeland in Gujarat, either through familial or religious ties. Many Gujaratis who have undertaken migration continue to maintain their links with relatives and religious institutions in Gujarat, however, for our respondents these links are non-existent due to the migration of families to East Africa and then to the West. Whilst many individuals of Gujarati ancestry in the West may have religious leaders who reside in Gujarat, and for whom there is therefore a sacred thread to this physical land, for the Ismailis this is not the case as their spiritual leader, Aga Khan IV, resides in France.

In summation, second-generation Nizari Ismaili Muslims of Gujarati ancestry have reconstructed the notion of what it means to be British and Canadian. It is this aspect of these individuals' identities that is often overlooked or omitted when constrained under the broad umbrella of diaspora. For the majority, the inclusion of their nationality in their ethnic self-identification, by the use of labels such as 'British Asian' and 'Canadian Indian', are indicators of their pride in their nationality alongside committed participation in distinct cultural and religious practices. These individuals are following in the footsteps of their ancestors by overcoming discrimination and integrating into mainstream society - they are the post-diasporic generation. Their journey, like that of their ancestors, is clearly enriched by culture, one that is not fixed and does not simply consist of customs that have been passed down from one generation to the next in a preserved state. It is this ability to maintain their cultural heritage whilst adapting to the local majority culture that has been one of the strengths of the Ismaili community.

'Ismailism has survived because it has always been fluid. Rigidity is contrary to our way of life and outlook' (Aga Khan III I954: I85).

\section{Notes}

I The Nizari Ismaili Muslims, otherwise known as the Shia Imami Ismaili Muslims, are a small minority within the global Shia Muslim faith who recognise His Highness Prince Karim Aga Khan IV as their Imam (spiritual leader).

2 Modood, I997a; Saeed, I999; Giampapa, 2001; Mukadam, 2003. 



\title{
9 Bollywood and the Indian diaspora
}

\author{
Reception of Indian cinema among Hindustani youth \\ in the Netherlands
}

Sanderien Verstappen and Mario Rutten

\section{Bollywood and the Indian Diaspora}

Reception of Indian cinema among Hindustani youth in the Netherlands

... deterritorialization creates new markets for film companies, art impresarios and travel agencies, who thrive on the need of the deterritorialized population for contact with its homeland (Appadurai I990: II).

... transnational bonds no longer have to be cemented by migration or by exclusive territorial claims. In the age of cyberspace, a diaspora can, to some degree, be held together or re-created through the mind, through cultural artefacts and through a shared imagination (Cohen I996: 516).

When media are discussed in the diaspora literature, usually the assumption is that transnational media reconnect diasporic communities to their home countries. Media feed the homesickness of first generation migrants (Karim 2003), who use movies and television serials to educate their children about their country of origin (Gillespie I995: 7895). Media invite viewers to identify transnationally (Mishra 2002: 250269), make migrants reconsider the boundaries of community (Morley 2000: IOO-IOI) and may even guide them into long-distance politics (Anderson 1998, Allessandrini 200I).

The assumed link between media from the home country and viewers' identification with that home country is problematic and must not be taken for granted. Indian diasporic communities in the Netherlands have watched Indian films from Bombay since 1958, and have been the initiators of a blossoming 'Bollywood scene' in The Hague. This article describes how Hindustani youngsters appropriate Indian cinema 
in this specific context. Transnational meanings can be found if one is determined to look for them, but these are not at all the most important aspects of Hindi cinema to the youngsters themselves. Their love for Indian movies is completely detached from the actual locations and people within India. The account that follows is based on four months of fulltime fieldwork in The Hague by one of the authors. ${ }^{\text {I }}$

\section{Bollywood}

The Indian film industry has always targeted audiences around the globe. ${ }^{2}$ Hindi films from Bombay (often referred to as 'Bollywood' films) have been popular in Afghanistan, Iran, the Middle East and Sri Lanka ever since the I940s. ${ }^{3}$ Overseas Indians and their offspring in the Caribbean and in Malaysia, for example, have always been an important target audience. In the second half of the twentieth century, a growing number of Indians moved to Western countries, and so the export of Hindi films moved to Europe, the United States, Canada, and Australia (Mishra 2002: 239-340). Since then, special efforts have been made by Indian filmmakers to appeal to the Indian diaspora audiences in the west. In order to compete with Hollywood, themes and story lines were changed and efforts were made to adapt the cinematographic outlook of Hindi cinema.

Diasporic audiences in the west turned out to be a small but lucrative market for Hindi cinema. In Europe and America, a ticket to the movie theatre was priced higher than in India, and was paid in desirable foreign valuta (Dwyer 2002: I78-I79). At the same time, however, the industry faced new problems in these western territories. The investments were high and the films had to be screened over a longer period of time to cover the costs. The predominance of American cinema in the west meant that viewers had specific cinematographic expectations, expectations that were not always compatible to the genre characteristics of Indian cinema. Attempts to live up to the audience's expectations included dubbing Hindi films into English, the deletion of song sequences and the export of 'uncensored' versions. Some of the three-hour films were even edited down to shorter versions that would be more acceptable to an audience accustomed to Hollywood featurelength films (Dwyer 2002: I80, Allessandrini 2001: 327). Although most of these experiments were seldom successful, they show that filmmakers were eagerly taking up the challenge of reaching out to the Indian diaspora in the west. This is also clear when we look at the content of Hindi films from that period, which was adapted considerably to match diasporic tastes. 
Indian filmmakers had always made movies about Indian migrants. The first documentary film made in India was Sir Wrangler Mr. R. P. Paranjpye (I902), about a man from Maharashtra that had studied math at Cambridge. A popular fiction film in I921, Bilet Pherat (England Returned), was also about an Indian man returning after a long stay in Britain. This returnee had strange habits and peculiar ideas about romantic love, and became the object of joking and ridicule in the movie. ${ }^{4}$ Purab aur Pachhim (East and West), a nationalist motion picture made in I970, showed Indians in London dancing and feasting in a haze of booze and cigarettes. The youngsters in the film were thoroughly westernised and had totally forgotten their own history, even despised it. Luckily, one honest and honourable young Indian man showed up, who taught the female star to love her country again.

When the film industry began becoming interested in the diaspora as a target audience, the imagery changed. A new 'transnational optic' in Indian media was the result (Moorti 2002). The first film that did not ridicule the diaspora, and instead tried to appeal to it, was Dilwale Dulhaniya Le Jayenge (I995). The film anticipated the supposed desire of the Indian diaspora to rediscover their homeland, and treated their feelings of nostalgia and longing very seriously. ${ }^{5}$ In the opening scene, we see a Punjabi migrant feeding the pigeons on Trafalgar Square, murmuring and dreaming about his wish to return 'to my land, to my Punjab’. After having lived in England for 22 years, his wish comes true when his daughter agrees to marry a Punjabi man. The return is conceived with great splendour: The land green and fertile, music echoes across the fields and females in colourful clothing sing: 'Come home stranger, your country calls you back!' In the meantime, the daughter has fallen in love - but not with the man that her father had chosen for her. The object of her love is a young man who has grown up in England, like her. This young diasporic hero turns out to be equally true to his Indian roots. He proves this by refusing to elope with his beloved until both her parents approve (Mishra 2002: 250258).

Dilwale Dulhaniya Le Jayenge (DDLJ) was very successful in India and abroad. In an interview with Lata Khubchandani, director Yash Chopra explains its tremendous success:

It's the story. It goes to the very roots of Indian culture. It highlights most importantly that we respect our elders. You just do not run away or elope with the person you fall in love (sic); instead you take the parents consent and their blessings... it's like 'I'll marry you only if your father gives your hand to me'. ... That's what made $D D L J$ a cult film. It became more so overseas because the characters in the film were ones based overseas who 
come to India to find their roots. ... I think the main reason [for its success] was the story and the fact that it helped people find their roots. ${ }^{6}$

$D D L J$ was the first in a series of films that fore grounded the diaspora. Other international box office hits with a diaspora dimension were Pardes (1997) Kuch Kuch Hota Hai (1998), Kabhi Khushi Kabhie Gham (200I), Mujhse Dosti Karoge (2002) and Hum Tum (2004). Like DDLJ, they show characters living in the west, or returning to India after a long stay abroad. These cosmopolitan characters are rich and young, consume themselves to death, are searching for romantic love, but are at the same time very inclined to maintaining Indian family values and Indian traditions.?

Kuch Kuch Hota Hai $(K K H H)$ is set in a high school in India. One of the female students has just returned after having lived abroad for years. When her classmates criticise her for having forgotten her Indian roots, she proves them wrong by singing a bhajan (Hindu song): Om Jai Jagadish. The classmates are stupefied. Diasporic elements are no longer the central theme of the story here, like in $D D L J$, but have been casually inserted into the love story. This is common procedure nowadays: filmmakers invariably include at least one migrant character even when the theme of migration is only of limited importance to the main story line; for example in Yaadein (200I), Om Jai Jagdish (2002), Devdas (2002), Kal Ho Naa Ho (2004) and many others.

This is also the case in Kabhi Khushi Kabhie Gham $\left(\mathrm{K}_{3} G\right)$, a movie that introduces the theme of diaspora only after I.5 hours of intense drama. The second part of the film brings us to London, where Indians drive around in expensive sport cars and own huge homes. Again, we see that the migrants have not forgotten their roots: 'It's all about loving your parents.' Female star Kajol performs puja every day and expresses her dislike for the English language and culture through grotesque imitations of her white neighbours. When her son is about to perform at school, she expects to hear the stiff and childish English song 'Do re mi'. To her astonishment, the boy starts to sing the Indian national anthem - and all his white classmates sing along. In this moment of ultimate motherly joy, she bursts into tears and runs to embrace her son.

Bollywood, of course, shows us an Indian fantasy about the diaspora (Mishra 2002: 266-269). In this fantasy, India is the centre of the world and the diaspora is its periphery. India is endowed with all kinds of desirable values such as purity, authenticity, and piety. The diaspora, on the other hand, is rich and free but corrupted and self-centred. These migrants can do everything that is forbidden in India, but still they crave for their long-lost homeland and often make sacrifices to reconnect with it. And so they prove, over and over again, that they are 
true to the authentic Indian morals represented in the films. Whether they live in London, in Sydney or in Paris, they will ultimately keep the Indian culture alive.

Bombay's film industry is often referred to as 'the dream factory of India' in that it appeals to poor viewers because the glamorised arena of cinema allows them for three hours to forget the harsh realities of their underprivileged lives. Nowadays, we could also call the Indian film industry a 'nostalgia factory'. Having looked into the specific dreams represented in successful films from the I990s, we see that nostalgia is a crucial theme. From the perspective of the filmmakers, overseas Indian viewers have specific desires and needs; they crave a sense of belonging and dream about being reconnected to their roots. If Indian cinema wants to appeal to these people, it must fulfil these wishes and help them reaffirm their Indian Identities. Director Mahesh Bhatt stated in an interview:

Hindi films have truly become a cross-border phenomenon. ... Asians are asserting themselves these days. They are trying to de-link from their own environment with a strong expression of taste. This is being manifested through Hindi cinema. For a long time they were completely preoccupied with making money. Now they are satiated and have the buying power. Music and films are what they are turning to. Films in the main allow them a nostalgia trip, a vision of the India they left behind (Bamzai I999).

If Hindi films provide a nostalgia trip, do the intended viewers actually embark on this trip? Do they indeed feel de-linked from their own environments, do they actually crave for a lost Bharat Mata, and do they use films purposefully to make up for this loss? According to Yash Raj Productions, the Netherlands is the second largest national market (after Great Britain) for Indian films in Europe. ${ }^{8}$ For decades now, it has been the Hindustani community from Suriname that has been the main audience for Hindi cinema here.

\section{Dollywood}

Surinamese Hindustanis in the Netherlands are so-called 'twice migrants': they are the descendants of indentured labourers from North India, who came to work on the sugarcane and rice plantations in the former Dutch colony of Suriname in the late nineteenth and early twentieth century. About 34,000 British Indians were shipped to Suriname in the decades after the abolition of slavery; only one-third of 
them would eventually return to British India. The migrants came from a poor region called Hindustan, nowadays referred to as Bihar and Uttar Pradesh, and were thus called 'Hindustanis'. 9 They came from various backgrounds, spoke different languages, and had varying religious beliefs. On the plantations, a koine language developed that was later given official recognition as one of the Surinamese languages: Sarnami, sometimes referred to as 'Hindustani' (Damsteegt 2002).

The labourers who remained in Suriname after their contracts expired were given a plot of land by the Dutch government, mostly in one of the isolated provinces of Nickerie and Saramacca. Their farms were able to profit from the decline of the Dutch plantations (Buddingh' I995: 255-26r) and a top level of successful Hindustani rice farmers developed. In the city, Hindustanis were active in transport and business, and aimed for upward mobility through education (Hira i998: I5-16).

Around the time of Suriname's independence in I975, large numbers of Surinamese migrated to the Netherlands. Job opportunities were much better there, and many of Suriname's inhabitants wished to retain their Dutch passports. Hindustanis, the second largest ethnic group in Suriname, also feared the independent country would be ruled by 'Creole' (black) politicians, the largest ethnic group.

At the moment, 325,000 Surinamese live in the Netherlands. ${ }^{\text {Io }}$ Of this total, I60,000 are Hindustanis. The Hindustanis thus compromise one percent of the total Dutch population (Choenni and Adhin 2003: 8). They themselves often claim to be very well 'integrated' into Dutch society, as they speak Dutch better than many other immigrant groups and do relatively well in terms of labour participation, education, and upward mobility. These statements are confirmed in some regards by recent research findings. ${ }^{\text {II }}$

Half of the Hindustanis are under 25 years old. Most of these youngsters are born and raised in the Netherlands (Choenni 2003: I70). Religiously, Hindustanis are divided: eighty percent are Hindu (Ramsoedh 2003: I08), fifteen percent are Muslim (Landman I992: 204) and about five percent are Christians; each of these religious groups has several subgroups, paralleled by a wide range of differing religious organisations.

About half of the Hindustani population in the Netherlands lives in or around The Hague, the administrative capital of the country. About ten percent of The Hague's population is of Surinamese Hindustani descent. Most of them live in the two downtown areas, the Schilderswijk and Transvaal, where one can find many temples, mosques, and volunteer organisations that cater to the spiritual and worldly needs of the Hindustani population. There are numerous import shops that sell products from India and Suriname; among them are at least ten specia- 
lised 'Hindustani' video rental stores. Every weekend, special events are organised for the Hindustani audience: fashion shows, dance events, music performances, live theatre, or movie screenings. Not surprisingly, the city has sometimes been referred to as the 'city of Hindustanis' or even 'Dollywood' (a combination of Den Haag and Bollywood). ${ }^{\text {I2 }}$

Indian cinema has always been a huge success among Hindustanis, ever since its introduction in Suriname in the I930s (Manuel I998: I9). In the I950s, an observer called it 'the principal expression of the cultural life of Hindustanis in Suriname' (De Klerk I998: 215). At that time, cinemas provided one of very few opportunities to go out. Farmers in the rural districts travelled large distances to the nearest movie theatre; the outings provided a rare opportunity to meet relatives, exchange the latest news, and look for potential marriage partners (Bijmans I996: 59-60).

When the first Hindustanis migrated to the Netherlands, Indian cinema moved with them. The first Indian movie shown here was Aan, in I958. It arrived in the Netherlands via Suriname: the celluloid film was transported in boxes along with tropical fruits, vegetables, and other 'homesick items' to be sold to Hindustanis who had migrated to the Netherlands (Bijmans I996: 6I-62).

The Dutch market grew rapidly in the I970s as a result of the mass migration of Surinamese Hindustanis to the Netherlands. The West-Indian Film Society and Roshni Film Society were founded. These companies had established trade connections with film entrepreneurs in England and were commercially successful. Beginning in I972, films were shown every Sunday in the four main Dutch cities The Hague, Amsterdam, Rotterdam, and Utrecht. Smaller theatres also showed films on an irregular basis. The Dutch government even established a travelling movie theatre in I975. The travelling theatre toured to the immigrant centres in the Northern provinces from 1976 to 1982, screening Hindi films in order to entertain new Surinamese immigrants (Bijmans I996: 62-64).

These booming years of Hindi cinema in the Netherlands lasted until the beginning of the I980s, even though overall cinema attendance in the Netherlands went steeply down in that same period as a result of the competition from television, video and other new forms of recreational entertainment. ${ }^{\mathrm{I} 3}$ It was video that would eventually drive the Hindustani crowds away from the theatres. The first official Hindustani video rental that opened in the Netherlands was Ram's Videotheek, in I974. Ahmed Video Centre, Roshan Video en Govinda's Video followed five years later. From I986 to I99I, not one Hindi film was shown in Dutch cinemas (Bijmans I996: 78-80). Hindustanis had retreated into their private spaces; watching films whenever, wherever, and with whomever they liked. 


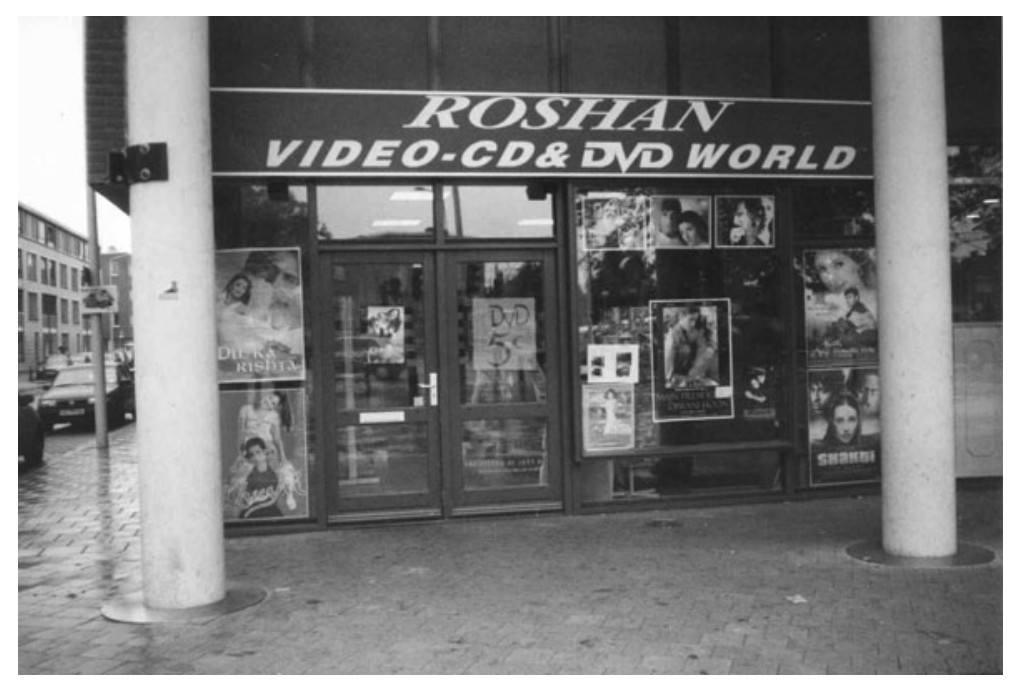

Roshan Video, a well known video store in The Hague Photo: Sanderien Verstappen

Young Hindustanis that had grown up in the age of video had never showed much interest in the Indian classics that their parents loved so much. Even though many of them felt an affinity with Indian music, most of them preferred to watch American movies. Compared to Hollywood, they found the three-hour long Hindi melodrama's boring, and cinematographically of poor quality.

Since 1998 however, a revival of Hindi cinema has occurred among the younger generation. For many of them, it all started with the movie Kuch Kuch Hota Hai. This film toured the Netherlands three times, and each time, theatres were sold out to the last seat. The film generated sizeable profits for its distributor Ramsfilm and, moreover, it marked a turning point in the market for Indian cinema in the Netherlands. For the first time in a long period, the young felt an affinity with a Hindi film. Their enthusiasm for Hindi cinema has continued ever since and so the younger generation of Surinamese Hindustanis became the driving force behind the re-emerging 'Bollywood scene' in The Hague, spending their pocket money on CDs and DVDs as well as keeping up with the latest gossip on their favourite Bollywood stars through magazines and cable television.

Since then, film screenings have been organised about once a month in The Hague; these have been commonly sold out even though tickets are relatively expensive. In 2004, mainstream Pathé movie theatres started to distribute Hindi cinema on a daily basis, so screenings be- 
came cheaper and more easily accessible. In the video rental stores, fifty percent of the visitors are now under thirty years of age. ${ }^{\mathrm{I}}$ Hindustani dance parties are also organised every weekend, sometimes in huge party halls on the outskirts of the city; teenagers and tweens come here to enjoy live performances and remixes of Bollywood songs, performed by local artists. A dozen movie dance schools teach young girls how to dance to this music; clothing shops in the Hindustani neighbourhood of Transvaal sell the matching outfits. Bollywood ringtones, Bollywood school organisers and Bollywood key holders are the appropriate gadgets available in both video rental stores and on the Internet. $^{\mathrm{I} 5}$

The revival of Indian cinema among Hindustani youth was partly a result of substantive changes in the aforementioned film scenarios. The young certainly noticed that the new love stories were 'more modern than before'. But formal improvements in Hindi cinema were equally important. Hindustanis in the Netherlands were happily surprised by the 'professional' appearance of the newest films, which integrated the latest camera, lighting, and editing techniques and were thus well-suited to compete with the Hollywood blockbusters.

Three other factors contributed to the Bollywood revival. First, the arrival of digital television, and consequently the timely availability of information among subscribers about upcoming films and stars, made people talk more frequently about Hindi cinema - and visit the video stores more often. Secondly, DVD came along (in 2002). This new data carrier was considered 'clean' because it lacked the annoying 'snow' and other distortions that had typified Hindi cinema in the era of video, and moreover it brought English subtitling.

Subtitling clearly helped trigger young people's interest, as many of them no longer speak much Hindustani (Sarnami) and have even less knowledge of 'proper Hindi'. One young man, Rakesh (25), explained:

Ever since subtitling came along, I watch Hindustani films more often. In the past, I did not like them at all, although I did feel connected to some of the stars like Amitabh Bachchan. Now, we have the films by Amitabh Bachchan on DVD. The other day I sat with my parents to watch Muqaddar Ka Sikandar. We had seen it before, but now for the first time it was subtitled. It was a revelation! I watched my eyes out. What beautiful dialogues ... and all of these years I had missed them! In the past, I used to make up my own story - in my head. I think I only understood 25 percent of the dialogue: I was happy to pick up any of the words. And when they danced, you knew they were in love. But now I understand why my parents cry, and I am myself deeply 
touched as well. When you know what they are saying, you have to cry.

Another factor that gave a strong impetus to the Bollywood revival among young people was the growing interest in Indian cinema in the wider Dutch context. New initiatives since 1995 has attracted a broader audience. The Royal Tropical Institute started the festival Cinema India, which generated serious reviews of Indian films for the first time in Dutch newspaper history. In 2000, the annual Hindustani Film Festival came into existence, working together with established art houses in various cities. Since 200I, the NPS (Dutch Broadcasting Foundation) has been programming Indian films on television several times a year, mostly on Sunday afternoons during the winter months. In 2002, Oscar nominee Lagaan toured the Dutch art house circuit and received very enthusiastic reviews from prominent Dutch movie critics. In 2005, when Amsterdam hosted the IIFA (Indian International Film Academy) Award Ceremony, 'the 'Indian Oscars', Indian cinema was suddenly news across all mainstream Dutch television channels and newspapers. Nowadays, regular movie theatres in The Hague, Amsterdam and Rotterdam show Indian films on a daily basis and regular video rental stores have a limited stock of Indian (art) films available.

The increasing availability of Indian cinema in the Dutch context reflects a broader tendency in international popular culture. In the I990s, trend watchers witnessed the breakthrough of Asian architects, Asian designers, and Asian musicians. By 200I, India had become 'cool' on MTV as well. Superstars like Madonna and Janet Jackson exhibited oriental styles in their videos, prominent disc jockeys produced club remixes of Bollywood soundtracks, and scenes from the colourful urban India even popped up in television commercials (Hulsman 200I, Moorman 200I).

In the past, India's culture was most commonly seen as age-old, traditional, and deeply spiritual. But nowadays, the attention is focussed on India's urban and popular culture. Indian clothing and jewellery are no longer considered 'religious' or 'traditional'; on the contrary, they have become perfectly suitable to wear to a dance party. Hindustani youngsters who are fine-tuned to these changes in imagery, happily followed this trend. For example, a teenage girls who bought a salwar kamis several years ago - for a wedding - suddenly realised how 'hip' it was, and showed it off at school dances.

Hindustani youth can now watch Hindi films with pride, not having to feel ashamed for watching 'low budget' and 'kitsch' musicals any longer. They can talk about the latest films at school with non-Hindustani friends more easily than ever, and many do so with great enthusiasm. 


\section{Bollywood and India}

Do the devoted film fans among Hindustani youth in The Hague correspond with the projected images of the diaspora audience we encounter in some of the literature? Do teenagers watch DVDs to learn more about their ancestral homeland? Do they go to the video rental store to reaffirm their Indian identities? What image do these movies conjure up of India? In what sense do these create a relationship to the homeland, a sense of roots or even long-distance nationalism ${ }^{\mathrm{I}}{ }^{\mathrm{among}}$ the youth, who are indeed highly aware that their family histories lie partly in India?

When asked openly about Indian cinema, Hindustani youths do not mention India that often. When asked specifically about the relationship between the movies and India, many respondents replied concisely: 'What you see in the movies is not India. It is a world of dreams. The setting is India, yes, but that is not of crucial importance to the story'. For any researchers immersed in the diaspora discourse, like us, these kinds of responses can hardly be very satisfying. When the interviewer pursued her point, however, asking, for example, what the respondent had learned about India by watching Hindi films, some of them got really annoyed. 'How could anyone believe that Bollywood represents India truthfully? It is all fiction, of course. If I want to learn something about India, I'll watch a documentary!'

In the eyes of these youngsters, there are only a few Hindi films that represent India accurately. A famous example is Lagaan: Once upon a Time in India (2003). Lagaan was the first Indian movie to be officially screened in the Dutch art-house circuit; a circuit that, according to one respondent, 'is usually preserved for highly intellectual French and Italian movies'. The educated elite among the Hindustanis took Lagaan very seriously because it was nominated for an Oscar and because it was received well in the Netherlands. In the Haags Filmhuis (The Hague Cinema House) for example, the audience for Lagaan consisted mainly of white people. ${ }^{I 7}$ Lagaan was also taken seriously because, contrary to many other films, 'it is about India'.

Lagaan takes place in a poor village in the northern Indian countryside during the age of British India. The villagers are upset because this years' harvest has been lost and the authorities have doubled the tax (lagaan). When they plead for an exemption to their local lord, a cruel British officer challenges them to join him in a game of cricket. If the villagers win, they will be freed from taxation. But if they lose, they will have to pay triple.

Some of the Hindustani students saw Lagaan in the art house and were struck by its 'authenticity'. The fact that it was spoken in Bojpuri, a language that they found unintelligible and unpretentious, certainly 
added to the authentic flavour. On the way home, one of the girls asked: 'Is this really how cricket got introduced into India?' One of the boys replied: 'Not exactly, but approximately'. Said, a I9-year-old psychology student, made the following remarks about Lagaan:

I thought Lagaan was excellent. Lots of deep layers. It is all about India's caste system, Hindu-Muslim relations, interactions between the British and the Indians ... and the integrity of it, just a village like that. No flashy cars, no beautiful clothes ... this is India, you know. It's just quite representative. I also bought the music tape and then you usually get this extendable cover showing pictures of beautiful clothes and all that ... here you just see that cricket team. If you go to a village in India, you'll see the same. This is what people wear in a village in India.

Said thinks Lagaan is special and 'not standard Bollywood fare.' He describes it in comparison to other Indian movies, in terms of what the film does not show: no flashy cars, no fancy clothes. Contrary to most other Hindi films, which show super-rich people living a shiny lifestyle full of glitter and glamour, Lagaan shows poverty in the countryside. Said thinks this is more like Indian reality, and that's why he likes this film so much.

We must emphasise here that Said is a fanatic viewer of world cinema and art cinema, a characteristic he does not share with most of his Hindustani peers. Said is very critical of Bollywood films. He calls them 'commercial' and 'standardised'. Lagaan is his favourite precisely because it is different. Although Said's taste is shared by some of the highly educated among Hindustanis, Lagaan did not become a huge hit. ${ }^{18}$ Most Hindustani youngsters saw Lagaan on DVD and thought it was 'rather amusing' but they did not feel a special connection to it, nor did they feel inclined to watch it a second time. Unlike Said, they do not care much for 'the reality of India'.

Most Hindustani film fans have no notion of what daily life in South Asia is like, and more importantly, they are not interested either. For example, out of eleven respondents that had access to ZEE TV at home, none watched the daily nine o'clock Indian news. They preferred Dutch news programs. One explanation given was that the Hindi vocabulary used by the ZEE TV reporters is 'difficult to understand'. But apart from that, the social and political affairs in South Asia are never an issue of conversation among Hindustanis. This is true not only for the youth but also for most of their parents. 'What happens there doesn't affect me', one mother said. 'I don't need to know if they are tearing down a temple, or if they've attacked Pakistan'. This lack of interest in India's social and political affairs partly explains why films 'about In- 
dia', like Lagaan, are not that popular among the Hindustani youth in The Hague. Gossiping about Indian film stars is standard behaviour during social gatherings, but the daily affairs of the common man in South Asia do not qualify as relevant.

\section{India and Hindustani}

It is clear from earlier research as well as ours that Hindustanis show ambiguous attitudes towards India. ${ }^{\text {I9 }}$ On the one hand, Hindustanis are highly aware that 'India is the country our ancestors came from', and many have foregrounded this Indian background in public discourse. On the other hand, Hindustanis also identify themselves as a separate category that has its own distinct language, history, and culture. When they compare themselves to the population of India, they usually describe themselves as financially better off, better educated, more modern, better suited to life in the west, and, in general, more comfortable. Indians are poor, repress women, and face brutal caste discrimination, while these aspects of Indian society are said to be absent in Hindustani culture in the Netherlands and Suriname. ${ }^{20}$

More than anything else, India is perceived as a poor country in the Netherlands. The slums, the beggars, the crowded streets, the earthquakes, and the floods are shown on Dutch news programmes and in Dutch newspapers on a regular basis, so anyone who lives in the Netherlands is accustomed to them. Hindustani children are also brought up with the idea that their ancestors worked hard to free themselves from poverty. Having come to Suriname with nothing but the clothes on their backs, the ancestors worked everyday and saved every penny, to give their children a better future. The idea that India is (still) poor and Hindustanis are not (anymore), is thus a vivid point of reference in any discussion about Hindustanis versus Indians.

The issue of female repression is similar. When asked to compare themselves with Indians, some Hindustanis remarked that women are treated worse in India than they are in the Netherlands. Spectacular stories about the burnings of widows, rape, and violence against women popped up every now and then during the interviews. These stories served mainly to bring Indians into disrepute vis-a-vis Dutch Hindustanis. Girls as well as boys emphasised for example that: 'Women in India are treated like slaves, especially in the villages ... here, a woman can more easily go her own way'.

A third issue that is said to set Indian society apart from Hindustani culture, is caste. According to Hindustani youth, the caste system is an essential characteristic of Indian society. It is not, however, part of Hin- 
dustani culture in the Netherlands. This point was emphasised during interviews, as well as in historical literature.

During the process of migration to Suriname, the power of the caste system as an organising principle of society was lost (De Klerk I998: I67). This started in the depot in Calcutta where the migrants waited for months to board a ship that would bring them to Suriname. In the harbour, it was impossible to maintain the prescribed purity regulations: high castes and low castes had to sleep side by side, stand in line collectively to wait for their food, and they were cared for by servants of varying social backgrounds. Keeping to your own kind was simply unworkable in those circumstances (Hira 2003: I28-I3I). Furthermore, there was a shortage of women among the migrants, so the endogamous marriage rules were impossible to maintain (De Klerk I998: I69-I70).

The Hindustani youth interviewed had a very negative impression of the caste system in India. They saw it primarily in terms of caste discrimination and seemed eager to announce that they themselves were 'beyond' that. Considering caste, gender and money, many Hindustani youth consider themselves as being more 'modern', more 'emancipated' and more 'well-to-do' than the India they visualise; an India that is essentially rural and poor, backwards, and in some sense morally unjust. That image of India can hardly be derived from Hindi films however: Other sources such as documentaries, news reports on Dutch television, rumours and orally transmitted stories inform them about the India they describe. In fact, most of the new movies actually contradict the imagery of poverty as described. Although poverty and violence against females used to be included in classical Hindi cinema, they are generally ignored in contemporary Hindi cinema. The caste system is barely evident in most movies: when it is portrayed, it is often in an ambiguous or indirect way.

Hindustani youth are not surprised about this paradox at all. First of all, poverty doesn't sell. 'Who wants to see a village where everybody walks around in dirty clothes?' one teenage boy said. 'Indians see that all day long.' Another boy said that 'in the Indian movies you can see everything you wish for, all the things you aspire to: large house, cars, a beautiful room, totally posh, luxurious tapestry, roses and moonshine ... what more do you want?'

Secondly, although violence against females was a common theme in the movies made in the I980s, the tone has changed significantly. However, viewers still notice elements that strike them as violent. This was revealed, for example, during a lively discussion about a short but remarkable scene in the popular film Devdas where a man slaps a woman in the face and gives her a scar, even though he loves her to death. The group consensus was that this behaviour was 'strange' and 
'ridiculous', but they also added that 'what you see in the movies is only the tip of the iceberg. Female repression is in fact much worse in India.' ${ }^{2 \mathrm{I}}$

Thirdly, caste is represented in contemporary Bombay blockbusters but rarely in an explicit way. In Kabhi Khushi Kabhie Gham for example, caste is not mentioned at all as an obstacle to the intended marriage between Kajol and Shahrukh Khan: the girl simply 'doesn't fit in with' and 'wouldn't understand' the boy's family traditions and status. In Devdas, caste differences between the two families is clear to the viewer, but nevertheless is left unspoken. Instead, the boy's father accuses the girl of indecent behaviour while his mother disdainfully ridicules the rude habits of the girl's mother.

This rather implicit, ambiguous approach fits in very well with the ambiguous attitude that Hindustani youth themselves feel towards the caste system. Although most of the young claim that the caste system is nonexistent in the Netherlands, many also noted that their own parents preferred that they marry 'within a family that befits us'. Common demands put forward by the parents are a certain amount of wealth and education, light skin, and, in any case, marrying within the Hindustani community. Literature on the subject explains that specific elements of the caste system, such as the varna consciousness, remain vibrantly alive in some Hindu families (Mungra I990: II6-II9). If the boy's family claims to be from a Brahmanic background (even though this claim may be disputed by others) they usually prefer the girl friend to be of the same status (even though they may avoid speak openly about such expectations in public).

The notions these youngsters have about Indian society are quite different. As they see it, caste discrimination is much harsher in India than it is in the Netherlands, and it is much more explicit in real India than in Bollywood movies, The 'Indian way' of dealing with caste, as deduced from the interviews, can only be seen in exceptional films like Lagaan. In Lagaan, a casteless man is explicitly bullied by his fellow villagers; they initially refuse to play on a cricket team with a man from a lower caste. The explicit treatment of caste here adds to the truly Indian flavour of that film, reaffirming its exceptional Indianness in comparison to most other Bollywood films that treat the subject indirectly

Having noted all this, it is hardly surprising that Hindustanis barely mention 'Indian movies' when describing the majority of commercial Bollywood blockbusters; they prefer the phrase 'Hindustani movies'. Most viewers have not given it much thought, but it nevertheless points out something significant: that for many Hindustanis these movies represent the Hindustani culture better than they represent their projected ideas of Indian society. 


\section{Hindustanis and Bollywood}

When discussing their favourite 'Hindustani films', the fans enthusiastically describe the handsome actors, the enchanting music, the wonderful dances, and the hilarious comedy scenes. Some viewers specifically note the fashionable clothing; others play the songs over and over to copy the dance steps. However, there's more to Bollywood: 'It is also about the story.'

Many respondents said they felt a thoroughly personal connection to some of the movies. Even those who watched only few movies per year claimed that their involvement was very strong. Their favourite films were usually the ones they related to in a personal way. Compared to American films, which they also liked to watch, they felt that Hindi films 'come closer to who I am'.

Avinash was born and raised in The Hague; he is the eldest son in a family of three children. He is 26 years old, lives with his parents, works fulltime at a ministry and is studying economics. Avinash sees Indian video clips and film scenes daily; his family has a subscription to the digital cable channel ZEE TV. About twice a month Avinash watches an entire Hindi film with his friends, either in the movie theatre or at home.

When Avinash was asked what it means to have watched so many Indian movies, he said they make him feel normal: 'Our traditions, the norms and values we grow up with, and the experience of that ... what you see in the films is the same.' For example, Avinash explained that his family has been very important to him all his life, and this special bonding with his family made him feel quite abnormal within the Dutch context. Whereas most Dutch youth spend limited amounts of time with their grandparents and extended families, Avinash keeps in close contact with many members of his rather large extended family by going to birthday parties, the hospital when an aunt is ill, helping an uncle out with his chores at home. Avinash has a close relationship to some of his nieces, whom he calls 'didi' (older sister), and he always invites his brother along when he is going out.

Avinash and his best friend Gopi could talk for hours about the 'special type of caring' experienced in their families, which they described as typically Hindustani, and which they recognised in 'Hindustani movies'.

Avinash: My parents were on holiday for two weeks. Everyone phoned: aren't you hungry, can I cook you something? Join us for dinner! At other times, they might phone and say: 'Can you help me in the house, I made pom especially because I know it is your favourite ...' You just feel that these people have you on their minds all the time. 
Gopi: When they know you like something, and they make it for you and then call you up, they can get really angry if you don't show up. It is a weird type of care, a very special type of care. Very beautiful.

Avinash: It is very different in Dutch families.

Gopi: In Dutch families, you might find elderly women who claim they have been forgotten that nobody comes to visit her. We think you should care for the ones that gave birth to you. When someone is in a nursing home, everyone comes by and brings food.

Avinash: When I was in hospital, it was really busy everyday with my parents, and all my family members, whoever. There was this Dutch boy in the same ward. His parents would visit him every now and then, maybe once a week! And when I took driving lessons, my parents came outside to take a look at how I it was doing. There was a Dutch girl in the car and she found that odd. But I think it's really great that they come and watch! Gopi: When I took driving lessons, my parents asked if they could come with me in the car! That was overdone, though. I said: 'Well, no. This is something I'm going to do on my own ...' Sometimes I have to slow them down ...

Gopi: And all those things, all these special types of care, you can see in the films. It is all really familiar.

Avinash: In the films, everything is more extreme. It's like: 'I'll die so you can have my eyes ... very extreme ... All these things are exaggerated in Hindustani movies.

Answering questions about their relation to Bollywood, Avinash and Gopi talked at length about the joint family structure they described as 'typically Hindustani'. Interestingly, the joint family was not imported straight from India. It has, in fact, a Surinamese history. The indentured labourers that came to Suriname came as isolated individuals and had to build up new families in the course of the settling process. On their new farms, the joint family structure proved instrumental: the labour force of many family members became a key to agricultural success. In the I940s, the joint family had become the dominant form of living in the Surinamese countryside (de Koning I998: I55). Nowadays in Suriname's cities and in the Netherlands, the family lives spread out over several houses while maintaining the ideal of the joint family (Choenni and Mathura I998: 254).

Avinash and Gopi seem to cherish the joint family structure. They describe it as loving, caring, and sometimes annoyingly intrusive, comparing it to the tolerant but indifferent atmosphere in 'Dutch' families. Their familiarity with Dutch family life is derived partly from everyday 
interactions with non-Hindustani peers but also from popular Dutch soap operas, which they watch several times a week. Having lived in the Netherlands all their lives, they perceive themselves as 'different'. Their otherness is in some sense neutralised and even celebrated by Hindi cinema, which shows them 'the things we learned at home, the culture we grew up with. It is very nice to notice that it wasn't all made up'.

Sharita is a 26-year-old film fanatic who watches an Indian movie every day. Her parents came from the agrarian district of Nickerie in Suriname. Sharita is the youngest daughter in a large family of nine children, and was just a baby when the family moved to The Hague. She dropped out of school before getting a professional diploma; since then, she has been temporarily employed in various low-paying occupations. Sharita's main problem in life is the difficult relationship she has with her parents. She is very distressed because her parents think she is the right age to marry and they try to talk her into getting married as soon as possible. Sharita currently has no partner and is in no hurry to find one; she says she has no desire to get married at all.

Sharita's favourite movie is Kabhi Khushi Kabhie Gham. It touched her so deeply it made her cry. The hero in Kabhi Khushi Kabhie Gham is pressured into marriage he doesn't want by his father; instead, he decides to marry the love of his life. As a consequence, his father throws him out of the house. Sharita comments:

What you see in these movies, has also happened in my life. It makes me think. Kabhi Khushi Kabhie Gham is truly about reality. All those demands raised by parents. They want him to marry someone, but he loves another. I had to cry.

During what scene did you cry?

After the wedding, when he wants to say goodbye, but his father refuses even to look at him anymore. I found that so sad ... and it made me wonder, because it could happen to me as well. What should I do? How should I deal with this?

Do you know anyone that was married off?

No. It doesn't happen here like you see in the movies. In the past, in Suriname it did happen, but not anymore.

So what's so realistic about it then?

Well, the pressure. You have to marry. You know, my parents want me to marry too. But I don't want to. I see it around me everywhere. When a girl marries, her husband wants her to do all kinds of things: stay at home, do the cooking ... When he comes home, everything has to be ready for him. These days it 
can be different, one day you might get home to a guy who is serving you dinner ... But that's not what I see in my sisters houses. They hardly have any time for themselves.

My parents have the same problem. My dad's the worst. He wants everything to be arranged for him, everything! Do this. Do that. My mother starts cooking early in the morning and she doesn't stop until three in the afternoon. I don't know what she is cooking! This morning I wanted to sleep late, but my mom woke me at seven. She wanted me to clean the house, vacuum, dust, you know. I was dog-tired. After a couple of hours I went back to bed. I don't understand why my mother stays with him. He even told her to leave him once, but she didn't. She says marriage is forever.

Arranged marriages are rare among Dutch Hindustanis. However, many parents do introduce their children to one or more suitable candidates, and they indirectly try to influence their children's choice of partner. Earlier research indicates that there is a certain amount of pressure on any daughter to keep her virginity and get married. This pressure becomes more intense when the girl seems to 'go in the wrong direction', for example, when she is unable to find a suitable candidate at a certain age (Lalmahomed I992: I60 and I93-I94; Mungra I990: 92-103). This is certainly the case for Sharita.

Sharita feels loyal to her parents and tries hard to live up to their demands: getting home early, doing domestic chores, handing over part of her income, babysitting her younger nieces, always keeping her mobile phone on when she is out of the house. On special occasions, she may ask for her parents' blessing by bowing down before them and touching their feet. She feels obliged to her father and mother, who raised her and still care for her, but cannot fulfil all their wishes. Marriage is not an option for Sharita. Instead she dreams of an independent future in her own house, with her own car and her own stable income, freed from all the family obligations she has to deal with in her parents' house.

It is precisely these tensions between personal desires and parental loyalties that are dramatised so intensely in movies like Kuch Kuch Hota Hai, Kabhi Khusie Kabhie Gham, or Main Prem Ki Diwani Hoon. Troubles between parents and children also occur in American movies and Dutch soap operas, but they usually have a very different form. 'American or English movies are less recognisable. That's why I usually find them boring,' says Sharita. Kabhi Khushi Kabhie Gham has had a particular effect on her because it shows a son who fails to accommodate his fathers' wishes and is subsequently banished. The son is or- 
dered to leave the family mansion and is no longer considered a family member. Sharita fears the same thing might happen to her if she keeps refusing to marry.

During the interviews with Hindustani youth, many of them emphasise the personal relationship they have with Hindi cinema, and usually illustrate this point by referring to their own social relations, within their families and beyond. The stories differ widely though, depending on their particular social position within their families. Avinash and Gopi, who are both the eldest sons in small households, have evaluated the Hindustani family structure much more positively than Sharita, the youngest daughter in a large nuclear family.

Earlier studies have explained that an 'illusion of realism' is a prerequisite to experiencing pleasure when viewing any type of audiovisual entertainment. In her study 'Watching Dallas', Ien Ang discerns two types of realism: empirical realism refers to visible or material resemblances between film and reality, while emotional realism refers to the feelings that the characters undergo, just like viewers do in real life.

The type of realism described by Sharita, and by many other Hindustani girls and boys, does not quite match either of these types of realism. Although emotional and empirical resemblances are present, it is the social reality that they point out over and over again. This social reality unfolds as the characters meet, greet, interconnect, and negotiate relationships in the course of the stories. Bollywood films thus function as a mirror of social relationships within the Hindustani community in the Netherlands.

'Hindustani movies' are truly Hindustani in that sense. They are read in contrast to other popular media, namely Dutch soaps and American movies, which fail to accommodate the Hindustani social situations and thereby emphasise the otherness of Hindustanis in the Dutch context. Contrary to expectations, Hindustanis do not watch these movies because they want to 'de-link from their own environment'. Instead, the movies help them to live their lives in the Netherlands by making them 'feel normal', and it is primarily within the Dutch context that we must look to explain their affinity to Hindi cinema.

\section{Conclusion}

Diasporic studies have rightly emphasised the significance of transnational media among diasporic communities, but have had difficulty grasping the varied and complicated meanings of the processes at stake. We suggest that diaspora studies must be more cautious to avoid implicit assumptions about the effects of transnational media. When people spend their money and time on import products such as movies 
from a certain country named India, 'Indianness' is not necessarily an important part of the bargain.

Aksoy and Robins (2003) made this point earlier in research they did among Turkish television viewers in London. They concluded that the diaspora perspective is in fact a faulty framework for media research, as it assumes too easily that media support the emergence of transnational imagined communities. It usually does not ask if, but how media support the emergence of transnational communities. However, 'transnational broadcasting is not about magically transporting migrant viewers back to a distant homeland. It is about broadcasting services being delivered to them in their new locations' (Aksoy and Robins 2003: 102).

From the point of view of most of our respondents, the link between India and Indian cinema is not the most interesting aspect of their viewing experience. Indian movies add to the variety of genres available to them, not because the films teach them about India, because most of the movies don't, but because they mirror their own lives here in the Netherlands. The pictures 'come close to who I am' because they show 'the things we learned at home'. The stories that get bottled up when we ask youth about their relationship to Hindi cinema thus emphasise the resemblances between the social affairs in the movies and those within the Hindustani community in the Netherlands. In the Dutch context, 'Hindustani movies' are truly 'Hindustani'.

Comparing this conclusion to research on other audiences among the Indian diaspora (Gillespie I995, Hansen 2005, Brosius 2005, and others) the apparent diversity in viewing experiences is striking. These empirical studies, which were done on the brink of diaspora theory and ethnographic audience research, provide an important contribution to diaspora studies. They show that messages of belonging and nostalgia, which have increasingly spread through audio-visual media over the last decades, are viewed and appropriated in highly diverse and often unpredictable ways. Such processes of appropriation can never be understood from the armchair: performing ethnographic research in interaction with the viewers themselves is crucial, ${ }^{22}$ just as it is crucial to analyse the findings within a broader framework of diaspora theory. $^{23}$

\section{Notes}

I This fieldwork was performed by Sanderien Verstappen as part of her masters thesis at the University of Amsterdam, which resulted in the book 'Jong in Dollywood. Hindostaanse jongeren en Indiase films' (2005). Verstappen observed activities in six video rental stores, in two dance schools, and at numerous cinema screenings; she also 
joined Hindustani youth during their outings in the evenings and weekends. She had informal conversations with about 80 youth, interviewed 42 who were between I6 and 29 years old, and also interviewed nine distributors and several other professionals in the Bollywood business. She also repeatedly performed 'couch observations' in five households, watching television with family members in their living rooms.

2 When we talk about Indian cinema or Hindi cinema here, we are referring to movies produced in India. This article thus does not take into account movies made by filmmakers with an Indian background who live outside India; such as Mississippi Masala (I99I, directed by Mira Nair) or Bend it Like Beckham (2002, directed by Gurinder Chadha). Indian movies are usually divided into three subcategories: commercial cinema, art cinema, and regional cinema. We only discuss commercial cinema from Bombay, commonly refererred to as 'Bollywood' films.

3 The phrase 'Bollywood' has been objected to by Indian filmmakers who find the term paternalistic, but Hindustani youth in the Netherlands use the nickname 'Bollywood' willingly and lovingly. In this article, we will follow Hindustani youth on this matter.

4 This film is not available in the Netherlands. Information is therefore derived from the Internet Movie Database: www.imdb.com (20 March 2004).

5 See, for a detailed analysis of the diaspora element in DDLJ, and in the film Pardes, Uberoi (1998).

6 Lata Khubchandani (200I), DDLJ story goes to the roots of Indian culture' Transcripts of the interviews, Yash Chopra. Website rediff.com: http://www.rediff.com/broadband/ 200I/feb/05trans.htm (2 September 2005).

7 Dwyer (2002: 179) refers to her own article "Indian values" and the diaspora, Yash Chopra's films of the I990s', in: Parthiv Shah (ed.), Figures, facts, feeling. A Direct Diasporic Dialogue, pp. 74-82. Catalogue that accompanied a British Council Exhibition, November 2000, West Coast Line.

8 Personal communication with Sammeer Shoekai (April 2002): he was a member of the organisation of the Hindustani Film festival in 2002 and handled communication with the staff of Yash Raj Productions.

9 The label 'Hindustanis' must not be confused with 'Indians', the label used in Suriname and the Netherlands to describe NRI's who have migrated directly from India. In contrast to Indians, Hindustanis have no personal memory of the villages of origin in Bihar or Uttar Pradesh, nor have they retained any personal relations in those villages (Bal and Sinha, this book). There is very little interaction between the two communities (Lynnebakke, this book).

Io Allochtonen in Nederland 2004. Centraal Bureau voor de Statistiek (CBS), Voorburg and Heerlen, 2004. www.cbs.nl.

II Choenni 2003: I70-I7I; Van Noort 200I: 55; Van Niekerk 2000: 159-I60 / I98-204.

I2 Dollywood is officially the name of Dolly Parton's Amusement Park in the United States.

I3 Cultuurbeleid in Nederland. Zoetermeer; Ministerie van Onderwijs, Cultuur en Wetenschappen; 2002. http://www.minocw.nl/cultuurbeleid/nota6/index.html (I2 November 2002).

I4 Result of people count in two popular video rental stores in The Hague, carried out by Sanderien Verstappen on two Saturdays from opening until closing time in January 2002.

I5 Photographs by Sanderien Verstappen; flyers collected during fieldwork period in 2003 .

I6 The term long-distance nationalism was introduced by Benedict Anderson in the Wertheim Lecture (1997) at the University of Amsterdam: 'Long-distance Nationalism. World Capitalism and the Rise of Identity Politics.' 
I7 According to an employee at the Haags Filmhuis.

I8 Films that were a hit in the Netherlands at the dawn of the 2ist century were Kuch Kuch Hota Hai (1998), Kaho Na ... Pyaar Hai (2000), Kabhi Khushi Kabhie Gham (2001), to a lesser extent Mujhse Dosti Karoge! (2002), Devdas (2002), Saathiya (2002), Dil Ka Rishta (2003), and Chalte Chalte (2003) and more recently Koi Mil... Gaya (2004), Kal Ho Naa Ho (2004) and Hum Tum (2004).

I9 Bloemberg 1995: 205; Klimmer 1999; Verstappen 2005.

20 This is the picture Verstappen deduced from 25 in-depth, taped interviews (varying in duration from I.5 to 3 hours) with Hindustani youth aged between I6 and 29 years.

2I This issue is quite complicated, however, as some girls claimed that Indian women have more freedom than Hindustani girls. Sharita, for example, noticed that 'women in India can walk on the streets with their bellies naked. If I tried that, my father would lock me in the house'.

22 This point is supported by anthropologists such as Baumann (I999: I50) and Ginsburg, Abu-Lughod and Larkin (2002: 6).

23 This link to diaspora theory is sometimes lacking in media studies, for example in the work of Straubhaar (1991/1997) and Burch (2002).

\section{Films}

Aan, directed by Mehboob Khan, 1952 .

Bilet Pherat (England Returned), directed by N.C. Laharry, I92I.

Chalte Chalte, directed by Aziz Mirza, 2003.

Devdas, directed by Sanjay Leela Bhansali, 2002.

Dil Ka Rishta, directed by Naresh Malhotra, 2003.

Dilwale Dulhania Le Jayenge, directed by Aditya Chopra, I995.

Hum Tum, directed by Kunal Kohli, 2004 .

Kabhi Khushi Kabhie Gham, directed by Karan Johar, 200I.

Kaho Na... Pyaar Hai, directed by Rakesh Roshan, 2000.

Kal Ho Naa Ho, directed by Nikhil Advani, 2004.

Koi Mil ... Gaya, directed by Rakesh Roshan, 2003.

Kuch Kuch Hota Hai, directed by Karan Johar, 1998.

Lagaan: Once Upon a Time in India, directed by Ashutosh Gowariker, 200I.

Main Prem Ki Diwani Hoon, directed by Sooraj R. Barjatya, 2003.

Mujhse Dosti Karoge!, directed by Kunal Kohli, 2002.

Muqaddar Ka Sikandar, directed by Prakash Mehra, 1978.

Om Jai Jagadish, directed by Anupam Kher, 2002.

Pardes, directed by Subhash Ghai, I997.

Purab aur Pachhim, directed by Manoj Kumar, 1970.

Saathiya, directed by Shaad Ali, 2002.

Sir Wrangler Mr. R. P. Paranjpye, directed by Harischchandra Sakharam Bhatavdekar, I902.

Yaadein, directed by Subhash Ghai, 200I. 



\title{
10 Contested Equality
}

\section{Social Relations between Indian and Surinamese Hindus in Amsterdam}

\author{
Brit Lynnebakke
}

\begin{abstract}
'I know a Surinamese Hindu woman who goes to India every year but wants nothing to do with the Indian people here in the Netherlands. Because she feels that they don't like her, that they think that they are more than her ... She loves India ... But she has no good things to say about the Indians who come here.' (Surinamese Hindu female, 55)
\end{abstract}

\section{Introduction}

In the academic debate on the Indian diaspora there is often an underlying assumption of a unified character of the diaspora in terms of religion, culture and imagined homeland. Nevertheless, religion, culture, and the imagined homeland have different local meanings for migrants with different migration patterns. In the Netherlands, direct migrants from India do not freely interact with Surinamese Hindus - the descendants of Indian indentured labourers. The supposedly shared Indian background does not unify the migrants, on the contrary, it seems to separate them.

This article attempts to explain why relations between Indian and Surinamese Hindus in the Netherlands are characterised by negative images, prejudices, and little interaction. Some reasons have to do with different migration histories, different educational levels, class and caste differences. This raises questions related to the construction of identity on the local level and the diaspora concept as a theoretical tool. The broad questions that will be explored are as follows: First, how do Indian and Surinamese Hindus view each other with reference to a shared Indian background? Second, how does the religious identity of being a Hindu impact on the contact between Indian and Surinamese Hindus? 
A situational perspective on identity is taken as a starting point. It is assumed that all individuals have multiple identities including, for instance, cultural, religious, gender, class and regional identities, which become relevant in different contexts. To an outsider, Indian and Surinamese Hindus seem to share some cultural and religious features. The article will discuss whether the minority context with reference to cultural and religious identities leads to unification. This will be explored by looking at common stereotypes each has of the other and asking whether they interact or not. This is followed by a discussion of the centrality of other identities and how these interact with religious and cultural identities. 'Interaction' between Indian and Surinamese Hindus is defined as involved contact through mutual exchange, which sometimes leads to friendships and closer connections, rather than the mere presence of people from both groups in the same locations.

Surinamese Hindus in the Netherlands have a history of 'twice migration' (Bhachu I984). The ethnic label 'Hindustani' comprises 76 per cent Hindus, 20 per cent Muslims and a small percentage of Christians. The forefathers of the Hindustanis living in the Netherlands today emigrated between I873 and I9I6 from India to the Dutch colony of Suriname (Dutch Guiana until I948) as contract labourers (Van der Veer I996). The background for their recruitment as indentured labourers to the plantations was the abolishment of slavery ten years earlier. Most of the emigrants came from Bhojpuri-speaking areas in today's Northern Indian states of Western Bihar and Eastern Uttar Pradesh, at the time called Hindustan. By I9I6, some 34,000 people had migrated to Suriname. Two-thirds of them stayed and settled after their five-year contract period was over (De Klerk I953, Sinha-Kerkhoff and Bal 2003, Van der Veer I996). ${ }^{\text {I }}$ Most Surinamese Hindus immigrated to the Netherlands when Suriname became independent in 1975 (Van der Avoird 2001: 92). ${ }^{2}$ Today, 309,000 Surinamese live in the Netherlands (IMES statistics, figures from 200I). There are no official figures for Hindustanis residing in the Netherlands, but various estimates suggest that the number is between IIO,000 (Van Der Avoird 2002: 96) and 150,000 (Sinha-Kerkhoff and Bal 2003: 3). It is again estimated that the number of Surinamese Hindus is between 80,000 and I00,000 (Martin Baumann I999: 62). The majority of Hindustanis live in Rotterdam, Amsterdam, and The Hague - with the largest number $(34,948)$ in The Hague. As of 2002, I8,570 Hindustanis were living in Amsterdam (Choenni 2003a).

Due to the substantial emphasis put on the religious identity of being Hindu in this article, I will mainly use the term 'Surinamese Hindu', following Martin Baumann (I999) and Van der Burg (I986, I99I), except when referring to the research of others where the term 'Hindustani' has been used.' 
There have - to my knowledge - been no social scientific studies conducted on direct migrant Indians in the Netherlands. There are currently $13,7 \mathrm{I} 3$ Indian citizens living in the Netherlands today (CBS, referred to in Indiawijzer, reference b). It has been estimated that whereas 83 per cent of the Hindus in the Netherlands in 2004 were Surinamese, II per cent were from India, on the basis of citizenship (CBS Statline, reference a). In 2004, there were an estimated 3,I49 first- and second-generation Indian citizens living in Amsterdam, (CBS Statline, reference b).

Contact between Indian and Surinamese Hindus in Amsterdam takes place within the context of Bollywood events, Sanatan Dharm ${ }^{4}$ temples, yoga classes, Indian music classes and events, and through joint shop keeping. This article is based on 44 semi-structured recorded interviews with Indian and Surinamese Hindus, as well as informal conversations that took place during two months of preparatory fieldwork at Hindustani cultural events and Sanatan Dharm temples ${ }^{5}$ in Amsterdam. The Sanatan Dharm temples were chosen as the main interaction context both in the participant observation and the interviews in order to make it possible to explore both cultural identity and religious identity as a basis for unification, and in what ways the two identities are connected. However, I also interviewed people who had experiences in other contexts where Indian and Surinamese Hindus interact or who knew many people from their own 'community'; representatives of cultural organisations, journalists in Hindustani or Hindu media, yoga teachers, teachers of Indian music and traders.

I formally interviewed 22 Surinamese Hindus, 2I Indian people (mainly from northern India) all of whom were Hindus except for one Muslim and one Sikh, and one Dutch Sanatan Dharm Hindu. Most of the informants were between 40 and 60 years old and thus had experienced migration to the Netherlands.

The article is organised in five parts. Following this introduction, the theoretical perspective will be presented. Subsequently, in the third section, I will discuss relations between Indian and Surinamese Hindus. I will show that, whereas one the one hand, there are potentially unifying factors and common meeting places, on the other hand, there is little unity. On the contrary, they have negative stereotypes of each other and little interaction. In the fourth section, I will suggest some possible explanations for this dual relation. Finally, these explanations are considered with reference to the diaspora debate. 


\section{Diaspora and the Question of Hindu and Indian Identity in Minority Contexts}

Vertovec, in one context, defines diaspora as 'an imagined connection between a post-migration (including refugee) population and a place of origin and with people of similar cultural origins elsewhere' (Vertovec 2000b: I2). In academic literature, Indo-Caribbean people are often included in the Indian diaspora category. This could be and has indeed been questioned (see, e.g., Sinha-Kerkhoff and Bal 2003). Given that Surinamese Hindus are part of 'an Indian diaspora', do many Surinamese Hindus experience an imagined connection with Indian Hindus and vice versa?

Vertovec (1999) has distinguished three meanings of diaspora that have been used in academic literature (see this book's introduction), where diasporic consciousness is one of them. There is a connection between marginalisation and diasporic consciousness. Vertovec has stated, with reference to diasporic consciousness, that 'Its particularity is variously described as being marked by a dual or paradoxical nature. It is constituted negatively by experiences of discrimination and exclusion and positively by identification with a historical heritage (such as 'Indian civilisation') or contemporary world cultural or political forces such as "Islam"“ (I999: 8, emphasis original). Others (e.g., Kurien 200I) have argued that diasporic consciousness is strengthened rather than automatically constituted by marginalisation.

One could argue that a diasporic consciousness was developed among the British Indians in Suriname. The background for this consciousness was the original goal of a temporary sojourn in Suriname, the continued arrival of new indentured immigrant labourers until I9I6, and finally, the fact that the British Indians held a marginal position in Surinamese society where indentured labour was equated with slave labour. For all these reasons, the British Indians made few attempts to assimilate into Surinamese society and instead a cultural orientation towards India through the reconstruction of pre-migration traditions and customs from India developed. The Indian cultural orientation involved the original goal of a temporary sojourn in Suriname, the continued arrival of new indentured immigrant labourers until I9I6, and finally, the fact that the British Indians held a marginal position in Surinamese society where indentured labour was equated with slave labour (Speckmann I967; Hoefte I998).

Among Surinamese Hindus living in the Netherlands today, some orient themselves towards India, but this is only one of several common orientations. A study by Choenni (200I, 2003c) on Surinamese Hindu youth suggests various common cultural orientations: towards India, the Netherlands and the West, or towards Suriname. Further- 
more, some of the informants in the study were oriented towards several of the three regions. This is not surprising from a perspective of multiple identities and a view of culture as fluid and continually changing (e.g., G. Baumann I999).

Heterogeneity of cultural orientations is especially salient when speaking of 'twice migrants', but reflects a general challenge when theorising diaspora. When one uses the diaspora term as a noun, one risks essentialisation and reification on the basis of only one criterion: ancestral background from a certain place (Shukla 200I; Brubaker 2005). This way of conceptualising diaspora leads, according to Brubaker, to a misleading 'metaphysics of community' (2005: I2). He has proposed that in order to avoid these problems of 'groupism' it is more useful to conceptualise diaspora 'not in substantialist terms as a bounded entity, but rather as an idiom, a stance, a claim. ... as a category of practice. ... As a category of practice, "diaspora" is used to make claims, articulate projects, to formulate expectations, to mobilise energies, to appeal to loyalties' (Brubaker 2005: I2). The concept of the diasporic stance is especially useful when speaking of 'twice migrants'.

With these considerations in mind, it is now possible to return to the question of possible identification between Indian and Surinamese Hindus in the Dutch context.

Whereas India has a population of a billion people and its diversity is similar to that of an entire continent, Lal states,

the question of the 'Indianness' of Indians acquires a particular poignancy overseas, as Indians abroad are presumed to shed their regional, linguistic and ethnic identities in deference to the more general identity of being an Indian. It is arguable that one is more easily an Indian abroad than in India; the category of 'Indian' is not contested abroad as it is in India (Lal n.d., UCLA website on the Indian diaspora).

Lal's statement is tentative - he neither states who has these presumptions nor what they are based upon, but from the perspective of being cultural and ethnic minorities in new contexts of settlement, there is a certain viability to the statement, which makes it an interesting starting point for research. One could reason that the cultural minority situation in the country of settlement reduces the significance of distinctions that were important in the country of origin. In this context, similarities, for instance, in customs that had not previously been obvious may become more salient. Hence, in this case, an all-Indian identity may arise and the previously strong regional and other identities may become less important. The process of an all-Indian unification can be further fostered by the ascription of the majority population as well as 
other minority groups in the country of settlement as 'Indians', whilst these other groups ignore distinctions within the category. Within the same line of reasoning, it is also possible that, in the minority situation, 'twice' and direct migrants with a diasporic consciousness imagine themselves as related on the basis of a common Indian background.

A similar process can be imagined with reference to Hindu identity. Even though Hinduism is extremely diversified in India, ${ }^{6}$ Hinduism unifies differently in the diaspora. According to Vertovec, 'in virtually every context outside India, Hinduism has emerged as a core feature of ethnic consciousness and community mobilisation (even into political spheres) among Indian migrants and their descendants' (Vertovec 2000a: I8). Again, the contrast with other groups could make diversified traditions of 'twice' and direct migrants seem similar, which could furthermore be fostered by the ascription by others. ${ }^{7}$

There are additional reasons why Hindu identity could become unifying in the minority context. Firstly, Hindu identity can be argued to be 'rooted' in India. Vertovec argues for a notion of a Hindu diaspora akin to that of a Jewish and Sikh diaspora because "no matter where in the world they live, most Hindus tend to sacralise India and therefore have a special relation to the homeland' (Vertovec 2000a: 3). Moreover, most Hindus are Indian, with 'the obvious exception of Balinese and Nepalese Hindus' (Vertovec 2000a: 3). Rootedness of Hindu identity varies for different Hindu movements. In the two largest Hindu movements of Suriname Hinduism, rootedness is more salient in the Sanatan Dharm movement than in the Arya Samaj reform movement. The latter movement emphasises Hinduism as a universal religion that is not tied to territory (Sinha-Kerkhoff and Bal 2003). ${ }^{8}$

The other reason is that religion has increased in importance as a social determinant in the Netherlands over the last twenty years (Van der Burg 2004). In conclusion, it is therefore possible that a lack of resources due to the relatively low number of Indian migrants in the Netherlands could have resulted in their uniting with Surinamese Hindus in religious practices (cf. Baumann I999).

Most of the studies on people who belong to religious, cultural, and ethnic minorities either discuss their relation to the 'country of origin' or how they relate to the country of settlement. As a reflection of this focus, few studies have been conducted on relations between Indo-Caribbeans and direct migrant Indians. Exceptions include Sinha-Kerkhoff and Bal (2003), who have researched relations between Indians and Hindustanis in Suriname. Written in the context of the new PIO legislation, Sinha-Kerkhoff and Bal emphasise that their informants do not feel Indian in their national identity even though many feel connected to India. Their informants instead felt Surinamese in their national 
identity and Hindustani in their cultural identity. In other national contexts, Manuel (I997) has described relations in the Caribbean and the US, Seenarine (n.d.) in the US and Vertovec (2000a) has devoted a whole chapter to the topic in the British context in the book The Hindu Diaspora.

To study relations between people who have migrated from a nationstate at different times and for different purposes enables extended knowledge on how the process of migration relates to views on tradition and to the way 'the country of origin' and co-ethnics are imagined. The way informants describe their own group and the other group can shed new light on cultural continuity and discontinuity. One can also elucidate how the context of settlement as well as the type and time of migration has an impact on identity formations. With reference to the academic debate on Indian diaspora, one can illustrate how these different identity formations lead to little contact and negative views on each other. By extension, one can question whether 'the Indian diaspora' is a useful concept to describe those who have emigrated from India for a wide range of purposes in different centuries.

\section{Relations between Indian and Surinamese Hindus in Amsterdam ${ }^{9}$}

\section{Potentially Unifying Factors}

At first glance, several factors seem to unite Indian and Surinamese Hindus in the minority situation. Their religious beliefs are similar, they share an interest in Bollywood films and Bollywood stars, and have similar ideas about family values and gender roles.

In the diaspora, the Hindu temple takes on a new social and cultural function and increases in importance compared to in India, where the Hindu temple plays a less central role in religious practices than the religious buildings in, for example, Christianity and Islam (Vertovec 2000a; Baumann I999; Choenni 200I). There are four Hindu temples established by Surinamese Hindus in Amsterdam and none established by Indian Hindus. ${ }^{\text {IO }}$ Many Indian Hindus say that they were 'surprised and happy' to see the Hindu temples established by Surinamese Hindus. Both Indian and Surinamese Hindus tend to emphasise the common nature of their religious beliefs, which is surprising considering the enormous variety of Hindu practices found in India. Most Indian Hindus do not consider the religious practices of Indian and Surinamese Hindus to be very different either. ${ }^{\text {II }}$

Many Surinamese Hindus express a strong interest in India and have either enjoyed visiting or would like to visit India. For many, the Hindu belief system plays an important role in the desire to visit India 
and many Surinamese Hindus who have been to India speak affectionately and enthusiastically of the holy places they visited.

Bollywood could also potentially play a unifying role for Indian and Surinamese Hindus. Bollywood films are very popular among both Surinamese and Indian Hindus. Indian Hindus appreciate that Hindustanis have made Bollywood accessible through numerous video rental stores in the Netherlands. Hindustanis have also arranged various Bollywood events where, for instance, Bollywood stars make appearances in the Netherlands. These events are also attended by Indian people. A few Indian and Surinamese Hindus I interviewed thought that the interest in Bollywood could bring the groups together, or believed that the shared interest reflects cultural commonalities like a similar sense of humour, for instance (for an in-depth analysis of Hindustanis and Bollywood see Verstappen and Rutten, this book).

Various media has been established by Hindustanis in the Netherlands, the national Hindu broadcasting body OHM - Organisatie Hindoe Media - being the most well known. One of the informants, a representative of an Indian cultural organisation, indicated that Indian people use the media established by Hindustanis in the Netherlands. One time after she had been interviewed by the OHM, where mostly Surinamese Hindus work, she had received many questions from Indian people.

To an outsider, there are also potential language links. In Suriname, the British Indians developed a language called Sarnami Hindi, which literally means Surinamese Hindi. The language draws on several Indian dialects as well as other languages such as Sranan Tongo and Dutch (Van der Avoird 200I). Many informants said that it is possible to communicate with the Sarnami Hindu and Hindi languages. Moreover, some Surinamese Hindus speak Hindi, and the popularity of Hindi courses is currently increasing among Surinamese Hindus, which could possibly provide an additional point of contact.

A value that is common in the self-perceptions of the respective 'communities' of Indian and Surinamese Hindus, is the emphasis put on socio-economic status. In the interviews, it was striking how often people from both groups commented on their own or the other national 'community' being extremely concerned with social status based on criteria of material wealth, occupation, or educational achievements.

In some instances, there are mutual benefits in the interactions for both Indian and Surinamese Hindus. In addition to the shared Hindi language and the fact that many Indians can understand Sarnami Hindi, the fact that - due to colonial history - Surinamese Hindus tend to have a better knowledge of the Dutch language creates an additional benefit for Indian Hindus in instances where the two groups cooperate on projects in Dutch society. Also, first-generation Indian Hindus have 
their life experiences from India, which many Surinamese Hindus are curious about. Occasionally, these mutual benefits lead to joint businesses like shop keeping, or the selling of food, jewellery or clothes. In the case of food shops, they also trade similar goods because the food has many of the same ingredients. Some Indian Hindus also stated that joint businesses were attractive because of the cultural similarity.

\section{Strained Neighbourly Relations}

Despite the potentially unifying factors, there is, generally speaking, little contact between Indian and Surinamese Hindus. One Surinamese Hindu described the contact - or lack thereof - in this way:

'The Indian people here have their own restaurants; their businesses and they also mind their own business. ... Concerning the Surinamese Hindus, one could maybe say that some of them are a little bit negative towards Indians living here and in India, the majority is indifferent and don't have anything to do with them, and a small minority is very interested in them.'

Others described relations as a marriage where the partners live apart or as neighbours; 'we say "hi and bye", they said.

Even the contexts that bring the groups together do not normally result in interactions. Close friendships and intermarriages are the exceptions. Previously, there were more intermarriages, most often between Indian Hindu males and Surinamese Hindu women. However, many of these marriages ended in divorce because the main purpose of the marriage for many of the Indian men had been to obtain a Dutch passport. From the Indian point of view, the reasons for the divorces were not only passport fraud, but also differences in gender role expectations. Many informants thought that Surinamese Hindu women were less submissive and more independent than Indian Hindu women, which tend to make marriages between an Indian Hindu male and a Surinamese Hindu female more challenging than between an Indian Hindu female and a Surinamese Hindu male. Because of the marriage deceits, there is a general distrust of Indian people among Surinamese Hindus today. This has, according to informants from both groups, not only led to a decrease in intermarriage, but also close contact in general.

This same difference in gender roles has brought about a recent trend of Surinamese Hindu males going to India to look for a marriage partner. ${ }^{\text {I2 }}$ These men feel that Surinamese Hindu women have become too independent and liberal since their migration to the Netherlands, and that the 'traditional' gender roles are impossible with a Surinamese Hindu marriage partner. It is significant that they do not look for a di- 
rect migrant Indian female in the Netherlands; Indian people prefer to marry Indians in India or direct migrant Indians, e.g., in the Netherlands, the UK, or Canada, rather than a Surinamese Hindu. The assumed hereditary background of Surinamese Hindus could partly explain the reason for this, as will be elaborated upon in section 4.3.

Surinamese Hindus/Hindustanis and Indian Hindus in the Netherlands normally organise separate cultural events. Indian Hindus show little interest in neither Hindustani cultural events with old, 'traditional' Indian elements, nor Hindustani parties where Indian elements are combined with Caribbean influences. Efforts to arrange joint cultural initiatives have tended to fail. According to a Surinamese Hindu journalist, the main reason for this is different educational levels. Conflicting views on the equality of the partners was another explanation, he suggested, with reference to a specific joint initiative:

They can't co-operate because the Indian people want to dominate it. Because they have the money and the knowledge they say. And the Hindustani people say "we don't want you to play the boss when more of our people are in attendance, because there are more Hindustanis than Indians" ... The Indian people have the contacts in India, they also have the cultural contacts here, in the Netherlands. So they have the best networks.

According to the informant, Indian direct migrants believe that they should play the lead role in this joint initiative despite the fact that Hindustanis significantly outnumber them in the Netherlands. The argument they give is that the financial resources and networks of direct migrant Indians are stronger than those of Hindustanis. Another possible contributing factor to a tense dynamic could be different views on who has 'the most representative' image of India as a result of different times of migration, a tension I will return to in section 4.I.

Few Indian Hindus attend the Sanatan Dharm temples established by Surinamese Hindus in Amsterdam. Some Indian Hindu informants expressed a strong desire to have a temple run by Indian Hindus in Amsterdam, because - amongst other reasons - they thought the Hindi and general knowledge levels of the priest were low. In a comparative European perspective, the desire for a separate temple is not surprising. Martin Baumann, in an article about Hinduism in Europe, has stated that 'In general, one might say, if the number of Hindus living in a city is large enough, a temple focusing on one's own religious and cultural particularities is set up' (I999: 68). ${ }^{\mathrm{I3}}$ On the other hand, the fusion of Hindus from different backgrounds sometimes is the case when there are few Hindus and few financial resources (Baumann I999). 
In instances where both Indian and Surinamese Hindus are present in the Sanatan Dharm temples, the national groups tend to stick together. Some Surinamese and Indian Hindus offer neutral explanations for this, which typically centre on language differences (Hindi and English vs. Dutch and Sarnami Hindi), or a general sense of being different due to different national backgrounds. More Indian Hindus than Surinamese Hindus I interviewed tended to give these kinds of neutral explanations. Surinamese Hindus active in the temples that I interviewed explained the low degree of contact with a general sense of sceptical or negative attitudes towards Indian Hindus, typical statements being 'they keep to themselves' or 'we don't trust them'.

The perceptions they have of each other typically range from indifference to negative views, with Indian Hindus being - at least on the surface - more positive about Surinamese Hindus than the other way around. Indian Hindu informants tended to, at first, express that relations were cordial and to describe Surinamese Hindus in a positive manner. Negative views were often expressed in a subtle manner, and often only when I probed more. By contrast, Surinamese Hindus more often than not had negative things to say about Indian Hindus as their initial response to questions about relations between the two groups.

There are some stereotypical views that informants from both groups shared. It is a common perception among Indian and Surinamese Hindus alike that Surinamese Hindus are 'more modern', 'more Western' or 'more Dutch' than Indian Hindus. Here, the cultural influence from the Surinamese experience is emphasised. On the other hand, when it comes to the practice of Indian and Hindu customs, Surinamese Hindus are typically seen as 'more traditional' by people from both groups in the sense that they are thought to 'retain' and practice old Indian and Hindu customs more vigorously.

To a large extent, however, self-images and images by people from the other group tend to diverge. This is especially the case when it comes to views on Surinamese Hindus' relation to India and Indian people. Many Indian Hindus tend to think that Surinamese Hindus are uncritical about everything Indian. A young Indian Hindu male, for instance, said that the Hindustanis are more Indian than the Indians' and thought that

the Surinamese have an Indian dream, not an American dream. Because they think that the Indian values are nice and they want to go back to the Indian values. ...I told them (his colleagues): Don't believe this dream because the realities are different there, don't go there. Bombay is not Bollywood. India is not Bollywood. 
By extension, there is a prevalent notion among Indian Hindus that Surinamese Hindus admire, respect, and are influenced by Indian people. An Indian Hindu female I interviewed, for instance, responded in this way to my question about whether Indian Hindus influence Surinamese Hindus: 'Yes. There are no big difficulties. With us they are easy. They listen to Indian people'. In her view, hence, a lack of conflict in her contact with Surinamese Hindus was interpreted as a reflection of Surinamese Hindus' supposed reverence for Indian Hindus.

Among Indian Hindus, there is a stereotype of Surinamese Hindus as uneducated in a general sense and 'undeveloped' in a cultural sense. Sometimes these views coexist with an admiration for Surinamese Hindus 'having kept ancient Indian customs'. These Indian Hindus tend to think that Surinamese Hindus can develop culturally by visiting India and by getting to know Indian people.

Many Surinamese Hindu informants thought that Surinamese Hindus are influenced by Bollywood films, ${ }^{\mathrm{I}}{ }^{4}$ but hardly any thought that Indian Hindus living in the Netherlands were influenced them. Few of the Surinamese Hindu informants would agree with the idea that they view Indian people with admiration; on the contrary, many consider Indian people arrogant and untrustworthy. A Surinamese Hindu female, for instance, said: 'Some Indian people have an attitude. There is a fighting for respect'. Thus, in her view, Indian people demand a kind of admiration from Surinamese Hindus that does not always match reality.

More than an uncritical attitude, Surinamese Hindu views on Indian Hindus are often dual. While most of the Surinamese Hindu informants offered negative statements about Indian people, at the same time, some identified with them on a religious, cultural or ethnic basis. When it comes to views on India, views were also dual. Many Surinamese Hindus expressed both negative and positive views about India. Some were very positive and grateful for their experiences in holy places, for instance, but usually also talked about what had shocked them in India, such as the poverty or the way people treated each other. ${ }^{15}$ Earlier research has also noted an ambivalent attitude towards India among Hindustanis (e.g., Van der Burg 2004; Van der Veer I996). Hence, India is not necessarily idealised despite a diasporic stance towards India or an interest in India.

One area in which there was consensus between Indian and Surinamese Hindu informants, was the notion of whether Surinamese Hindus influence Indian Hindus in a cultural or religious sense. Almost no one thought this was the case, and the few who did, referred to close friendships or intermarriages. In short, potentially unifying factors normally do not lead to mutual exchange, influence, and interaction. Furthermore, there seems to be discrepancies regarding the ex- 
pected roles of Indian and Surinamese Hindus; Indian Hindus seem to expect a kind of respect and admiration with which Surinamese Hindus do not gladly respond.

Some Indian Hindu informants who had been in the Netherlands for several decades, in the beginning experienced a lot of curiosity from Surinamese Hindus. This curiosity had - to put it mildly - over time decreased. The current prevalent sceptical attitudes among Surinamese Hindus towards Indian Hindus indicates a shift in their attitudes. I argue that this shift is not only a result of marriage deceits but that it also is due to negative encounters that are rooted in the equality of the partners being contested.

\section{Possible Explanations for Strained Relations}

The reasons for the general lack of interaction between Indian and Surinamese Hindus is due to many factors. ${ }^{16}$ Obviously, many things have changed both in India and in the cultural patterns of Surinamese Hindus in the I30 years that Surinamese Hindus have lived in Suriname and the Netherlands. There is a profound difference in habitus due to differences in national socialisations that can make the differences hard to pinpoint. Several informants noted that they were very different from each other but that they could not verbalise in what ways. In the following section, I will discuss the different periods of migration, different educational levels, and the different imagined communities with reference to the Indian background as possible explanations for the low degree of interaction.

\section{Different Periods of Migration}

In the interviews, the topic that was explored in depth was the religious customs of the Sanatan Dharm movement, whereas cultural customs were discussed to a lesser degree. Surinamese Hindus are stereotypically seen as more religious and devotional than Indian Hindus. As mentioned above, they are also seen as more traditional. When it comes to Hindu customs, the experience from Suriname is not seen as

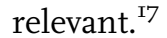

Both Indian and Surinamese Hindu informants often said that the Hindu customs of Surinamese Hindus were longer and more elaborate than what is normally observed in India. ${ }^{18}$ The vast majority of the informants from both groups thought that the customs were authentic; 'the way they were practised in India I50 years ago'. ${ }^{\text {I9 }}$

Even though the belief in continuity seems to be shared, the valorisation on continuity differs depending on one's individual religious approach as well as one's personal and national background. Comments 
from Indian Hindus ranged from 'they saved it, I really admire that', to 'I always tell them that they are frozen in time'. For some, this admiration for 'saving it' coexisted with the view that Surinamese Hindus should 'develop Indian culture' or update their Hindu beliefs by visiting India. Many Indian Hindus, especially those with higher educations and with an urban Indian background, typically found the Sanatan Dharm movement dogmatic, superstitious and old-fashioned. Furthermore, even if they did admire the 'traditionalism' of Sanatan Dharm Surinamese Hindus, many at the same time considered them to be less knowledgeable of Hinduism. A few Indian Hindus did also question authenticity, but what is most relevant for this discussion is the fact that regardless of their views on authenticity, Indian Hindu informants tended to view India as the standard. For some, it is the standard for more updated practices and knowledge, for others, it is the standard for authenticity. In the U.S. context, Seenarine has argued that direct migrant Indians view Indo-Caribbeans in a parent-child manner. After observing that Indo-Caribbeans are rarely included in South Asian umbrella organisations, he states; 'Of course, there has always been religious linkages, however, it is always in the father/child mode and the child never grows up' (Seenarine n.d.: 6). Perhaps there is also something to this observation in the Dutch context. In the parent-child views on relations, Surinamese Hindus can develop culturally and religiously if they visit India and become acquainted with Indian people.

Similarly to among Indian Hindus, opinions among Surinamese Hindus on the assumed higher levels of traditionalism vary greatly. ${ }^{20}$ Some find the Sanatan Dharm movement overly ritualistic and dogmatic. Meanwhile, among Surinamese Hindus active in the Sanatan Dharm movement it is common perspective to take pride in having 'kept alive' Hindu traditions better than Indians precisely because of the separation from India. ${ }^{2 \mathrm{I}} \mathrm{A}$ board member of one of the other temples, for instance, stated:

our puja is according to the original Hindu system .... We have maintained it ten times better (than those in India). The problem is that they are born there, so they think that they know better.

A Sanatan Dharm priest in another temple in Amsterdam said that the temple regularly had visits from Surinamese priests in order to nourish 'the ancient practice of Hinduism' and feared that these practices would 'die out' if many Indian Hindus were to migrate to the Netherlands in the future. The tendency to valorise the practices in Suriname Hinduism above the Hinduism practised in India is not free of ambiva- 
lence due to the status of India as a holy land, as has also been noted in other research (Van der Veer 1996, Sinha-Kerkhoff and Bal 2003). Nevertheless, in relations with Indian Hindus, the ambivalence seems to have been toned down and the view that Surinamese Hindus are superior due to a greater level of authenticity is emphasised. The "problem', according to the board member, could due be to diverging views on what is most valuable. Put simply; whereas Surinamese Hindus in the movement think they have knowledge about ancient forms of Hinduism, Indian Hindus think they have access to 'true' and more enlightened forms of Hinduism through their life experiences gained in India. As a result, there are divergent views on who should learn from whom. The different valorisations of practising 'ancient Indian and Hindu customs' are central to the tense relations between Indian and Surinamese Hindus as they hinder communication both ways and lead to contested views on 'who has the standard'.

Whether the customs are authentic is an entirely different discussion. According to Sökefeld, there is a duality between change and continuity in the diaspora and 'The rhetoric of continuity obscures that actors constantly re-constitute and re-invent (or refuse to reconstitute) in diverse manners what is imagined as simply continuing' (Sökefeld 2000: 23, quoted in Vertovec 200ob: I7). Moreover, rituals tend to deny change (Van der Veer, I996). ${ }^{22}$ At the same time, increased traditionalism is a typical process of migration in the sense that some customs and images become 'frozen' and symbolic of the cultural or ethnic group identity. The emotional importance of these symbols for group identity often leads to disappointment when migrants and their descendants visit the 'homeland' that has undergone changes since emigration. The images of India that are based on Surinamese Hindu forefathers' memories (modified or not) or the media or their visits to India differ greatly from the images of India based on the life experience of direct migrant Indian Hindus. Within this perspective, it is not surprising that an Indian Hindu female considered relations difficult because when Indians are asked questions about India 'Indian people cannot meet Surinamese Hindu expectations.'

\section{The Importance of Educational Levels}

When Indian and Surinamese Hindus describe each other and the dynamics between the two groups, other identities than those related to a common Indian background are often emphasised. In particular, identities that relate to occupational position and educational levels are seen as more important than a shared interest in India and religious beliefs that, at least in the Dutch context, seem similar.

According to a study by Van der Avoird, most Hindustanis 'have jobs associated with [a] lower socio-economic status or are unemployed' 
(200I: 97). Other research has concluded that the socio-economic position of 'Surinamese Hindus is lower than the position of the indigenous population' and that the unemployment rate in I990 was 'three times higher than among the Dutch population' (Berten 1992: quoted in Van der Avoird, 200I: 97). At the same time, the Hindustani group is advancing in its social mobility. Lately, more and more Hindustanis have been successful on the job market or in creating their own employment in small enterprises, shops and businesses (Van der Avoird 200I). Hindustanis are often seen as 'a successful immigrant group' in Dutch society socio-economically speaking (Choenni 2003b; Van Niekerk 2002: 232).

Among the direct migrant Indians in the Netherlands, a large number of the recent migrants are highly skilled. The socio-economic background of direct migrant Indians in the Netherlands is, however, not homogenous socio-economically speaking. In addition to the I5,000 registered Indians in the Netherlands ${ }^{23}$, there are estimated 3000 to 5000 irregular Indians in the Netherlands, most of whom come from Punjab (Indiawijzer, reference a). ${ }^{24}$ According to some of the informants, there is an overlap of regional background and occupation sector among direct migrant Indians in the Netherlands.

When they speak about each other, a topic that is often brought to attention is the difference between Surinamese Hindus and the segment of Indian Hindus who are highly educated. Indian and Surinamese Hindus alike pointed out that there is a lack of meeting points due to different socio-economic positions; they do not meet at work, they live in different neighbourhoods and their children go to different schools, and few highly educated Indian Hindus attend the Sanatan Dharm temples. Furthermore, many of the informants emphasised that different educational levels also have led to different ways of thinking. Especially highly educated Indian Hindus with an Indian urban background emphasised this latter aspect. 'They don't have a common base', one Indian Hindu working in IT commented.

It might be a reflection of the aforementioned valorisation of socioeconomic success that Surinamese Hindus tend to identify more with those Indian people who have done well socio-economically than those who have not. The Surinamese Hindu journalist quoted previously also noted that, 'if it's a lawyer or an architect they (Surinamese Hindus) are proud to see that an Indian person is in such a high position'. This kind of identification is exemplified by a quote from a Surinamese Hindu administrative employee:

Indian people are typically very hard working people. Here in Holland I have noticed that they work very hard. ...They have reached a good standard of living here in a short period of time. 
... But Hindustanis are also hard working. Let's say there are several races in Suriname. The whole Surinamese economy is in Hindustani hands because they are also ... their roots are in India and so they are also hard-working people. The richest people in Suriname are Hindustani.

Van Niekerk has noted similar identification processes in her research. When explaining the socio-economic success of the Indo-Surinamese in the Netherlands, her informants sometimes also referred to 'the success of East Indians elsewhere in the world' (Van Niekerk 2002: 235). Some of her informants gave religious or cultural explanations for the success of East Indians, while others explained it in ethnic terms, 'the Indo-Surinamese desire for progress as an inherited trait [is] "in their blood"' (Van Niekerk 2002: 235).

Parallel to the identification with Indian people who have reached a high socio-economic status, there is often a dissociation from Indians with a lower socio-economic status. Our Surinamese Hindu journalist noted that Surinamese Hindus tend to look down upon the lower-educated Indian people, some of whom are illegal immigrants and work in the market or run small shops. These Indians have acquired the nickname 'Indiaman' among Surinamese Hindus, with its negative connotations of untrustworthiness - in business matters as well as when they marry Surinamese Hindus to obtain a Dutch passport. An example of dissociation can be seen in the following quote by a Surinamese Hindu who works in the banking sector. In general, she did not trust direct migrant Indians, but also thought that it was easier to give better-educated Indian people a chance:

Some Indians one can invite home. If they study here in the Netherlands one thinks that they are more open than someone who looks like he has bad manners. With the Indians who have bad manners, you always think "how will they be?" and doubt whether they are good or not. But if an Indian studies here, one will think "OK, he has good manners and comes from a good family".

Hence, one important reason for little interaction may simply be a result of the common social phenomenon that people have more contact with persons of similar educational and occupational backgrounds. In addition to lack of meeting points, there also comes along a kind of cultural difference with different levels of education. According to Gellner (1983), an important feature of national socialisation is education, what he calls a common 'exo-socialisation'. Analogous to this, one could argue that the chances of cultural similarity are greater between 
people with the same levels of education than between those with different levels - regardless of cultural and national background. There are some shared symbols and therefore shared culture because educational institutions are often international in their knowledge base. However, I also argue that the emphasis on educational levels might be of particular importance for Surinamese and Indian Hindus due to strong community values regarding education and occupational status, as noted in the section 'Potentially Uniting Factors' ${ }^{25}$

Different Imagined Communities: Region and Caste vs. All-Indian Identity One can now return to Vertovec's definition of diaspora as 'an imagined connection between a post-migration (including refugee) population and a place of origin and with people of similar cultural origins elsewhere' (Vertovec 200ob: I2). In the following section, I will argue that the imagined connection and hence identification is more common among Surinamese than Indian Hindus with a diasporic stance and that this is because of the different contexts of settlement as well as the socio-economic composition of the migrants.

\section{Indian Hindus: 'They Were Indentured Labourers from Bihar'}

When Indian Hindus discuss the Indian background of Surinamese Hindus, it is often in a way that dissociates them from Surinamese Hindus. When I asked Indian Hindus why there was so little interaction, typical comments focussed on the fact that Surinamese Hindus had been land workers in Suriname and that their forefathers were Biharis, had been land workers in India, and had chosen to become indentured labourers. Regional and caste identities seem to play a role in these comments.

'We think that they are working class because of the language they speak', a 27-year-old Indian Hindu stated. Sarnami Hindi does not, as previously suggested, unite Indian and Surinamese Hindus. On the contrary, the language is a major characteristic in the development of negative stereotypes that many Indian Hindus have of Surinamese Hindus as uneducated and 'undeveloped'. Among the languages that Sarnami Hindi is influenced by, linguists believe that it shares the most unique features with Bhojpuri' (Van der Avoird 200I: 3I), one of the main languages of the Indian state of Bihar. According to the informants, Biharis are stereotypically seen as being rural, poor, and uneducated and are seen as labourers because many Biharis migrate to other Indian states in that capacity. Being a labourer has lower class connotations for some and low caste for others (one informant explained that his Punjabi colleagues thought Biharis were from the lower castes because most labourers in Punjab are Biharis). Bhojpuri is also considered to be grammatically somewhat unrefined by Indian Hindus. An 
Indian financial expatriate expressed the relationship between Sarnami Hindi and Bihar in this way:

the language they speak is typically rural I would say. ... It's like a villager who goes to the city and tries to speak the language ... the Surinamese language is inspired by the language of Bihar, which is not spoken in urban India ... So when a Surinamese speaks Hindi it gives one the impression that it is someone speaking with a disadvantage. And I guess that this aspect in particular immediately gives one the feeling of "look, he can't, he's not up to it".

The Bihari language and the Bihari people are often the subject of jokes in India and are also satirised by Bollywood characters (Sinha 2000). Various articles and essays in the Indian media and on Internet discussion sites also portray Biharis as a stigmatised people because of that state's poverty, its tradition of labour emigrants, its caste wars and it being the most undeveloped state in India. ${ }^{26}$

Direct migrant Indian Hindus consider the indentured labourer as lower class. Many also see it as an indication of being from a lower caste. ${ }^{27}$ When I asked Indian Hindus about the low degree of interaction, many were quick to point out that the Surinamese Hindu forefathers emigrated as indentured labourers and that they had been labourers and farmers in India and Suriname. These comments insinuate the lower castes in the Varna system (Encyclopaedia Britannica). For instance, a young Indian Hindu male said;

They were indentured labourers, whereas the Indians who come directly from India to the Netherlands are usually highly educated. The caste system is of no importance today, but my father who is Brahmin only wants to associate with Brahmins from Tamil Nadu.

Current and present educational levels are closely connected in the argument, which is logical because caste in the sense of secular status (as opposed to ritual status) is connected to occupation (Stevenson I953).

Several informants considered low caste assumptions to be among the reasons why there was so little intermarriage between Indian and Surinamese Hindus. ${ }^{28}$ If this is the case, it is also possible that, consciously or unconsciously, their preferred acquaintances are often still guided by caste notions. Furthermore, low caste views may also partly explain why few Indian Hindus attend the temples run by Surinamese Hindus, It may well be that the main reason for the desire of some In- 
dian Hindus for a separate temple has to do with the cultural and social function that religious buildings have in minority situations (cf. Vertovec 2000a: I24); due to this function migrant religious buildings are often organized according to country of origin. But an additional explanation which is related to caste is also relevant to consider. Vertovec, in a discussion on caste inside and outside India, has stated that 'In India, the caste system (with all its variations) revolves around individual membership through birth in hierarchically ranked, mutual interdependent, endogamous corporate groups often associated with given occupations, ritual duties and roles, modes of economic and behavioural transaction, essential attributes surrounding degrees of purity/ pollution, specific customs and traditions of worship. Outside of India, the complex systems of interaction which comprise the living stuff of caste are absent; caste identities are usually all that remains' (Vertovec 2000a: 24, emphasis added). In the interviews, no informants from either group thought that the Indian Hindu beliefs that Surinamese Hindus are of lower castes explains the low temple attendance by Indian Hindus and the wish that some of them have for a separate temple. The topic of caste is sensitive and needs to be researched in greater depth $^{29}$ before conclusions can be made. Within a theoretical perspective, however, it is viable that caste does play a role in the desire to have a separate temple. Ritual and tradition emphasise continuity (e.g., Van der Veer 1996) and because direct migrant Indians have had life experience from India, it would be surprising if caste identities were irrelevant regarding the 'specific customs and traditions of worship' that are currently preferred.

Regional and caste connotations are of importance in and of themselves for Indian Hindus living in the Netherlands. This was shown in the quote where an Indian Hindu expressed that to speak the Sarnami Hindi signals 'to speak with a disadvantage'. To speak of an 'Indian community' in the Netherlands is an abstraction (to a greater degree than to speak of a 'Hindustani community') because direct migrant Indians are divided into various communities where region of origin and not common Indian background is one of the main common denominators. ${ }^{3 \circ}$ Caste and region, however, has a particular explanatory dynamic when Indian Hindus are talking about Surinamese Hindus. Because of the indentured labourer background and the assumed Bihari and low caste heritage, many Indian Hindus think that Surinamese Hindus have an uneducated and 'undeveloped' background. The emphasis on an assumed uneducated background is combined with current educational levels in their description of Surinamese Hindus. The stereotypes involving 'low development levels' is further fuelled by the view that Surinamese Hindus did not develop Indian culture but that it instead was kept 'frozen in time.' Sometimes the assumed structural 
background is used to explain experiences of cultural incompatibility. For instance, an Indian Hindu who thought that Surinamese Hindus on average were old-fashioned and unenlightened, explained this as largely being a consequence of migrating from India at different times; their cultural experiences and images of India therefore differed. But she also explained what she called 'backwardness' of Surinamese Hindus with their hereditary background from India;

I would say that they come from a lower class, not that they are born into poor families but that they all come from lower classes ... They did not have much money, not much education - they were backward people. ... Maybe not all of them, there are always exceptions, but generally speaking this was the case. I think they were part of the working class, who used to work there as labourers, and they emigrated to make money. These people are normally not very educated, they come from poor families. And of course these are the children, so the blood is the same.

However, this informant also stressed that 'the younger generation is different'; in the sense that she thought that they were more openminded and knowledgeable. She also stated that 'There are some very good people who have studied a lot, gone to university, been to India, know many Indian people. When they see the everyday-life [of Indians], their mentality changes'. Hence, in these instances it seems that 'the same blood' no longer matters; through education, contact with Indians and visits to India, Surinamese Hindus can become cultivated and the hereditary background is no longer an issue for this informant.

\section{Surinamese Hindus: All-Indian Identity and All-Hindu Identity}

In the introduction, I discussed the heterogeneity of cultural orientations among Surinamese Hindus. With this in mind, it would be misleading to assume that most Surinamese Hindus are oriented towards India even though the previous section described a tendency of situational identification with Indian Hindus who have done well socio-economically. However, what I do want to draw attention to is that among those Surinamese Hindus who take a diasporic stance towards India, there seems to be a contradiction between their imagined community (Anderson 1983) and the imagined communities of most of the Indian Hindus. More of the Surinamese Hindus than the Indian Hindus that I interviewed stressed unity and identification with the other group on the basis of culture, religion, or ethnicity. Some thought that Indian 
Hindus did not accordingly identify with them. For instance, a 59-yearold Surinamese Hindu administrative employee said:

Surinamese Hindus feel that they are equal and if they discover that the other group (Indians) feels that they are better, then they are a bit disappointed. Because they feel the that the [two groups] are equal: they are Indian, we are Indian, we have lived abroad for a few centuries but we maintain our Hindu customs and suchlike.

A Surinamese Hindu lawyer in her forties who was active in the Sanatan Dharm also emphasised Hinduism as a binding point:

There is a big difference between Indian and Surinamese Hindus. They see us as foreign.

- But you don't see them as foreign?

No, we don't see them as foreign. The goddess in the Ramayana is from there. But Indian people are reserved towards us.

The particular identity processes that took place in Suriname can explain this contradiction. In Suriname, as well as other locations where indentured labourers migrated to, the caste system gradually disintegrated. The process had already started during emigration on the ships and continued under the structure of indentured labour (Van der Veer and Vertovec I99I). ${ }^{3 \mathrm{I}}$ It has been argued that, parallel to the dissolution of the caste system, an exclusionary 'Indian caste' of Hindustanis developed in Suriname that was closed by endogamy and in other ways to the rest of Surinamese society (Speckmann I967; Hoefte I998). Speckmann argues that feelings of self-worth based on birth 'shifted from a caste proper to an ethnic group as a whole' (1967: 212). The fact that as many as 80 per cent of the indentured labourers came from the same region in India may have made negotiations of the all-Indian identity smoother. In addition, most Surinamese Hindus gradually lost contact with their relatives in India (Van der Veer I996). Furthermore, Indian commercial mass culture arrived in the Caribbean in approximately I930 and emphasised a pan-Indian tradition over a regional Bhojpuri identity. Meanwhile, contact with Bhojpuris in Fiji, Mauritius and South Africa was almost non-existent (Manuel I997). The all-Indian unification was further fostered by the aforementioned fact that the Indian indentured labourers had a marginal position in Suriname. Indentured labour was associated with slavery and the religious practices were looked down upon (Hoefte I998; Van der Veer and Vertovec 
I99I). There was, in fact, a small group of Sindhi ${ }^{32}$ business people who settled in Surinam but did not join the Hindustanis in the all-Indian identity (Ellen Bal, personal communication I5 June 2005). The notion of a connection between socio-economic marginalisation and unification, as well as the importance of socio-economic identities discussed in the previous section, may explain why.

The all-Indian identity was manifested by the merging of various cultural customs and the development of Sarnami Hindi (Hoefte I998). Hinduism also became a symbol of group identity for the indentured labourers. According to Van der Veer and Vertovec (I99I), a result of the disintegration of the caste system as well as the Brahmanisation process in Caribbean Hinduism was that Hinduism became ethnisised. The link between ethnicity and Hinduism was further strengthened by the fact that because most Hindustanis were Hindus, the Hindu Brahmanical organisations also developed into movements that politically represented the communal interests of the Indians. In Jayawardena's account, the institutionalisation of Brahmanical Hinduism and the unification of Hinduism can be connected to 'a consciousness of being Indians in a multi-ethnic society, where only this dimension of their social personality was significant and all [the] finer distinctions of caste, ritual, and belief were unappreciated and ignored' (i968: 444). The all-Indian and all-Hindu identities thus became intertwined. One sees this interconnectedness of Hindu and Indian identities in the quotes by the two Surinamese Hindu informants above.

In the introduction, I referred to the research of Sinha-Kerkhoff and Bal whose informants felt they were Surinamese in their national identity and Hindustani in their cultural identity. The Surinamese Hindu informants in this research also stressed that they were Surinamese or Dutch in their national identity. However, the situational identification with Indian Hindus who have done well socio-economically, the general identification that some Surinamese Hindus have with Indian Hindus and the theory about an all-Indian endogamous 'caste', sheds light on the ethnic dimension of the Hindustani identity.

\section{Conclusion}

In summary, this article first of all showed how different times of migration have led to strained relations between Indian and Surinamese Hindus due to their varying images of India and the contested views they have on where the 'standard' for Hindu customs should be. Therefore the Indian and Hindu backgrounds often diverge rather than unify Indian and Surinamese Hindus. Secondly, the importance of educational levels and class identities was discussed. We here saw that class 
identities often override religious and cultural identities in importance because of the limited interaction contexts and different ways of thinking. For Surinamese Hindus, we also saw how class identities interact with ethnic and cultural identities in that they situationally identify with Indian Hindus. Thirdly, a discrepancy in the imagined communities of Indian and Surinamese Hindus with reference to the Indian and Hindu background has been suggested. Furthermore, the Indian and Hindu backgrounds tend to separate rather than unify Indian and Surinamese Hindus.

Contrary to Lal's statement, ${ }^{33}$ an all-Indian identity process does not seem to have taken place for Indian Hindus in the Netherlands. Socioeconomic, caste and regional identities appear to be of greater importance than similar cultural origins, possibly making internal divisions among direct migrant Indian Hindus in the Netherlands just as strong as the division between Indian and Surinamese Hindus. It is likely that the overlap between occupational and regional backgrounds among Indian Hindus strengthens the importance of regional identity.

While the regional composition of the migrants and the amount of time that has passed since emigration might make Lal's statement more likely, the context of settlement may prove to be at least as important in deciding whether an all-Indian identity that transcends all other distinctions becomes important in minority contexts. Is it beneficial to unite around cultural and religious identities in the minority context? Marginalisation for socio-economic or religious reasons seems to be important, as does the socio-economic composition of the settlers. The Surinamese Hindu forefathers had a similar societal position because all were indentured labourers. The marginalisation for socio-economic and religious reasons contributed to their uniting politically and socially around an all-Indian identity. In contrast, there is a socio-economic heterogeneity of direct migrant Indian Hindus in the Netherlands. Moreover, direct migrant Indians in the Netherlands may be a minority, but not a particularly stigmatised or marginalised minority in that the majority have a high socio-economic position. They do not experience religious stigmatisation either, on the contrary, Hindu religion and India have attained a certain level of popularity in the Netherlands as in many other Western nations today (Van der Avoird 200I: 37; cf. also Seenarine n.d.).

Vertovec has stated in his article regarding the British context that 'Indo-Caribbeans are regularly identified as 'Asians' by most whites and similarly subjected to racial discrimination - they are often simultaneously excluded (or at best regarded as a low-status, adjunct group) on social and cultural grounds by most other 'Asians'. This, in turn, leads to many Indo-Caribbeans reciprocally dissociating themselves from subcontinental Indians' (Vertovec 2000a: IIo). One could argue 
that similar processes take place in the Dutch context. As mentioned earlier, Indian Hindu informants who had been in the Netherlands for several decades said that they experienced great curiosity from Surinamese Hindus in the beginning. Even if Indian Hindus initially offer more positive statements regarding their relations with Surinamese Hindus, negative stereotypes are strong and prevalent. One important reason for the Surinamese Hindu dissociation has to do with marriage deceits. Surinamese Hindus may also dissociate due to contested equality, as seen in the quote: 'Surinamese Hindus feel that they are equal and if they discover that the other group (Indians) feels that they are better, then they are a bit disappointed. Because they feel that the [two groups] are equal:' Equality is also contested because of the various imagined communities. It is also contested because of the different views regarding the standard of Indian and Hindu customs. With these aspects in mind, it is not surprising that joint initiatives have tended to be of a strained character.

A final comment should be made about the diaspora concept. The research results about Indian Hindu views are in favour of Brubaker's critique of the diaspora concept. In one sense, the caste, class, and regional differences that would have separated these two groups and the Indian people themselves in the Indian context are reproduced in the Dutch context. When using the diaspora concept as an analytical tool, therefore, it is essential to not overestimate the centrality of ancestral and biological national background as a basis for self-understanding, self-categorisation, and group formation.

\section{Acknowledgements}

This article is a shorter modified version of an MA Thesis in Migration and Ethnic Studies at the University of Amsterdam. Thanks to Mario Rutten and Ellen Bal for supervision on the thesis and advice before writing the article. Also thanks to Gijsbert Oonk for feedback and suggestions on the shorter version.

\section{Notes}

I For a more elaborate overview of migration and settlement in Surinam, see, for example. Hoefte 1998; Sinha-Kerkhoff and Bal 2003 or Van der Veer 1996 in English and De Klerk I953 and the book Hindostanen. Van Brits-Indische emigranten via Suriname tot burgers van Nederland Choenni and Adhin (eds.) 2003.

2 One-third of the Surinamese population emigrated to the Netherlands in the I970s (Van der Avoird, 200I:IoI). At the time of Suriname's independence, the Netherlands tried to limit immigration to the Netherlands by allowing free movement between 
Suriname and the Netherlands between 1975-1980. The unintended result - two large emigrations of Surinamese to the Netherlands at the beginning and the end of the five-year period migration - however, was partly due to insecurity about the economic and political stability in Suriname, (Van Amersfoort and Penninx, I998).

3 The term is not used in the sense of citizenship because Surinamese Hindus have been Dutch citizens since I927 (Sinha-Kerkhoff and Bal 2003), but as a notion that signifies the distinct experience of Hinduism through generations in Suriname (see, e.g., Van der Burg 2004 or Van der Veer and Vertovec I99I for an overview of Hinduism in Suriname and the Caribbean).

4 In this context, 'Sanatan Dharm' is the term used to denote the largest institutionalised movement in Suriname Hinduism.

5 The research took place between November 2004 and February 2005. In the fieldwork, the nature of Surinamese Hindus' connection to their Indian background and the Indian people (common stereotype and settings for contact) was explored through informal conversations and participant observation. In the interviews, the questions were made open and general to ensure as many individual perspectives as possible and to avoid putting words into people's mouths. The first twelve interviews were exploratory, and, together with the informal conversations during the fieldwork, formed the basis of a checklist that was used in the following interviews. As my own knowledge accumulated, new sub-topics were included in order to confirm or discount common opinions. The sub-questions thus became more specific over time even though the interviews always started with the same general questions, which often led the informants to introducing other topics on the checklist. At the end of the interviews, I raised the topics on the checklist that had not been discussed.

6 For a discussion of heterogeneity of Hindu beliefs and practices in India and an examination of the concept of 'Hinduism' as a construction that suggests a unitary phenomenon that does not reflect reality, see Vertovec $2000 \mathrm{a}, \mathrm{pp} 7-\mathrm{I3}$.

7 An example of the influence of ascription is that the term 'Hindu' originally derives from the term Persians used in the first millennium AD 'to designate generally the people of India (that is, of the region of the river Indus, after which the term derives)' (Vertovec 2000a: 9).

8 This was one of the main reasons why the Sanatan Dharm was chosen for the research. Moreover, the movement is institutionally strong in Amsterdam - there are four Sanatan Dharm temples but no Arya Samaj temples in the city and both Indian and Surinamese Hindus informants thus tended to refer to the movement when speaking of Suriname Hinduism. These reasons, among other theoretical considerations, took precedence over the fact that the Sanatan Dharm movement does not have a hegemonic status among Surinamese Hindus in the Netherlands today (Van der Burg 2004; Baumann I999).

9 When relevant, the term 'Hindustani' will be used in this section.

Io A differentiation should possibly be made between North Indian and South Indian in the Netherlands; according to a South Indian informant, many South Indians do not go to the Surinamese Hindu temples because the practices were similar to those used in Northern Indian temples. Most of the informants in the study were North Indian, which may somewhat account for this finding.

II Another new trend that could be an interesting topic for further research is marriages between so-called second-generation Indian Hindus and Surinamese Hindus.

I2 In The US, by contrast, 'most Hindu temples are ecumenical to some degree' (Williams I992: 228-257, quoted in Baumann I999: 70).

I3 An interest in Bollywood films does not necessarily indicate an interest in India. Verstappen and Rutten (this book) have discussed the way their Hindustani informants associate Bollywood films with anything but India; India merely serves as a back- 
ground and Indian reality is seen as far removed from the glamorous world that is often depicted in Bollywood films.

I4 Some said 'thank God I was not born there' after talking about their good and bad experiences in India, even though they felt a strong connection because of Hinduism or because of their forefathers. Similar views have been noted in the research of Sinha-Kerkhoff and Bal, who state that 'Some informants explicitly expressed their gratefulness to their forefathers, whose migration saved them from poverty' (SinhaKerkhoff and Bal 2003: I6).

I5 Some reasons for the low degree of interaction that will not, due to space limitation, be discussed in the article include notions of cultural purity and different gender role ideologies. The latter is especially central in images of each other and seems to a large degree to account for the distance held by Indian Hindus. Even though there are many similarities in the gender discourse (that typically centre on the purity of the girls and whether or not they are allowed to go to discothèques), both Indian and Surinamese Hindus tend to think that Surinamese Hindu women are more independent and more liberal sexually. The frequency of which this was discussed in the interviews indicated that differences in gender role patterns strongly divide Surinamese and Indian Hindus.

I6 On the other hand, concerning cultural customs, two views of Surinamese customs coexist among Indian Hindus: on the one hand, a view that the Surinamese experience has led to cultural 'impurity', on the other hand, a view of Surinamese Hindus as being more traditional than Indian Hindus.

I7 The longer rituals reflect the congregational form of worship that developed in Suriname (cf. Van der Veer and Vertovec I99I).

I8 Several Surinamese Hindu informants thought that Surinamese Hindus are internally divided in the Netherlands with half of them active in the Sanatan Dharm and the other half not.

I9 This view on Suriname Hinduism as has been previously noted in other research (Van der Veer I996; Sinha-Kerkhoff and Bal 2003; Vertovec 2000a). Similarly, in studies on music, Manuel (I997) has found that due to the assumed 'greater authenticity' of Indian music practices in the Caribbean, Indo-Caribbeans tend to evaluate their own practices above those found in India.

20 In the case of Suriname Hinduism, according to Van der Veer and Vertovec (I99I), there has been a process of homogenisation of Hinduism in almost all of the foreign colonies where Indian labour migrants emigrated. Hinduism in the Caribbean was the result of a merging of 'the lowest common denominators' (Van der Veer and Vertovec I99I: 4) of beliefs from Hindus of different castes and geographical and linguistic backgrounds.

2I Counting first- and second-generation Indians, including those who have become Dutch citizens.

22 The Indiawijzer website is written by Wahid Saleh who was secretary of the Netherlands-India Association for fifteen years and who has an extensive network of Indian people in the Netherlands.

23 Van Niekerk (2002) explains the importance of education among Indo-Surinamese with 'the history of East Indians in Suriname and the specific economic niche they occupied (in Surinam)' (Van Niekerk 2002:235). Another possibility - which takes into consideration that this value also is strong among Indian Hindus - is that caste consciousness has remained among Surinamese Hindus on the level of status evaluation in occupation, wealth and education (see Jayawardena I968; Speckmann I967 and Seenarine n.d.).

24 Patna Daily 2005; Shubhrangshu 2003; Bhartiya n.d.; Srinivasan 2003; Asian Age 2003 . 
25 The British Indian indentured labourers who migrated to Suriname had different social and caste backgrounds (Hoefte I998; de Klerk I953; Van der Veer and Vertovec I99I; Speckmann I968). It is not possible to fully know the caste origins because the registers rely on self-reporting where some may have reported a higher caste; others may have reported a lower caste (because the labour recruiters assumed that low caste migrants would be more experienced farmers and labourers) than what was actually the case (Hoefte I998). This being said, according to the various records and accounts, the caste and social background of the indentured labourers varied. In Hoefte's words: 'the quite complete data ... show that the migrants represented an average sample of the population, without an extraordinarily high number coming from low castes' (Hoefte i998: 37). In the British colonial authority records, for example, which used some very broad (and, according to Van der Veer and Vertovec, 'somewhat superficial') caste classifications, only 31.4 \% of the indentured labourers were from the lower castes (Van der veer and Vertovec I99I).

26 Other reasons that informants gave for the low degree of intermarriage were different educational levels, language differences, skin colour ('Biharis have darker skin', some Indian informants stated), and differences in gender role ideologies.

27 With long-term fieldwork rather than interviews being a preferable approach.

28 Again, caste identities would need to be researched more extensively before conclusions on whether it is one of the main common denominators can be made.

29 The reasons for the disintegration were mainly that the rules of endogamy and work could not be maintained during the plantation period (Van der Burg 1993). Moreover, most of the indentured labourers migrated individually from different locations in India and it was not possible to create common categories based on the vast variety of 'demographics, roles, networks, attributes, categories, and views surrounding caste' (Van der Veer and Vertovec I991: 4). Furthermore, there was no need for the colonial authorities to maintain caste constructions, as had been the case in British India (Van der Veer and Vertovec I99I).

30 Wikipedia.org states: 'Sindhi refers to an ethnic group of people originating in Sindh which is part of present-day Pakistan. Many Sindhis live in Pakistan but many Sindhis emigrated to India when the subcontinent was partitioned in I947. The language of these people is also known as Sindhi'.

3I 'Indians abroad are presumed to shed their regional, linguistic, and ethnic identities in deference to the more general identity of being Indian' (Lal n.d., UCLA website on Indian diaspora http://www.sscent.ucla.edu/southasia/Diaspora/reflect.html) 


\title{
11 Afterword
}

\section{Stray Thoughts of an Historian on 'Indian' or 'South Asian' 'Diaspora(s)'}

\author{
Claude Markovits
}

This volume adopts a cautiously critical stance vis-à-vis the framework of diaspora as applied to the Indian case. It does so through the use of different approaches, and, although the various authors do not necessarily agree on all points, the overall effect achieved is impressive, and refreshingly original. The only justification for this 'afterword' is to offer a slightly 'décalée' view coming from an historian who has worked exclusively on one aspect of the South Asian diaspora, the dispersal of South Asian traders, a fairly specialised area of research, and someone who feels no particular loyalty, institutional or affective, to the diaspora framework. Here I shall try to reframe some of the questions regarding "diaspora" in a more historical mode, by trying to look both at empirical facts and perceptions as they evolved over time. I am not going to consider the instrumental uses of the term "Indian diaspora". It is clear that the Government of India, for its part, has good reasons to promote that notion, in the hope of economic and political gains, and nobody is going to begrudge them the right to do so. Similarly, diaspora studies have become a recognised sub-field within the broader field of South Asian studies, providing research grants and jobs aplenty, and it would be foolish to object to that. Last but not least, people of South Asian origin all over the world often feel that thinking of themselves as members of an overarching "Indian" or "South Asian" diaspora brings them benefits, both emotional and material, which are worth fighting for, and it would be churlish to deny them those benefits, however imaginary they might appear to be.

In discussing the genealogy of the "diaspora" approach, which became dominant in the I980s and I990s, and replaced, as mentioned by Gijsbert Oonk in his very thorough introduction to this book, an earlier focus on "Overseas Indians", I do not have a broad survey of the existing literature in mind, stressing its fortes and weaknesses, an exercise for which I do not feel qualified. As Oonk himself mentioned, one 
can find plenty of empirical cases, which do not fit within the "diaspora" framework, but this, to my mind, is not a sufficient reason to reject it out of hand, as the same could be probably said of any similarly broad notion. Rather, I propose starting with a brief excursus into what some would call the "prehistory" of diaspora. Oonk's introduction mentioned the various streams that went into the making of what became later known as the 'Indian' or 'South Asian' diaspora (I shall come back later to that important distinction). I shall here focus on two of them. Firstly, the stream of merchant circulations from the subcontinent which started in the medieval period and continues to this day, and secondly the much more time-bound export of indentured labour which spanned the I830-I9I6 period. On prior examination, it would seem that those two streams have very little in common and that bracketing them under the all-encompassing label of 'Indian' or 'South Asian' diaspora can be done only at the cost of ignoring the vast spatial and temporal disjunctures between them. Gijsbert Oonk in his text, has mentioned some of these disjunctures. However, taking a closer look, one also finds certain commonalities. Firstly, it is not certain that merchant circulation and indentured migration can be contrasted in terms of 'free' versus 'forced' migration. The idea of indentured labour migration as forced migration owes a lot to the pioneering work of Hugh Tinker ${ }^{\mathrm{I}}$, who rightly stressed certain similarities between slavery and indenture, but was perhaps insufficiently aware of some of the differences. While indenture undoubtedly implied an element of coercion and a deliberate withdrawal of information as to the real conditions of labour in the sugar colonies, it was nevertheless 'contractual' in a way slavery could never be, and, more importantly, held a promise of return (although mostly unfulfilled), which was of course absent in slavery. On the other hand, it is not certain that merchant circulation was as 'free' as it is made out to be. Merchant networks that I have studied, such as those which originated in the two medium-scale towns of Shikarpur and Hyderabad in Sind $^{2}$, consisted of different types of operators. The dominant ones were so-called 'capitalists' who generally remained based in Sind and were content with advancing finance to 'working partners' who did the actual travelling. The latter could be considered 'free', except that they accumulated debts vis-à-vis their capitalist employers that they could often repay only through further travel in their service. But, more importantly, there emerged, especially in Hyderabad, a class of salaried employees, either shop assistants, or 'servants', who travelled on contracts which were in many ways modelled on indenture contracts. This was true in particular of the contracts of 'servants', who were menial labourers providing domestic services to the partners of the merchant firms. Their wages were very low, they had to live in very unhygienic and cramped quarters in the shops 
(somewhat similar to the plantation 'lines' in which indentured sugar plantation workers crowded), and their earnings were retained by the firms, which were supposed to transmit them to their families, but probably did not always do so. Although these contracts, prior to the Emigration Act of I922, which introduced regulations covering all aspects of emigration from India, were purely private and not underwritten by the state, they were not widely dissimilar to indenture contracts, in creating a category of labour which was at best 'semi-free'.

But there were other points at which so-called 'passenger' migration (thus called because the migrants paid their own passage on ordinary ships, in contrast to the indentured labourers, who travelled on specially chartered ships) intersected with indentured migration. Most of the examples concern Africa. The best-known case is that of the indentured labourers recruited in rural Gujarat and Punjab (two areas of recruitment not traditionally known for that kind of labour, which came mostly either from the Bhojpur area of Bihar and the Eastern United Provinces, or from Tamilnadu), amongst the Patels and Ramgharia Sikhs, to build the Uganda railway in the early twentieth century. A few thousand out of a total of 40,000 (many of whom died on the job) stayed behind in East Africa, at the expiration of their contracts, and formed the backbone of the class of small traders or dukawallas, which dominated trade in the interior of East Africa ${ }^{3}$. These dukawallas received their goods, both British and Indian, largely via the Indian commercial firms created in the ports by 'passenger' migrants, mostly $\mathrm{Gu}$ jaratis belonging to the trading classes. Thus there emerged a kind of unified Indian commercial network mixing arrivals from two very different streams. The second case is that of South Africa, particularly Natal, where indentured labour started arriving in around I860 and preceded commercial migration by two decades. This is where the passenger migrants, subjected to increasing residential restrictions by the colonial authorities, responded by specialising partly in the import and sale of goods destined for the indentured labourers. In the case of South Africa, there was an intermediate category between, on the one hand, the few rich 'Arab' (i.e., Gujarati Muslim) traders of Durban, and, on the other hand, the mass of indentured coolies, mostly Tamilian and Telinga (the latter are covered in Chandrasekhar Bhatt's article); they were the peddlers, small traders of various origins, who earned a precarious living by peddling manufactured goods in the African locations of the Transvaal in particular. They assumed particular importance at the time of Gandhi's first satyagraha launched in Johannesburg in 1906, when they provided the future Mahatma with a kind of mass base which allowed him to challenge the authorities in a new way, different from the petitions which had been his favourite mode of intervention when he was acting as a spokesman for the merchant elite 
of Durban ${ }^{4}$. South Africa is of course a special case, as it saw the early emergence of a kind of unified Indian political community around Gandhi's leadership. The case of the Indian Ocean island of Mauritius is different: There, Indian traders arrived with the Bombay army in I8Io at the time of the island's capture from the French, and the first indentured labourers were brought in 1834 , following the abolition of slavery. But the Indian traders there also tended to increasingly specialise in the selling of goods to the labourers. The emergence of a political community was a much later development, dating from the I950s.

I have gone into this small historical digression to show how two streams of migration which had completely different trajectories could partly mesh within the context of the creation of an imperial economy in which Indian traders became junior partners of British imperial capitalism, and of an imperial political system in which, through the struggle for civil and political rights in India and in other regions of the Empire, close links could be forged across the Indian Ocean. This is also meant to underline the importance of historical context to the study of diaspora, which cannot be carried out in isolation from broader trends in world economic and political history, a point which Scott Levi also stresses in his paper on Indian traders in Central Asia. A similar blurring of boundaries can be shown to have existed in some Asian countries, where Indian immigration did not take the form of indenture, but was organised through the system known as kangani, i.e., mostly in Ceylon, Malaya, and Burma. Some of the kangani migrants branched out into small-scale trade, while some 'passenger' Indians, like those Oriyas and Telingas who came each year to lower Burma for the rice harvest, were in fact agricultural labourers.

Could it be said that people of South Asian origin dispersed around the world on the eve of World War II, already formed a kind of diaspora, even if the term was not in use at the time ? The answer is in the affirmative if diaspora is not used as an equivalent of 'transnational' community, but is seen in relation to both Empire and nation. Most people of Indian origin outside of India in I939 lived in countries of the British Empire, the most significant exceptions being Dutch Guiana, and the French islands of Martinique, Guadeloupe, and Réunion. The British imperial authorities saw them as imperial subjects, entitled to some basic rights (which of course did not include political rights), but even this was often not accepted by local British settlers in settler colonies where the Indians were treated as foreigners and discriminated against. In spite of the fact that, during the inter-war period, British India had evolved into a kind of semi-autonomous appendage of imperial Britain, following its own 'foreign policy' and that New Delhi, often under pressure from nationalist opinion in India, sometimes intervened in support of the interests of Indian communities outside 
India. In contrast to this British view of overseas Indians as imperial subjects in need of protection, Indian nationalists thought of them as dispersed fragments of a great Indian nation-in-the making who had their role to play in the struggle for freedom. Money was collected from amongst these 'overseas Indian communities' to support nationalist activities in India, and Indian nationalist opinion was mobilised in support of the specific grievances of particular overseas Indian groups, such as the clove traders of Zanzibar, when they faced difficulties in the late I930s. While there was some talk of Indian culture and of its universal reach, with Rabindranath Tagore in particular acting as its self-proclaimed messenger to the outside world, the Bengali poet did not target specific Indian audiences in the course of his travels to the West and East. Religion, more than an Indian culture which remained largely undefined, was often seen as the major link between these dispersed communities and the 'Motherland'. Hindu preachers, both Arya Samajists and 'Sanatanists' as well as Sikh priests, and Muslim mullahs often visited these communities, and, in a reverse movement, pilgrims from as far away as Fiji or Guyana travelled to Benares, Amritsar, and other holy places in India. Obviously, before the era of mass air travel, these movements were on a relatively modest scale, but they occurred nevertheless. So, if the notion of 'diaspora' did not exist, some of its underpinnings were already there. British and Indian nationalist views of the Indian overseas communities, although contrasted, were not incompatible: some Indians found it possible to be at the same time loyal imperial British subjects and patriotic overseas Indians. During World War II, however, for some, a choice had to be made between two loyalties: when Subhas Bose created his government in exile and his Indian National Army, he tried to enlist the support of existing Indian communities in the various countries under Japanese occupation where they were present. He had some success in mobilising the Indian population of Malaya in particular, and traders in various places joined his movement in significant numbers. ${ }^{5}$ For two years (1942-44) Indian nationalism was more in evidence outside India than inside, where it was severely repressed by the British. This was the real moment of glory of 'Overseas India', although it was never much celebrated later because of the Congress's ambivalent appraisal of Bose and his movement. In the post-I947 phase, major changes occurred both in migration flows and in relations with the 'homeland', but it took several decades before the interpretive framework changed in its turn. A brief summary of the main changes is in order at this point.

One major change, of course, has been directly linked to the independence and partition of India. With the birth of the two independent and mutually hostile states of India and Pakistan, the relationship of expatriate Indians to the 'homeland' underwent a transformation. 
Firstly, for the ex-imperial subjects, there arose the question of political allegiance to one nation-state: if Hindus and Sikhs naturally tended to swear allegiance to India, the overseas South Asian Muslims had a more difficult choice to make: while the majority chose Pakistan, a small minority opted for India and others, such as the Ismailis, tried to remain uncommitted. In spite of the incipient split created by the partition of the subcontinent, South Asians tried to maintain a united front in the complicated politics of decolonisation of the post-war period. This was the case in East Africa, and particularly in Kenya, where Indians were in a delicate position, torn between loyalty to a colonial regime which had allowed them a degree of economic prosperity, and anti-colonial feelings which pointed towards an alliance with African nationalism. The fact that the Mau-Mau targeted Indians as enemies and killed a few did not help. It was at this time that the Government of India, under Nehru, took the line that Indians had to forge an alliance with Africans, and could not count on India to defend their (relative) privileges after independence. This led many Asians in East Africa to opt for the alternative option of getting British passports, resulting ultimately in their migration to Britain. These 'twice migrants', mentioned by Oonk in his introduction as one sub-category of the Indian diaspora, pose an important question: Is 'Indianness', which they often claim, compatible with a deliberate rejection of political allegiance to India (of course, it must not be forgotten that India did not welcome them and the few who had opted for Indian nationality after the East African nations gained their independence had great difficulties actually relocating there). I tend to think that this group is a rare case of a really 'transnational' population, devoid of strong national-political loyalties, whose inclusion into the 'Great Indian Diaspora' fold is somewhat spurious. The Hindustani 'twice-migrants' from Suriname now living in the Netherlands represent a specific case within this category, and Brit Lynnebakke, in her very informative paper, shows how delicate their relations are with the 'direct' migrants from India in the Netherlands.

I now come to the two major recent migration streams: on the one hand; the massive movement of workers, clerks and nurses from India, Pakistan, and Bangladesh to the Gulf countries, which is mostly temporary, and rarely results in settlement, and on the other hand, the migration of professionals, overwhelmingly from India, in particular IT specialists, to the countries of the First World, primarily, of course, the US, but also Australia, Canada, New Zealand, and the UK. Although the latter includes an element of circulation, since some of these professionals tend to go back to India after a few years, it is clear that the majority are bound to establish their permanent residence in these countries of destination. While this new wave of migration has not 
completely obliterated older streams, and in particular Sikhs of a rural background continue to emigrate in large numbers to Canada, and in smaller numbers to Australia, New Zealand, Britain, Italy and the US, it has become clearly dominant in regard to First World countries. Does it make any sense to bracket these two groups under an overarching category of 'Indian' or 'South Asian' diaspora? It is clear that sociologically it does not, because while the former belongs overwhelmingly to the working class and the lower-middle class, the latter is mostly upper-middle class. Besides, the former is made up mostly of sojourners while the latter consists mostly of potential settlers. Their categorisation under the umbrella of the 'Great Indian Diaspora' seems mostly a device, encouraged, of course, by the Government of India, to increase the numbers and show that the Indian diaspora is almost as large as the Chinese one. Another problem is that, while the upper middle-class migrants to the First World have produced an abundant literature of their own, and have attracted a lot of attention from scholars, mostly based in the US and the UK - some of whom even belong to that group - we know much less about the Gulf migrants: They do not as a rule write their own experiences, and scholars who have studied them have mostly focused on factual questions, such as migration streams and remittances, rather than on their self-perceptions and their relationship to the homeland.

We are therefore faced with a kind of paradox: the more fragmented and diverse the actual Indian or South Asian diaspora tends to become, encompassing experiences and trajectories which appear largely incommensurable to each other, the more inclusive the discourse about diaspora tends to become, either because of a kind of nationalist appropriation or because it becomes enclosed within a more general discourse of globalisation. Nationalism and globalisation of course do not represent two polar opposites, but, on the contrary, as shown by Arjun Appadurai ${ }^{6}$ and others, two sides of the same coin. In the face of such confusion, the temptation naturally arises to deconstruct the notion of Indian diaspora itself and some of the papers in the collection attempt to do it in their own way. The strategy used by them is to break that diaspora into some of its components, taking advantage of its enormous ethnic, religious and linguistic diversity . But the question then becomes what is the most appropriate category to choose for this exercise. Happily, the collection tends to avoid the pitfall of going for the more obvious, such as the overall religious categories of Hindu, Mus$\mathrm{lim}$, Sikh, etc. Steven Vertovec's attempt to define a Hindu diaspora ${ }^{7}$, which I always found slightly spurious, and in danger of fitting (even inadvertently) within some kind of Hindutva agenda, is fortunately not echoed here. The Sikh diaspora, a notion that W.H. McLeod had criticised long ago on sane grounds ${ }^{8}$, also does not appear in these pages. 
It is true that 'Muslims' make their appearance in one article, but in a way which is sufficiently qualified to avoid ambiguities. On the other hand, the following, more discrete categories do appear: Telugus, British Gujarati Hindus, Patels, Multanis and Shikarpuris, Nizari Ismaili Muslims of Gujarati ancestry. I do not intend to discuss them in detail here, but their simple enumeration points to a problem of a conceptual nature: they are absolutely heterogeneous, and do not amount to a classificatory system, but are simply a list. While such a list helps in mapping the empirical terrain, one will have to move beyond it if the ultimate aim is to offer some coherent counterpoint to 'Indian diaspora'.

To illustrate some of the difficulties involved in such a project, I shall offer a brief case study of one specific diaspora from South Asia, the so-called Sindhi diaspora, with which I am familiar. Firstly, it has to be noted that 'Sindhi diaspora' generally refers to the dispersion of Sindhi 'Hindus' (I shall come back to the tricky question of their religious identity), a phenomenon that has a long history, and ignores the much smaller dispersion of Sindhi Muslims, which is a more recent trend. The present-day Sindhi diaspora outside India (leaving aside the question of the dispersion of Hindu refugees from Sind within India, which is also after all a form of diaspora) is probably less than 200,000strong', thus accounting for approximately I\% of the total 'Indian diaspora' as measured by the slightly dubious Government of India calculations. In terms of 'regional diasporas', it certainly pales into insignificance in comparison with the big battalions of the Gujarati, Bhojpuri, Punjabi, Tamilian, Telugu and Kashmiri (Mirpuri) diasporas, which account for the bulk of South Asians outside the subcontinent. This may be one of the reasons why the 'diaspora literature' studiously ignores this stream, which is, however, remarkable in at least two ways: it is the most widely dispersed of all the South Asian diasporas, with a world presence unmatched by any other, including in regions such as Latin America and Western Africa, which never attracted Indian migrants in significant numbers, and, in terms of wealth, it is probably second only to the Gujarati diaspora (which itself is of course extremely diverse). Prior to the rise of the Marwari transnational steel magnate Lakhsmi Mittal, the richest Indian business family outside India was the Hinduja family, a family of Shikarpuri (Sindhi) origin, which made its fortune in Iran in the I920-I979 period before enlarging its operations to many other parts of the world. And, apart from the Hindujas, other Sindhi businessmen are amongst the richest of business magnates of South Asian origin outside the subcontinent ${ }^{\mathrm{IO}}$.

The history of this diaspora falls into three distinct phases. The first one covers the period between the fifteenth century and I860. During that period, Bhatia traders from the main Sind port of Thatta established an important colony in Muscat, which prospered till the mid- 
eighteenth century, and played an important role in the maritime trade between Western India and the Arabian Peninsula. Offshoots of it were established in the eighteenth century in Bahrain and other Gulf ports, while in Muscat itself, in relation to the decline of Thatta as a port (due to ecological factors, such as silting), Thatta Bhatias tended to give way to Kutchi Bhatias, originating from the region of Kutch, a border area between Gujarat and Sind. While the Thatta network was in decline by the mid-eighteenth century, Shikarpur, a town in Upper Sind, became the centre of a powerful financial and commercial network oriented towards Central Asia, a development which is covered in Scott Levi's article. By the I870s, that network faced difficulties owing to the Russian conquest of Central Asia, which affected the multi-secular trading links between Northern India and Central Asia. Nevertheless, it somewhat survived till the time of the Russian Revolution, which led to its disappearance from large parts of Central Asia. However, it continued to operate in Afghanistan, Iran, and Chinese Sinkiang, while Shikarpuri moneylenders expelled from Soviet Central Asia relocated to Bombay, Southern India, Ceylon and Burma, where they emerged as an important community of 'informal' or 'indigenous' bankers in the I920s and I930s. But, from the I860s onwards, a new Sindhi trading network had developed in the second largest town of the province, Hyderabad, which was directly connected with Bombay. Hyderabadi traders, known as Sindworkies, specialised in the sale of silk and curios, using Bombay as a springboard to the following of maritime routes to the four corners of the earth, setting up shop in the main ports and becoming a significant force in the international textile trade in the interwar period. At the time of the partition of the subcontinent, there were probably some ten to fifteen thousand Sindhi traders and moneylenders, mostly Hyderabadis, dispersed across the world in small colonies of merchants that benefited from British consular protection. The largest concentrations, never more than one or two hundred-strong, were in Panama, Teneriffe, Gibraltar, Tangiers, Port-Said, Colombo, Hong Kong, Singapore, Surabaya, Manila, and Kobe. With partition, despite the fact that Sind was not affected by violence on a scale comparable to what happened in the Punjab, there was a massive exodus of Sindhi Hindus towards India: They went mostly to Rajasthan, Gujarat and Bombay, but, from there, fanned out across the whole subcontinent, establishing significant colonies in northern and central India. Gradually, those among them who had kin outside India, especially amongst the Sindworkie community, tended to join them abroad: From the late I940s to the I96os, there was a significant influx of Sindhi traders into Hong-Kong (where they were estimated to be around 15,000 in I966 ${ }^{\mathrm{II}}$ ), Singapore, Indonesia, the Philippines, the Canary Islands, Nigeria, etc. By the I96os, a new stream developed, amongst profes- 
sionals, that belonged to the Amil community (a 'scribal' community somewhat similar to the Kayasths of Northern India), who went mostly to the US, Canada, Britain, and, more recently, Australia.

This Sindhi diaspora has certainly followed a rather unusual historical trajectory, but nowadays it tends to think of itself as part of the 'Great Indian Diaspora', a claim which is sometimes, but not always, accepted by other members of that diaspora. On the other hand, it is probably the most 'transnational' of all the sub-diasporas, not only because of its very wide dispersion across the world, but also because, to promote its wide-ranging business interests, it tends to follow strategies regarding nationality which are very complex. A typical Sindhi transnational business family will include people with many different locations and many different passports. There is generally one branch in Bombay, which is the hub of that diaspora, but the rest can be residents of many different countries, whose nationalities they might take, while often retaining their Indian nationality (in spite of the non-recognition of dual nationality by the Indian Government). Although they profess strong attachment to some overarching Indian culture, Sindhis can be in very diverse cultural situations. The linguistic situation, which attracted Oonk's attention in his paper on East Africa, varies widely amongst Sindhi communities. The Sindhi language is undoubtedly losing ground to English as the most ordinary medium of communication, while also Hindi has its place, as well as the languages of the various places where Sindhis have been residing. Thus Sindhi merchants in Singapore often speak Malay and Chinese, while those in Manila speak Tagalog and those in the Canary Islands are fluent in Spanish. Multilingualism is of course a trait of all dispersed merchant groups, but it is not without its effect on patterns of identity formation in a diaspora which is still dominated by commercial elements. The question of identity also arises in the context of religion. Sindhi Hindus, in pre-partition days, were overwhelmingly Nanakpanthis, belonging to the so-called Sahajdhari (i.e., non-Khalsa) Sikhs, but they often had close relations with Khalsa Sikhs. In some places, like Manila or Singapore, which had both Punjabi and Sindhi communities, the first gurdwaras were established there thanks to donations from rich Sindhi merchants, although Punjabis managed them. But Sindhis often prayed there, as well as in Hindu temples. The tragic events of 1984 , leading to the assassination of Mrs Gandhi by two of her Sikh bodyguards, and to a spate of anti-Sikh riots in Delhi, led to an estrangement between Sindhis and Khalsa Sikhs. It was noted that, in many places, Sindhis ceased going to gurdwaras to pray, and often built their own temples. However, it has recently been reported that Sindhis have again found their way to the gurdwaras, and that they have financed the building of some in Europe. Another specific trait of the religious 
identity of Hindus in pre-Partition Sind was that many were murids of the Sufi pirs, who were very respected in Sind by Muslims and Hindus alike. After Partition, attachment to the pirs clashed with the resentment vis-à-vis Muslims felt by many following their expulsion from their native province, and this contributed to a religious identity crisis amongst Sindhis.

Given these complexities, what is gained in analysing the Sindhi diaspora within the broader framework of the Indian diaspora? If we use the three meanings of diaspora identified by Steven Vertovec and mentioned in Oonk's introduction, we can see that as a social form, the diaspora is decidedly 'Sindhi', in the sense that the actual networks binding together its members do not crucially interact with India at the economic or political level. On the other hand, as a type of consciousness, it is ambiguous: Sindhi identity vies with Indian identity (often equated with Hindu identity) in complex and changing ways. It is probably in its meaning as mode of cultural production that the diaspora is most 'Indian', in the sense that 'Sindhiyat', in spite of half-baked efforts at promoting it, offers little in terms of cultural resources, and raises the delicate question of the relationship of the Sindhi Hindu diaspora to the Sindhi culture as it evolves in Pakistan. Regarding the heuristic gains of using an Indian diaspora framework to account for the Sindhi diaspora, we cannot therefore come to a clear-cut conclusion. The few authors who have written on the Sindhi diaspora, such as MarkAnthony Falzon ${ }^{\mathrm{I} 2}$ have chosen to privilege the 'Sindhi' angle over the 'Indian' one, but their approach has not raised many echoes, given the continuing power of the 'Indian diaspora' narrative.

In this afterword, I have been echoing some of the doubts vis-à-vis the 'Indian diaspora' framework voiced by many authors in the collection, and attempting to reframe them within a more historical approach to the problem, but I am not in a position to suggest a satisfactory alternative framework. This is perhaps as well with an afterword; otherwise, it would become a foreword. 



\section{Bibliography}

Africa Today (I959) 'The Ismailis in East Africa: Small but Progressive Community', East Africa Today quoted in Kadende-Kaiser, R.M. and P.J. Kaiser (I998) 'Identity, Citizenship, and Transnationalishm: Ismailis in Tanzania and Burundians in the Diaspora', Africa Today, 45 (3/4).

Aga Khan III (I954) The Memoirs of Aga Khan, London: Cassell.

Aksoy, Asu and Kevin Robins (2003) 'Banal transnationalism, the difference that television makes', in: Karim H. Karim (ed.), The media of Diaspora, pp. 89-I04. London: Routledge.

Alam, Muzaffar (I994) 'Trade, state policy and regional change; aspects of Mughal-Uzbek commercial relations, C.I550-I750', Journal of the Economic and Social History of the Orient 37: 202-27.

Alladina, S. (2004) 'Mainstreaming Indian Culture', Shades Between, Feb. < http://www.shadesbetween.com (Accessed: 5 Feb. 2004).

Allessandrini, Anthony C. (200I) “My Heart's Indian for All That”: Bollywood Film between Home and Diaspora'. Diaspora io (3): 315-340.

Amersfoort, H. van and R. Penninx (I998) 'Western Europe as an immigration area.' In Hans van Amersfoort and J. Doomernik (eds.), International migration: Processes and interventions. Amsterdam: Het Spinhuis.

Anderson, Benedict (1983) Imagined Communities: Reflections on the Origins and Spread of $\mathrm{Na}$ tionalism. London: Verso.

- (I992) Long-distance nationalism: World capitalism and the rise of identity politics. G. Kligman, The Wertheim Lecture.

- (1998) The Spectre of Comparisons: Nationalism, Southeast Asia and the World. London and New York: Verso.

Ang, Ien (1985) Watching Dallas: Soap opera and the Melodramatic Imagination. New York: Methuen \& Co [original Dutch edition Het Geval Dallas i982, Amsterdam, SUA].

Anthias, Floya and Nira Yuval-Davies (1992) Racialised Boundaries: Race, Nation, Gender, Colour, Class and the Anti-Racist Struggle. London: Routledge.

Antonova, K.A., N.M. Gol'dberg and T.D. Lavrentsova (eds.) (I958) Russko-indiiskie otnosheniia $v$ XVII v., sbornik dokumentov. Moscow: Nauka.

Antonova, K.A., and N.M. Gol'dberg (eds.) (I965) Russko-indiiskie otnosheniia v XVIII v., sbornik dokumentov. Moscow: Nauka.

Anwar, Muhammad (I975) Between Two Cultures. London: Community Relations Commission.

Appadoo, Ramasamy (I990) 'The first Telugu temples in Mauritius', Telugu Vani, Special Issue of the Third World Telugu Conference.

- (I994) 'Mauritius and the Telugu people', Telugu Jagathi, Souvenir Issue of First World Telugu Federation.

Appadurai, Arjun (I990) 'Disjuncture and Difference in the Global Cultural Economy', Public Culture 2 (2): I-24.

Asian Age, The, 'How to Hate a Bihari in Io easy steps.' Posted on 22 November 2003. http://www.mjakbar.com/default.asp?headline=24459\&rm=archive. Accessed 24 March 2005 . 
Avoird, Tim van der (200I) Determining language vitality - the language use of Hindu communities in the Netherlands and the United Kingdom. Dissertation Tilburg University.

Ballard, Catherine (I978) 'Arranged marriages in the British context', New Community 5: I8II95.

Bamyeh, M.A. (I993) 'Transnationalism’. Current Sociology 4I(3): I-95.

Bamzai (I999) 'Back to Bollywood', Business India (I2 July).

Barth, F. (I969) 'Introduction,' in: F. Barth (ed.), Ethnic Groups and Boundaries: The Social Organization of Culture Difference. London: George Allen \& Unwin.

Baumann, G. (I996) Contesting Culture: Discourses of Identity in Multi-ethnic London. Cambridge: Cambridge University Press. Cambridge Studies in Social and Cultural Anthropology.

- (I999) The Multicultural Riddle: Rethinking National, Ethnic and Religious Identities. New York and London: Routledge.

Baumann, Martin (I999) 'The Hindu Diaspora in Europe and an Analysis of Key Diasporic Patterns'. In T.S. Rukmani (ed.), Hindu Diaspora: Comparative Patterns. Montreal: Chair in Hindu Studies.

Bernier, Francois (189I) Travels in the Mogul Empire, AD 1656-1668. Trans. by Irving Brock and edited by Archibald Constable. Westminster: Archibald Constable.

Bhachu, Parminder (1985) Twice Migrants: East African Sikh Settlers in Britain. London and New York: Tavistock.

Bharati, A. (I970) 'A Social Survey', in: D. Ghai and Y. Ghai (eds.) Portrait of a Minority; Asians in East Africa. Nairobi: Oxford University Press.

Bhartiya, Tarun (n.d.) 'Loneliness of a long distance Bihari', essay posted on Sarai Net: http://www.sarai.net/language/popularculture/essays/lonely_tarun.htm (accessed 25 March 2005).

Bhaskar, T.L.S. (I999) Telugu diaspora in the United States. MPhil. Dissertation, University of Hyderabad, Hyderabad.

- (2003) Identity maintenance in the Telugu diaspora. Ph.D. Thesis, University of Hyderabad, Hyderabad.

Bhat, Chandrashekhar (1998) India and the Indian diaspora: policy issues, Occasional Paper 3. Hyderabad: Centre for the Study of Indian Diaspora.

- (2003) 'India and the Indian diaspora: inter-linkages and expectations', in: Ajay Dubey (ed.) Indian diaspora: global identity, pp.II-22. Delhi: Kalinga Publications.

Bhat, Chandrashekhar and Ajaya K. Sahoo (2003) 'Diaspora to transnational networks: the case of Indians in Canada', in: Sushma J Varma and Radhika Seshan (eds.), Fractured identity: the Indian diaspora in Canada, pp. I4I-67. New Delhi: Rawat Publication.

Bijmans, Kristel (I996) Bollywood in Nederland, Een beschrijvend onderzoek naar de Indiase film in Nederland. Doctoral thesis, University of Utrecht, Utrecht.

Blair, T. (I995) Speech to the I995 Labour Party Conference, 3 October. London: Labour Party.

Bloemberg, Lucie (I995) Tussen traditie en verandering. Hindostaanse zelforganisaties in Nederland. Ph.D. thesis Koninklijk Nederlands Aardrijkskundig Genootschap / Instituut voor Sociale Geografie, Utrecht and Amsterdam.

Boudon, Raymond (I986) Theories of Societal Change: A Critical Appraisal. London: Polity Press.

Brah, Avtar (1987) Women of South Asian origin in Britain: Issues and Concerns', South Asia Research 7: 39-54.

Bramshad, M. et al. (I998) 'Female gene flow stratifies Hindu castes', Nature 395:65I.

Brosius, Christiane (2005) 'The scattered homelands of the migrant: Bollyworld through the diasporic lens', in: Raminder Kaur and Ajat J. Sinha (eds.), Bollyworld; popular Indian cinema through a transnational lens, 207-238. New Delhi, Thousand Oaks and London: Sage. 
Brubaker, Roger (2005) 'The “diaspora” diaspora.' Ethnic and Racial Studies, vol. 28 no. I, II9.

Buchignani, N, D.M. Indra and R. Srivastava (1985) Continuous Journey: A Social History of South Asians in Canada. Toronto: McClelland and Stewart.

Buddingh', Hans (1999) Geschiedenis van Suriname. Utrecht: Het Spectrum [first edition I995].

Burch, Elizabeth (2002) 'Media Literacy, Cultural Proximity and TV Aesthetics: Why Indian Soap Operas work in Nepal and the Hindu Diaspora', Media, Culture and Society 24: 57I579 .

Burg, Corstiaan J.G. van der (I99I) Structural conditioning of identity formation. Surinamese Hindus and religious policy in The Netherlands.' W.A.R. Shahid, and P.S. van Koningsveld, (eds.), The Integration of Islam and Hinduism in Western Europe. Kampen: Kok Pharos Publishing House.

- (I993) 'Suriname Hinduism in the Netherlands and social change.' Rohit Barot (ed.), Religion and ethnicity: minorities and social change in the metropolis. Kampen: Kok Pharos Publishing House.

- (2004) 'The Hindu diaspora in the Netherlands: Halfway between local structures and global ideologies.' Knut A. Jacobsen and P. Pratap Kumar (eds.), South Asians in the diaspora. Leiden: Brill.

Burg, Cors van der and Peter van der Veer (I986) 'Pandits, power and profit: religious organizations and the construction of ethnicity among Surinamese Hindus.' Ethnic and Racial Studies, 9: 514-528.

Burnes, Alexander (I834) Travels into Bokhara ... 3 vols. London: John Murray.

- (I843) Cabool; a personal narrative of a journey to, and residence in that city, in the years 1836, 7, and $8 \ldots 2$ d ed. London: John Murray.

Burton, Richard (1851) Sindh and the races that inhabit the valley of the Indus. London: William H. Allen.

Butler, Kim D. (200I) 'Defining Diaspora, Refining a Discourse', Diaspora, Io(2).

Caswell, M. (2004) The God Commodity <http://www.redhotcurry.com/views/hindugod_lunchbox.htm (28 March).

CBS (Centraal Bureau voor de Statistiek) Statline: http://www.cbs.nl/

a) 'Islamieten en Hindoes in Nederland, I Januari'. http://statline.cbs.nl/StatWeb/start. asp?lp=Search/Search Accessed to May 2005.

b) 'Allochtonen per regio naar herkomstgroepering en geslacht, I januari' http://statline. cbs.nl/StatWeb/table.asp?STB=GI, G2, G3, G4\&LA=nl\&DM=SLNL\&-

$\mathrm{PA}=377 \mathrm{I} 3 \& \mathrm{DI}=0 \& \mathrm{D}_{2}=2 \mathrm{I} \& \mathrm{D}_{3}=26 \& \mathrm{D}_{4}=0 \& \mathrm{D}_{5}=1 \& \mathrm{HDR}=\mathrm{T}$

Central State Historical Archive of the Republic of Uzbekistan: 'O paralizaovanii ekspluatsii tuzemnogo nasaleniia indeiskimi vykhodtsami.'Fond I-I, opis’ II, delo 39 (25 June I877-IO April I893).

— 'Po povodu vzyskaniia s indeitsev shtrafa za torgovliu bez dokumentov.' Fond I-I, opis' II, delo 200 (29 May I88I-II December I884).

Chardin, John (Jean) (I686) The Travels of Sir John Chardin into Persia and the East-Indes...to which is added, the coronation of this present king of Persia, Solyman the Third. London: Moses Pitt.

- (I8II) Voyages du Chevalier Chardin, en Perse, et autres lieux de l'Orient. Io vols. Paris: Le Normant.

- (1924) Sir John Chardin's travels in Persia. London: Argonaut Press.

Choenni, Chandersen (200I) Hindu youngsters in the Netherlands'. Hinduism Today. http:// hinduismtoday.com/in-depth_issues_dutch_survey (accessed 20 September 2005). 
Choenni, C.E.S. (2003) 'Hindostaanse jongeren in beeld', in: Chan E.S. Choenni and Kanta Sh. Adhin (eds.), Hindostanen, Van Brits-Indische emigranten via Suriname tot burgers van Nederland, I68-I89. Den Haag: Sampreshan.

- (2003a) 'Migratie en vesteging in Nederland.' Chan E.S. Choenni and Kanta Sh. Adhin, (eds.), Hindostanen. Van Brits-Indische emigranten via Suriname tot burgers van Nederland. Den Haag: Sampresan, pp. 54-69.

- (2003b) 'De maatschappelijke positie van Hindostanen.' Chan E.S. Choenni and Kanta Sh. Adhin (eds.), Hindostanen. Van Brits-Indische emigranten via Suriname tot burgers van Nederland. Den Haag: Sampresan, pp. 70-89.

- (2003c) 'Hindostaanse jongeren in beeld.' Chan E.S. Choenni and Kanta Sh. Adhin, (eds.), Hindostanen. Van Brits-Indische emigranten via Suriname tot burgers van Nederland. Den Haag: Sampresan, pp. I68-I88.

Choenni, Chan.E.S. and Chander Mathura (I998) Hindoe jongeren in beeld. Een onderzoek naar de religieuze beleving van Hindoe jongeren. Hilversum: Stichting Organisatie voor Hindoe Media.

Choenni and Kanta Sh. Adhin (eds.) (2003) Hindostanen, Van Brits-Indische emigranten via Suriname tot burgers van Nederland. Den Haag: Sampreshan.

Çizakça, Murat (I996) A comparative evolution of business partnerships; the Islamic World and Europe, with specific reference to the Ottoman archives. Leiden: E.J. Brill.

Clarke, C., C. Peach and S. Vertovec (I990) 'Introduction: Themes in the Study of the South Asian Diaspora', in Clarke, C. et al. (eds.), South Asians Overseas, pp. I-29. Cambridge: Cambridge University Press.

Clifford, J. (I994) 'Diasporas', Cultural Anthropology 9: 302-338.

Cohen, Abner (I97I) 'Cultural strategies in the organization of trading diasporas', in Claude Meillassoux (ed.), The Development of Indigenous Trade and Markets in West Africa, pp. 266-8I. London: Oxford University Press.

Cohen, Robin (1996) 'Diasporas and the nation-state: from victims to challengers', International Affairs $72(3)$ : 507-520.

- (1997) Global Diasporas: An Introduction. London: UCL Press.

- (I997) Global Diasporas: An Introduction. Seattle: University of Washington Press.

Connor, Walker (I986) 'The Impact of Homelands upon Diasporas', in Gabriel Sheffer (ed.), Modern Diasporas in International Politics, New York: St. Martin's Press.

Cornell, Stephen and Douglas Hartmann (1998) Ethnicity and Race: Identities in a Changing World. Thousand Oaks: Pine Forge Press.

Curtin, Philip D. (I984) Cross-Cultural Trade in World History. Cambridge: Cambridge University Press.

Curzon, George (1889) Russia in Central Asia in 1889 and the Anglo-Russian Question. London: Longmans, Green.

Dale, Stephen (1994) Indian Merchants and Eurasian Trade, 1600-1750. Cambridge: Cambridge University Press.

Damsteegt, T. (2002) 'Sarnami as an immigrant koine', in E.B. Carlin and J. Arends (eds.), Atlas of the Languages of Suriname, 249-263. Leiden: KITLV Press.

Das, N.P. (2000) 'The Growth and Development of Scheduled Caste and Tribe Population in Gujarat and Future Prospects' Unpublished paper presented at the Seminar Gujarat 2010: Challenges and Opportunities, State Planning Commission, Govt. of Gujarat, Gandhinagar.

Dasti, Humaira (I990) 'Multan as a centre of trade and commerce during the Mughal period', Journal of the Pakistan Historical Society 38: 247-56.

- (1998) Multan, a province of the Mughal Empire (1525-1751). Karachi: Royal Book Company.

Davis, K. (I968) The population of India and Pakistan. New York: Russel and Russel [first edition I95I]. 
Della Valle, Pietro (1972) I Viaggi Di Pietro Della Valle; Lettere Dalla Persia. Edited by F. Gaeta and L. Lockhart. Rome: Instituto Poligrafico Dello Stato.

Desai, M.B. (I948) The Rural Economy of Gujarat. Bombay: Oxford University Press.

Desai, R. (I963) Indian Immigrants in Britain. London: Oxford University Press.

Dhaliwal, Spinder and Andy Adcroft (2005) 'Sustainability and Ethnic Minority Businesses: An Examination of the Asian Business Sector in the U.K.', Journal of Asia Entrepreneurship and Sustainability I [online journal]

Dmitriev, G.L. (I972) 'Iz istorii Indiiskikh kolonii v Srednei Azii (vtoraia polovina XIX-nachalo XXv.)', in D. A. Ol'derogge (ed.), Strani i narodi vostoka, vol. I2, part 2, Indiia; strana $i$ narod, pp. 234-47. Moscow: Nauka.

Dobbin, Christine (1996) Asian Entrepreneurial Minorities: Conjoint Communities in the Making of the World-Economy, 1570-1940. Richmond, Surrey: Curzon Press Ltd.

Druhe, David N. (1970) Russo-Indian Relations, 1466-1917. New York: Vantage Press.

Durrani, Ashiq Muhammad Khan (I990) 'The role of the Pathans during the Sikh period in Multan (I818-1849)', Journal of the Pakistan Historical Society 38: 103-26.

- (I99I) History of Multan (from the early period to 1849 A.D.). Lahore: Vanguard.

Dwyer, Rachel (I994) 'Caste, Religion and Sect in Gujarat: Followers of Vallabhacharya and Swaminarayan', in: R. Ballard (ed.) Desh Pardesh, I65-I90. London: Hurst \& Co.

- (2002) 'Real and Imagined Audiences. Lagaan and the Hindi Film after the I990s', Etnofoor XV(I/2): I77-I93.

Eisenlohr, Patric (2002) 'Language and identity in an Indian diaspora: "multiculturalism" and ethno-linguistic communities in Mauritius', Internationales Asienforum 33:IOI-II4.

- (2004) 'Temporalities of community: ancestral language. pilgrimage, and diasporic belonging in Mauritius', Journal of Linguistic Anthropology I4: 8I-98.

Elphinstone, Mountstuart (1839) An account of the Kingdom of Caubul, and its dependencies, in Persia, Tartary, and India..., 3rd ed., 2 vols. London: Richard Bentley.

Encyclopaedia Britannica:

'Caste.' Encyclopcedia Britannica from Encyclopædia Britannica premium service. http:// www.britannica.com/eb/article?tocId=9020678 (accessed I5 Jan.2005).

'Varna' Encyclopadia Britannica from Encyclopædia Britannica premium service. http:// www.britannica.com/eb/article?tocId=9074859 (accessed I5 Jan. 2005).

'Sudra.' Encyclopadia Britannica from Encyclopædia Britannica Premium Service. http:// www.britannica.com/eb/article?tocId=9070I52 (accessed I5 Jan. 2005).

Eriksen, Thomas H. (I996) 'Ethnicity, Race, Class and Nation,' in: John Hutchinson and Anthony D. Smith (eds.), Ethnicity. Oxford: Oxford University Press.

Fenton, Steve (2003) Ethnicity. Cambridge: Polity Press.

Ferrier, J.P. (I976) Caravan journeys and wanderings in Persia, Afghanistan, Turkistan, and Beloochistan... Ed. by H.D. Seymour and trans. by Capt. William Jesse. Karachi: Oxford [first edition I857].

Forster, George (I970) A Journey from Bengal to England. 2 vols. Delhi [first edition 1798].

Fryer, John (I9I2-I5) A new account of East India and Persia, being nine years' travels, 16721681. 3 vols. Ed. by William Crooke. Hakluyt Society Publications, 2d series, nos. 19-20, 39. London.

Gale, Richard and Simon Naylor (2002) 'Religion, planning and the city: The spatial politics of ethnic minority expression in British cities and towns', Ethnicities 23: 387-409.

Gans, H.J. (I979) 'Symbolic Ethnicity: The Future of Ethnic Groups and Cultures in America', Ethnic and Racial Studies, 2(I).

Gellner, Ernest (1983) Nations and Nationalism. Oxford: Basil Blackwell. 
Giampapa, F. (200I) 'Hyphenated Identities: Italian-Canadian Youth and the Negotiation of Ethnic Identities in Toronto', The International Journal of Bilingualism, 5 (3).

Gilanentz, Petros di Sarkis (1959) The chronicle of Petros di Sarkis Gilanentz concerning the Afghan invasion of Persia in 1722, the siege of Isfahan and the repercussions in northern Persia, Russia and Turkey. Trans. by Caro Owen Minasian. Lisbon: Imprensa Nacional.

Gillespie, Marie (I995) Television, Ethnicity and Cultural Change. London and New York: Routledge.

Ginsburg, Faye, Lila Abu-Lughod and Brian Larkin (2002) Media Worlds: Anthropology on New Terrain. Berkeley, Los Angeles and London: University of California.

Glazer, Nathan and Daniel Patrick Moynihan (1975) Ethnicity: Theory and Experience. Cambridge: Harvard University Press.

Goitein, S.D. (1967-88) A Mediterranean Society. 5 vols. Berkeley: University of California Press.

Gopal, S. (I969) 'Social Set-up of science and technology in Mughal India', Indian Journal of the History of Science IV: 38-65.

Gopal, Surendra (1988) Indians in Russia in the 17th and 18th Centuries. Calcutta: Naya Prokash.

- (I992) 'Indians in Central Asia, Sixteenth and Seventeenth Centuries', Presidential Address, Medieval India Section of the Indian History Congress, New Delhi, February I992. Patna: Patna University.

Govinda, Bal (I98I) 'Telugus in Fiji', Second world Telugu conference, International Telugu Institute, I82-I84.

Gowricharn, R. (2003) 'De emancipatie van Hindostanen'. Chan E.S. Choenni and Kanta Sh Adhin. (eds.): Hindostanen. Van Brits-Indische emigranten via Suriname tot burgers van Nederland. Den Haag: Sampresan, pp. 90-I05.

Gregory, Robert G. (1993) South Asians in East Africa: An Economic and Social History, 189o1980. Boulder: Westview Press.

Grin, F. (I993) 'The Relevance of Thresholds in Language Maintenance and Shift: A Theoretical Examination' Journal of Multilingual and Multicultural Development, I4(5).

Guha, Amalendu (ed.) (I970) Central Asia; movement of peoples and ideas from times prehistoric to modern. Delhi: Vikas.

Gupta, Akhil and James Ferguson (1992) 'Beyond "Culture": Space, Identity and the Politics of Difference', Cultural Anthropology, 7(I).

Habib, Irfan (1964) 'Usury in Medieval India', Comparative Studies in Society and History 6: 393-4I9.

— I986 An Atlas of the Mughal Empire. Delhi: Oxford University Press [first edition I982].

Hafiz, Muhammad Fazil Khan (1993) The Uzbek Emirates of Bukhara and Khulum in the Early 19th century as described in an Indian travelogue; Tarikh-i-manazil-i-Bukhara (1812 A. D.). Ed. and trans. by Iqtidar Husain Siddiqui. Patna: Khuda Bakhsh Oriental Public Library.

Hansen, Thomas Blom (2005) 'In search of the diasporic self: Bollywood in South Africa', in: Raminder Kaur and Ajat J. Sinha (eds.), Bollyworld: Popular Indian cinema through a transnational lens, pp. 239-260. New Delhi, Thousand Oaks and London: Sage.

Hardhill, Irene (I999) Diasporic business Connections: An Examination of the Role of Female Entrepreneurs in a South Asian Business District, Nottingham Trent University: EGRG Working paper 99/02.

Hardiman, D. (I98I) Peasant Nationalists of Gujarat: Kheda District 1917-1934. Delhi: Oxford University Press.

Heelsum, A. van (1997) The Ethno-cultural position of second-generation Surinamese in the Netherlands. Ph.D. dissertation Vrije Universiteit. Amsterdam: Het Spinhuis. 
Helweg, A.W. (1987) 'Why leave India for America? A Case Study Approach to Understanding Migrant Behaviour', International Migration XXV: I65-78.

- (I990) 'Sikh identity in England; Its Changing Nature', in: J.T. O'Connell et. al (eds.), Sikh History and Religion in the Twentieth Century, pp. 356-375. , Delhi: Manohar Publications.

Herzig, Edmund (I99I) The Armenian Merchants of New Julfa, Isfahan: A Study in Pre-Modern Asian Trade. [Ph.D. thesis, University of Oxford.]

- (I996) 'The Rise of the Julfa Merchants in the Late Sixteenth Century', in Charles Melville (ed.), Safavid Persia: The History and Politics of an Islamic Society, pp. 305-22. London: I.B. Tauris.

Hinsliff, G. (2002) 'Speak English at Home, Blunkett Tells British Asians', The Guardian, I5 Sept.

Hira, Sandew (I998) 'I25 jaar sociaal-economiche ontwikkeling van de Hindostanen in Suriname', in: A. Hassankhan and S. Hira (eds.), Van Gya en Boodheea tot Lachmon en Djwalapersad, grepen uit 125 jaar maatschappelijke ontwikkeling van Hindostanen, pp. I0-24. Paramaribo and Den Haag: IMWO/ Nauyuga/ Amrit.

- (2000) Terug naar Uttar Pradesh: op zoek naar de wortels van Surinaamse Hindostanen. Den Haag: Amrit.

- (ed.) (2003) Het dagboek van Munshi Rahman Kahn. Den Haag and Paramaribo: Amrit/ NSHI.

Hoefte, Rosemarijn (I998) In Place of Slavery: A Social History of British Indian and Javanese Labourers in Suriname. Gainesville: University Press of Florida.

Hookoomsing, V. (2003a) 'Preserving pluralism in the context of development and modernization', in: Sharma, Rekha and E. Annamalai (eds.), Indian diaspora: in search of identity, pp.I55-166. Mysore: Central Institute of Indian Languages.

- (2003b) 'Chota Bharat, Mauritius: Myth and Reality', in: Parekh, Bhikhu, Gurharpal Singh and Steven Vertovec (eds.), Culture and Economy in the Indian Diaspora, pp.I-I3. London: Routledge.

Hulsman, Bernard (200I) 'In de ban van Bollywood', NRC Handelsblad (7 June): 3I.

Humphrey, David and David Ward (1974) Passports and Politics. Harmondsworth: Penguin [Penguin Special].

Hutnik, Nina (I99I) Ethnic Minority Identity: A Social Psychological Perspective. Oxford: Clarendon Press.

Ibbetson, Denzil (I916) Panjab Castes... Lahore: Government Printing, Punjab [first edition I883].

IMES Statistics, 'Basic data and information on migration and minorities': http://www2. fmg.uva.nl/imes/stats.htm (accessed 30 March 2005).

Indiawijzer

a) 'Indians in diaspora. For example the Netherlands' www.indiawijzer.nl/indian_diaspora/nri_pio_in_nederland_txt.htm. (accessed 22 Nov. 2004).

b) 'Indian in the Netherlands. A few numbers' http://www.indiawijzer.nl/indian_diaspora/indians_in_netherlands_cbs.htm (accessed 6 May 2005).

Isajiw, Wsevolod W. (I975) 'The Process of Maintenance of Ethnic Identity: The Canadian Context', in: Paul M. Migus (ed.), Sounds Canadian: Languages and Cultures in Multi-Ethnic Society. London: Peter Martin Associates.

- (I999) 'Definitions and Dimensions of Ethnicity', in: Paul R. Magocsi (ed.), Encyclopedia of Canada's People. Toronto: University of Toronto Press.

Ismaili Canada (1994) Journey into Hope: A Chronicle of the Ugandan Asian Migration, Toronto: The Ismaili, Canada.

Israel, Milton (I999) 'Ismailis' in: Paul R. Magocsi (ed.), Encyclopedia of Canada's Peoples. Toronto: University of Toronto Press. 
Ivanov, P.P. (I954) Khoziaistvo dzhuibarskikh sheikhov; $k$ istorii feodal'nogo zemlevladeniia $v$ Srednei Azii v XVI-XVII vv. Moscow: Nauka.

Jackson, Peter (I999) The Delhi Sultanate: A Political and Military History. Cambridge: Cambridge University Press.

Jain, L.C. (I929) Indigenous Banking in India. London: Macmillan.

Jain, R.K. (1993) Indian Communities Abroad: Themes and Literature. Delhi: Manohar Publications.

- (2004) Indian diaspora, old and new: Culture, class and mobility. Delhi: Indian Anthropological Association.

Jayawardena, Chandra (i968) 'Migration and social change: A study of Indian communities overseas.' Geographical Review vol. 58, No. 3 (Jul., I968), pp. 426-449.

Jenkinson, Anthony (1886) Early voyages and travels to Russia and Persia... Ed. by E. Delmar Morgan and C.H. Coote. Hakluyt Society Publications. 2 vols. Ist series, nos. 72-73. London.

Kaempfer, Engelbert (I977) Am Hofe des persischen Grosskönigs 1684-1685. Ed. by Walter Hinz. Tübingen and Basel: Horst Erdmann Verlag.

Karim, Karim H. (I993) 'Constructions, Deconstructions, and Reconstructions: Competing Canadian Discourses on Ethnocultural Terminology', Canadian Journal of Communication [online], I8 (2).

- (2003) The Media of Diaspora. London: Routledge.

Kaushik, Devendra (I985) India and Central Asia in modern times. Calcutta: Satvahan.

Kemp, P.M. (I958) Bharat-Rus; an introduction to Indo-Russian contacts and travels from mediaeval times to the October Revolution. Delhi: Iscus.

- (I959) (trans.) Russian travellers to India and Persia [1624-1798]; Kotov, Yefremov, Danibegov. Delhi: Jiwan Prakashan.

Keppel, George (I827) Personal narrative of a journey from India to England...in the year 1824 . London: Henry Colburn.

Khan, Ahmad Nabi (I983) Multan; history and architecture. Islamabad: Institute of Islamic History, Culture and Civilization, Islamic University.

Klerk, C.J.M. de (I953) De immigratie der Hindostanen in Suriname. Amsterdam: Urbi et Orbi.

- (I998) Boek I Cultus en ritueel van het Orthodoxe Hindoeisme in Suriname. Boek II De Immigratie der Hindostanen in Suriname. Den Haag: Amrit [first edition I953].

Klimmer, Anja (I999) 'Want dan wil ik India echt zien.' Hindostaanse toeristen verkennen het land van hun voorouders. Doctoral thesis University of Amsterdam, Amsterdam.]

Koning, Anouk de (I998) 'Als jij Ram bent ... Veranderingen in het leven van Hindostaanse vrouwen in Paramaribo vanaf de jaren vijftig', in: M. Hassankhan and S. Hira (eds.), Van Gya en Boodheea tot Lachmon en Djwalapersad. Grepen uit 125 jaar maatschappelijke ontwikkeling van Hindostanen, pp I5I-I89. Paramaribo. and Den Haag: IMWO/Nauyuga/Amrit.

Kotecha, Bhanubhen (trans. Reynell, Lenore) (1995) On the Threshold of East Africa. London: Jyotiben Madhvani Foundation.

Kurien, Prema (200I) 'Religion, ethnicity and politics: Hindu and Muslim Indian immigrants in the United States.' Ethnic and Racial Studies vol. 24 no. 2, pp. $263-293$.

Lal, Vinay (n.d.) 'Reflections on the Indian Diaspora, in the Caribbean and elsewhere.' http://www.sscent.ucla.edu/southasia/Diaspora/reflect.html (accessed 22 September 2004).

Lall, M.C. (200I) India's Missed Opportunity: India's Relationship with the Non Resident Indians. Aldershot: Ashgate. 
Lalmahomed, Bea (1992) 'Hindostaans-Surinaamse Wegloopsters', in: L. Brouwer, B. Lalmahomed and H. Josias (eds.), Andere tijden, andere meiden. Een onderzoek naar het weglopen van Marokkaanse, Turkse, Hindostaanse en Creoolse meisjes, pp. I55-262. Utrecht: Jan van Arkel.

Landman, Nicolaas (1992) Van mat tot minaret: de institutionalisering van de islam in Nederland. Ph.D. thesis, Vrije Universiteit, Amsterdam.

Levi, Scott C. (Forthcoming) 'Shikarpuri merchants in Durrani Afghanistan', in Y. Rosser and A. Singh (eds.), Voices of Sindh, vol. 3, Sindhis in Diaspora, New Delhi: Observer Research Foundation.

- (2002) The Indian diaspora in Central Asia and its trade, 1550-1900, Leiden: E J. Brill.

Likoshin, N. (I894) 'Pis'ma iz tuzemnago Tashkenta', Turkestanskiie vedomosti 9.

- (I896) 'Pis'ma iz tuzemnago Tashkenta', Turkestanskiie vedomosti 96.

Lyon, M.H. and B.J.M. West (I995) 'London Patels: Caste and Commerce', New Community, 2I(3): 399-4I9.

Madood, Tariq et al. (I997) Ethnic Minorities in Britain: Diversity and Disadvantage. London: Policy Studies Institute. [4 ${ }^{\text {th }}$ PSI Survey]

Magee, Brian (I997) The Philosophy of Schopenhauer revised edition. Oxford: Oxford University Press.

Majmu'a-i Watha'iq Oriental Studies Institute of the Academy of Science of the Republic of Uzbekistan. Ms. No. I386.

Majmuder, P.P. et al. (I998) 'Human-specific insertion/deletion polymorhisms in Indian populations and their possible evolutionary implications', European Journal of Human Genetics 7: $435-446$.

Malik, K.N. (1997) India and the United Kingdom: Change and Continuity in the 1980s. New Delhi: Sage Publications.

Mamdami, Mahmood (1976) Politics and Class Formation in Uganda. London: Heinemann.

Mans, Raphaël du (I890) Estat de la Perse en 1660. Paris: Ernest Leroux.

Manuel, Peter (I997) 'Music, identity, and images of India in the Indo-Caribbean diaspora' Asian Music, vol. 29, no. I, I7-35.

- (I998) 'Music, Identity and Images in the Indo-Caribbean Diaspora', Asian Music 29(I): I7-35.

Markovits, Claude (2000) The Global World of Indian Merchants, 1750-1947: Traders of Sind from Bukhara to Panama. Cambridge: Cambridge University Press.

Marrett, Valerie (1988) Immigrants Settling in the City. London: Leicester University Press/ Pinter Publishers.

- (I992) 'Resettlement of Ugandan Asians in Leicester', Journal of Refugee Studies 6: 248259.

Mattausch, John (I993) The Gujaratis and the British: A social and historical survey, with special reference to the Gujarati tradition of 'arranging' marriages. CEMS Occasional Papers, no.I.

- (I996) "A "Penury of Bookes": the Printing Press and Social Change, in an Indian setting', South Asia XIX: 59-84.

- (1999) 'From Subjects to Citizens: British East African Asians', Journal of Ethnic and Migration Studies 2: I2I-I4I.

- (2000) "A case of mistaken identity: Why British "African Asians" are not an "ethnic" community', South Asia Research 20: I7I-I8I.

— (200I) 'After “Ethnicity": Migration, Identity and Political economy', Immigrants Q Minorities 20: 59-74.

- (2003) 'Chance and Societal Change', Sociological Review 51: 507-527.

Mawani, Sharmina (2006) The Construction of Identities Amongst Young Adult Nizari Ismailis in Toronto And Mumbai. Ph.D. Thesis, SOAS, University of London. 
May, S. (2000) 'Uncommon Languages: The Challenges and Possibilities of Minority Language Rights', Journal of Multilingual and Multicultural Development, 2I (5).

McCabe, Ina Baghdiantz (I999) The Shah's Silk for Europe's Silver: The Eurasian Trade of the Julfa Armenians in Safavid Iran and India (1530-1750). Atlanta: Scholars Press.

Melady, T.P. and M.B. Melady (I976) Uganda: The Asian Exiles. New York: Orbis Books.

Mercer, K. (I990) 'Welcome to the Jungle: Identity and Diversity in Postmodern Politics', in: Jonathan Rutherford (ed.), Identity: Community, Culture and Difference. London: Lawrence \& Wishart.

Metcalf, Hilary, Tariq Modood, and Satnam Virdee (1995) Asian Self-employment: the Interaction of Culture and Economics in England. London: Policy Studies Institute.

Michaelson, Maureen (I979) 'The relevance of caste among East African Gujaratis in Britain', New Community 7: 350-360.

Ministry of External Affairs (MEA) (200I) Report of the high level committee on Indian diaspora. New Delhi: Indian Council of World Affairs.

Mir, Izzet Ullah (I843) 'Travels beyond the Himalaya, by Mir Izzet Ullah. Republished from the Calcutta Oriental Quarterly Magazine, I825.' Journal of the Royal Asiatic Society VII: 283-342.

Mirza, Kalichbeg Fredunbeg (trans.) (1979) The Chachnamah, an ancient history of Sind. Delhi [first edition I900].

Mishra, Vijay (2002) Bollywood Cinema: Temples of Desire. New York: Routledge.

Modood, Tariq (I997) 'Culture and Identity', in Tariq Modood, et. al. (eds.), Ethnic Minorities in Britain: Diversity and Disadvantage. London: Policy Studies Institute.

- (2005) Remaking Multiculturalism After 7/7 <www.openDemocracy.net (Accessed: 8 Jan. 2006), 29 Sept.

Modood, T., R. Berthoud, J. Lakey, J. Nazroo, P. Smith, S. Virdee, and S. Reishon (I997) Ethnic Minorities in Britain: Diversity and Disadvantage. London: Policy Studies Institute.

Mohamed, H.E. (I992) 'Our African Legacy', Hikmat 3 (6).

Mohan, Lal (I97I) Travels in the Panjab, Afghanistan, Turkistan, to Balkh, Bokhara and Herat ... Patiala: Punjab Language Department [first edition I846].

Montgomery, Sir Robert (comp.) (I862) Report on the trade and resources of the countries on the north-western boundary of British India. Lahore: Government Press.

Moorman, Mark (200I) 'Bollywood is overal' Het Parool [8 September]: 54.

Moorti, Sujata (2002) Imaginary Homes, Transplanted Traditions: The Transnational Optic and the Production of Tradition in Indian Television. Paper presented on the conference 'Media in Transition 2: Globalization and Convergence', IO-I2 May 2002, Cambridge, Massachusetts. Http://cms.mit.edu/conf/mit2/Abstracts/MoortiPaper.pdf, visited on I5 November 2003.

Morley, David (2000) Home Territories: Media, Mobility and Identity. London: Routledge.

Morris, H.S. (1968) The Indians in Uganda. London: Weidenfeld and Nicholson.

- (1970) The Indians in Uganda. London: Oxford University Press.

Mukadam, Anjoom (2003) Gujarati Speakers in London: Age, Gender and Religion in the Construction of Identity. Ph.D. Thesis, University of Reading.]

- (2004) Indobrit: What's in a Name? <www.indobrit.com (accessed: 2 Feb. 2004).

Mukadam, Anjoom and Sharmina Mawani (2005) 'The Best of Both Worlds: Myth or Reality?', paper given at the CRONEM conference on The Future of Multicultural Britain: Meeting Across Boundaries, Roehampton University, London, UK, I4-I5 June.

- (2006) 'Post-Diasporic Indian Communities: A New Generation' in: S. Coleman and P. Collins (eds.), Locating the Field: Metaphors of Space, Place and Context in Anthropology, London: Berg.

Mukminova, R.G. (I985) Sotsial'naia differentsiatsiia naseleniia gorodov Uzbekistana v XV-XVI vv. Tashkent: Fan. 
Mukta, P. (I999) 'The public face of Hindu nationalism', Ethnic and Racial Studies 23: 442466.

Mungra, Gjaanchand (1990) Hindoestaanse gezinnen in Nederland. [Ph.D. thesis, Centrum voor Onderzoek van Maatschappelijke Tegenstellingen, Leiden.

Murugaiyan, A. (2003) 'Indian Languages in Mauritius', in: Sharma, Rekha and E. Annamalai (eds.), Indian diaspora: in search of identity, pp.I88-I99. Mysore: Central Institute of Indian Languages.

Naik, Balwant (1997) Passage from Uganda. Southall: Naik \& Sons.

Nanji, Azim (I974) 'Modernization and Change in the Nizari Ismaili Community in East Africa - A Perspective', Journal of Religion in Africa, 6 (2).

Nederveen Pieterse, J. (I994) 'Globalisation as Hybridisation', International Sociology 9(2): I6I-84.

Niekerk, Mies van (2000) 'De krekel en de mier'. Fabels en Feiten over maatschappelijke stijging van Creoolse en Hindoestaanse Surinamers in Nederland. Amsterdam: Het Spinhuis.

- (2002) Premigration Legacies and Immigrant Social Mobility: The Afro-Surinamese and the Indo-Surinamese in the Netherlands. Lanham and Oxford: Lexington Books.

Nizamutdinov, Il'ias (I969) Iz istorii Sredneaziatsko-indiiskikh otnoshenii, (IX-XVIII vv.). Tashkent: Fan.

Noort, R.B.J.C. van (ed.) (200I) Allochtonen in Nederland 2001. Voorburg and Heerlen: Centraal Bureau voor de Statistiek.

O’Brien, Anthony (I996) The ancient chronology of Thar; the Bhâttika, Laukika and Sindh eras. Delhi: Oxford University Press.

Olearius Adam (1667) The voyages and travels of the ambassadors sent by Frederick Duke of Holstein, to the Great Duke of Muscovy, and the King of Persia... Trans. by John Davies. London.

Olufsen, O. (I9II) The Emir of Bokhara and his country; journeys and studies in Bokhara. London: William Heinemann.

Oonk, Gijsbert (2004) 'The Changing Culture of Hindu Lohanas in East Africa', Contemporary Asian Studies 13:83-97.

- (2006) 'South Asians in East Africa (I880-I920) with a Particular Focus on Zanzibar: Toward a Historical Explanation of Economic Success of a Middlemen Minority', African and Asian Studies 5: 57-89.

Pallas, Peter Simon (1802-3) Travels through the southern provinces of the Russian Empire, in the years 1793 and 1794. 2 vols. Trans. by Francis L. Bludgon. London: T.N. Longman and O. Rees.

Pandey, V.S. (I992) Himalayan trade routes to Central Asia. Patna: Janaki Prakashan.

Parekh, Bhikhu (200I) Integrating Minorities, London: Institute of Contemporary Arts.

Patel, Pravin and Mario Rutten (1999/2000) Long-distance Familialism: Social Linkages between Patidars in India and Britain: A View from Central Gujarat. IPDAD, Occasional Papers.

Patna Daily Online (I9.6.2005) Comment by RC to the article 'English media responsible for Bihar's sorry state of affairs.' http://www.patnadaily.com/readerswrite/2004/raghu_yadavi.html (accessed 23 March 2005).

Peach, Ceri (2006) 'Muslims in the 200I Census of England and Wales: Gender and economic disadvantage', Ethnic and Racial Studies 29: 629-655

Phinney, Jean (1992) 'The Multigroup Ethnic Identity Measure: A New Scale for Use with Adolescents and Young Adults', Journal of Adolescent Research, 7: 156-176.

Phyu, U. (200I) 'Indians in Myanmar (Burma)', CSID Lectures, University of Hyderabad, 26 Feb. 
Pilkington, Andrew (2003) Racial Disadvantage and Ethnic Diversity in Britain. New York: Palgrave Macmillan.

Pocock, D.F. (I972) Kanbi and Patidar; A Study of the Patidar Community of Gujarat. Oxford: Clarendon Press.

Prabhakaran, Varijakshi (I994) 'Telugus in South Africa', Telugu Jagathi, (World Telugu Federation First Conference Souvenir Issue).

Ram, S. (1989) Indian Immigrants in Great Britain. Delhi: Inter India Publications.

Ramsoedh, Hans (2003) 'Religieuze organisatievorming bij Hindoes', in: Chan E.S. Choenni and Kanta Sh. Adhin (eds.), Hindostanen. Van Brits-Indische emigranten via Suriname tot burgers van Nederland, I35-I53. Den Haag: Sampreshan.

Rao, G.S. (2003) 'Retention and maintenance of Telugu', in: Sharma, Rekha and E. Annamalai (eds.), Indian diaspora: in search of identity, pp. I72-187. Mysore: Central Institute of Indian Languages.

Rao, Raghunatha P. (1983) History of modern Andhra. New Delhi: Sterling Publishers.

Ratcliffe, Peter (2004) 'Race', Ethnicity and Difference: Imagining the Inclusive Society. Berkshire: Open University Press.

Ray, Rajat Kanta (I984) 'The Bazar; Indigenous Sector of the Indian Economy', in Dwijendra Tripathi (ed.), Business communities of India; a historical perspective, pp. 24I-67. New Delhi: Manohar.

Raychaudhuri, Tapan and Irfan Habib (eds.) (I984) The Cambridge Economic History of India. 2 vols. Hyderabad: Orient Longman [first edition I982].

Robinson, Vaughan (1986) Transients, Settlers and Refugees: Asians in Britain. Oxford: Clarendon Press.

- (I993) 'Marching into the Middle Classes? The Long-term Resettlement of East African Asians in the UK', Journal of Refugee Studies 6:230-247.

Rudner, David (1994) Caste and Capitalism in Colonial India: The Nattukottai Chettiars. Berkeley: University of California Press.

Russell, R.V. (I9690 Tribes and castes of the central provinces of India 4 vols. Oosterhout, N.B.: Anthropological Publications [first edition I9I6].

Rutten, M. (I995) Farms and Factories: Social Profile of Large Farmers and Rural Industrialists in West India. Delhi: Oxford University Press.

Sadr al-Din 'Aini (I959) Yaddashtha Vols. 3 and 4. Stalinabad (Dushambe): Nashriyat Daulati Tajikistan.

Saeed, A., Blain, N. and Forbes, D. (I999) 'New Ethnic and National Questions in Scotland: Post-British Identities', Ethnic and Racial Studies, 22(5).

Safran, William (I99I) 'Diasporas in modern societies; myths of homeland and return.' Diaspora: A Journal of Transnational Studies I: 83-99.

Said, Edward (I993) Culture and Imperialism. London: Vintage.

Schopenhauer, Arthur (trans. R.J. Hollingdale) (I970) Essays \& Aphorisms. London: Penguin.

Schuyler, Eugene (1877) Turkistan; notes of a journey in Russian Turkistan, Khokand, Bukhara, and Kuldja 2 vols. New York: Scribner / Armstrong.

Seenarine, M. (n.d.) 'The persistence of caste and anti-caste in India and the diaspora.' In M. Gosine and D. Narine (eds.), Sojourners to settlers. The Indian migrants in the Caribbean and the Americas. http://www.saxakali.com/indocarib/caster.htm (accessed I7 April 2005).

Sen, Surendranath (ed.) (I949) Indian travels of Thevenot and Careri. New Delhi: National Archives of India.

Shamansurova, A.Sh. (I966) 'Noviie danniie po istorii Afganistana (Orenburgskii Gosudarstvennii Arkhiv)', in M.G. Nikulin (ed.), Ocherki po novoi istorii Afganistana, pp. I05-I6. Tashkent: Fan. 
Sharma, G.D. (1984) 'The Marwaris; economic foundations of an Indian capitalist class.' in Dwijendra Tripathi (ed.), Business communities of India: A historical perspective, pp. 185-207. New Delhi: Manohar

Shubrangshu, Roy (2003) Comment to the article 'Bihar, India and hope'. Posted on December 3I 2003. http://www.yazadjal.com/2003/r2/bihar_india_and_hope.html (accessed 25 March 2005).

Shukla, Sandhya (200I) 'Locations for South Asian diasporas', Annual Review of Anthropology, vol. 30: 55I-572.

Simon, Bernd (2004) Identity in Modern Society: A Social Psychological Perspective. Oxford: Blackwell.

Singh, Chetan (I99I) Region and empire: Panjab in the seventeenth century. Delhi: Oxford University Press.

Sinha, Lata, 'Bihar express. Entering Laloo land'. India Times Online, June 2000 http:// downloads.movies.indiatimes.com/site/june2000/ifr.html (accessed 23 March 2005.

Sinha-Kerkhoff, Kathinka and Ellen Bal (2003) "Eternal call of the Ganga." Reconnecting with people of Indian origin in Surinam.' Economic and Political Weekly. http://www.epw. org.in (accessed 3 November 2004).

Sinha-Kerhoff, K., and E. Bal (2003) 'Eternal Call of the Ganga: Reconnecting with People of Indian Origin in Surinam', Economic and Political Weekly 38 (38): 4009-402I.

Smith, Anthony D. (1986) The Ethnic Origins of Nations, Oxford: Blackwell.

Speckmann, J.D. (I967) 'The caste system and the Hindustani group in Surinam'. Barton M. Schwartz (ed.): Caste in Overseas Indian communities. San Francisco: Chandler Publishing Company.

Srinivasan, R. (2003) 'Bullish on Bihar: Go east young man!' Rediff.com News: Columnist October 3I, 2003, http://www.rediff.com/news/2003/oct/3Irajeev.htm (accessed 25 March 2005).

Stephan, C.W. and Stephan, W.G. (2000) 'The Measurement of Racial and Ethnic Identity', International Journal of Intercultural Relations, 24.

Stevenson, H.N.C. (I953) 'Status evaluations in the Hindu caste system'. Man, vol. 54: 8-9.

Straubhaar, J.D. (I99I) 'Beyond Media Imperialism: Assymmetrical Interdependence and Cultural Proximity'; Critical Studies in Mass Communication 8(I): 39-59.

- (I997) 'Distinguishing the global, regional and national levels of world television', in: A. Sreberny-Mohammadi, D. Winseck, J. McKenna and O. Boyd-Barret (eds.), Media in Global Context. A Reader, 284-298. New York: Oxford University Press.

Tambs-Lyche, H. (I975) 'A comparison of Gujarati communities in London and the Midlands', New Community IV: 349-355.

- (1980) London Patidars: A Case Study in Urban Ethnicity. London: Routledge and Kegan Paul.

Tavernier, Jean-Baptiste (I7I2) Les six voyages de Jean Baptiste Tavernier, Ecuyer Baron d'Aubonne ... 2 vols. Utrecht: Guillaume and Jacob Poolsum.

- (I995) Travels in India. 2nd ed. 2 vols. Ed. by William Crooke and trans. by V. Ball. New Delhi: Munshiram Manoharlal [first edition I676].

Timberg, Thomas (1978) The Marwaris: from traders to industrialists. New Delhi: Vikas.

Tignor, Robert et al. (2002) Worlds Together, Worlds Apart. New York: W.W. Norton.

Tinker, Hugh (1973) A New System of Slavery: The Export of Indian Labour Overseas 1830-1920. London: OUP.

Tölölyan, Khachig (I99I) 'The nation-state and its others; in lieu of a preface', Diaspora: A Journal of Transnational Studies I: 3-7.

- (I996) 'Rethinking diaspora(s); stateless power in the transnational moment.' Diaspora: A Journal of Transnational Studies 5: 3-36. 
Twaddle, Michael (I990) 'East African Asians through a hundred years', in: C. Clarke, C. Peach, and S. Vertovec (eds.) South Asians Overseas. London: Oxford University Press.

Udovitch, Abraham (I970) Partnership and Profit in Medieval Islam. Princeton: Princeton University Press.

- (I979) 'Bankers Without Banks: Commerce, Banking, and Society in the Islamic World of the middle ages', in The Dawn of modern banking, pp. 255-74. New Haven: Yale University Press.

Varma, Sushma J., and Radhika Seshan (eds.) (2003) Fractured identity: the Indian diaspora in Canada. New Delhi: Rawat Publication.

Veer, Peter van der (I996) 'Authenticity and authority in Surinamese Hindu ritual.' In David Dabydeen and Brinsley Samaroo (eds.), Across Dark Waters: Ethnicity and Indian Identity in the Caribbean. London and Basingstoke: Macmillan Education Ltd.

Veer, Peter van der and Steven Vertovec (I99I) 'Brahmanism abroad: On Caribbean. Hinduism as an ethnic religion, Ethnology, vol. 30, no. 2: I49-I66.

Verma, H. (200I) 'NRIs Rethink Dual Nationality'. Delhi: NRI World News Service. Source: http://www.nriworld.com/diaspora/morearticles.asp (accessed 27 Dec. 2005).

Verstappen, Sanderien (2005) Jong in Dollywood. Hindostaanse jongeren en Indiase films. Amsterdam: Het Spinhuis.

Vertovec, Steven (I997) 'On the reproduction and representation of Hinduism in Britain', in: T. Ranger et al. (eds.) Culture, Identity and Politics. Aldershot: Avebury.

- (1999) 'Three Meanings of Diaspora Exemplified with South Asian Religions.' Diaspora, $7(2)$.

- (2000) The Hindu diaspora Comparative patterns. London and New York: Routledge.

- (2000b) 'Religion and diaspora' Presented at the conference on 'New Landscapes of Religion in the West'. School of Geography and the Environment, University of Oxford, 27-29 September. Downloadable Transcomm working paper: WPTC-oI-oI http://www.transcomm.ox.ac.uk/working\%2opapers/Vertovecor.PDF.

Vertovec, Steven and Robin Cohen (ed.) (I999) Migration, Diasporas and Transnationalism. Cheltenham, UK: Edward Elgar Publishing Ltd.

Vigne, G.T. (1982) A personal narrative of a visit to Ghuzni, Kabul, and Afghanistan... Lahore: Sang-e-Meel Publications [first edition I840].

Visram, Rozina (2002) Asians In Britain: 400 Years of History. London: Pluto Press.

Walji, Shirin R. (I974) A History of the Ismaili Community in Tanzania. Ph.D. Thesis, University of Wisconsin.

- (I995) 'Ismailis in Kenya: Some Perspectives on Continuity and Change', in M. Bakari and S.S. Yahya (eds.) Islam in Kenya: Proceedings of the National Seminar on Contemporary Islam in Kenya, Kenya: Mewa Publications.

Waring, Edward Scott (I807) A tour to Sheeraz ... London: T. Cadell and W. Davies.

Weber, Max (1992) The Religion of India. New Delhi: Munshiram Manoharlal.

Weedon, C. (2004) Identity and Culture: Narratives of Difference and Belonging. Maidenhead: Open University Press.

Weeks, J. (I990) 'The Value of Difference', in: Jonathan Rutherford (ed.), Identity: Community, Culture and Difference. London: Lawrence \& Wishart.

Wikipedia.org ,'Sindhi' http://en.wikipedia.org/wiki/Sindhi (accessed I8 June 2005).

Williams, Raymond Brady (1984) A New Face of Hinduism; The Swaminarayan Religion. Cambridge: Cambridge University Press.

- (I988) Religions of Immigrants from India and Pakistan: New Threads in the American Tapestry. Cambridge: Cambridge University Press. 
Wink, André (1987) 'The Jewish diaspora in India; eighth to thirteenth centuries', The Indian Economic and Social History Review 24: 349-66.

- (I990) Al-Hind: the making of the Indo-Islamic World vol. I, Early medieval India and the expansion of Islam, seventh to eleventh centuries. Leiden: E.J. Brill.

- (I997) Al-Hind: the making of the Indo-Islamic World vol. 2, The slave kings and the Islamic conquest, 11th-13th centuries. Leiden: E.J. Brill.

Woodward, Kathryn (1997) Identity and Difference. London: Sage.

Yelaja, Prithi (2004) 'A Passage to India, via Sears', The Toronto Star, Mar 29. < http://www. thestar.com (accessed: 3 April 2004).

Yinger, J. Milton (I994) Ethnicity: Source of Strength? Source of Conflict? New York: State University of New York Press.

Zahir al-Din Muhammad Babur (1989) Babur-nama: memoirs of Babur. Ed. and trans. by Annette Beveridge. Delhi [first edition I905].

Zia ud-Din Barani (I860-62) Târîkh-i Firûz Shâhi. Ed. by Saiyid Ahmad Khan, W. N. Lees and Kabiruddin. Bib. Ind., Calcutta: Bib. Ind. 



\section{Contributors}

Ellen Bal is Assistant Professor in the Department of Social and Cultural Anthropology at the Vrije Universiteit of Amsterdam. She received her Ph.D. at Erasmus University, Rotterdam. A revised and updated version is forthcoming under the title They ask if we eat frogs: Garo Ethnicity in Bangladesh (Singapore: ISEAS, 2007). Between 200I and 2005 , she was involved in a project involving the Indian diaspora in Suriname and the Netherlands, and their relation to 'motherland' India. She worked closely with Dr. Kathinka Sinha, with whom she coauthored 'Eternal Call of the Ganga: Reconnecting with People of Indian Origin in Surinam'. In: Economic and Political Weekly (2003), vol. XXXVIII, no. 38, September 20-26: 4008-4022.

T.L.S. Bhaskar is a partner at the Byrraju Foundation, Hyderabad where he heads the Voice of Participants module. He is currently engaged in a project on Diaspora Philanthropy by Overseas Telugus. He has published in both the fields of social development and diaspora studies. His recent publications include: 'Sustainable Rural Transformation: Experiences of the Byrraju Foundation' in Harsh Bhargava and Deepak Kumar (eds.), NGOs: Role and Accountability, an Introduction, 223-248. Hyderabad: ICFAI University Press (2006); 'An Introduction on Emigration of Telugus: A Working Paper', Hyderabad: Diaspora Foundation (2007).

Chandrashekhar Bhat is Professor at the Department of Sociology and the Director of the Centre for the Study of Indian Diaspora at the University of Hyderabad. He is currently engaged in a UGC Major Research Project on Diaspora, Religion and Transnational Networks. His recent publications include: 'Continuity and Change in the Perception of "Indianness": Issues of Identity among Indians at Home and in the Diaspora', in Martina Ghosh-Schellhorn (ed.), Peripheral Centres, Central Peripheries: India and its Diaspora(s), 243-250. Berlin: LIT Verlag (2006); 'Transnational Networks of Indian Diasporic Communities: The Case of Telugu Diaspora' (with Ajaya Sahoo), in Man in India, 2005, 85 (I\&2), 6I-80; 'India and the Indian Diaspora: Linkages and 
Expectations', in Ajay Dubey (ed.) Indian Diaspora: Global Identity. Delhi: Kalinga Publications (2003), II-22.

Kathinka Sinha-Kerkhoff resides in Ranchi (Jharkhand, India) and is a Senior Research Fellow at the Asian Development Research Institute (ADRI) in Patna (Bihar, India). In I995, Sinha-Kerkhoff received her Ph.D. degree (cum laude) from the Centre of Asian Studies (CASA), University of Amsterdam with 'Save Ourselves and the Girls! Girls in Calcutta under the Raj' (Rotterdam: Extravert I995). At present she is also affiliated to the International Institute of Social History (IISH) in Amsterdam and involved in the project 'A Diaspora Coming Home? Overseas Indians re-establishing links with India' supported by WOTRO (the Netherlands) (September 200I to September 2005, parttime). Selected publication with Dr. Ellen Bal: 'Eternal Call of the Ganga: Reconnecting with People of Indian Origin in Surinam'. In: Economic and Political Weekly (2003), vol. XXXVIII, no. 38, September 20-26: 4008-4022.

Scott Levi is Assistant Professor of Central Asian history in the History Department of the University of Louisville. He is the author of The Indian Diaspora in Central Asia and its Trade, 1550-1900 (Leiden: E. J. Brill, 2002), and the editor of India and Central Asia: Commerce and Culture, 1500-1800 (New Delhi: Oxford University Press, 2007).

Brit Lynnebakke has an MA in Migration and Ethnic Studies (Hons) from the University of Amsterdam. She now works as a freelance journalist in Oslo specialising in migration and multicultural issues. The main topics she covers as a journalist are transnationalism, the relationship between migration and development, the immigration discourse in mainstream media and the development of more accurate multicultural reporting.

Claude Markovits is Directeur de Recherche (Senior Research Fellow), Centre National de la Recherche Scientifique, Paris. Authored The Global World of Indian Merchants 1750-1947: Traders of Sind from Bukhara to Panama. Cambridge: Cambridge University Press 2000.

John Mattausch is a lecturer in the Department of Politics and International Relations at Royal Holloway College, University of London. He has published on the history and sociology of Britishers and Gujaratis in Gujarat, East Africa and contemporary Britain. His recent publications include: 'A Case of Mistaken Identity: Why British East African Asians are not an "ethnic" community', South Asia Research 20(2) 2000, I7I-I82; 'Chance and Societal Change' The Sociological Review 
vol. 5I (4) 2003, 505-527; 'We Are Family: the changing British Gujarati community' in: A. Mukadam and S. Mawani (eds.) Gujaratis in the West: Evolving Identities in Contemporary Society. Cambridge: Scholars Press, forthcoming 2008. His book on Chance, Character and Change will be published by Transaction in the Spring of 2008 .

Sharmina Mawani received her doctorate from the Department of the Study of Religions at SOAS, University of London in 2006. Her thesis, The Construction of Identities Amongst Young Adult Nizari Ismaili Muslims in Toronto and Mumbai, investigated the role of language in the transmission of religious knowledge through the ginans (devotional songs) amongst young Nizari Ismailis of Gujarati ancestry in Canada and India. She is particularly interested in the manner in which traditional religious practices are evolving in contemporary Western society. Sharmina is currently co-editing a volume on Gujaratis in the West.

Anjoom Amir Mukadam is currently a Research Fellow at SOAS, University of London and working on a project that looks at the needs of heritage language students from Gujarati, Turkish, Polish, and Latvian backgrounds. She received her doctorate in Socio-linguistics from the University of Reading in December 2003. Her thesis was entitled Gujarati Speakers in London: Age, Gender and Religion in the Construction of Identity. At present, her research interests lie in the inter-disciplinary areas of ethno-religious and linguistic identities of second-generation individuals in London.

Gijsbert Oonk is Associate Professor of 'Non-Western History', in the History Department at Erasmus University Rotterdam. He has published material on the history of the cotton textile industry in West India and on the Indian diaspora in East Africa. His recent publications include: 'The Changing Culture of the Hindu Lohana Community in East Africa', Contemporary Asian Studies, I3(I) 2004, 7-23; 'After Shaking his hand, start counting your fingers. Trust and Images in Indian Business networks, East Africa I900-2000', Itinerario, 2004 I8(3), 7088; 'South Asians in East Africa (I880-1920): With a Particular Focus on Zanzibar. Towards a historical explanation of economic success of a Middlemen minority'. Journal of African and Asian Studies, 2006 (I), $57-89$.

Pravin J. Patel is a sociologist. He did his post-doctoral research at Columbia University, New York. He has won several awards and honours including a Fulbright Fellowship (US), Charles Wallace Fellowship (UK), Visiting Professorship at Charles Gordon University, U.K., and University Grants Commission's Visiting Professorships/Fellowships at 
various Universities in India. His publications include Industrial Sociology in India (with N.R. Sheth), Sociology of Robert K. Merton (in Gujarati) and a number of research papers. He is on the editorial boards of several academic journals including the British Sociological Society's Work, Employment and Society. He was Professor of Sociology and Dean, Faculty of Arts, at M.S. University of Baroda, and Vice Chancellor of Sardar Patel University, Gujarat, India.

Mario Rutten is Professor of Comparative Sociology of Asia at the Department of Sociology and Anthropology, University of Amsterdam. He has extensive research experience in rural entrepreneurship and labour relations in India, Indonesia, and Malaysia, and on Indian migrants in Europe. His book publications include Farms and Factories (OUP 1995), Small Business Entrepreneurs in Asia and Europe (co-edited, Sage I997), Development and Deprivation in Gujarat (co-edited, Sage 2002), Rural Capitalists in Asia (Routledge Curzon, 2003), Asia in Europe, Europe in Asia (co-edited, ISEAS-IIAS 2004), Labour and Capitalist Transformation in Asia (Special Issue of The Indian Journal of Labour Economics, co-edited 2004), and Leuke Vakantie Gehad? Verhalen over Antropologisch Veldwerk (Aksant 2007).

Sanderien Verstappen is Junior Lecturer at the Department of Sociology and Anthropology at the University of Amsterdam. Her masters thesis in anthropology received an award from the University of Amsterdam. Her book Jong in Dollywood; Hindostaanse jongeren en Indiase films (2005), on the reception of Hindi cinema among Surinamese Hindustanis, was based on ethnographic research in The Hague. Sanderien Verstappen is a specialist in visual anthropology and made three documentary films; e.g. Take Away Ritual (2002), made in co-operation with Koen Alefs, on backpackers and locals in the village of Pushkar (Northern India). 